University of Pennsylvania Carey Law School

Penn Law: Legal Scholarship Repository

Faculty Scholarship at Penn Law

1995

\title{
Justice, Liability, and Blame: Community Views and the Criminal Law
}

Paul H. Robinson

University of Pennsylvania Carey Law School

John M. Darley

Princeton University-Department of Psychology

Follow this and additional works at: https://scholarship.law.upenn.edu/faculty_scholarship

Part of the Courts Commons, Criminal Law Commons, Criminology and Criminal Justice Commons, Ethics and Political Philosophy Commons, Law and Philosophy Commons, Law and Psychology Commons, Law and Society Commons, Legal Theory Commons, Public Law and Legal Theory Commons, Social Control, Law, Crime, and Deviance Commons, and the Social Psychology Commons

\section{Repository Citation}

Robinson, Paul H. and Darley, John M., "Justice, Liability, and Blame: Community Views and the Criminal Law" (1995). Faculty Scholarship at Penn Law. 1634.

https://scholarship.law.upenn.edu/faculty_scholarship/1634

This Book is brought to you for free and open access by Penn Law: Legal Scholarship Repository. It has been accepted for inclusion in Faculty Scholarship at Penn Law by an authorized administrator of Penn Law: Legal Scholarship Repository. For more information, please contact PennlawIR@law.upenn.edu. 


\section{JUSTICE,}
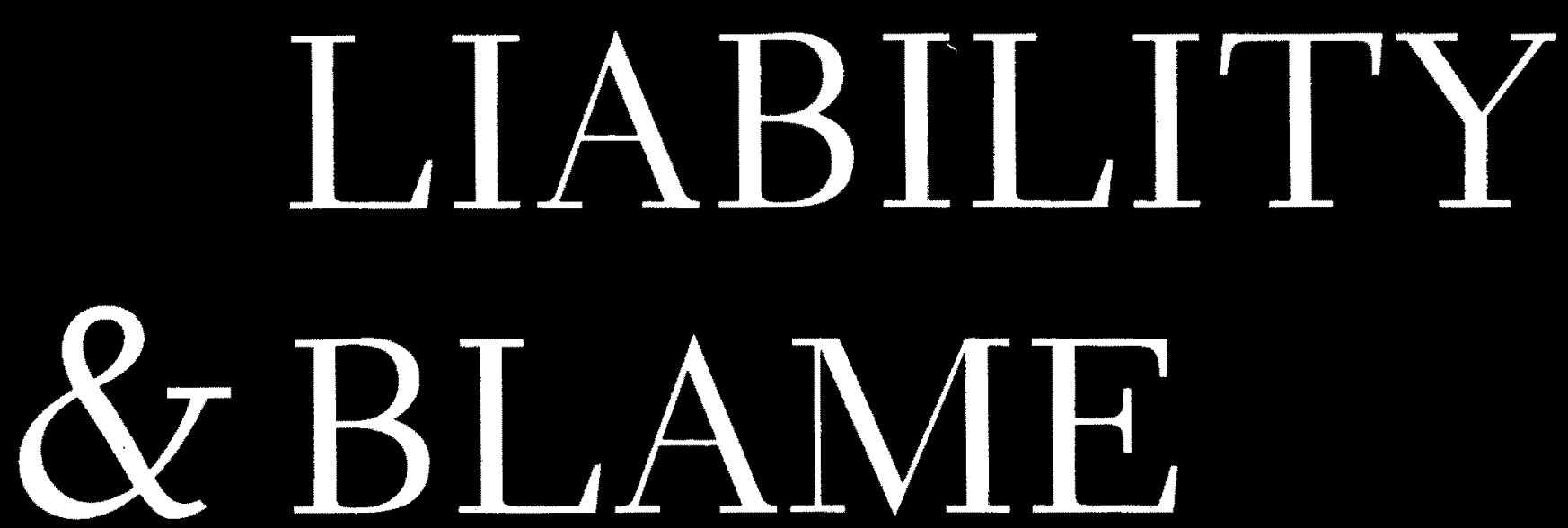

Community Views and the Criminal Law

Paul H. Robinson and John M. Darley

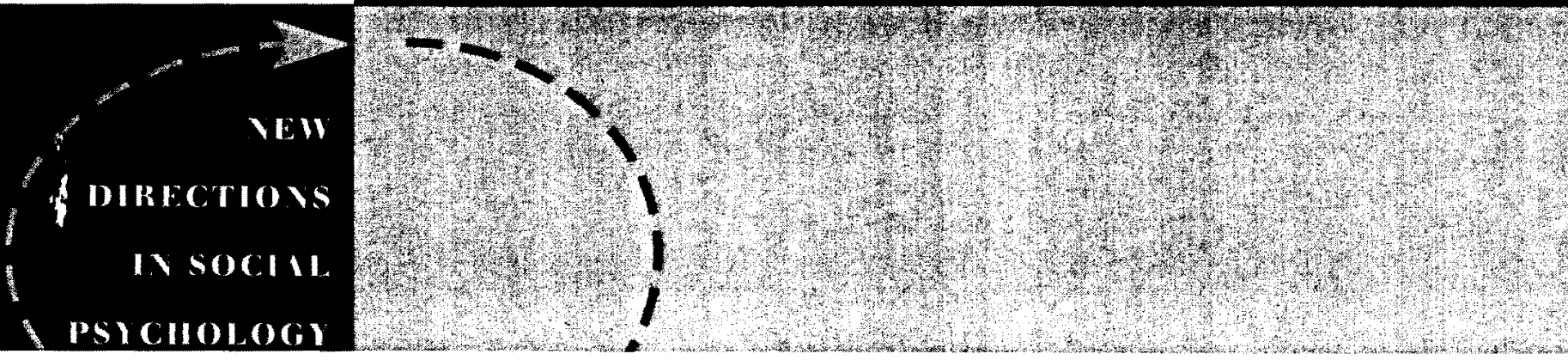




\section{Justice, Liability, and Blame}




\section{About the Book and Authors}

Drafters of legal codes often implicitly or explicitly seek to incorporate community standards. To what extent have they succeeded? This book examines shared intuitive notions of justice among laypersons and compares the discovered principles to those instantiated in current American criminal codes. After discussion of the proper role of community views in formulating legal doctrine, Robinson and Darley report eighteen original studies on a wide range of issues in dispute among legal theorists. The authors compare lay intuitions and code provisions on such questions as the justified use of force, insanity, causation, complicity, risk-creation, omission liability, culpability requirements, duress, entrapment, multiple offenses, and criminalization matters such as felony-murder and sexual offenses. Many important differences between the legal code and community views are found, and the authors discuss the implications of those differences. One implication is the possibility that such conflicts could lead to reduced compliance as the code loses its moral authority with the community.

Paul H. Robinson is professor of law at Northwestern University. John M. Darley is Dorman T. Warren Professor of Psychology at Princeton University. 


\title{
Justice, Liability, and Blame
}

\author{
Community Views \\ and the Criminal Law
}

\author{
Paul H. Robinson \\ John M. Darley
}

Westview Press

BOULDER • SAN FRANCISCO • OXFORD 
New Directions in Social Psychology

All rights reserved. No part of this publication may be reproduced or transmitted in any form or by any means, electronic or mechanical, including photocopy, recording, or any information storage and retrieval system, without permission in writing from the publisher.

Copyright (C) 1995 by Westview Press, Inc.

Published in 1995 in the United States of America by Westview Press, Inc., 5500 Central Avenue, Boulder, Colorado 80301-2877, and in the United Kingdom by Westview Press, 12 Hid's Copse Road, Cumnor Hill, Oxford OX2 9JJ

Library of Congress Cataloging-in-Publication Data

Robinson, Paul H., 1948-

Justice, liability, and blame : community views and the criminal

law / Paul H. Robinson and John M. Darley.

p. cm. - (New directions in social psychology)

Includes bibliographical references and index.

ISBN 0-8133-2450-5 (HC). - ISBN 0-8133-3281-8 (pbk.)

1. Criminal law-Social aspects-United States. 2. Criminal law-

United States-Psychological aspects. I. Darley, John M.

II. Title. III. Series.

KF9219.R6 1995

$345.73-\mathrm{dc} 20$

[347.305]

94-29250

Printed and bound in the United States of America

The paper used in this publication meets the requirements

$\infty$ of the American National Standard for Permanence of Paper for Printed Library Materials Z39.48-1984. 
In memory of

\section{Ann Harper Robinson}

March 16, 1917-October 25, 1994

in love with people, life, and learning

-P.H.R.

\section{John Gordon Darley}

February 20, 1910-September 6, 1990

a man who had little security in his own early life

yet devoted himself to providing security

for those with whom he worked and lived

-J.M.D. 


\section{Contents}

List of Tables and Figures

xi

Preface

1 Community Standards and the Criminal Law

An Overview, 4

Why Community Views Should Matter, 5

Research Methods, 7

2 Doctrines of Criminalization: What Conduct Should Be Criminal?

Study 1: Objective Requirements of Attempt, 14

Study 2: Creating a Criminal Risk, 28

Study 3: Objective Requirements of Complicity, 33

Study 4: Omission Liability, 42

Chapter Summary, 50

3 Doctrines of Justification: When Should It Be Lawful for One to

Engage in Conduct That Normally Would Constitute a Violation?

Study 5: Use of Deadly Force in Self-Defense, 54

Study 6: Use of Force in Defense of Property, 64

Study 7: Citizens' Law Enforcement Authority, 72

Chapter Summary, 79

4 Doctrines of Culpability: When Is One's Violation

of a Legal Rule Blameworthy?

Study 8: Offense Culpability Requirements and

Mistake/Accident Defenses, 84

Study 9: Culpability Requirements for Complicity, 96

Study 10: Voluntary Intoxication, 105

Study 11: Individualization of the Objective Standard of Negligence, 116

Chapter Summary, 123 
5 Doctrines of Excuse: When Is One's Rule Violation Blameless?

Study 12: Insanity, 128

Study 13: Immaturity and Involuntary Intoxication, 139

Study 14: Duress and Entrapment Defenses, 147

Chapter Summary, 155

6 Doctrines of Grading: What Degree of Punishment Is Deserved for One's Blameworthy Violation?

Study 15: The Seriousness of the Offense-Sexual Offenses, 160

Study 16: The Culpability of the Person-Felony Murder, 169

Study 17: The Strength of the Person's Connection with the Prohibited Result-Causation Requirements, 181

Study 18: Punishment for Multiple Offenses, 189

Chapter Summary, 197

7 Conflict Between Community Views and Criminal Codes

When Code and Community Agree, 203

When Code and Community Disagree, 204

Liability Requirements Versus Liability Factors and Dichotomous

Functions Versus Continuous Functions, 208

Criminal Liability Without Punishment, 210

The Jury as a Resolver of Code-Community Conflicts, 212

Appendix A: Research Methodology

Our Research Design in Context, 217

Strengths and Limitations of Our Research Methods, 219

The Penalty Scale and What Can Be Learned from the

Subjects' Penalty Responses, 223

The Question of "Consensus": Agreement and Disagreement

Among Respondents, 225

Appendix B: Text of Stimulus Instrument Scenarios

Appendix C: Liability Score/Imprisonment Term Translation Table

References 


\section{Tables and Figures}

Table 2.1 Attempt Scenarios

Table 2.2 Liability for Various Degrees of Conduct Toward a Completed Theft Offense

Figure 2.3 Liability for Various Degrees of Conduct Toward Theft

Figure 2.4 Percentage of Subjects Assigning No Liability or Liability But No Punishment

Figure 2.5 Effect of Renunciation in Reducing Liability 24

Table 2.6 Subjects' Perceptions of the Creation of Risk 30

Table 2.7 Liability for the Creation of Risk 31

Figure 2.8 Liability as a Function of Risk and Injury 32

Table 2.9 Liability as Related to Objective Requirements of Complicity 36

Figure 2.10 Liability Assigned to the Accomplice as a Function of His Involvement

Figure 2.11 Effects of Success or Failure of Killing on Liability for the Accomplice

Table 2.12 Liability for Commission and Omission 45

Table 2.13 Respondents' Perceptions of Commission and Omission Cases 47

Figure 2.14 Liability as a Function of the Degree of Sacrifice Necessary to Rescue

Table 3.1 Self-Defense Liability

Figure 3.2 Liability Assigned for Defensive and Nondefensive Killing Scenarios

Figure 3.3 Liability as a Function of Maximum Force Allowed 、 $\quad 59$

Table 3.4 Subjects' Perceptions of Self-Defense Cases ' 61

Table 3.5 Liability for the Use of Force in Protection of Property 66

Table 3.6 Subjects' Perceptions of the Use of Force in Protection of Property

Table 3.7 Liability for Exercise of Citizens' Law Enforcement Authority 74

Figure 3.8 Effect of Mistake on Liability for Exercise of Citizens' Law Enforcement Authority

Figure 3.9 Effect of Use of Deadly and Nondeadly Force on Liability for Exercise of Citizens' Law Enforcement Authority

Table 3.10 Subjects' Perceptions of the Exercise of Citizens' 
$\begin{array}{lll}\text { Table 4.1 Liability for Mistake/Accident } & 88\end{array}$

Figure 4.2 Liability as a Function of Culpability Level $\quad 90$

Figure 4.3 Liability as a Function of Culpability as to Different Offense Elements: Rape and Statutory Rape 91

Figure 4.4 Liability as a Function of Culpability as to Different Offense Elements: Damage to House

Figure 4.5 Liability as a Function of Culpability as to Different Offense Elements: Damage to Unimproved Property

Table 4.6 Liability as Related to Culpability Requirements for Complicity

Table 4.7 Subjects' Perceptions as to Culpability Requirements for Complicity

Figure 4.8 Liability as a Function of Accomplice's Culpability as to Resulting Death

Table 4.9 Liability for Voluntary Intoxication

108

Figure 4.10 Liability as a Function of Pre-Intoxication Culpability as to Killing

Figure 4.11 Liability as a Function of Pre-Intoxication Culpability as to Becoming Intoxicated

Table 4.12 Liability and Culpability in Core Cases

Table 4.13 Factors in Individualization of Negligence Standard

Table 5.1 Respondents' Perceptions of Cognitive and Control Dysfunctions

Table 5.2 Liability as Related to Insanity

Table 5.3 Respondents' Perceptions of Cognitive and Control

Dysfunction: Agreement with Common and

Legal Language Formulations

Table 5.4 Key to Table 5.3-Questions for Common and

Legal Language Formulations

Table 5.5 Liability as Related to Immaturity and Involuntary Intoxication

Table 5.6 Subjects' Perceptions of Immaturity and Involuntary Intoxication Cases

Table 5.7 Liability and Subjects' Perceptions as Related to Duress and Entrapment

Table 6.1 Liability for Sexual Offenses

Table 6.2 Subjects' Perceptions of Sexual Offenses 163

Table 6.3 Liability for Felony Murder 172

Figure 6.4 Liability as a Function of the Role of the Actor 175

Figure 6.5 Liability as a Function of the State of Mind of the Actor as to Killing 
Figure 6.6 Liability as a Function of Role and State of Mind as to Killing

Figure 6.9 Liability for Perpetrator and Lookout in Causation Scenarios 186

$\begin{array}{ll}\text { Figure 6.10 Liability as Related to Causation } & 187\end{array}$

Table 6.11 Subjects' Perceptions of Multiple Offenses 192

Table 6.12 Liability for Multiple Offenses

193

Figure 6.13 Total Liability as a Function of Number of Offenses

Figure 6.14 Total Liability as a Function of the Interval Between

Two Offenses

195

Figure 6.15 Past and Future Likelihood of Committing Similar Offenses 


\section{Preface}

Members of the criminal law community regularly make assertions about "the community's sense of justice" on a particular issue and claim that, therefore, to be true to this sense of justice, a particular formulation or interpretation of a criminal code provision is required. Such claims typically express the speaker's own intuitions, which the speaker believes are shared by other people of common sense. Such thoughtful speculation commonly is the basis upon which formulations of criminal law are proposed, adopted, and interpreted.

A social scientist may cringe at hearing this. The community's intuitions on blame and punishment are not matters that one need speculate about. Modern behavioral science is well equipped to determine with some reliability the rules that laypersons use in assessing blame and deserved punishment. Basing criminal law formulation on speculation rather than fact suggests that the criminal law community is out of touch with modern science in an important and damaging way.

In this book we report eighteen original studies on a wide range of issues that are central to criminal law formulation, including issues relating to the justified use of force, insanity, causation, complicity, risk-creation, omission liability, culpability requirements, duress, entrapment, multiple offenses, and criminalization matters such as felony murder and sexual offenses. The questions selected for investigation are those for which the community's intuition would be of importance to the legal decision-makers. In addition to reporting the community's views, we compare those views to the rules instantiated in current criminal codes. Many important differences between code and community are found, and we discuss the implications of those differences.

Social scientists may look at these studies and wonder: What is it that makes these authors think the world breathlessly awaits yet another series of studies on "the law and social science"? There already exist a number of studies that trace relationships between various legal concerns and the findings of social and psychological science. How do the studies reported in this book differ from other studies? What sorts of new contributions do they make?

First, our studies differ from others in the specific questions we investigate. As noted, we test the views of ordinary people on the issues that govern the formulation of criminal codes. An example may make this clearer. Criminal codes are quite strict about what actions can be committed in self-defense. Roughly, the de- 
fender can use only force sufficient to defend against the attack and can use deadly force only if serious harm is threatened and safe retreat from the attacker is not possible. One of our studies demonstrates that ordinary people hold considerably looser standards for acceptable force in self-defense. We then say what we can about the possible meanings of this code-community difference and, somewhat gingerly, discuss possible implications for code modification.

Our second claim to rareness, if not uniqueness, lies in this: the accuracy of our understandings of the legal codes. Frequently, when social scientists set out to do research relevant to legal concerns, they do so without a careful examination of the structure of the legal system that generates the issues to be examined. This has meant, much more than has been generally realized, that the studies do not make contact with the concerns of the legal system or make contact in a way that flaws the extrapolations that the social scientists wish to make. Thus, their intended audience-legal professionals-is not reached or is not moved by their arguments.

For example, an empirical study investigating lay intuitions on the blameworthiness of "recklessness" and "negligence" may give interesting results. Yet, if the definitions of "recklessness" and "negligence" used in the study are different from those used in criminal codes-where the two terms typically are given detailed definitions - the results will be of little or no use to criminal law decision-makers. Those familiar with social science research on insanity will be able to supply many examples of a similar sort; studies in which the questions that were raised with the study respondents were not in the form required to give answers to questions of interest to the legal decision-makers and scholars.

All too often, social scientists have aimed to collide with legal concerns-but missed their target. No doubt we make mistakes in this book, but this is not one of them. One of us has extensively studied criminal codes and has been involved in code-drafting efforts. Throughout the book, we discuss what weight should be given to a code-community discrepancy. That turns out to be a complex question. However, when our research demonstrates a discrepancy between code and community, we have confidence that it is a real one, rather than one that can be explained away by some misunderstanding of the code.

Aside from our deep conviction that any human being with pretensions to live the "life of the mind" would benefit from a copy of this book-or perhaps two copies-we can specify sets of readers to whom we address the book. First, and most obvious, our audience includes those who are involved in the processes of code drafting and interpretation-those legislators, committee staffers, and think-tank and university scholars who participate in creating criminal codes as well as those judges who must interpret code provisions and explain them to jurors. Second, our audience includes those research scholars and legal philosophers who do empirical and theoretical work on criminal justice issues or, more broadly, who work on issues of society and morality. By extension then, we also think that social scientists who study various issues of contact between law and 
social science might find at least some of our findings and perhaps our research methods to be of interest. Instructors of seminars or courses on law and social science might want to explore at least some of the issues we raise and examine our research methods.

Many people have helped us carry out the research we report in this book, and we gratefully acknowledge their assistance. The studies were conceived, designed, and executed during the fall of 1990 and the spring of 1991 in seminars at Rutgers University School of Law, where Paul Robinson then taught. Our greatest debt is to the students in those seminars who enthusiastically did more than any seminar student could be expected to do: Cynthia Adler, Blake Bolinger, Amy Bosacco, Alison Brown, Kara Bruge-Holland, Michelle Carter, Ron Fisher, Gary Gallant, Geoff Garner, Tim Hartigan, William Horan, Kimm Lacken, Alfred Low-Beer, James Passantino, Eric Riso, Linda Thomas, Liz Varki, Ann Waybourn, and John Young. They learned more about research methodology than they wanted to learn, out of a conviction that criminal law ought to be based on more than speculation.

Anne Marie Carosella, while a graduate student at Princeton, was the teaching assistant for the Rutgers seminars and labored long and gallantly for experimental designs that would test the hypotheses set forth herein and provide analytically tractable data. Dan Bailis did much in analyzing the data after Ms. Carosella's graduation. The law-psychology research group at Princeton University, including at various times Dan Bailis, Marisa Reddy, Kathryn Oleson, Beth Bennett, Robert Harlow, and Holly Sukel, helped interpret the data patterns. Emily Reber helped prepare the data tables and figures that are presented throughout the text. Deborah Prentice tactfully coped with a number of data-analytic questions, some of a regrettably elementary sort, and accurately identified various incoherences in manuscript drafts. Natasha Goldstein, a law student at Northwestern University, did valiant work of every sort on the final manuscript. The willingness of Professors Stephen Morse, Tom Tyler, and Nelson Polsby to provide wise advice on aspects of the project also is gratefully acknowledged.

Rutgers University School of Law financed the data-collection and related activities. Deans Roger Dennis at Rutgers and Robert Bennett at Northwestern provided Paul Robinson with financial and moral support for the many years of this work. The National Science Foundation, the Center for Advanced Study in the Behavioral Sciences, the Institute of Governmental Studies at the University of California at Berkeley, and Princeton University provided research support to John Darley during the period.

We have benefited from the discussions we have held with those we acknowledge and others, but the views that we express, of course, are our own.

Paul H. Robinson John M. Darley 


\section{Community Standards and the Criminal Law}

A common form of argument and analysis when discussing legal liability is to claim that "justice" requires one result or another. The "justice" argument is used most often and with greatest conviction when analyzing criminal liability, because criminal law, more than any other, is thought to be premised on principles of blameworthiness and desert. Various conceptions of justice have been proposed by moral philosophers, but when laypersons claim that justice requires a particular criminal liability or punishment in a case, rarely are they referring to conceptualizations derived from moral philosophy. Instead, they see the proper result as one that is in accord with their intuitive notions. Persons can articulate reasons for their intuitive judgments, of course, and importantly they of ten believe that those reasons are not idiosyncratic to themselves but are held by a broad community of moral persons. Thus, the argument that "justice would be served if ... " is a claim not only of the speaker's personal view but of an intuitive but grounded notion of justice that the speaker believes is shared by the community of moral individuals.

It is these notions of just results held by ordinary people that we set out to investigate. Since we collected the moral intuitions of more than thirty people about each set of cases, we were also able to determine the degree to which these intuitions actually were shared among individuals, thus testing the belief of many individuals that their moral intuitions reflect a community consensus. Thus, one focus of our investigation has been on the following questions: What are the moral intuitions of individuals about the sorts of blameworthiness and just-deserts issues that arise in criminal cases? To what extent are these intuitions shared (that is, do shared standards of justice exist)? In this book, we report the results of several of our investigations into these and related questions. By empirical procedures, we determine at least the beginnings of the outlines of "community standards" - those views that are held by ordinary members of our communities about criminal liability and punishment.

Rather than addressing this "moral intuitions" question across the spectrum of possible issues-all criminal activities-we allowed the specific cases we examined to be dictated by our second focus. Professor Robinson is knowledgeable 
about criminal law as it is represented in the legal codes that govern the criminal justice system's determinations of trial outcomes and assignments of criminal liability. Those individuals versed in criminal law often are struck by the thought that the results dictated by criminal codes are at variance with our notions of the moral intuitions of individuals in our culture. Are these "secondhand intuitions," these intuitions of legal scholars about code-community discrepancies, correct? This became the second focus of our investigation. We strategically aimed our investigations of community standards at areas in which we suspected that such discrepancies existed or in which a discrepancy might be of particular interest. Are there really times when community standards are importantly different from the liability and punishment provided by legal codes?

Our studies follow a set form: We contrast the empirical judgments made by community members with those liability judgments determined by current versions of the legal code-particularly, those assigned by the Model Penal Code (the Code) but also those assigned by other codes or proposed codes that have some claim on the attention of legal scholars and code drafters. Our purpose is to cause a particular sort of controversy. We seek to bring the legal community to consider the consequences of discovered discrepancies between the moral intuitions of ordinary people and legal codes. Additionally, we will discuss what rides on the answers to the previous questions and what such discrepancies might imply for the criminal justice system.

In our investigations we discover that often the legal codes and the community standards reflect similar rules in assigning liability to a case of wrongdoing; but also often they do not. For each instance of a discovered similarity or discrepancy, we discuss the possible implications of the similarity or the difference. To signal our conclusions, we will argue that a discrepancy between code and community is by no means always an argument for changing the legal code, but it is an argument for careful examination of the possible roots of the discrepancy. At certain times, one would choose to "go with the code," to retain the code's formulation of an offense and the range of punishment for the offense that the code prescribes. At other times, the weight of the argument lies with the community standards; the code drafters should consider reformulating the legal codes to come into harmony with the moral judgments that our subjects provide. In still other cases, we see multiple possible directions that a code-community standard could take and are genuinely puzzled about what to recommend.

In summary, this book investigates the existence, nature, and implications of community views on the rules and principles of criminal liability and punishment by contrasting those views to the rules and principles embedded in legal codes. By doing so, we frankly hope to generate controversy-to generate debate on criminal codes.

But haven't the social sciences charted the moral intuitions of ordinary individuals? One might expect that a vast research literature on this subject already ex- 
ists. Certainly we expected this. We expected our contribution to be an examination of current legal code principles in the light of existing social science research. But for reasons that we do not fully understand, there has been little previous work in this area. Social scientists have not mapped the contours of the moral intuitions of our culture; psychologists - who one would expect to be particularly keen on carrying out this mapping-have not done so. (For a more detailed discussion of why this might be so, see Darley and Schultz, 1990.) There are only a scattered set of studies that examine the issue of code-community discrepancies, which we will cite as they become relevant to the particular elements of the code that we are examining.

This is not to say that there are not a good many studies about ordinary people's perceptions of various "law-psychology" issues. Much empirical work has been done on criminal justice issues, especially those that relate to the causes of crime and its effective treatment or control (Fox, 1985). Public attitudes toward crime and fear of it have been examined (Eitzen and Timmer, 1985, pp. 86-111), as well as attitudes toward particular aspects of the criminal justice system, such as the police and the death penalty. (See, e.g., Cowan, Thompson, and Ellsworth, 1984.) One aspect of this work that may be useful to substantive criminal law reform is the investigation of people's assessment of the relative seriousness of different offenses (Wolfgang and Weiner, 1982). Many procedural aspects of the system also have been investigated. Empirical research has proved useful in learning about the effect of the physical appearance of litigants (Dane and Wrightsman, 1982; Baumeister and Darley, 1982; and Kulka and Kessler, 1978), the reliability of eyewitness testimony (Wells and Loftus, 1984), the group decision-making processes of juries (Kassin and Wrightsman, 1988), strategies for biasing jurors during voir dire (Blunk and Sales, 1977), the effect of jury instructions (Kassin and Wrightsman, 1979), and sentencing disparity among judges (Hogarth, 1971). There also is a vast literature on the relationships between-or more accurately the contradictions between-legal and psychiatric definitions of mental illness. Little has been done, however, in assessing lay views on what some might argue is the one subject on which the community view is the final authority-the assessment of deserved liability and punishment. ${ }^{1}$

In light of the social science interest in a wide range of criminal justice issues, the absence of liability and punishment studies puzzles us. Especially in a system such as ours-which ultimately relies upon layperson juries for the final liability judgment ${ }^{2}$ and often empowers them to grade the seriousness of the violationone would expect that public conceptions of liability and punishment would be matters of keen interest. As a practical matter, given the evidence of the limited effect of jury instructions in the jury decision-making process (Elwork, Sales, and Alfini, 1982), one might guess that litigants on both sides would want empirical evidence of the intuitive liability rules that juries are likely to follow. Yet, for whatever reason, examination of community views on the substantive rules for assign- 
ing criminal liability and punishment does not appear to be high on the social science agenda. A primary theme of this book is to argue that it should be.

Social scientists have little reason to undertake this work, however, unless the criminal law community is persuaded that studies of community views are important to the development of criminal law and policy. If criminal law drafters see such information as important to their work, social psychologists will be motivated to undertake such studies, and their legal counterparts will be encouraged to participate. Toward this end, much of the argument in this work is directed at lawyers, judges, legal scholars, and legislators. We attempt to show that community standards are of relevance to the legal community and also what that relevance consists of in specific cases.

\section{AN OVERVIEW}

An overview of the book will be helpful to the reader. In our previous discussion we seemed to imply that the liability and punishment principles instantiated in legal codes ought to match, in large measure, those that would be employed to judge cases according to community standards. It may seem natural to some that the legal doctrine ought to track the community's views, especially in a democracy and in a system that relies upon the lay jury. But, like any other proposed principle for the distribution of criminal liability, this principle requires explicit justification. Why, exactly, should the community's views of liability and punishment be taken into account? The next section of this chapter examines that question. It concludes that community views are an essential consideration and ought to be an influential factor in the policy-making and code-drafting process but that such views ought not to be taken as determinative.

Even in those circumstances in which community views have a legitimate role to play, there may be hesitation in looking to them because of the existing difficulties and uncertainties of such empirical research. A brief description of the research methodology of the pilot projects presented in this book appears at the end of this chapter. Appendix A contains a more detailed description of methodology, as well as a discussion of the significant limitations inherent in all research of this kind. The pilot projects described hereinafter do not always provide complete, comprehensive, or definitive conclusions, but we mainta in that research using social science methods similar to the ones we have used for our pilot projects can provide reliable data for criminal law code-drafters and policy-makers.

In Chapters 2 through 6, we present a number of studies that examine the community's views on a variety of criminal liability and punishment issues. We also examine whether, if such shared community views exist, they match the rules and principles embodied in the legal codes that currently dictate criminal liability and punishment. The results of our studies suggest that shared notions of appropriate liability and punishment do exist on some issues. The comparisons to current law show that the subjects' views frequently do support the codes' positions, some- 
times even for provisions that commentators have assumed have little public support. Often, however, the subjects' views are markedly different from those of the codes. In each instance, we discuss the implications of the results for the legal codes and for future research.

Our discussion of the studies is divided into three sets of chapters to address separately each of the three major functions of criminal law doctrine. First, the doctrine must define the conduct that is prohibited (or required) by the criminal law. Such "rules of conduct," as they have been called, provide ex-ante direction to the members of the community as to the conduct that must be avoided (or that must be performed) upon pain of criminal sanction. This may be termed the rule articulation function of the legal doctrine. When a violation of the rules of conduct occurs, the criminal law must take on another role. It must decide whether the violation is sufficiently blameworthy to merit criminal liability. This second function, the liability assignment function, sets the minimum conditions for liability. It is the initial step of the adjudication process. Here the law assesses ex post whether a person who violates a rule of conduct is blameworthy for the violation and therefore ought to be held criminally liable for it. Finally, in those instances in which liability is to be imposed, the criminal law must assess the seriousness of the violation and blameworthiness of the offender in order to determine the general amount of punishment that is appropriate. While the liability function requires a simple yes or no decision as to whether the minimum conditions for liability are satisfied, this third function, the grading function, requires judgments of degree. For a general discussion of these three functions of criminal law doctrine, see Robinson (1990) and Robinson (1994).

\section{WHY COMMUNITY VIEWS SHOULD MATTER}

Next we take up the question we previously raised. What relevance should the community's views of liability have for formulations of criminal codes? The question of relevance is central to the value of the studies that we propose, so we need to give a general defense of the proposition here.

The claim that a community's shared notions of condemnation and punishment should guide the formulation of criminal law may be criticized for several reasons. For example, desert theorists argue that criminal law doctrine should be formulated to punish blameworthy offenders; the distribution of just punishments ought to be the ultimate goal of criminal law. A distribution of punishment according to community views would be immoral, they might argue, because the members of the community may well express views about proper punishment that they would find unfair if they themselves were to be judged by such views or that are in some other way unfair when examined from some rational moral perspective.

Utilitarians generate punishment rules from a quite different perspective. Utilitarians argue that doctrine should be formulated in a way that efficiently mini- 
mizes future criminal violations; efficient crime prevention ought to be the goal. A distribution according to community views, they might argue, would be detrimental to society because it would not maximize the efficient crime-prevention potential of criminal liability and punishment. That is, avoidable offenses (under efficient minimization practices) would be committed if such a distribution were adopted. To summarize and conjoin the arguments of the desert and utilitarian groups, it would be both immoral (from a deserts-theory perspective) and detrimental to society (from a utilitarian perspective) to distribute liability and punishment according to such community notions.

We would suggest that, if desert is the governing distributive principle, the community's view is relevant, because it is one source of determining what counts as the just desert. Admittedly, a moral philosopher might be reluctant to defer to the community for an assessment of what is morally deserved. Desert is not a matter of intuition, the philosopher might argue, but is to be logically derived from principles of fairness and good. At the very least though, the community's views may play a role in testing the derived rules. That is, if a rule derived by desert theorists is judged overwhelmingly by the community to be unjust, such disagreement may cast some doubt upon the accuracy of the rule in assessing a person's moral blameworthiness, at least suggesting that closer scrutiny of the reasoning behind the rule is required.

Under a utilitarian rationale for distributing liability, the community's views are of somewhat more direct importance. First, moral condemnation is an inexpensive yet powerful form of deterrent threat. It demands none of the costs that attend imprisonment or even supervised probation; yet, for many persons, it is a sanction to be very much avoided. The more importance a person places upon social acceptance, the more terrible (ergo efficient) this threatened sanction becomes. This marvelously cost-efficient sanction is available, however, only if the system retains its moral credibility. Each time the system is seen to convict in cases in which no community condemnation is appropriate, the system weakens the underlying force of the moral sanction.

Furthermore, recent empirical evidence suggests that criminal law's most effective mechanism of compliance is not the deterrent threat of sanction; it is its capacity to authoritatively describe the moral and proper rules of conduct. People will follow those rules not because they fear punishment for violating them but because they see themselves as good and law-abiding people who are inclined to obey the law because it is the right thing to do. Most important, the compliance power of criminal law is directly proportional to its moral credibility (see, e.g., Tyler, 1990). If the criminal law is seen as unjust in one instance, its moral credibility and its concomitant compliance power are, accordingly, incrementally reduced.

In addition to these effects, the perceived "justice" of the system is crucial to gaining the cooperation and acquiescence of those persons involved in the process (offenders, potential offenders, witnesses, jurors, and so on). Greatest coopera- 
tion will be elicited when the criminal law's liability rules correspond with the community's views of justice. Conflict between the two undercuts the moral credibility of the system and thereby engenders resistance and subversion (see, e.g., Kassin and Wrightsman, 1988, pp. 158-159; Scheflin and Van Dyke, 1980; and Kadish and Kadish, 1973).

The legal system that the community perceives as unjustly criminalizing certain conduct is one that is likely to cause the society governed by those laws to lose faith in the system-not only in the specific laws that lead to the unjust result, but in the entire code and criminal justice system enforcing that code. ${ }^{3}$ The reverse is also true. A rule that is strongly and persistently supported by the community as accurately reflecting moral blameworthiness but that is not followed by the criminal justice system raises similar destructive possibilities. The community is likely to engage in extralegal vigilante actions, with all of the dangers that that suggests. ${ }^{4}$

Empirical research suggests that a tension or contradiction between the legal code and a community standard does have some of the consequences we suggest. Studies show that the degree to which people report that they have obeyed a law in the past and plan to obey it in the future correlates with the degree to which they judge that law to be morally valid (Grasmick and Green, 1980; Jacob, 1980; Meier and Johnson, 1977; Silberman, 1976; and Tittle, 1980). Tyler's more recent Chicago panel study (1990) draws similar conclusions. The degree to which his subjects saw the legal authorities as having legitimate power predicted their willingness to obey various laws promulgated by those authorities.

Note that it is not the moral accuracy of the criminal law-as moral philosophers would define it - that is important for the utilitarian value of doing justice. Rather, it is the community's perception of the law's moral correctness that assists the law's effectiveness in gaining compliance. That is, the community's view of justice provides the standard by which the system's perceived moral credibility is judged. For these reasons then, an understanding of the community's notions of justice is needed for informed analysis of legal systems.

\section{RESEARCH METHODS}

We will now briefly overview the procedures we used for examining the community's views on appropriate liability and punishments for various conduct. We contacted people to participate in our studies and had them give us their views on the appropriate liability to assign to perpetrators of various criminal episodes that we described to them. Each individual read about a particular crime case-a "scenario" in our vocabulary-and decided whether to assign criminal liability and, if so, the general range of appropriate punishment. Individuals, "subjects" or "respondents" as we will call them, then read another crime scenario, which differed in certain critical ways from the first scenario, and made similar determinations as to liability and punishment. The text of the scenarios is reproduced in Appen$\operatorname{dix}$ B. 
In recruiting our subjects, we sought to involve persons from many walks of life. We did not test those familiar samples of convenience, such as college sophomores; and we also did not test persons involved in the criminal justice system, such as judges, law students, or police officers, figuring that those people would have opinions that were to some extent formed by their contact with the system. Instead we tried to recruit "ordinary citizens." In Appendix A, we report on the demographic distributions of our subjects; we found them sufficiently broad that we feel we have the beginnings of a set of demonstrations of the judgment patterns of typical citizens of the United States on liability and punishment issues.

In all the studies we conducted, we presented subjects with a scale on which to indicate their assignments of liability for the persons in the scenarios. As shown here, that scale consisted of a choice of $\mathrm{N}$ (no criminal liability); 0 (criminal liability but no punishment); or 1 through 11 on a scale that corresponded to prison sentences of from one day (1) to the death penalty (11).

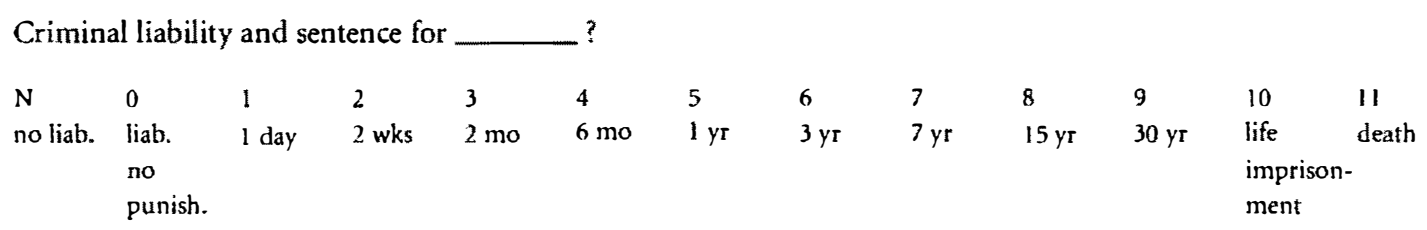

The table used to translate liability scores into terms of imprisonment appears in Appendix C.

As the reader will notice, the length of the prison sentences increases differentially as the scale advances. For instance, the difference between scale value 5 (a sentence of one year) and scale value 6 (a sentence of three years) is only two years. However, the difference between scale value 8 (a sentence of fifteen years) and scale value 9 (thirty years) is much greater. We set up the scale in this way for two reasons. First, it corresponds, at least approximately, to the psychological perspectives on equal distances between punishments (Erikson and Gibbs, 1979; Gescheider, Catlin, and Fontana, 1982). Second, the scale's punishment differences also correspond to the grading categories that are used in the typical American criminal code. (Given the psychological perspectives on equal distances between punishments, it should come as no surprise that legislators use these distinctions in creating the punishment categories for criminal codes.) This means that the punishment choices we presented to our subjects are similar to those available to legislators when they decide how to grade an offense.

The several scenarios given to each respondent usually were identical in a set of core elements and differed only on the dimensions that we thought would make a difference in the subjects' liability judgments (or are held by criminal codes to make such a difference). By examining the differing sentences assigned to closely related cases (scenarios), we sought to determine whether shared community notions of justice exist, and, if so, on what issues they exist and how those notions 
compared to current law. An example will help to make this clear. Criminal codes sometimes treat the crime of forcible sexual intercourse differently if it is committed between individuals who have had a previous sexual relationship. Is this in accord with the way people currently think about rape? To determine this, we first wrote a core story in which an incident of rape was described. We then built that core story into a number of different scenarios. So in scenario variations, the incident was described as occurring between two individuals who had had a previous sexual relationship or two who had not had such a relationship. As we will show you in Chapter 6, our subjects assigned liability judgments to those cases in ways that differ in some respects from judgments instantiated in criminal codes.

Each subject read one version of a scenario, then another. Sometimes a subject judged as many as seven or more versions of a scenario. Obviously then, they were aware of the differences that were built into the different versions of the scenarios, and their attention was focused on those differences. The danger here is that the subjects would feel that we (the researchers) thought that the differences were important and that they should change the liability they assigned, even if they themselves did not think it appropriate. To avoid this problem, we instructed subjects that they should not read the differences in this way (as requiring them to assign different liabilities). As the reader will see as we progress through the study discussions, the subjects often judged different cases alike in the liabilities that they assigned to the perpetrator of the crimes. In other words, they were not unduly influenced by thoughts that the researchers wanted them to see differences between cases that they (the subjects) reasoned should be treated similarly.

This experimental design, in which each subject responds to every version of the scenario (called a "within-subjects design" in the vocabulary of experimental research) is a very powerful one, in that it is highly likely to find statistically reliable differences in the subjects' responses, even when those differences are comparativley small. Particularly for the initial investigations in the field, we thought that this property of the research design was an important one to employ.

As we said, different scenarios were variant versions of each other. Sometimes the differences were obvious and direct, such as the variations between the sexual offense studies just described. (In one scenario the rapist had a prior relationship with the victim; in another, he was a stranger.) In some of the other scenarios, the differences were both less direct and more subtle. For instance, in another case we described one set of actions that we thought would suggest that a perpetrator's conduct was necessary but not sufficient in causing another's death, and in a related scenario, conduct that was sufficient but not necessary in causing the death. It is a genuine question whether subjects perceived the concrete descriptions as being necessary in one instance and sufficient in another. The standard solution to this (in scenario research) is to ask the subjects questions that not only measure the punishments they want to assign but also probe for their psychological perceptions of the circumstances of the scenario. So we asked subjects in the cases 
described whether they thought that the actions were, for instance, sufficient in themselves to have produced the death and necessary to produce the death. As we will see, we were sometimes successful in producing the perceptions of the situations that we wished to produce and sometimes less successful. When we were less successful-and we have noted these instances-more complicated and more tentative interpretations of our results are necessary.

We have conducted upward of twenty different studies (not all of which are reported herein). The studies were designed and executed in seminars at Rutgers University School of Law at Camden in the fall of 1990 and spring of 1991, with the help of faculty and graduate students from the Princeton University Department of Psychology.

In the following chapters, we discuss the results of our studies and attempt to draw out the implications of our findings for the criminal law. In those discussions, we will be fairly bold; we will sometimes make suggestions for code alterations or other modifications of criminal justice procedures. This seems to us to be the best way that we can contribute to what we hope will become a debate. But we need to be clear that we do not regard our empirical studies as the last word. This is true for two sets of reasons.

First, our studies have various general and specific imperfections. We have not tested the large and randomly selected sets of subjects that would provide an entirely convincing mapping of community standards at the state or national level. Because we did not do this, we also have not given the question of what exactly constitutes a community standard the full consideration that it warrants before one would want to consider code alteration based on a conflict with community standards. Simply to signal how this community-standard consideration would go, we now provide a brief sketch: Whenever one polls a community about an opinion on some issue, whether politics, preferences, or legal codes, one can derive an "average opinion." But to say that the average opinion is a "community standard" is to claim more. It has sometimes occurred in presidential elections that some states voted for $A$ by a 51 percent to 49 percent majority, others for $B$ by a similar margin. Obviously, it would be absurd to say that $A$ was the "community standard" in the states that he carried, and $B$ likewise in the states that he carried. What needs to be recognized is that there was nothing that we should be comfortable in calling a community standard in either state. Therefore, in our studies, we need to require that some substantial majority holds a view before it begins to fulfill the requirements for being a community standard.

Actually, we need to require more. If we find some subgroup in sharp disagreement with the majority, this challenges the idea of a community standard more than would be the case if their disagreement was a matter of degree rather than of kind. For example, a majority of people may think that the existence of a previous relationship between two people does not affect the gravity of the offense if one of the individuals rapes the other. However, a minority does think that the existence 
of a previous relationship matters. If that minority thinks that it only slightly mitigates the offense, then it would be possible to make the case, on the one hand, that there is a community standard about the seriousness of such an offense. If, on the other hand, the minority thinks that a rape that takes place within a marriage is no offense at all, the case for a community standard is at a minimum considerably harder to make. These are the sorts of considerations that need to take place when the existence of a community standard is asserted. In our discussions of the studies that follow, we will recognize this task by signaling the reader when we see evidence of sharp disagreements on legal standards among our subjects. Interestingly, sharp disagreements occurred rarely. (In technical terms, we rarely saw signs of a bimodal distribution of responses.)

These are the general problems with our studies. Specific studies can also have specific flaws and problems. In some of our studies, in which we intended subjects to read the cases we presented them in a particular way (as perhaps establishing a particular state of mind on the part of the perpetrator), our subjects read them in importantly different ways; because of this, some of our conclusions require complex qualifications. In other studies, the set of scenarios that we presented turned out to represent a spectrum of possibilities that was more restricted than was adequate to test the legal code provisions. In other studies, still other difficulties came up that will require correction in future studies. ${ }^{6}$ Again, the function of these studies - and this book - is to begin a discussion of the interplay between law and social science on issues of criminal liability; and to both illustrate the kinds of important information that social scientists should be asked to provide to the legal community generally, and code drafters specifically, and to stimulate the kinds of empirical and philosophical considerations that will need to be addressed in future discussions on these matters. A contradiction between the legal code and community standards by no means automatically argues for the alteration of the code in the direction of the standards. There may be good reasons why the legal codes should deviate from community standards. The discovery of a contradiction simply points to a tension that is worthy of analysis.

Do such tensions exist? Are there, in fact, important differences and conflicts between the legal codes that prevail in our country and the community standards of those governed by the code? Are there shared moral intuitions about when punishment is deserved and about how much is deserved? We address these questions empirically in the research reported in the following chapters of the book. 


\section{Doctrines of Criminalization: What Conduct Should Be Criminal?}

What conduct should be criminal? Most people would agree that homicide, rape, and theft, for example, ought to be criminalized. Some current offenses, like price-fixing, are less intuitively improper conduct. The common law distinguished the former kind of offense, called "malum in se" offenses, from the latter kind, called "malum prohibitum" offenses. Malum prohibitum offenses may seem somewhat artificial in what they prohibit; however, there is likely to be some consensus, at least within a jurisdiction, on their ultimate objectives-in this instance increasing the competitiveness of the market. Some people might disagree that the particular offense formulation is the best means of achieving the ends, but few would dispute that the offense helps toward the goal and that the goal is desirable. ${ }^{1}$

However, a significant potential for disagreement exists between code and community with regard to "victimless crimes," such as prostitution, gambling, or distribution of certain drugs. The criminalization of such conduct is designed in part to enforce the community's conceptions of morality. However, as the 1920s "Prohibition" and its failure illustrate, different groups may have different conceptions of what constitutes immoral conduct. As the community consensus on a morality issue fades, so can consensus on the laws that enforce it. As one would expect, in current American culture, there is lack of consensus on the enforcement of laws against victimless crimes such as prostitution (Levi and Jones, 1985; Chilton and DeAmicis, 1975; Newman and Trilling, 1975).

A related question is the degree of seriousness that the community assigns to different crimes - victimless or otherwise-and whether there is consensus on the degree of seriousness. These are issues of offense grading, and we will take them up in Chapter 6.

A second area of potential disagreement between code and community is what we examine in this chapter. It concerns what might be called the code's "secondary prohibitions." These rules extend each primary prohibition to include certain variations of it. For example, if the primary prohibition is killing another person, secondary prohibitions broaden that offense to include attempting to kill another, creating a risk of death to another, assisting in the killing of another, or causing death by omission. 
Another group of doctrines-called "justifications"-creates general exceptions to the primary prohibitions. Doctrines of justification define the circumstances under which the law permits a person to cause the harm or evil of an offense without liability. Self-defense, defense of property, and authorized use of force during arrest by law enforcement officials are examples of common justifications offered as defenses.

There appears to be little or no empirical work on such secondary prohibitions and justifications, and it is in this area that we focus much of our research. In this chapter, we examine views on secondary prohibitions. In Chapter 3, we will deal with justifications.

\section{STUDY 1: OBJECTIVE REQUIREMENTS OF ATTEMPT}

Consider the intriguing case that arises when an individual takes steps toward committing a crime but does not actually commit it. Thinking about committing a crime is not itself a crime. However, at some point in a person's course of conduct, after the initial thought but before actual commission of the offense, the person becomes criminally liable. The history of Anglo-American criminal law reveals that at one time or another the law has used several remarkably different definitions of the point at which a person's preparation becomes a criminal attempt. State laws still disagree on this issue. The underlying practical considerations are twofold. On the one hand, the law does not want to assign liability to a person who has not committed a crime and, in the final event, would not do so. On the other hand, the law wishes to be able to "head off" crimes before they are committed and to punish those who have manifested their intention to commit a crime. On a more theoretical level, there generally is thought to be insufficient moral blameworthiness in thoughts alone to support criminal conviction and condemnation, but at some point between the thought and the completed off ense sufficient blameworthiness comes to exist. Thus, there is the need to define a category of "criminal attempt."

In such cases, because the harm or evil of the actual offense has not occurred, the liability assigned to the attempt is termed "inchoate liability." In most current legal codes, inchoate liability leads to less punishment than would be given if the same offense had been completed, but there is some controversy on this point. Indeed, the Model Penal Code, the provisions of which have served as a model for code reform, generally grades an attempt on equal footing with the completed offense. ${ }^{2}$ Most-but not all-jurisdictions, however, have been reluctant to adopt the Code's inchoate grading provision.

The older (common law) legal tests for determining when a person's conduct reaches the point of criminal attempt tend to be quite demanding, in the sense that such tests require the person to come close to committing the crime before attempt liability is imposed. Under the "dangerous proximity" test (a common formulation), a person typically has to reach a point where the offense is likely to 
be successfully completed-arrest before this point does not result in liability. As an example of dangerous proximity, consider a locksmith who decides to rob a coin shop safe he recently worked on. He goes back to the shop and confirms that the safe is still there. He then tells a friend of his plan to rob the coin shop the next day. Unbeknownst to the locksmith, his friend notifies the police. The next day, the locksmith goes to the coin shop and begins to crack the safe. Suddenly, two police officers burst in and arrest him. Although the locksmith has not completed the robbery, he has come dangerously close to its completion; his conduct satisfies the requirements of the dangerous proximity test, thus making him liable for attempt. The test reflects a view that the moral blameworthiness sufficient for criminal condemnation does not arise until a point where commission of the offense is a danger. This test seeks to balance the two practical considerations governing dangerous proximity cases in a specific way-to allow some opportunity for successful intervention by those who would prevent the crime but also to delay the point of liability until the time when completion is a real danger. ${ }^{3}$ The dangerous proximity test is somewhat pragmatic in that it does not ask complex questions about what can be inferred about the person and his intentions. It simply requires citizens to avoid bringing plans for criminal activities to a point at which they could be successfully completed.

The most common test in modern American codes, however, is the "substantial step" test, as formulated in Model Penal Code $\$ 5.01$ (1)(c). Rather than focusing on how close the person has come to completion of the offense, as does the dangerous proximity test, the substantial step test focuses on how far the person has gone after forming the intention to commit the offense. Any "substantial step" in the direction of commission is adequate (assuming the person's intention to commit the offense is clear and unequivocal). This substantial step test (1) typically imposes liability at an earlier point in the steps toward commission than does the dangerous proximity test; (2) reflects a claim that the moral blameworthiness required for criminal condemnation comes into play earlier; and (3) alters the balance of interests between the individual and society toward the interests of society, by reducing an individual's opportunity to desist on his own, in favor of allowing earlier intervention.

Other tests for determining attempt focus on criteria other than whether the person has come dangerously close or whether he has externalized his intention in performing a substantial step toward commission. The "probable desistance" test focuses on whether the person, without intervention by others, would have been likely to continue in the actions necessary to complete the offense. The "unequivocality" test attaches liability at the point where an observer, knowing only of the person's actions toward committing the offense without knowing the person's state of mind, would believe that the person intended to commit the offense. The warning to members of society in this case is clear: Do not carry out a series of actions that would lead a reasonable observer to believe that you intend 
to commit a crime. Each of the four tests represents not only a different point at which attempt liability attaches and relies on different criteria, but each has a distinct rationale and uses attempt liability for a somewhat different purpose. ${ }^{4}$

The effect of a person's voluntary desistance also has received different treatment at different times and in different jurisdictions. The older common law treated an attempt no differently than a substantive offense in this regard; once the elements of the offense were satisfied, there was no "undoing" the offense. Attempt liability was imposed no matter what the person did after passing the point where his preparation became a criminal attempt. Model Penal Code $\$ 5.01(4)$ introduced a renunciation defense for attempt and other forms of inchoate liability, which provides a complete defense if the actor's desistance is complete and voluntary. (The defense is not available if the actor renounces out of fear or delays the planned attempt until a later date.) The defense is provided in part because the Code's substantial step test advances the point of criminalization considerably in the chain of events. Combined with the Model Penal Code's grading of an attempt as equal to the completed offense, the substantial step test would mean that once anyone takes a substantial step toward commission, that person has no incentive to stop; the person's liability will be that of the completed offense-whether the offense was completed or not. The common law and modern codes that maintain a grading difference, in contrast, have a built-in incentive for the perpetrator to desist at any point before completion of the offense. Thus, such codes have no practical need for a renunciation defense. It has been retained in most jurisdictions, however, including those that grade inchoate offenses less seriously than completed offenses, perhaps because voluntary renunciation is thought to reduce a person's blameworthiness.

We designed a study that sought to examine the community's views on these conduct requirements for attempt liability. To study these views, we presented subjects with a core scenario. Subjects were told that a locksmith, who is called to repair a safe in a coin dealer's store, notices that valuable coins are always kept in the safe. The locksmith decides to break in and rob the coin dealer by opening the safe and taking its contents. We then added to the core story various elements that created combinations of circumstances to which some common law and modern tests would assign attempt liability and to which others would not. For instance, in another scenario, we added the fact that the locksmith returns to the coin shop to make sure that the safe is still there, whereupon the locksmith is arrested and charged with attempted robbery. This variation satisfies the Model Penal Code's requirement, relied on in many jurisdictions, that the attempter need only take some "substantial step" in the direction of committing the offense. Our intent, by introducing these variations, was to determine under which circumstances our respondents would assign liability and how this pattern of liability matched the various tests. 
Therefore, in the design of the present study, each subject read eleven versions of the same core scenario to which various alterations had been made. Each scenario is identical to every other one except for the facts describing how far the person progresses after forming the criminal intention. Each scenario corresponds to one of the current legal tests. Table 2.1 outlines the eleven versions of the scenario and the legal test to which each version corresponds. The initial core scenario, in which the person only forms the intent to commit the crime, is shown in the first row. The substantial step scenario, in which the person returns to the shop to see if the safe is still there, is shown in the second row. Brief characterizations of the other scenarios are given in the "description" column of the table. The "summary" column of Table 2.1 gives a summary description of each scenario, and these are used to identify each scenario in subsequent tables. The "comment" column gives further explanation of the legal treatment of the case.

After reading each scenario, subjects indicated what criminal liability, if any, they would assign to the locksmith. The liability results of the study are reported in Table 2.2. Columns $d$ and $e$ summarize the liability that would be assigned to the scenario by the common law and the Model Penal Code.

We will first consider the different liabilities assigned to the various attempt scenarios and later turn to examine the effects of renunciation of the crime and the related act of desisting out of fear of being apprehended.

Table 2.2 arrays the various scenarios from top to bottom in terms of the general progression of how close the locksmith comes in each version to the actual commission of the crime. In the first scenario, the individual develops an intention to commit the crime and goes no farther. In the last scenario (row 6), the individual actually commits the crime.

As we will use many similar tables throughout this book to report our research results, we will briefly comment on the composition of the tables to facilitate their interpretation. Adjacent to the scenario descriptions are three columns indicating related but different ways of analyzing the degree of liability that our respondents assigned to the perpetrator whose actions were described in the specific case under discussion. Column a reports the average amount of liability assigned to the perpetrator on the eleven-point scale we discussed in Chapter 1. Subjects who assign no liability or liability without punishment are included in this calculation as assigning a liability of zero. Column $b$ reports the percentage of the respondents who chose "No Liability" for the locksmith, roughly equivalent to a jury verdict of "not guilty." Column $c$ reports the percentage of respondents who chose either the "No Liability" or "Liability But No Punishment" options of the scale: This indicates the percentage of subjects who would impose no punishment on the defendant. This percentage will always be higher than the percentage shown in column $b$, because column $c$ includes the subjects reported in column $b$ and adds to that the percentage of subjects who report that they judge that the perpetrator de- 


\section{TABLE 2.1 Attempt Scenarios}

Core Story: A locksmith, Ray, recalls working on a safe in a coin shop. The safe was kept in the back room and always contained valuable coins. Ray thinks about how easy it would be to "crack" the safe. Ray decides he will rob the safe in the coin shop.

Scenario Number, Description

(and Abbreviation)

Summary Comment

1. The actor only thinks about robbing the safe and decides to do so. He takes no action toward committing the crime. (TH)

2. After deciding to rob the shop, the actor goes to the coin shop to make sure the safe is still there. (SS)

Only thinks about offense

Substantial step test satisfied

Unequivocality test satisfied actor makes a special tool to crack the safe with. (EQ)

3a. The actor cases the shop and meets the owner while he does so. Out of pity for the owner, he gives up his plan to rob the safe. (EQR)

4. Having told a friend he intends to rob the shop, the actor drives there. Before he can get to the shop he is stopped by police, who were informed of his intent by the actor's friend. (PD)

5. The actor is in the process of cracking the safe in the coin shop when he is stopped by two undercover policemen. (PX)

5a. When he is in the shop and about to crack the safe, the actor feels pity for the shopowner and decides not to rob the safe. (PXR)

\section{Probable Without outside inter- desistance test ruption the actor would satisfied \\ Dangerous proximity test satisfied \\ have completed the offense. Actor is liable under this test. \\ Actor is liable because the offense is nearly completed.}

Renounces after reaching point of dangerous proximity

MPC allows a defense when actor renounces his criminal intent "completely and voluntarily." No liability if this
No test would assign liability.

Actor is liable under this test, because "reconnoitering" (casing) the shop is a substantial step.

The actor is liable under this test because action manifests criminal intent.

The Model Penal Code (MPC) allows a defense if an actor's renunciation of criminal intent is "complete and voluntary." No liability if this defense is available. defense is available. 
TABLE 2.1 (Continued)

Scenario Number, Description

(and Abbreviation)

Summary Comment

5b. When he is in the shop and about

to crack the safe, the actor stops

Desists out of

fear after

because he sees a policeman in the

front of the store and he fears getting

caught. (FR)

dangerous

proximity

6. The actor completes the robbery and returns home with the coins. (CP)

6a. The actor completes the robbery and returns home. On the way home, he feels pity for the shopowner and returns the coins to the safe. (CPR)

6b. The actor completes the offense, feels pity for the shopowner, tries to return the coins to the safe, but is caught by police. (UNR)
Offense complete, no renunciation

Renounces after offense is complete

Renounces, but is unsuccessful at "undoing"
Actor is allowed no renunciation defense because renunciation was not voluntary. Actor is liable for full attempt.

The actor is liable for the completed offense.

Actor is liable for completed offense because renunciation defense not available. Actor is liable for completed offense because renunciation defense unavailable.

serves criminal liability but does not deserve any punishment. As you will see as the reports of our studies cumulate, the "Liability But No Punishment" category proves an interesting judgment to track.

Finally, and again, we usually attempt to remind the reader of the legal code treatments that are given to the various cases. In this table, columns $d$ and $e$ characterize the treatment of the offense given by various legal formulations. When different legal codes differ in their treatments of the scenarios, as do the common law and the Model Penal Code in this case, we provide several columns-one for each of the different legal treatments.

Many people find tables hard to scan and comprehend. (So, frankly, do we.) Therefore, we often provide graphs or figures that compare liability ratings among cases (as in our next presentation). Figures 2.3 and 2.4 present a visual representation of the liability means and percentage of respondents choosing "No Liability" or "Liability But No Punishment" that are presented in columns $a, b$, and $c$ of Table 2.2. In these two figures, only a subset of the cases is included (excluding scenarios with renunciation or desistance) because we want to highlight specific important conclusions to be extracted from these results. The two-letter descriptions along the horizontal axis of each figure correspond to the abbrevia- 
TABLE 2.2 Liability for Various Degrees of Conduct Toward a Completed Theft Offense

\begin{tabular}{|c|c|c|c|c|c|}
\hline $\begin{array}{l}\text { Attempt } \\
\text { Scenarios }\end{array}$ & Liability & $\begin{array}{l}\text { (b) } \\
\text { \% No } \\
\text { Liability } \\
\text { (N) }\end{array}$ & $\begin{array}{c}\text { (c) } \\
\% \text { No } \\
\text { Liability } \\
\text { or No } \\
\text { Punishment } \\
(N+0)\end{array}$ & $\begin{array}{c}\text { (d) } \\
\\
\begin{array}{c}\text { Common } \\
\text { Law Result }\end{array}\end{array}$ & $\begin{array}{l}\text { Model Penal } \\
\text { Code Result }\end{array}$ \\
\hline $\begin{array}{l}\text { 1. Thought only } \\
\text { (TH) }\end{array}$ & 1.46 & 65 & 77 & No liability & No liability \\
\hline $\begin{array}{l}\text { 2. Substantial } \\
\text { step (SS) }\end{array}$ & 1.54 & 50 & 73 & No liability & Attempt liability \\
\hline $\begin{array}{l}\text { 3. Unequivocality } \\
\text { (EQ) } \\
\text { 3a. Renounces }\end{array}$ & $\begin{array}{l}1.81 \\
0.38\end{array}$ & $\begin{array}{l}42 \\
85\end{array}$ & $\begin{array}{l}65 \\
92\end{array}$ & $\begin{array}{l}\text { b } \\
\text { No defense }\end{array}$ & $\begin{array}{l}\text { Attempt liability } \\
\text { Complete } \\
\text { defense }\end{array}$ \\
\hline $\begin{array}{l}\text { 4. Probable } \\
\text { desistance (PD) }\end{array}$ & 1.88 & 27 & 62 & b & Attempt liability ${ }^{a}$ \\
\hline $\begin{array}{l}\text { 5. Dangerous } \\
\text { proximity (PX) } \\
\text { 5a. Renounces }\end{array}$ & $\begin{array}{l}5.35 \\
0.69\end{array}$ & $\begin{array}{r}0 \\
46\end{array}$ & $\begin{array}{r}0 \\
85\end{array}$ & $\begin{array}{l}\text { Attempt liability } \\
\text { No defense }\end{array}$ & $\begin{array}{l}\text { Attempt liability }{ }^{\mathrm{a}} \\
\text { Complete } \\
\text { defense }\end{array}$ \\
\hline $\begin{array}{l}\text { 5b. Desists } \\
\text { out of fear }\end{array}$ & 1.58 & 35 & 65 & No defense & No defense \\
\hline $\begin{array}{l}\text { 6. Completed } \\
\text { offense (CP) }\end{array}$ & 6.12 & 0 & 0 & $\begin{array}{l}\text { Full offense } \\
\text { liability }\end{array}$ & $\begin{array}{l}\text { Full offense } \\
\text { liability }\end{array}$ \\
\hline $\begin{array}{l}\text { 6a. Renounces } \\
\text { and "undoes" } \\
\text { 6b. Renounces } \\
\text { but unable } \\
\text { to "undo" }\end{array}$ & 3.23 & 12 & 27 & No defense & No defense \\
\hline
\end{tabular}

Liability Scale: $N=$ No criminal liability, $0=$ Liability but no punishment, $1=$ 1 day, $2=2$ weeks, $3=2$ months, $4=6$ months, $5=1$ year, $6=3$ years, $7=7$ years, $8=15$ years, $9=30$ years, $10=$ life, and $11=$ death.

${ }^{a}$ An attempted theft under the Model Penal Code is graded the same as a completed theft.

bThis depends upon which of the common-law tests is applicable in the jurisdiction. 
FIGURE 2.3 Liability for Various Degrees of Conduct Toward Theft

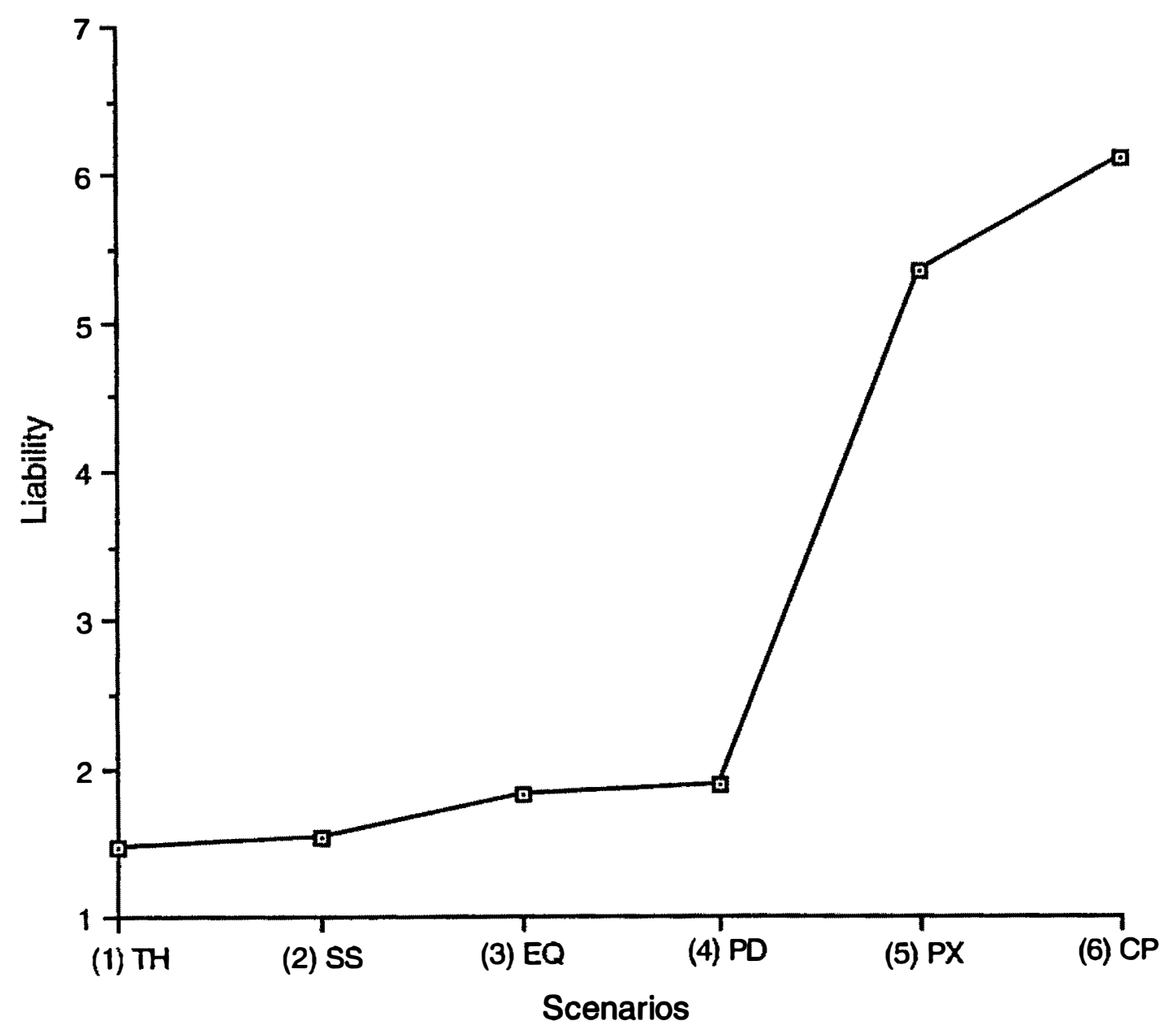

tions assigned to each scenario in Table 2.2. In Figure 2.3, the vertical axis represents the subjects' judgment as to the actor's amount of liability. The higher the number, the more severe the sentence. In Figure 2.4, the vertical axis represents the percentage of respondents who assign either no liability or liability but no punishment to the attempter; the higher the percentage, therefore, the fewer the respondents who would impose liability or punishment for the attempt.

With that explanation, let us turn to the results of this study. Look at the result for the "thought-only scenario (TH)" in Figure 2.3. It appears that even thinking about committing an offense generates some assignment of liability from our average subject. Recall that this is the case in which the locksmith forms a settled intention to rob the coin dealer's safe but takes no further steps to do so. Looking at the same scenario in Figure 2.4, we notice that 65 percent of the subjects assign no liability, and therefore 35 percent of the subjects impose liability in this thoughtonly scenario. (However, about one-third of those imposing liability-13 percent of all subjects-assign no punishment.) 
FIGURE 2.4 Percentage of Subjects Assigning No Liability or Liability But No Punishment

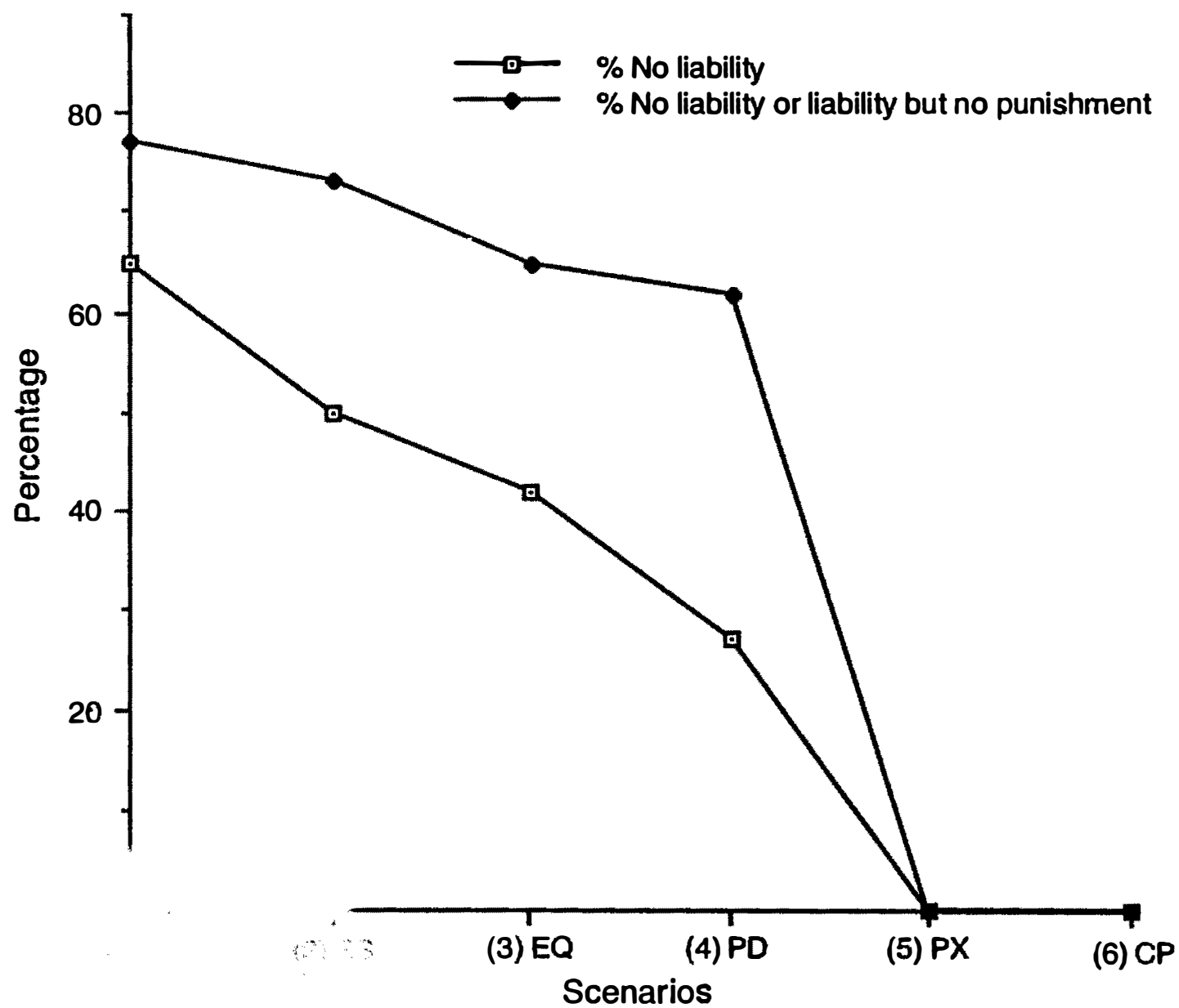

iui de:

son to commit an offense has been shown to be a power-

the $\mathrm{pi}$ $v$ in other contexts. It should be no surprise to see that by a mis. $e$, has some effect in generating judgments of liability se rch may create a ..ference between our result and the result that would likely emerge from an actual court process. Our scenarios were written "from the eye of God," as it were, and gave the readers access to the inner workings of the person's mind. Thus, in this case our subjects were able to believe unequivocally that a person had formed a settled intent to commit a crime. In the real world, it would be extraordinarily difficult to establish intention with such certainty in the absence of any conduct and, as a result, more difficult to successfully prosecute the individual.

The scenarios in which the dangerous proximity test criteria are not met are scenarios 1 through 4 . Notice that they get very low assignments of liability, and the line connecting them in Figure 2.3 is essentially flat, which suggests that respondents are seeing these cases as alike in the degree of liability they generate. In scenario 5, in which the criteria for "dangerous proximity" are met, the liability 
ratings of our subjects become correspondingly much higher. This suggests that dangerous proximity best reflects what our respondents perceive to be the critical point after which attempt liability should be assigned. Figure 2.4 indicates that between 27 percent and 65 percent of our subjects indicate no liability in the first four scenarios, where the defendant does not reach the point of dangerous proximity. However, this percentage drops universally to zero in the scenarios where the dangerous proximity test criteria are met (scenarios 5 and 6 ), a difference that is statistically significant $(p<.01)$. (To say that a result, in this case a difference in the percentages, is "statistically significant" is to say that it is highly unlikely to have occurred due to some chance fluctuation. Thus, it is appropriate to interpret it as a "real" difference in subjects' responses, caused by the differences between the scenarios. The term " $p<.05$ " means that there are only five chances out of one hundred that the result could have occurred by chance; " $p<.01$ " indicates one chance out of a hundred.) Even more strikingly, the percentage of subjects who would impose no liability or no punishment ranges between 62 percent and 77 percent for scenarios 1 through 4 but drops to zero for the latter two scenarios 5 and $6(p<.01)$. These results reveal a relatively dramatic difference in the subjects' view of the scenarios where the dangerous proximity test is not met (scenarios 1 through 4), and those where it is, (scenarios 5 and 6). This suggests that, of the available tests, the common law's dangerous proximity test, as applied to this case, seems to best reflect the views of a majority of the subjects.

Our respondents assign different liabilities for attempts than for completed crimes: the liability mean for the dangerous proximity scenario in Table 2.2 (row $5-5.35$, or 1.8 years $^{5}$ ) is significantly lower than the completed offense scenario's liability mean of 6.12 , or 3.4 years (row 6 ). This result is consistent with the traditional grading of attempt as less serious and is inconsistent with the Model Penal Code's grading of attempt as being on an equal footing with the completed offense. ${ }^{6}$ The Code's grading of attempt seems all the more incongruous when the liability for a completed offense, 6.12 (3.4 years), is compared to that for the Code's test for attempt, the substantial step test, of 1.54 (7.5 days). While the Code dictates that a person held for attempt is liable at a grade equal to that for the full offense, a majority of our research subjects ( 73 percent-see row 2 of column $c$ ) think that no liability or punishment is appropriate for a mere "substantial step." In Chapter 6, we further examine these matters of proper grading.

We turn our attention next to the effects of an individual's voluntary desistance from committing the crime or the renunciation of it after its completion (Table 2.2 , scenarios $3 \mathrm{a}, 5 \mathrm{a}$, and $6 \mathrm{a}$ ). Figure 2.5 presents the data for these scenarios. In that figure, bar graphs are presented, with each scenario involving renunciation shown paired with its nonrenunciation equivalent. (The data for the nonrenunciation equivalents are found in scenarios 3,5 , and 6 .

We call your attention first to the leftmost pair of scenarios, which are the cases in which the individual takes an unequivocal step in the direction of the crime. Clearly, renunciation reduces the assigned penalty; but notice again that our re- 
FIGURE 2.5 Effect of Renunciation in Reducing Liability

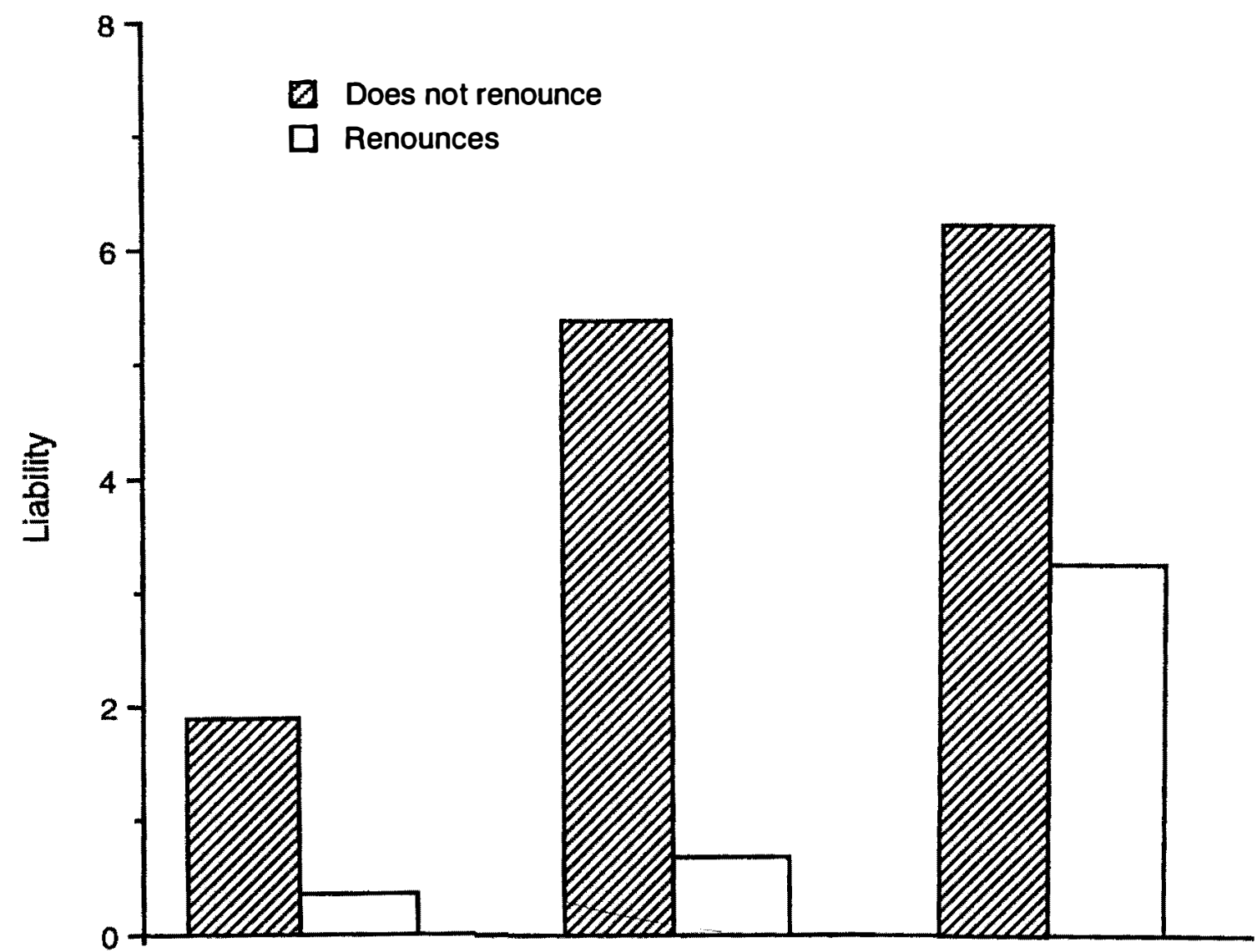

(3) Unequivocality

(5) Dangerous Proximity

(6) Completed Offense

\section{Degree of Attempt}

spondents assign very little penalty in the first place to that case ( $1.81 ; 11.4$ days), so we do not want to make much of this result. Looking next at the case where renunciation comes after dangerous proximity (case 5a, the middle pair of bars), we note that the judgments of our subjects conflict with aspects of both the common law doctrine and the Model Penal Code. While the common law does not provide a defense when a person renounces after satisfying the dangerous proximity test, our results indicate a sharp (and statistically reliable, $p<.05$ ) decrease in punishment assigned. Referring again to Table 2.2, 85 percent of the subjects think either no liability or no punishment is appropriate in this renunciation case while no subject thinks no punishment is appropriate for the individual who reaches the level of dangerous proximity and does not renounce the attempt; that is, it seems that the majority of subjects view renunciation even after taking the dangerous proximity step - the step that they think generally created an attempt of fense-as a legitimate defense. Unlike the common law, the Model Penal Code does provide a defense in such a case-if the renunciation is complete and voluntary-and this 
seems to fit our subjects' intuitions; if the locksmith decides not to commit the crime for his own reasons, very low liability is incurred.

This result is somewhat ironic. As noted previously, the common law recognized no renunciation defense. However, the Model Penal Code introduced the renunciation defense. Why? The drafters realized that they were essentially required to create it to avoid a problem created by their other planned changes. Specifically, the early intervention authorized by their substantial step test means that a person who is in the early stages of committing a crime is liable. This factor, combined with the Model Penal Code drafters' grading of attempts as equal to the substantive offense, means that a person who has taken a substantial step toward a crime is liable for the full penalties for the commission of that crime. Thus, there is no incentive for the "rational criminal" who has taken a substantial step to stop before commission of the crime; surely a socially undesirable reinforcement contingency! Here, again, is the problem: If the person who begins a crime is liable at a level equal to the full substantive offense, he or she has little reason to stop once his or her conduct constitutes an offense. Because the substantial step test for commission is satisfied early in the process, this incentive to continue kicks in early. Thus, the renunciation defense is provided to give attempters a reason to stop-right up until the moment before the offense is complete. If one rejects the Code's equal grading provision and substantial step provision, as our test subjects appear to do, the reasons that led to the creation of the renunciation defense in the Model Penal Code disappear. Yet the data suggest that the subjects would keep such a defense. Thus the Code's defense is supported by the subjects but apparently for reasons other than those given by the Code.

Note that the effect of renunciation on liability according to our subjects is significantly less after completion of the of fense (as illustrated by the rightmost pair of bars) than before completion (as with the two other example pairings). The assigned liability drops from 6.12 (3.4 years) for the unrenounced completed offense (case 6) to 3.23 (2.8 months) for the completed but renounced and "undone" offense (case 6a). The Code also gives significance to the point of completion-even more so than our subjects-it denies a defense for renunciation after the of fense is complete. That our subjects give a significant mitigation even after the offense is complete may reflect a view that such renunciation undercuts the resoluteness of the offender's original intent and, therefore, retroactively alters their assessment of the offender's original culpability. As discussed below, an alternative explanation arises from the absence of the harm of the offense.

In comparing the case in which the person desists (our of fear of being caught) after satisfaction of the dangerous proximity test to the case in which the person renounces due to a change of heart about the misdeed, we find that the liability assigned by our subjects decreases from 1.58 ( 8.8 days) to 0.69 (less than 1 day). (Please again refer to Table 2.2 for these comparisons-scenarios $5 \mathrm{a}$ and $5 \mathrm{~b}$, col- 
umn a.) A good majority of the subjects (65 percent) still think no punishment is appropriate (column $c$ ), although 65 percent would assign liability (column $b$ ). The Model Penal Code joins the common law, however, in barring a defense based on these facts. The absence of the harm or evil of the completed offense appears to have a greater effect on our subjects than it has in the legal doctrine.

Our subjects' focus on the occurrence of the harm or evil of the offense also is highlighted by their collective response to the case of the offender's renunciation after completion of the offense. That the offender "undoes" the harm (returns the stolen goods) does not exempt him from liability according to our subjects (see the rightmost pair of bars in Figure 2.5) but significantly reduces the offender's punishment from 6.12 (3.4 years; 100 percent imposing punishment) to 3.23 (2.8 months; 73 percent imposing punishment). Notice also that when the offender, as above, renounces after completion but is unable to "undo" the offense, liability is much closer to the unrenounced completed offense than it is to the renounced completed offense. The renouncing thief who cannot "undo" the offense is given an average score of 5.35 ( 1.8 years; 96 percent imposing punishment).

Further results suggest that occurrence of the harm or evil is not the only influential factor; remorse counts as well. The two may be equally influential. (Again, please refer to Table 2.2 for these comparisons.) Note that the liability means are the same in the dangerous proximity attempt scenario (scenario 5) and the completed offense scenario in which the offender would like to but is unable to "undo" the offense (scenario $6 \mathrm{~b}-5.35 ; 1.8$ years). In the former case, the person has the evil desire to commit the offense but has not caused the harm of the offense. The latter scenario has the harm of the offense but a change of heart leading the offender to want to "undo" the offense. These liability means differ significantly from other scenarios in crucial ways: They are each significantly lower $(p<$ .05 ) than the liability assigned to the successful, unrepentant offender (scenario $6-6.12 ; 3.4$ years), in which the harm exists in the absence of any remorse; and both means are higher than in the scenarios in which (1) renunciation occurs before completion (scenarios $3 \mathrm{a}$ and $5 \mathrm{a}-0.38$ and 0.69 , respectively; both less than 1 day) and (2) renunciation occurs after completion (scenario 6a-3.23; 2.4 months). This patterning of results suggests that both the occurrence of the harm and the perpetrator's remorse about that occurrence figure in our respondents' assessments of punishment.

Finally, it is important to note that our respondents frequently selected the "liability but no punishment" option in this study (as is effectively shown in Figure 2.4). This option was used not only in the case of renunciation and desistance immediately after the point of dangerous proximity but also in those scenarios in which the person satisfies an attempt test short of dangerous proximity. (Compare columns $b$ and $c$ for scenarios 2,3 , and 4 in Table 2.2.) These results may suggest that our subjects think it important to disapprove of the person's conduct (and thus a majority would impose liability in each case - 50 percent, 58 percent, 
and 73 percent, respectively; these percentages are obtained by subtracting the no-liability percentages from 100 percent) but are hesitant to impose punishment in the absence of sufficient proximity to the harm or evil of the offense. The subjects may want to disapprove of the person's conduct and intention but, because they ultimately see insufficient blameworthiness, are hesitant to impose punishment. The interesting implications of the use of the "liability but no punishment" option, and what our respondents are attempting to communicate by it, are discussed further in Chapter 7. We note here, though, that the use of this option illustrates the distinctly dual nature of the law's function: rule articulation (announcing ex ante the rules of proper conduct) and liability assignment and grading (ex post adjudication of violations of the rules).?

\section{Study 1: Summary}

The liability results of the objective requirements of attempt study might be summarized in psychological terms as follows. In the view of our subjects, punishment ought not to be imposed until a person has reached a point of dangerous proximity to completion of the offense. ${ }^{8}$ Further, the level of punishment for attempt ought to be significantly less than that for the completed offense. Once the point of dangerous proximity is reached, punishment still may be avoided by complete and voluntary renunciation. Finally, when an offense is completed, a change of heart will only mitigate punishment, although undoing the offense will mitigate punishment still further.

With respect to legal implications, this study sought to determine which of the tests for the objective requirement of attempt best reflects the community's view. In the scenarios in which the person has gone just far enough to satisfy the substantial step test, the unequivocality test, or the probable desistance test, a strong majority of subjects would impose either no liability or no punishment. But, in the scenarios in which the person satisfies the common law's dangerous proximity test, a dramatic shift in opinion occurs: All of the subjects would impose both liability and punishment. This would seem to suggest that, if the community's view were to be the guiding principle in the definition of the offense, criminal codes should revert to the common law's dangerous proximity test. If early intervention by law enforcement is desired to increase the effectiveness of crime prevention, legislation could create authority for enforcement officials to intervene without holding the person liable for an attempt to commit the substantive offense or to intervene by holding the person liable only at a low level. Liability might be imposed at a fixed misdemeanor level, for example, for an offense of "Preparing to Commit an Offense" or something of such nature.

While preferring the common law's dangerous proximity test for determining when attempt liability should attach, our subjects also recognize a def ense for voluntary and complete renunciation, as does the Model Penal Code. Indeed, many subjects indicate that they would permit a defense-and a majority would impose 
no punishment-if the person desists out of fear of being caught rather than simply from a change of heart. This confirms what we will present in several other studies: Unlike the Model Penal Code, which downplays the significance of resulting harm, our subjects' liability and punishment judgments are highly influenced by whether harm or evil occurs. Indeed, a significant minority of subjects impose no punishment on the person who completes the offense but soon thereafter renounces and undoes the primary effects of his offense. Chapter 6 discusses further the community's and the law's treatment of resulting harm in grading offenses.

\section{STUDY 2: CREATING A CRIMINAL RISK}

Just as someone may be liable for attempting to cause a prohibited harm, so too may one be liable for creating a risk of causing a prohibited harm, even if the harm does not come about. Not every risk created is a criminal risk. Current codes typically limit liability to substantial risks of harm. Legal codes set a minimum standard of criminal risk to distinguish those risks to be regarded as criminal from those that are not. Where to set the minimum standard is a complex question for legal code drafters, but most are in agreement that the ultimate judgment of criminality of the risk is a product of, among other things, the seriousness of the harm risked, the probability of the harm occurring, and the purpose of the conduct. ${ }^{9}$ For example, one may create a high risk of getting a passerby wet in the way one sets a lawn sprinkler, but the seriousness of the harm risked may be sufficiently low so as not to make this a criminal matter. Whenever one drives a car, one risks causing death to pedestrians; but the likelihood of killing one is low enough, and the purpose of the conduct is valuable enough, that the simple act of driving is not considered a criminal risk.

Thus, an assessment of whether someone creates a criminal risk depends in large measure on the degree of harm and the probability of the harm occurring. In this criminal risk study, we sought to determine both the minimum level of potential harm and the degree of risk that the community believes are necessary for assignment of criminal liability. In addition, we tried to determine what interaction, if any, may exist between these two factors.

In particular, we set out to determine whether these two elements of risk affected liability independent of what the respondents believed to be the person's "culpable state of mind" as to causing the prohibited result. To do this, we needed to counter a common psychological tendency of individuals reading descriptions of cases. If a person is described as creating only a slight risk of harm, it might commonly be thought that he or she is at most simply aware of such risk. By comparison, observers may think that a person who creates a great risk of harm is more than just "aware" of that risk; the person may be seen as at least knowing and perhaps in some sense intending that such harm will come about (Karlovac and Darley, 1988; Fischoff, 1975). Thus, if one compares a case in which a person 
creates only a small risk to a case in which a person creates a high risk, greater liability assigned in the latter case may be a function of a belief that that person has a more culpable state of mind.

In the following study, we attempted to hold constant the person's culpable state of mind in order to determine whether increased degree of risk and increased potential harm would, according to our subjects, carry the same increases in liability and punishment that the code suggests, without the possibility that subjects would infer a higher culpable state of mind of the person when that person took greater risks. To accomplish this, we created a scenario in which we specified the person's state of mind, and we set the person's state of mind at "purposeful." This means that our conclusions will be limited to cases in which some degree of harm was intended.

The design of this study - and almost all other studies in this book-is identical in overview to that described in Study 1: Respondents read several versions of the same core scenario and responded to questions including judgments of liability and punishment. In this risk study, we presented the respondents with the following core case: A wife, wishing to kill her spouse, puts poison into his breakfast food. In different versions of the case, the poison (unbeknownst to the wife), if ingested, would cause only minor stomach cramps (slight injury), material and substantial damage to the digestive tract (moderate injury), or alternatively, and as planned, death (high injury). We varied the risk of harm by altering the likelihood that the husband would actually eat the poisoned food. Our results are presented in two tables later in this section.

We hoped that our subjects would interpret the scenarios in the ways we intended. For instance, in this study, we hoped that it would be clear to our subjects that the wife intended to kill her husband. However, in research of this sort, it is always wise to check to see how the subjects actually did perceive the stories. To do this, we asked our subjects to report their perceptions of the case, as well as the liability they would assign to the perpetrator. These check questions are called "checks on the manipulations." In this risk study, we asked such questions. Before discussing liability judgments, let us first look at whether the respondents perceived the various facts of the case as we intended them to. This is determined by examining the respondents' answers to the various questions shown in columns $a$ through $c$ of Table 2.6. (The exact version of the questions and the numerical scales on which the subjects responded to those questions are included in the footnotes to the table.) We note that we were reasonably successful in setting the readers' perceptions of the offender's state of mind ( column $c$ ). Their ratings were between 3, which would be agreement with the statement that "she knew or was practically certain that the victim would die," and 4, "it was her purpose to cause the victim to die," with the average rating falling considerably closer to 4 , or "purposeful." " Second, the respondents perceived the variations of risk as we hoped they would, with the slight-risk scenarios providing an average risk rating of 3.59 
TABLE 2.6 Subjects' Perceptions of the Creation of Risk

\begin{tabular}{lccc}
\hline Scenarios & $\begin{array}{c}\text { (a) } \\
\text { Degree of } \\
\text { Risk }\end{array}$ & $\begin{array}{c}\text { (b) } \\
\text { Severity of } \\
\text { Outcome }\end{array}$ & $\begin{array}{c}\text { (c) } \\
\text { Actor's State } \\
\text { of Mind }\end{array}$ \\
\hline $\begin{array}{c}\text { Slight risk } \\
\text { 1. Slight injury }\end{array}$ & 3.21 & & \\
2. Moderate injury & 3.62 & 3.29 & 3.63 \\
3. High injury & 3.95 & 5.39 & 3.76 \\
Medium risk & & 8.15 & 3.76 \\
4. Slight injury & 5.17 & & 3.74 \\
5. Moderate injury & 5.27 & 3.29 & 3.69 \\
6. High injury & 5.67 & 5.61 & 3.71 \\
High risk & & 8.46 & 3.81 \\
7. Slight injury & 9.90 & & 3.79 \\
8. Moderate injury & 9.17 & 3.48 & 3.88 \\
9. High injury & 9.30 & 5.86 & 3.80 \\
Accomplished & & 8.76 & 3.81 \\
10. Slight injury & 9.90 & & 3.88 \\
11. Moderate injury & 10.02 & 3.02 & \\
12. High injury & 10.46 & 5.55 & 8.79 \\
\hline
\end{tabular}

Key to column heads:

(a) The chances that the attempt will succeed and the victim will suffer from its effects on this occasion are approximately: $0=$ doesn't occur, $1=10 \%$ chance, $2=20 \%$ chance, $\ldots 10=$ near $100 \%, 11=$ the event occurs.

(b) If the attempt does succeed, the result will likely be: $1=$ no effect, $5=$ significant or substantial injury, $9=$ death.

(c) Pick one or more of the following to describe the actor's state of mind:

1. The actor did not realize that there was a risk that the victim would die.

2. The actor realized that there was a risk that the victim would die, but did not care.

3. The actor knew or was practically certain that the victim would die.

4. It was the actor's purpose to cause the victim to die.

(column $a$ of Table 2.6), the moderate-risk cases an average rating of 5.37, and the high-risk cases an average rating of 9.46. In the "accomplished" cases, in which the risked harm actually occurred and the husband either suffered stomach cramps, digestive-tract damage, or died, the risk ratings were higher ( 10.13 on average) but only slightly higher than the ratings in the high-risk cases. Our respondents also perceived the severity of the outcome (column $b$ of Table 2.6) as we had intended, with the slight injury receiving an average severity rating of 3.27 , the moderate injury an average of 5.60, and the high injury an average of 8.54 $[\mathrm{F}(2,78)=260.54, p=.001]$. (The $\mathrm{F}$ test is another way of testing the statistical 
TABLE 2.7 Liability for the Creation of Risk

\begin{tabular}{|c|c|c|c|}
\hline Scenarios & Liability & $\begin{array}{c}\text { (b) } \\
\% \text { No Liability } \\
\text { (N) }\end{array}$ & $\begin{array}{c}\text { (c) } \\
\% \text { No Liability or } \\
\text { No Punishment } \\
(\mathrm{N}+0)\end{array}$ \\
\hline \multicolumn{4}{|l|}{ Slight risk } \\
\hline 1. Slight injury & 6.81 & 0 & 10 \\
\hline 2. Moderate injury & 7.48 & 0 & 2 \\
\hline 3. High injury & 8.24 & 0 & 0 \\
\hline \multicolumn{4}{|l|}{ Medium risk } \\
\hline 4. Slight injury & 6.93 & 0 & 10 \\
\hline 5. Moderate injury & 7.71 & 0 & 0 \\
\hline 6. High injury & 8.51 & 0 & 0 \\
\hline \multicolumn{4}{|l|}{ High risk } \\
\hline 7. Slight injury & 7.39 & 0 & 7 \\
\hline 8. Moderate injury & 8.00 & 0 & 2 \\
\hline 9. High injury & 8.95 & 0 & 0 \\
\hline \multicolumn{4}{|l|}{ Accomplished } \\
\hline 10. Slight injury & 7.33 & 0 & 7 \\
\hline 11. Moderate injury & 8.17 & 0 & 0 \\
\hline 12. High injury & 9.81 & 0 & 0 \\
\hline
\end{tabular}

Liability Scale: $\mathrm{N}=$ No criminal liability, $0=$ Liability but no punishment, $1=$ 1 day, $2=2$ weeks, $3=2$ months, $4=6$ months, $5=1$ year, $6=3$ years, $7=7$ years, $8=15$ years, $9=30$ years, $10=$ life, and $11=$ death.

significance of the obtained differences between groups. The " $p<.001$ " element of the statistic tells us that the result obtained would have occurred by chance only once in a thousand times.)

Now that we have established that our subjects saw the case as we had hoped, we can turn to an examination of the liability results. Table 2.7 reports liability ratings assigned in each scenario, along with percentages of respondents who chose "No Liability" and percentages of those who chose either "No Liability" or "Liability But No Punishment."

Note that in all variations of the scenario, our subjects assign some liability; no respondents recommend "No Liability" in any of the scenarios. This suggests that, while the extent of harm risked and the probability of its occurrence may be relevant to grading, no minimum level of potential harm or minimum probability is required before liability can be assigned. Or, if there is such a minimum, it is below even the lowest levels of harm and probability tested here. Presumably, the person's intention here to commit the offense and the poisoning of the cereal, without more, are sufficient for criminal liability. This is consistent with the results of the attempt study discussed previously. 
FIGURE 2.8 Liability as a Function of Risk and Injury

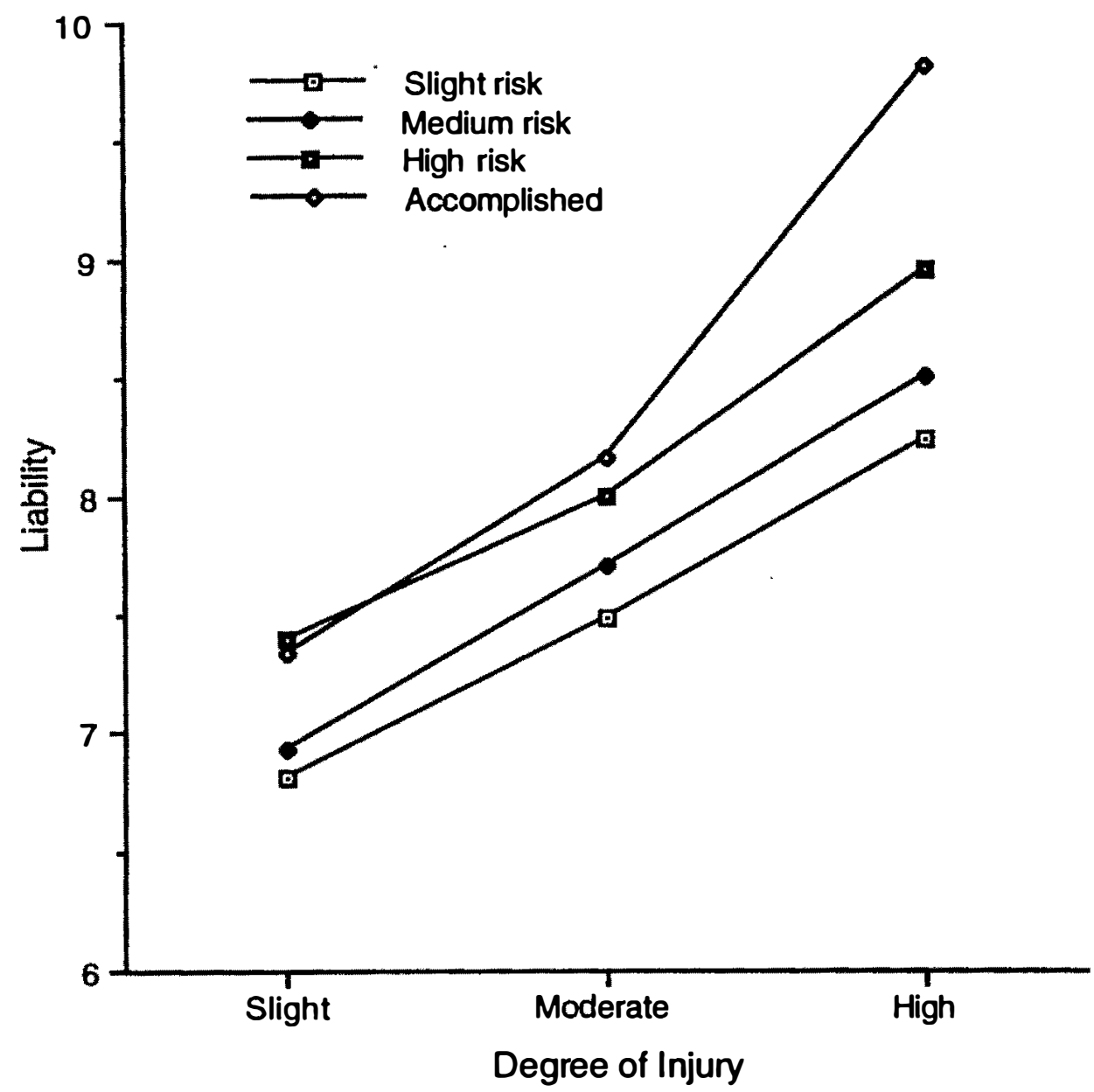

Because of this, most of the results of this study concern issues of grading, which is the subject of Chapter 6, but we will review those issues here in preparation for a more complete discussion in Chapter 6. Figure 2.8 suggests that as either the probability of injury or the severity of the risked injury increases, the liability assigned to the risk-taker increases. [Risk: $\mathrm{F}(3,117)=11.28, p=.001$; Severity: $\mathrm{F}(2,78)=24.96, p=.001$.]

Interestingly, the interaction between these two factors is statistically significant $[F(6,234)=7.53, p=0.001]$. This result suggests that the probability and harm variables, taken together, have effects on judgments of liability that are not equivalent to the sum of their independent effects. Specifically, Figure 2.8 shows that the accomplished, high-injury scenario draws an assignment of liability that is considerably more severe than the others (and thus may be the liability score that makes the interaction significant). There is a distinct tendency for respondents to be particularly severe in assigning liability to the case in which the wife intends to kill her husband and actually does so. In this planned and successful murder, our subjects assign her a sentence that corresponds to nearly life imprisonment. 
With the exception of this particular case, however, one is struck by the general continuity of the respondents' judgments. As either the probability or the severity of the harm risked increases incrementally, so too does the liability judgment in an essentially corresponding fashion.

Are our respondents' reactions consistent with the criminal codes? Only in a broad sense. Because all of our scenarios described an individual who was purposeful as to committing the crime, the Code would treat all of our scenarios as ones of attempted murder, without making distinctions depending on the probability of the harm or the severity of the harm risked. Our respondents, in contrast, alter their sentences depending on these factors-and do so in a nontrivial way. First, they assign greater liabilities as a function of the degree of risk. (This is shown by the consistent differences in elevation of the high, moderate, and slight risk lines of Figure 2.8.) In other words, our respondents judge that the actual risk created is relevant to their liability judgments. This is consistent with their tendency to be more harm-oriented than the Code, with the present harm being in the creation of risk. Second, as the quite steep slopes of the four lines of Figure 2.8 show, our respondents also base their liability judgments on the amount of injury that is actually intended or "risked." Again, we see their judgments based on the extent of the risk actually created; not just that intended. We will return to this issue in Chapter 7 for a fuller discussion of its implications.

What remains to be investigated are those cases in which an individual creates a risk of a serious harm with a high probability of success-but does so at a much lower level of culpability (for instance, recklessly or even negligently). How would research subjects assign liability to those cases? Another useful study would test scenarios in which the person intentionally creates only a risk of harm and in which the extent of harm risked varied. This would reveal whether the subjects punished intentional risk creation of different extents of harm differently. Much remains to be studied in this area.

\section{STUDY 3: OBJECTIVE REQUIREMENTS OF COMPLICITY}

One can be held accountable for another person's conduct if one is judged to be "an accomplice" of that other person. In this study, we examine the objective requirements of "complicity" - that is, what a person actually must do in order to be liable as an accomplice. (In study 9-in Chapter 4-we consider the culpability requirements for complicity: that is, the culpable state-of-mind requirements.)

What sorts of actions has the law treated as sufficient for complicity? To be an accomplice under common law a person has to encourage or assist the perpetrator in some way. Two general ways of behaving complicitously were thereby recognized: First, by encouraging another to commit a crime, one may cause or reinforce another's settled intention to commit the crime; second, by assisting another to commit a crime, one not only implies encouragement but more 
strongly and causally contributes to the commission of the offense. Note that the common law did not require that the action of the accomplice be necessary for commission of the offense-one could be an accomplice by standing watch even though those who would commit the crime do not show up or by being ready to drive a backup getaway car even though it is not needed. Similarly under common law, encouraging a principal to commit a crime engenders liability whether or not that encouragement was necessary for the commission of the crime.

It was not enough under common law (for liability), however, that a person merely tries to assist or encourage the perpetrator if such attempts by the person are unsuccessful. If the person provides neither actual assistance nor actual encouragement (because his unsuccessful attempt to assist was unknown to the perpetrator, for example), he is not liable as an accomplice.

The Model Penal Code drafters found this common-law exemption for an unsuccessful attempt to encourage or assist inappropriate; they broaden the scope of complicity by assigning liability to an actor's unsuccessful attempt to encourage or assist-A person need simply "aid or agree or attempt to aid" the perpetrator to be held liable as an accomplice.

Where complicity liability is established, the actor is held liable for the full offense. Unlike inchoate offenses, such as attempt, in which the actor commonly is accountable for a lesser grade of liability than the offense attempted, complicity is a means of establishing full-offense liability. Thus, from the law's view, an accomplice has the same liability as the perpetrator.

In this study, we tested our subjects' views on the minimum amount that a person could contribute in encouraging or assisting an offense to be held criminally liable for it. We also tested whether our subjects would alter the degree of liability that they would impose according to the person's degree of contribution to the offense. Few codes take degree of contribution into account in setting the grade of an accomplice's liability, but such a scheme has been introduced, albeit with relatively broad categories, by the United States Sentencing Commission. ${ }^{11}$

In this study, we presented our subjects with a series of scenarios, each of which presented a different degree of contribution to a killing, including scenarios in which the person attempts to assist but fails. In order to test whether our subjects' assessment of liability depended on the actual occurrence of a resulting harm, such as causing a death (we have demonstrated in other studies-for instance, Study 1 -that resulting harm is a powerful determinant of liability and punishment), several of the scenarios presented our respondents with instances in which the principal actor-the "perpetrator"-was not successful in his attempt to kill.

The core of these scenarios involves an unhappily married woman who "longs for her husband's death, which would make her a rich widow." A friend of the wife is aware of her feelings and assists or tries to assist her in various ways to bring about her husband's death, and these various methods form the variation in the scenarios. The wife alternatively kills her husband or attempts to do so and fails. 
In Table 2.9, the three "murder fails" cases are scenarios $2 a, 4 a$, and $6 a$, and their scores are boldfaced.

The variations in the actions of the friend of the wife constitute the different scenarios in Table 2.9. Column a shows the liability assigned to the wife for her actions - she is assigned a liability of 10 or above (the equivalent of a life sentence) when the murder succeeds. When her actions fail to kill her husband, her liability drops to about 7.5 ( 11 years, $p<.05$ ). We see again the pattern of our subjects giving lesser sentences for an attempt than for a completed crime. In the specific description of the failed attempt, it is reported that the wife "shot at her husband but missed"-therefore, no wound is inflicted. The respondents could have interpreted the miss as signaling that the wife is irresolute in her purpose. These two facts (no injury/possible lack of resolve) may help explain the considerable reduction in sentence for the wife in the three no-death scenarios.

Let us next examine the central question of this third study, which is the liability assigned to the accomplice. In scenario 1, the male friend is described as realizing that "if she did decide to do it, he would be willing to help her," but before he can communicate this to her, "she shoots her husband dead." Look at columns $b$, $c$, and $d$ for scenario 1 , in which the liability assignments for the complicit friend of the wife are given. In this scenario, no liability is assigned to the friend. As we have done before, we asked our subjects various questions about how they perceived the case. The exact questions are given in the footnotes to the table, and our subjects' numerical responses make up columns $e$ and $f$. As column $e$ of scenario 1 indicates, our respondents agree that the accomplice approved of the wife's murderous actions, with average ratings of between 8 and 9 on a scale in which 7 indicates agreement and 9 indicates strong agreement. (Notice, too, that in all cases the respondents agree that the friend approves of the wife's actions; thus, that fact can be taken as established for our discussion of all of these scenarios.) As column $f$ of scenario 1 indicates, the respondents agree that the friend "does not help (the wife) at all."

In various of our other scenarios described in this and other chapters, the respondents assign some liability if they decide that the individual has formed a settled intention to commit a crime and acts upon that intention. But here they assign no liability to the accomplice who decides he would be willing to help. What might cause this difference? We submit two possible explanations: (1) Deciding that one is willing to help in the commission of a crime is one step more removed than deciding to commit the crime, and that step might have been sufficient to make a difference to our subjects; and (2) Alternatively, "realizing that one would be willing to help" may be read as a less-settled and -formed intention than, for instance, the intention formed in the attempt case of Study 1, in which the person plans to rob the safe.

Look next at scenarios 2 and $2 a$, in which the friend attempts to help the wife kill her husband but fails to do so even though the murder is accomplished (2) or 


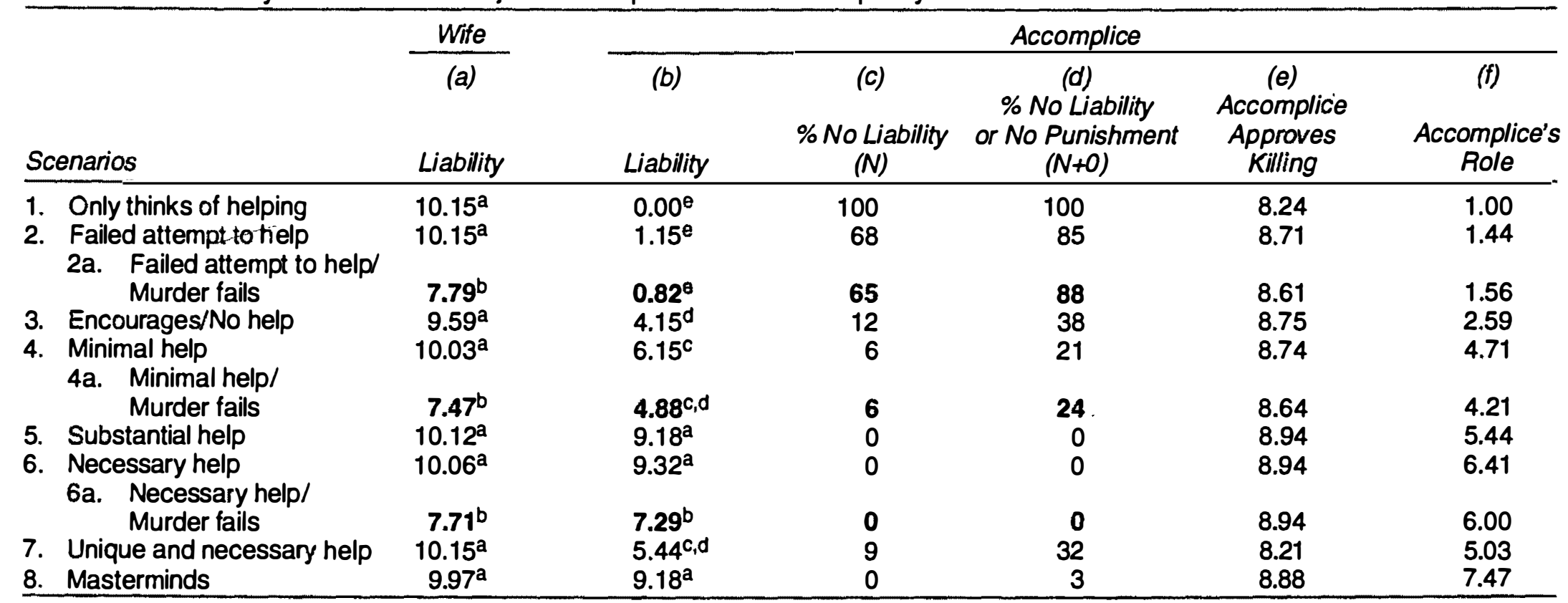

Liability Scale: $\mathrm{N}=$ No criminal liability, $0=$ Liability but no punishment, $1=1$ day, $2=2$ weeks, $3=2$ months, $4=6$ months, $5=1$ year, $6=3$ years, $7=7$ years, $8=15$ years, $9=30$ years, $10=$ life, and $11=$ death.

Key to column heads:

(e) The accomplice approves of the wife killing her husband: 1=strongly disagree, 3=disagree, 5=unsure, 7=agree, 9=strongly agree.

(f) The accomplice's role in the crime can best be described by which of the following statements?

1. The accomplice does not help the wife at all.

2. The accomplice attempts to help the wife but is unsuccessful in the effort.

3. The accomplice and the wife reach an agreement that she is going to kill her husband.

4. The accomplice provides minimal help to the wife.

5. The accomplice provides substantial help to the wife.

6. The accomplice's assistance is necessary if the wife is going to kill her husband.

7. The accomplice provides unique help that is necessary for the wife to kill her husband.

8. The accomplice masterminds the crime.

Note: Superscript letters indicate significance at the $p<.05$ level by a Newman-Keuls test. Matching superscripts indicate means that are not statistically significantly different from each other. Means are compared within columns only. 
not accomplished (2a). (The attempt to help is unknown to the wife.) These are examples of cases in which the accomplice provides no real assistance or encouragement of any kind. That individual incurs very little liability-next lowest to the liability assigned to the individual who only thinks about helping. This result is dramatically different from the Code's imposition of full offense liability for such a failed attempt to assist.

In the "encourages" scenario (row 3), the person has agreed with the wife that she should go ahead with her plan to murder her husband. Note from column $f$ that respondents tend to agree that the two of them have reached an agreement that she will kill her husband. This "giving of encouragement" is recognized by both the common law and the Model Penal Code as filling one of the tests for accomplice liability and is seen by our subjects as requiring the assignment of some liability, although not a large amount. ${ }^{12}$ (Such agreement also would satisfy the test for conspiracy liability, which the Model Penal Code sets at the same grade as the substantive offense but which most jurisdictions grade as less than the full offense.)

The liability assigned to the friend, 4.15 , is equivalent to a sentence of about 7 months. But notice that about 38 percent of the respondents think that, whether they find the person guilty or not, the person does not deserve any time in jail. Again, this seems significantly less severe than the punishment provided by the Code. (However, the extent of the code-community difference may not be as great in other "agreement" cases. In this scenario, the wife is described as already having decided to murder her husband-so the agreement of the friend is probably not seen as necessary to the wife's decision, although her decision is undeniably reinforced by the agreement. The contrast case to this, that might have caused subjects to assign more liability to the accomplice, would occur when he gave encouragement before the wife decided to kill her husband.)

With this general introduction to the results, let us look at the patterning of the liability judgments. The eight murder scenarios describe what we hoped would be seen as an increasing degree of help and encouragement to the wife in her plan to kill her husband. The checks-on-the-manipulations questions help us determine if the subjects perceived the scenarios in the way that we had hoped. In the "failed attempt to help" scenarios (rows 2 and $2 a$ ), the friend overhears the wife tell her plan to her sister, and he then attempts to meet the wife to supply the necessary gun. However, before he reaches her, she has already shot at her husband. Respondents see this as midway between providing no help and an attempt to provide help that is unsuccessful (ratings of 1.44 and 1.56, respectively, in column $f$ ). In the minimal help scenarios (rows 4 and $4 \mathrm{a}$ ), the wife has formed the plan to shoot her husband, and the friend tells her where to buy the gun. Obviously, his agreement with the plan is implicit in that action. Respondents see this as providing somewhere between minimal and substantial help (ratings of 4.71 and 4.21 , respectively, in which $4=$ minimal help and $5=$ substantial help). In scenario 5 , the 
friend gives the wife his gun with which to shoot the husband, thus providing substantial help, and she uses the gun to kill her husband. (We did not run the scenario in which the friend gives substantial help, and she shoots at her husband and misses.) The respondents agree that he in fact provides substantial help (column $f$, a rating of 5.44, where $5=$ substantial help). In scenarios 6 and $6 a$, the friend provides necessary help. The wife has been unable to obtain a firearm and is given one by the friend. She then confesses that she does not know how to shoot it, and he teaches her how. The respondents saw this as we had hoped, giving ratings of 6.41 and 6 respectively (where $6=$ necessary help).

In scenario 7, the friend provides what we considered to be unique and necessary help; he alerts the wife to the fact that her husband, suspicious of her intentions, is fleeing town, and she goes home and kills him before he can leave. But column $f$ indicates that our subjects did not see the case the way we had hopedinstead, they see the accomplice as providing only substantial help. We will come back to a discussion of this shortly.

In scenario 8, the friend is described as a business partner of the husband and as a person who will be relieved of debt if the husband dies. Knowing that the wife is unhappy with her husband, he provides her with a plan in which she can shoot her husband and make it look like an accident. She follows the plan and kills her husband. While we labeled this the "mastermind" scenario, about half of the respondents agree (column $f$ ) that he "masterminds the crime," while the other half respond that he "provides unique help that is necessary for the wife to kill her husband."

So with the rather important exception of scenario 7, our subjects see the role of the accomplice approximately as we had hoped. What differences did this make in their liability assignments? Comparing the liability ratings of eleven cases is not an easy matter-but we believe that Figures 2.10 and 2.11 will help.

Figure 2.10 is designed to facilitate examination of the effects of increasing degrees of accomplice complicity on the liability he is assigned.In this figure, all of the cases in which the wife successfully kills her husband are charted (except scenario 7, the one that our subjects see so differently), and all of the cases in which the wife fails to kill her husband are eliminated; we will consider them later. As the involvement of the friend moves from "thought only" to failed attempt, and so on, up through masterminding of the crime, the liability ratings of the respondents increase; that is, the liability assignments to the friend increase as his causal involvement in the incident increases $[\mathrm{F}(2,66)=85.90, p<.001]$. Notice, interestingly, that the liability assignments level off once the complicit individual has reached the level of substantial involvement in the killing: To the cases of substantial involvement, necessary involvement, and masterminding the crime, our respondents assign a sentence of about thirty years in prison. This suggests that substantial assistance is something of a threshold after which greater assistance is of little consequence to liability. ${ }^{13}$ The flattening of the accomplice's liability graph 
FIGURE 2.10 Liability Assigned to the Accomplice as a Function of His Involvement

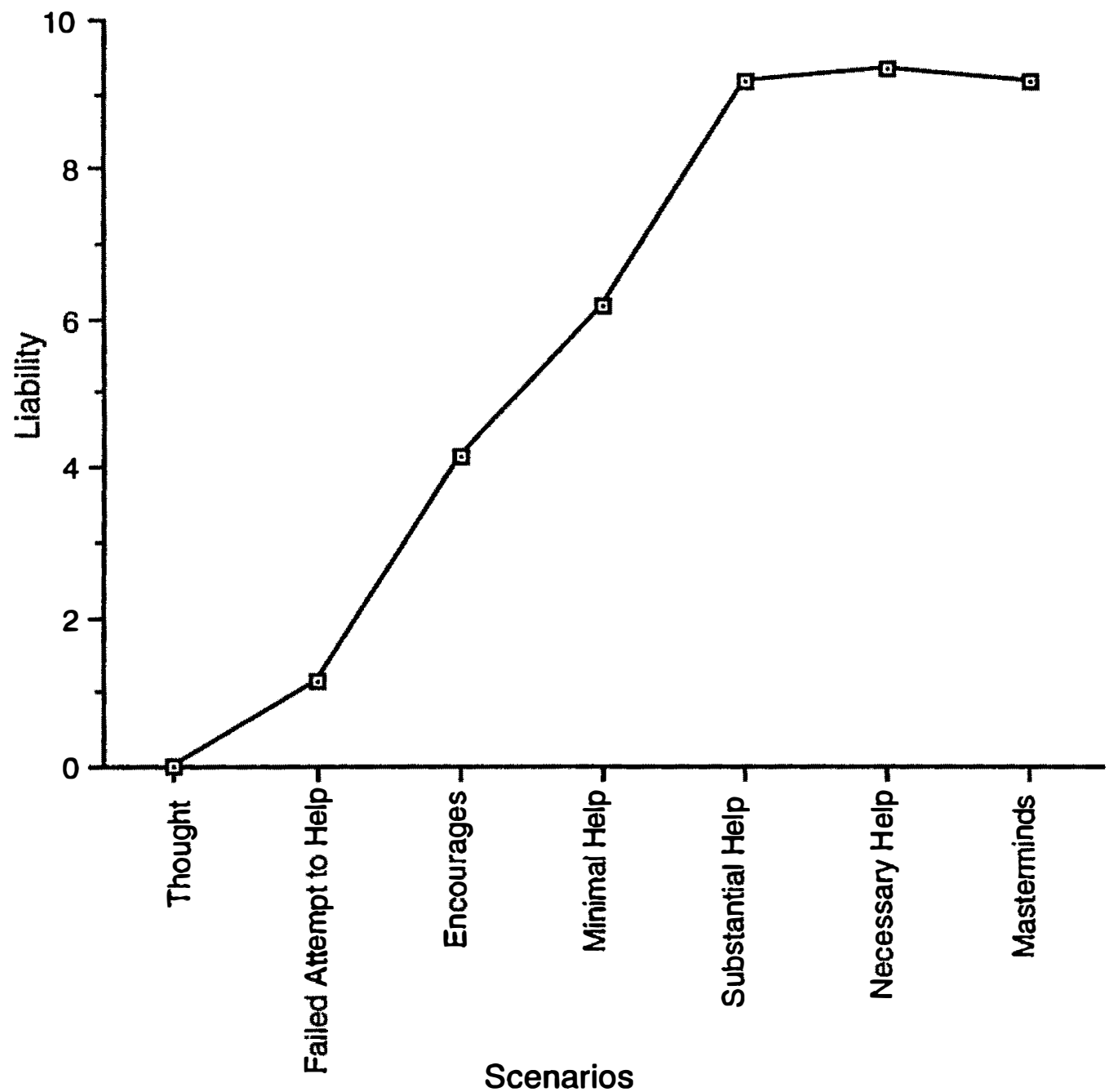

at a level lower than the liability assigned to the perpetrator $(9.18,9.32$, and 9.18 for the accomplice versus $10.12,10.06$, and 9.97 for the perpetrator) also confirms that our subjects see reduced liability as appropriate for the accomplice (as compared to the perpetrator), apparently without regard to how active a role the accomplice played in the three most serious scenarios.

The "mastermind" scenario hints at the possibility of a limit of the liability grade reduction for accomplices. The liability assigned to the masterminding friend is high, above thirty years in prison, but still below that assigned to the wife. Yet, as a glance at Table 2.9 will confirm, the liability assigned to the wife is lower than it is in cases in which she acts more independently. It is interesting to note that some of the responsibility fo: the crime might be beginning to be shifted away from the wife here; this is the only succesful scenario in which she receives less than a life sentence for her actions. As her accountability for the death is reduced, one might expect the mastermind's to increase, perhaps eventually eliminating the usual accomplice grade reduction. 


\section{FIGURE 2.11 Effects of Success or Failure of Killing on Liability for the Accomplice}

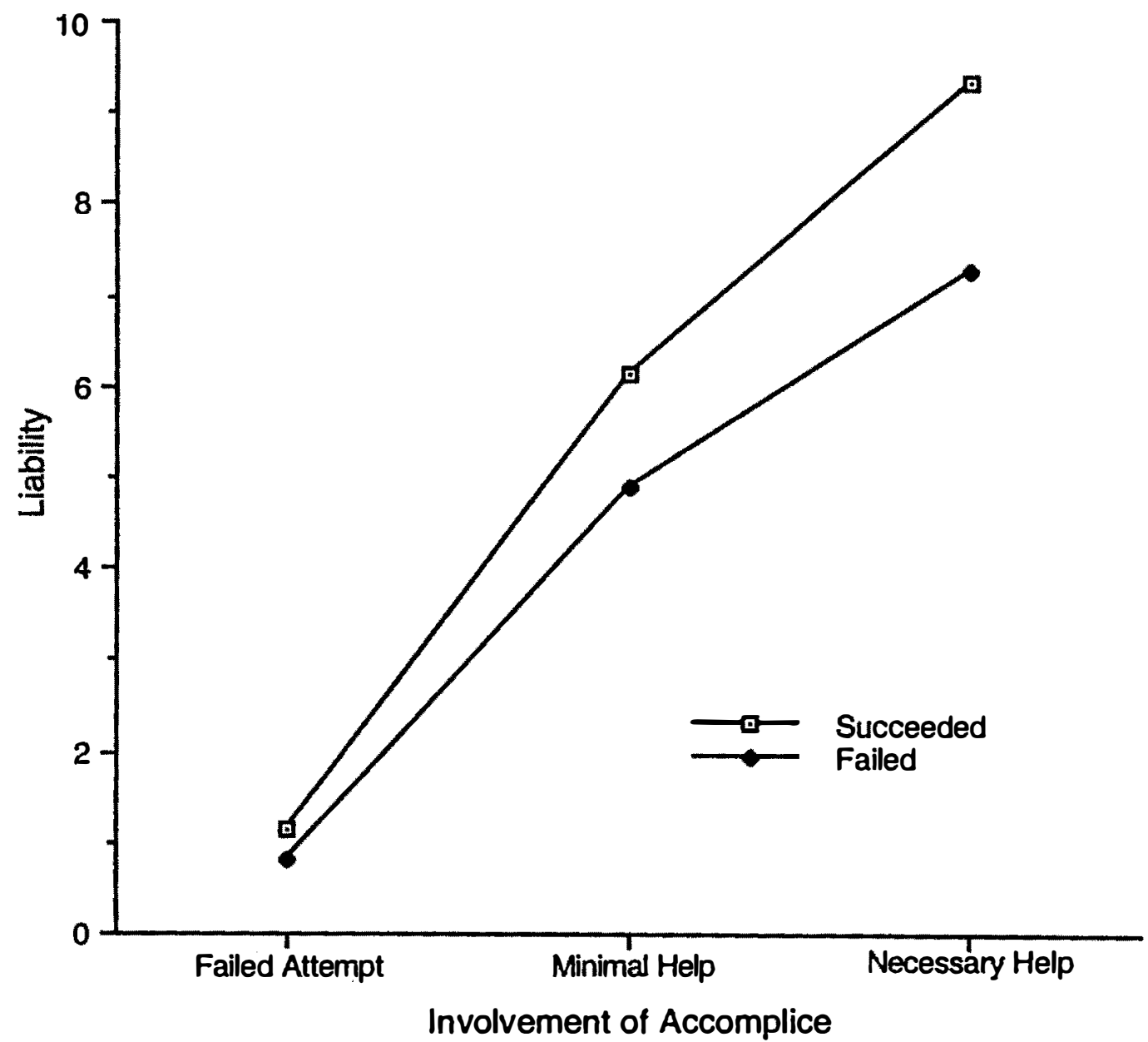

We now say what we can about scenario 7, which we have labeled "unique and necessary help." Recall that this case was not perceived by our subjects as providing unique and necessary help; such would have entailed an average rating of 7 in column $f$. Instead, in this case the accomplice is perceived as simply providing substantial help to the wife ( 5.03 rating, where $5=$ substantial help). Future research will need to create a case in which respondents perceive that unique and necessary help is given by a complicit individual in order to see if the liability scores associated with such a case approach the liability given a mastermind, as we would predict. However, it is interesting to contrast the liability assignment of case 7 with that of case 5, in which the respondents did perceive that (as we had hoped) substantial help was given. The accomplice in case 5 draws a significantly higher liability assignment (a sentence of more than thirty years) than does the accomplice in case 7 (a sentence of only about two years), even though both are roughly matched on what we know of the nature of our respondents' perceptions of the complicit individual's involvement in the case. This suggests that our respondents may be considering some as yet undiscovered factors that are influenc- 
ing their decisions, and future research should attempt to discover what these factors are.

Next, what difference does it make to the accomplice's liability whether the wife successfully kills her husband or shoots and misses? This is answered in Figure 2.11 , in which we examine the three pairs of cases in which the friend fails in his attempt to help, provides minimal help, or provides necessary help, and the woman succeeds in killing her husband or fails. (See Table 2.9, scenarios 2 and 2a, 4 and $4 \mathrm{a}$, and 6 and $6 \mathrm{a}$.) As the figure shows, the respondents consistently give a somewhat reduced liability to the accomplice friend in the cases in which the perpetrator wife fails to kill her husband $[F(1,33)=39.68, p<.001]$. (That is, the "failed" line is consistently lower on the liability axis than the "succeeded" line.) We have commented previously on the general tendency of our respondents to follow this pattern - to give reduced sentences when the harm of the offense does not actually occur. This is-on first glance-consistent with the Model Penal Code's treatment of such cases. While the accomplice's failed attempt to assist is treated the same as successful assistance, the perpetrator's failure to commit the crime does affect at least the label that is given to the accomplice's liability: His liability is only that of complicity in an attempt rather than complicity in the full offense. Recall, though, that what the Code gives with one hand, it takes away with the other. While most jurisdictions give a somewhat reduced grade for attempt liability, the Code grades attempts the same as the substantive offense, so that no reduction in accomplice liability would be achieved.

\section{Study 3: Summary}

The results of this complicity study are generally what intuition would have led us to expect. The greater the degree of help provided by the accomplice-where help is conceived of on a rough continuum beginning with encouragement and ending with criminal master minding - the greater the liability assigned to the accomplice. The significance of these results for various code formulations is, first, support for the common-law rule and against the Model Penal Code in the debate between the two (respectively) on whether actual assistance is required for accomplice liability or whether an unsuccessful attempt is sufficient. Our subjects tend to agree with the common-law formulation that requires actual encouragement or assistance.

Second, the gradations in liability assigned by our respondents to the person, depending on his degree of assistance in the crime, represent a pattern that we will see repeatedly in our data and one that frequently contradicts the legal system's tendency to treat various actors who play "supporting roles" in the commission of a crime as equally liable with the individual who commits the crime. Complicity, in the eyes of our respondents, is a matter of degree. Within legal codes, it is of ten treated as an all-or-nothing issue. If one fails to qualify as an ac- 
complice, there is no liability; if one is an accomplice, full liability for the offense is imposed, equal to that assigned the principal in the crime. Our respondents persist in making finely graduated liability distinctions. This gradation of liability is what the sentencing guidelines (see note 11) are attempting to provide, at the level of actual sentences assigned to accomplices. Note the similarity of this graduated pattern to the pattern assigned by respondents in our study of causation (Study 17), again a continuum of liability in a situation treated within legal codes as a dichotomous cutoff.

Finally, our subjects seem to disagree with the codes' view that an accomplice's liability ought to be the same grade as the perpetrator's. This is true even in those cases in which the degree of assistance is very high - even essential to the successful commission of the offense. Our subjects would give a minimum of one grade reduction to accomplices, much as most jurisdictions now do for attempt liability.

\section{STUDY 4: OMISSION LIABILITY}

The definitions of substantive offenses, together with the secondary prohibitions of attempt, risk creation, and complicity, give a complete account of what a person must not do. But the rules of conduct enforced by the criminal law occasionally require that a person perform specific conduct. People must pay taxes, register for the draft, obtain a license to engage in certain regulated activities, and so forth. While we do not fully address it here, a subsequent study might examine whether current codes accurately map the conduct that the law ought to require upon pain of criminal liability for failure to act. Are some failures (omissions) currently punished by legal codes perceived by the community as of insufficient seriousness for liability? Should the criminal law create duties to act in situations not now required?

In one aspect of this study, we focus on the practice of current codes in imposing the same degree of liability on a person who commits an offense through commission as through omission. The codes see as equivalent, for example, affirmative conduct causing a death and an omission to perform a legal duty that results in a death, all other things being equal.

In another aspect of this study, we focus on the most controversial instance of the law's failure to create a legal duty to help-in the case in which another person is in danger of serious injury or death. Anglo-American law has generally resisted imposing liability for a person's failure to act to help a stranger in distress. Under current doctrine, liability may be imposed for an omission to help only if the person has a specific duty to act [see Model Penal Code $\$ 2.01(1)$ ], and such duties are relatively rare and narrowly defined. For example, consider the case of a person who comes upon a drowning person whose life could be saved by the witness merely throwing the victim a nearby life preserver. The law imposes a duty for the witness to assist the drowning person-and thus imposes liability if such 
assistance is o mitted-only if the witness has one of several defined relationships to the endangered person. The most common sources of a duty to rescue are the duty of a parent to protect his or her child and a duty created by virtue of contractual agreement between parties - for instance, when a swimming club hires a person to serve as a lifeguard. A duty to rescue also may be created if one undertakes to help a person in distress, which may signal to others that the situation is under control, and then the volunteer fails to help, thereby leaving the person less likely to be assisted by another. Once one assumes the responsibility to rescue, even voluntarily, one has a legal duty to carry it to completion. ${ }^{14}$

However, if none of these relationships exist, the law holds that the person is under no obligation to help. Thus, in the case of the drowning individual, the witness who knows of the danger and can avert it generally has no duty to do so. This is so even if the act of helping, such as throwing the life preserver, presents no danger or even inconvenience to the person-even if the witness knows that the imperiled person otherwise will drown without the life preserver. Because the person has no duty to act, there is no criminal liability for failing to act.

The debate on this issue has an old and distinguished history. Several commentators have criticized the restrictive view of omission liability. Livingston, for example, argues that one should have a legal duty to act to save a stranger if such can be done without personal danger or pecuniary loss (Livingston, 1833, chp. II, articles 12-13). Such proposals to create a general duty to rescue have been criticized, in turn, as being too broad (Macauley, 1837, Note M, pp. 53-54). Macauley argues in the foregoing cite that "there may be extreme inconvenience without the smallest personal danger or the smallest risk of pecuniary loss." More generally, proposals to create a general duty to rescue are thought by many to go beyond the appropriate realm of criminal liability and into the sphere of moral accountability:

It is, indeed, most highly desirable that men should not merely abstain from doing harm to their neighbors, but should render active services to their neighbors. In general however the penal law must content itself with keeping men from doing positive harm, and must leave to public opinion, and to the teachers of morality and religion, the office of furnishing men with motives for doing positive good. It is evident that to attempt to punish men by law for not rendering to others all the service which it is their [moral] duty to render to others would be preposterous. We must grant impunity to the vast majority of those omissions which a benevolent morality would pronounce reprehensible, and must content ourselves with punishing such omissions only when they are distinguished from the rest by some circumstance which marks them out as peculiarly fit objects of penal legislation (Macauley, 1837, pp. 55-56).

While an omission to act may not be morally correct, the argument goes, it is not the sort of thing that ought to generate criminal liability other than in exceptional circumstances. 
This is the prevailing view that is instantiated in the laws of our society, although there are occasional exceptions. Despite such general reluctance to create omission liability, a few states have enacted a limited general duty to rescue, typically limiting the duty to cases of serious danger to the victim in which the rescuer need not endanger him or herself. [See, e.g., Rhode Island General Laws $\$$ 11-561; Wisconsin Statutes Annotated $\$ 940.34(2)]$. The statutes also tend to provide only minor penalties in case of conviction.

Our omission study sought to test the community's views on whether criminal liability and punishment are appropriate for a failure to rescue a stranger and, if so, to determine how the assignment of liability and punishment may vary with different levels of danger or inconvenience. This study also examined the community's views of the comparative liability for a commission and an omission under each of the existing traditional sources of duty-parental or contractual relationship or assumption of responsibility to rescue. Subjects were given a series of scenarios involving one actor pushing another into the water in circumstances in which it is apparent that the victim will likely drown if not rescued; another actor observes this, but fails to act to rescue the victim. For the first subset of scenarios (1 through 4 in Table 2.12), a flotation device is present; all that is necessary for the bystander to do is to throw it to the victim. For the second subset (scenarios 5 through 8 ), since we were interested in whether the respondents would require bystander action of a more major sort, it is necessary for the bystander to swim to the aid of the victim. (The bystander is described as a strong swimmer.) We asked our respondents to rate the liability that they would assign both to the perpetrator (who affirmatively pushes the victim into the water) and to the nonacting bystander. The scenarios differed in the relationship between the bystander and the victim and in the degree of danger or inconvenience that rescuing the victim would impose on the bystander.

The first point of interest is a global one: When compared with the liability judgments for the person who created the danger, the liability judgments for the bystander's failure to act are greatly mitigated. Liability and punishment for the person who pushes the victim into the water and thereby causes the death through commission, column $a$, is constant in all scenarios, at approximately 8.6 (24.4 years). For the bystander who does not help, liability and punishment for failing to rescue is consistently significantly less. This is most easily seen by scanning column $d$, which lists the liability scores assigned to the person who fails to help; at no point does bystander liability even approach that assigned to the person who commits the act.

Mitigation from full liability is given even in those cases in which the bystander has a legal duty to act, as in scenarios 2 through 4 . (In scenario 2 , the bystander is a parent of the victim; in scenario 3 , he has a contractual obligation to rescue the victim because he is a security guard at the site; and in scenario 4, the actor tells another that he will rescue the victim, thus assuming the obligation.) Even in 
TABLE 2.12 Liability for Commission and Omission

\begin{tabular}{|c|c|c|c|c|c|c|c|}
\hline Scenarios & $\begin{array}{c}\text { (a) } \\
\text { Liability }\end{array}$ & $\begin{array}{c}\text { (b) } \\
\text { \% No } \\
\text { Liability }\end{array}$ & $\begin{array}{c}\text { (c) } \\
\% \text { No Liability } \\
\text { or } \\
\text { No Punishment }\end{array}$ & $\begin{array}{c}\text { (d) } \\
\text { Liability }\end{array}$ & $\begin{array}{c}\text { (e) } \\
\text { \% No } \\
\text { Liability }\end{array}$ & $\begin{array}{c}(f) \\
\% \text { No Liability } \\
\text { or } \\
\text { No Punishment }\end{array}$ & $\begin{array}{l}\text { (g) } \\
\text { Model Penal } \\
\text { Code Result } \\
\text { (for omission) }\end{array}$ \\
\hline $\begin{array}{l}\text { 1. Stranger } \\
\text { 2. Parent } \\
\text { 3. Contract } \\
\text { 4. Assumption } \\
\text { 5. Stranger-high } \\
\text { danger } \\
\text { 6. Stranger-low } \\
\text { danger } \\
\text { 7. Stranger-high } \\
\text { inconvenience } \\
\text { 8. Stranger-low } \\
\text { inconvenience }\end{array}$ & $\begin{array}{l}8.55 \\
8.66 \\
8.62 \\
8.62\end{array}$ & $\begin{array}{l}0 \\
0 \\
0 \\
0\end{array}$ & $\begin{array}{l}0 \\
0 \\
0 \\
0\end{array}$ & $\begin{array}{l}2.93^{a} \\
5.10^{b} \\
6.21^{b} \\
5.55^{b}\end{array}$ & $\begin{array}{r}21 \\
7 \\
0 \\
3\end{array}$ & $\begin{array}{l}52 \\
31 \\
10 \\
24\end{array}$ & $\begin{array}{l}\text { No liability } \\
\text { Same liability as commission } \\
\text { Same liability as commission } \\
\text { Same liability as commission }\end{array}$ \\
\hline
\end{tabular}

Liability Scale: $N=$ No criminal liability, $0=$ Liability but no punishment, $1=1$ day, $2=2$ weeks, $3=2$ months, $4=6$ months, $5=1$ year, $6=3$ years, $7=7$ years, $8=15$ years, $9=30$ years, $10=$ life, and $11=$ death.

Note: Superscript letters indicate significance at the $p<.05$ level by a Newman-Keuls test. Matching superscripts indicate means that are not statistically significantly different from each other. Means are compared within columns only. 
these duty scenarios, omission liability-5.10 (1.2 years) to 6.21 ( 3.8 years) -is significantly lower than commission liability for the same death-8.6 (24.4 years).

Table 2.13 reports, among other things, the respondents' perceptions of various aspects of the state of mind of the person who fails to rescue the victim; these perceptions suggest that part of the difference in liability that our subjects assign to the perpetrator and the bystander might be partially due to perceptions that the two actors have different culpable states of mind as to causing the death. Our respondents judge that the individual who pushes the victim into the water wants him to drown, while the individual who fails to help him is not seen as wanting the victim to drown. (For the omission actor, these ratings range between 3.38 and 4.76, with a rating of 3 meaning the respondents "disagreed" with the statement that the individual wanted the victim to drown and a rating of 5 indicating "unsure.")Still, as column $c$ shows, the respondents agreed that the potential rescuer is practically certain that the victim would drown. This suggests that the respondents give a liability discount to the person who fails to help, as compared to the person whose act of commission created the situation in the first place, even though they do regard the omission as blameworthy.

Returning to considerations affecting the level of liability assigned to the observer who fails to act, as Table 2.12 shows, our subjects clearly do distinguish between the stranger (no-duty) scenarios (1 and 5 through 8 ) and the duty scenarios ( 2 through 4 ). In the latter set of cases, a large majority of our subjects impose liability and punishment (93 percent to 100 percent). ${ }^{15}$ These results confirm the importance of the legal doctrine's consideration of whether a legal duty exists and suggest that the community sees the same sorts of relationships as creating this duty to rescue as does the Code. Thus the study results suggest that violation of a duty is recognized by the community as grounds for assigning a person criminal liability. However, the liability scores assigned in the duty cases are by no means as severe as those that the Code would assign in the same cases. The Code's penalties for omission would be the same as those assigned for commission of the act, which in our scenarios would be punishment levels of approximately 8.6 (24.4 years). Consistently, our subjects assign liability levels well below 8.6, ranging from 5.1 to 6.2 (1.2 years to 3.8 years).

It is not the case that our subjects are lenient in all of their judgments. In contrast to the legal duty scenarios, subjects appear to be stricter than the Code in cases where no legal duty exists. In all scenarios where a bystander fails to rescue a stranger, except the one involving high danger to the rescuer, a majority of the subjects would impose criminal liability in such cases (from 79 percent to 86 percent). ${ }^{16}$ Even in the high-danger scenario, 45 percent would impose liability. Yet, the legal doctrine imposes no liability where no duty to rescue exists. In the eyes of our respondents, absence of a duty does not exempt a person from liability for failing to save a stranger's life. As the responses to scenarios 5 through 8 show, our 


\begin{tabular}{|c|c|c|c|c|c|c|}
\hline \multirow[b]{2}{*}{ Scenarios } & \multicolumn{2}{|c|}{ Commission } & \multicolumn{4}{|c|}{ Omission } \\
\hline & $\begin{array}{c}\text { (a) } \\
\text { Knowledge }\end{array}$ & $\begin{array}{c}\text { (b) } \\
\text { Purpose }\end{array}$ & $\begin{array}{c}\text { (c) } \\
\text { Knowledge }\end{array}$ & $\begin{array}{c}\text { (d) } \\
\text { Purpose }\end{array}$ & $\begin{array}{c}\text { (e) } \\
\text { Inconvenience }\end{array}$ & $\begin{array}{c}(f) \\
\text { Dangel }\end{array}$ \\
\hline 1. Stranger & 6.48 & 5.86 & 6.71 & 3.45 & 1.48 & 1.45 \\
\hline 2. Parent & 6.41 & 6.10 & 7.28 & 4.17 & 1.21 & 1.28 \\
\hline 3. Contract & 6.45 & 6.03 & 6.90 & 4.28 & 1.48 & 1.24 \\
\hline 5. Stranger-high danger & 6.48 & 6.03 & 6.72 & 3.38 & 5.21 & 6.93 \\
\hline 6. Stranger-low danger & 6.45 & 6.00 & 6.79 & 4.10 & 4.03 & 4.55 \\
\hline 7. Stranger-high inconvenience & 6.48 & 5.83 & 6.79 & 4.28 & 4.59 & 2.45 \\
\hline 8. Stranger-low inconvenience & 6.62 & 5.86 & 6.69 & 4.21 & 3.21 & 2.34 \\
\hline
\end{tabular}

Key to column heads:

Statements (a) through (d) were responded to on a scale where $1=$ strongly disagree, $3=$ disagree, $5=$ unsure, and $9=s t r o n g l y$ agree.

(a) The actor is practically certain that the victim will drown.

(b) The actor wanted the victim to drown.

(c) The potential rescuer is practically certain that the victim will drown.

(d) The potential rescuer wanted the victim to drown.

(e) To what extent would it have been inconvenient for the potential rescuer to help the victim? $1=$ not at all inconvenient and $9=$ extremely inconvenient.

( $f$ ) To what extent would it have been dangerous for the potential rescuer to help the victim? $1=$ not at all dangerous and $9=$ extremely dangerous. 
respondents think that a bystander who can swim should swim to the rescue of a drowning individual and should be criminally liable for failing to do so.

In saying this, we do not overlook that our subjects make some carefully nuanced qualifications of the duty to rescue a stranger. The results of these four nonduty scenarios are illustrated in Figure 2.14. In this figure, we have arrayed the four scenarios in terms of the degree of sacrifice required of the possible helper, with the inconvenience cases assumed to require less sacrifice. Notice that the respondents lower their liability judgments as the inconvenience and particularly the danger to the potential rescuer increases; the less the inconvenience or danger to the bystander in attempting a rescue, the more the liability he incurs for not doing so. (An analysis of variance indicates that the degree of either danger or inconvenience makes a reliable difference in the respondents' assignment of liability $[F(1,27)=11.23, p<.002]$. As the figure also indicates, the degree of danger that exists for the potential helper mitigates the respondents' condemnation of him for not intervening-more so than does the degree of inconvenience $[\mathrm{F}(1,27)=18.22, p<.001]$.

But details of the patterning aside, our respondents see a very far-reaching duty to intervene, one that generally goes beyond the views instantiated in the codes. In the high-danger case, involving the necessity to jump into shark-infested waters to attempt the rescue (scenario 5 of Table 2.12), 45 percent of our subjects assign liability to the person who chooses not to help, although the punishments assigned in this case were low.

The code-community difference in the no-duty cases is not as great, however, when one focuses on punishment rather than liability. Many subjects impose liability but no punishment (compare columns $e$ and $f$ of Table 2.12). In the two scenarios with elements of danger, only a minority of subjects impose punishment (38 percent in the low-danger scenario, 14 percent in the high-danger scenario). There is a possible pattern here, in which the respondents are using an assignment of criminal liability to censure conduct, without wishing to impose an actual punishment on the censured individual. (We will see similar patterns of responses in other studies and will return to this theme in Chapter 7.) In the nodanger cases (in which a majority of subjects do impose punishment), the degree of punishment is not high, ranging from 2.93 ( 7.4 weeks) to 3.79 (5.2 months). ${ }^{17}$

\section{Study 4: Summary}

The results of this study indicate that our subjects would support a system in which causing a death by omission receives some liability, but less liability and punishment than if the death is caused by commission, all other things being equal. Some of the omission study's results support the standard legal distinctions: In those cases in which there are relationships that the law suggests create a duty to act, our respondents assign more liability and punishment for failing to act than in those cases where no such duty exists. Where no duty exists, the degree 
FIGURE 2.14 Liability as a Function of the Degree of Sacrifice Necessary to Rescue

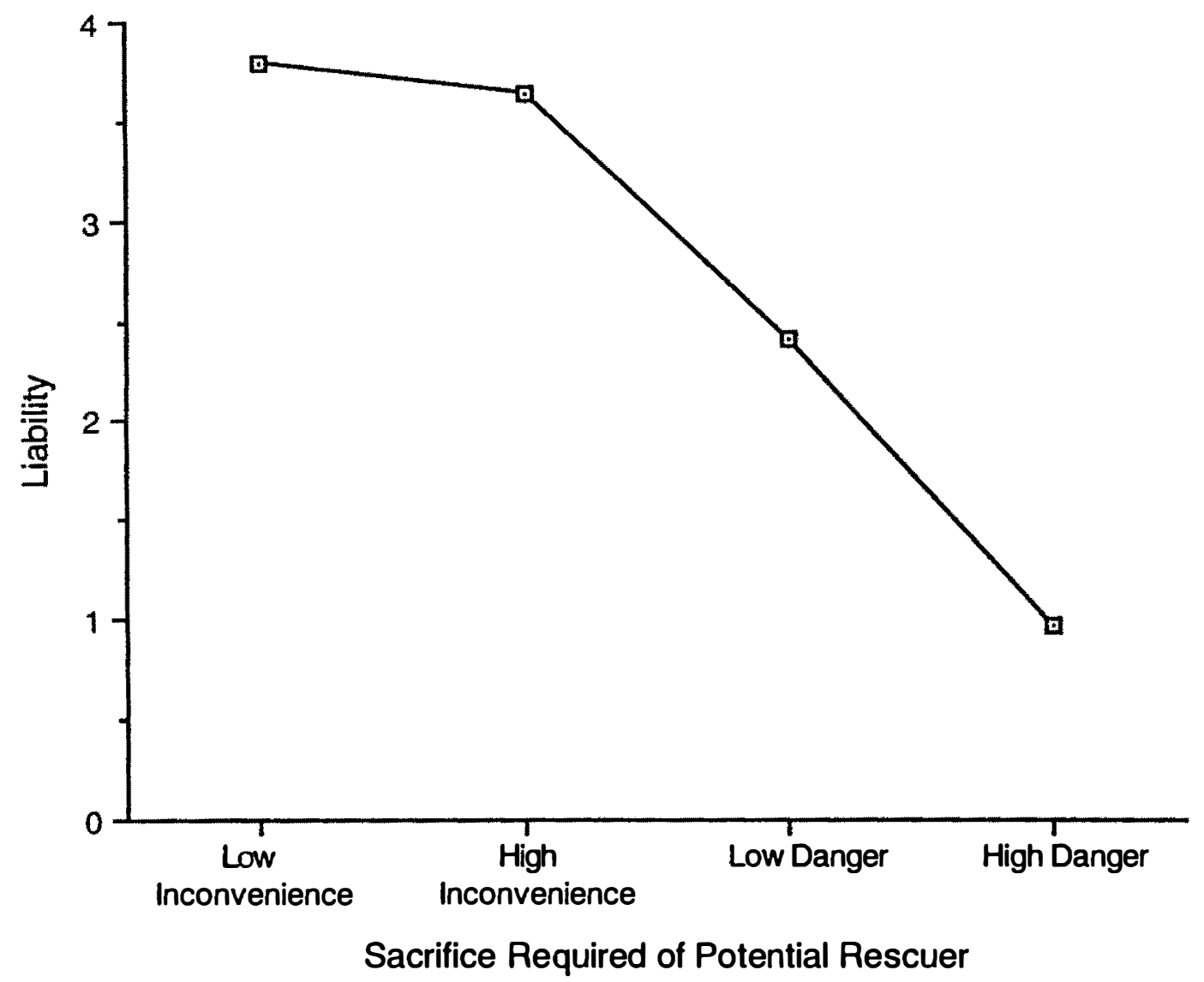

of liability and punishment is reduced as the degree of danger or inconvenience to the rescuer increases. Still, only in the case of high danger is the potential rescuer judged free from liability by a majority of respondents, and only in the case of noticeable danger is the potential rescuer assigned no punishment by a majority of respondents. Inconvenience never exempts the potential rescuer from liability, but in such cases the degree of punishment is low. These results appear to support the few American state statutes that create a limited duty to rescue strangers from serious threats.

When a person fails in a legal duty to rescue, created by contractual agreement, parental relationship, or voluntary assumption of responsibility, the subjects impose significantly lower liability than current doctrine would. Apparently, causing a death by omission is judged less blameworthy than causing the same death by commission (with the potential rescuer sharing the same state of mind concerning whether the victim was likely to die as the perpetrator). Current doctrine imposes full liability for the substantive offense for such cases of omission, while our subjects discount liability for omission. Our findings suggest that code drafters should provide significant grade reductions in those cases in which liability is based on a failure to perform a legal duty. 
Finally, our respondents make nuanced distinctions between similar but not identical cases. For instance, our subjects vary the amount of liability assigned according to the nature of the circumstances that create the duty to rescue. A continuum of accountability also exists, in the context of rescue of a stranger, where liability varies with the degree of danger or inconvenience. ${ }^{18}$ This is another example of the law's discontinuous treatment of what our subjects see as a continuous function, an issue we take up again in Chapter 7.

\section{CHAPTER SUMMARY}

The four studies reviewed in this chapter suggest that secondary prohibitions are indeed a rich source of disagreement between community views and criminal codes. Codes frequently impose liability where our subjects would not-or where they would at least impose considerably less. For instance, our subjects find the dangerous proximity test embodied in the common law a better trigger for attempt liability than the substantial step test of the Model Penal Code. Further, our respondents give more weight to the renunciation of a criminal attempt even when that attempt has progressed far enough to trigger criminal liability. Unsuccessful attempts to encourage or assist in a crime seem to our subjects to call for little or no liability, more in keeping with the common-law treatment of these unsuccessful attempts than the Code treatment, which would impose full offense liability. Also, a person who intends murder but creates only a slight risk of minor harm receives a sentence from our subjects that is greatly reduced from the codes' treatment of the act as attempted murder. Our respondents also assign an accomplice to a crime higher liability as his contribution to the crime increases, but that level of liability does not rise high enough to equal the liability assigned the principal criminal - as the codes provide. A person who has a duty to rescue another and fails in that duty (and the person who might have been saved dies) is liable, but not for murder, which is the liability that the codes would assign.

In other instances, our respondents either impose liabilities greater than those imposed by legal codes or assign liability in cases in which the codes assign none. For example, some degree of liability is assigned by our subjects to individuals who develop a settled intention to commit a crime-a case in which the codes assign none. Our respondents also would impose some liability on persons who fail to assist a person in distress, even though the codes impose none.

This last result is worth further comment. Except in limited cases, current legal codes impose no omission liability on one who fails to help another in distress, even when that help would be easy to give. Our respondents disagree with this; they impose some degree of liability in those situations. The liability they impose is small, and they frequently suggest a verdict of "liability but no punishment." This suggests to us that they would support the broadening of duty-to-assist laws. It also suggests that they are discriminating between two functions of liability as- 
signments - two functions that are sometimes not differentiated. First ${ }_{2}$ and uppermost in the minds of people thinking about legal systems, the criminal justice system assigns punishments. But it also communicates community consensus on what is desirable and undesirable conduct, and it may have been this second message-sending function that our respondents were thinking of when they assigned this small omission liability. We will have more to say about the dual functions of liability in upcoming chapters.

The previous discussion has focused on liability discrepancies between code and community standards in individual cases; it is also possible to focus on the difference in patterning of responses across cases and the associated differences between code and community. Examining those differences highlights what might be called the underlying conceptual differences between code and community standards. One very apparent pattern of differences is worthy of note. Our respondents consistently assign reduced liabilities to individuals who play secondary roles in the commission of a crime, even though the codes assign those individuals with liabilities that are equivalent to those of the principal. Also, and closely connected with this, our respondents assign reduced liability for the violation of secondary prohibitions, such as attempt, even when the Model Penal Code assigns liabilities equivalent to those assigned for the commission of the primary prohibited act. We will see further instances of this respondent pattern in upcoming chapters.

Finally, one other overarching pattern in our respondents' system of judgment requires noting: The community is more "harm-oriented" than is the Model Penal Code. That is, our subjects' liability judgments are more affected by whether a harm actually comes about. For example, a person intends to poison another. If she succeeds, she receives a severe sentence; if she fails, she receives a reduced sentence, graded by our respondents by the degree of actual harm done to the victim. A wife intends to kill her husband and shoots at him. If he is killed, our subjects assign a severe sentence; if not, they assign a much less severe sentence. In contrast, the Model Penal Code generally looks to the intent of the harm-doer and assigns sentences to that harm-doer that set the liability at the level that would be given for the successful accomplishment of the crime intended. Of course, our case that most clearly demonstrated this point is the case in which it was murder that was attempted. Interestingly, the Model Penal Code makes an exception to its general tendency and punishes an attempted murder at one grade lower than a successful murder. However, we will see in upcoming studies that the respondents' tendency to assign liability according to the actual occurrence of the harm exists for offenses other than murder. 


\section{Doctrines of Justification: When Should It Be Lawful for One to Engage in Conduct That Normally Would Constitute a Violation?}

Taken together, the criminalization doctrines (some of which we have examined in Chapter 2), give a complete account of what a person must or must not do in order to obey the criminal law. The doctrines are not, however, a complete statement of the criminal law's rules of conduct. The law recognizes that in some instances a greater harm can be avoided or a greater good can be achieved by allowing a person to engage in conduct that normally would constitute a violation. Burning another person's property is a violation, but it is to be tolerated (and even encouraged) if the burning acts as a firebreak to save a town. Striking another person without consent is a violation but is permitted if a police officer finds it necessary in order to overcome resistance to a lawful arrest. While shooting another person normally would be illegal, it may be justified if it is a necessary defense against unlawful force. The doctrines defining when conduct constituting a violation is nonetheless lawful are known as justification defenses. They are permissive only: They tell people when they will be permitted to act in violation of the doctrines of criminalization; they do not require one to act.

The criminal law recognizes a number of justification defenses. Self-defense and defense of property, which we examine in this chapter, are examples of defensive force justifications: They allow a person to defend him or herself or property against an aggressor's threat. Law enforcement authority, also discussed in this chapter, such as the right to use force to arrest a violator, allows the use of nondefensive force. An officer or a private citizen in some cases (also examined in this chapter) may use force to effect an arrest even though the violator is no longer presenting a threat. Other justification defenses allow nondefensive use of force by, for example, teachers, prison guards, military personnel, parents and custodians punishing children, persons responsible for maintaining order on 
public vehicles, doctors treating patients, and persons acting under a judicial order. As we shall see, the law's requirements for all justification defenses are analogous in several respects. Basically, the law requires that the force used be the minimum necessary to avoid the threatened harm or to further the defined interest. The law also requires that the amount of force used not be disproportionate to the value of the interest to be protected or furthered (see Model Penal Code (MPC), Article 3; Robinson, 1982).

In this chapter's studies, we examine not only the rules of justified conduct but also those governing the effects of a person's mistake as to whether his conduct is justified. While there is some legal controversy surrounding the term "justified" when used to describe these cases, for the purposes of our discussion, we shall distinguish conduct that is actually justified from conduct that the person only mistakenly believes is justified. The latter cases are in truth instances of excuse, not justification, which are the subject of Chapter 5.

Unlike some of the other areas that we have reviewed, there are a few studies in the psychological literature bearing on ordinary people's perceptions of the legitimacy of justifications for acts that would otherwise generate liability. Darley and Zanna (1982), for instance, have demonstrated that even young children are capable of recognizing and granting validity to some of the most common classes of justifications recognized by the legal system. In the studies in this chapter, we measure the precise fit of community judgments with the patterns of justifications given validity within legal codes.

\section{STUDY 5: \\ USE OF DEADLY FORCE IN SELF-DEFENSE}

The law allows a person to use force to defend himself or herself, even deadly force on occasion. What otherwise would be murder (intentional killing) is fully exculpated as long as the conditions of self-defense are met. It is universally required that the use of force in self-defense be necessary. This notion of "necessity" means that if less force (than that used) would have been adequate to one's defense, then the force used is not necessary and therefore not justified. If a person can protect himself by using no force at all, then any use of force is unnecessary. Thus, codes typically oblige a person to retreat before using deadly force if he or she can do so in safety. The law limits one's duty to retreat, however, by not requiring retreat from one's home or workplace, on the theory that such retreat would expose the person to greater danger. A second, equally important condition of self-defense requires that the person's use of force take account of the seriousness of the threat. That is, even if it is necessary to protect oneself, a person is not justified in using deadly force to defend against a kick in the shin. This required proportionality between the nature of the threatened harm and the nature of the defensive force is manifested in the law's limitation of the use of deadly force to instances in which serious bodily injury is threatened. 
A person may fail to meet some of the conditions for the use of deadly force in self-def ense yet receive a defense or mitigation if he or she (mistakenly) believes that the conditions are satisfied. For example, a person who mistakenly but reasonably believes that he or she cannot safely retreat nonetheless will receive a defense for the use of deadly force in self-defense. Similarly, a person who mistakenly but reasonably believes that an attacker is threatening serious bodily injury will receive a defense. If the person's mistake is culpable (reckless or negligent), some jurisdictions deny a def ense while others impose reduced liability. In the latter, for example, if a person is reckless as to the existence of a serious threat, that person may be liable for manslaughter rather than murder if he or she kills in mistaken self-defense. If the person's mistake is negligent, liability for negligent homicide may follow. If the mistake is reasonable (nonnegligent), the person may have no liability [MPC $\$ 3.09(2)$ ]. If a person accurately perceives the situation but is mistaken as to what the law permits, that person's mistake does not provide a defense or mitigation. Thus, there is no defense for a person who mistakenly believes that he or she is legally justified in killing an attacker who does not present a serious threat [MPC $\$ 3.09(1)(b)]$. The law also denies a defense to a person who provokes an attack in order to kill the attacker in self-defense [MPC $\$$ $3.04(2)(\mathrm{b})(\mathrm{i})]$.

As is obvious, the Code's self-defense rules are detailed and complex. In our self-defense study, we examine the community's views on the use of deadly force in self-defense and compare those views to the legal doctrine's rules and conditions. The core of this study's scenario is as follows: A man who legally carries a gun for protection is walking on a deserted street in a city at night. He is accosted by another man (under various circumstances) and shoots him, killing him. The liability results are summarized in Table 3.1 .

To begin discussion of these results, look first at the lower and upper boundaries of liability established by our two "control" cases (rows 1 and 2 of the table). The lower-boundary control scenario (row 2) involves a case in which a person is attacked with a deadly weapon and responds by killing the attacker. These results confirm that our subjects give a defense to a person who kills under conditions that satisfy the legal requirements for self-defense. First, the assignment of liability was vanishingly low, an average of 0.14 , which scales to well below 1 day in jail. Of the respondents, 71 percent gave no liability; 97 percent gave no liability or liability but no punishment.

For a killing that meets none of the doctrine's requirements for justification, the upper-boundary control scenario (row 1) establishes the baseline liability of 7.97 (approximately 15 years). This result surprised us because this level of liability is noticeably less than the liability typically given to murderers by other respondents in the other study scenarios that we have presented or will present later in this book. After reexamining this scenario, we came up with a possible interpretation. In this case, a person is approached by a beggar and then shoots the 


\begin{tabular}{|c|c|c|c|c|c|c|}
\hline Scenarios & $\begin{array}{c}\text { (a) } \\
\text { Liability }\end{array}$ & $\begin{array}{c}\text { (b) } \\
\% \text { No } \\
\text { Liability } \\
\text { (N) }\end{array}$ & $\begin{array}{c}\text { (c) } \\
\text { \% No Liability or } \\
\text { No Punishment } \\
(\mathrm{N}+0)\end{array}$ & $\begin{array}{c}\text { (d) } \\
\text { Model Penal } \\
\text { Code Result } \\
\end{array}$ & $\begin{array}{c}\text { (e) } \\
\text { "Force Was } \\
\text { Reasonable" }\end{array}$ & $\begin{array}{c}(f) \\
\text { Maximum } \\
\text { Force } \\
\text { Permissible } \\
\end{array}$ \\
\hline 1. Killing, no self-defense & 7.97 & 3 & 9 & Liable for murder & 2.20 & 2.34 \\
\hline $\begin{array}{l}\text { 2. Killing, self-defense } \\
\text { Knows deadly force is not } \\
\text { necessary because: }\end{array}$ & 0.14 & 71 & 97 & Complete defense & 7.97 & 7.83 \\
\hline 3. Unarmed attacker & 6.66 & 6 & 14 & Liable for murder & 2.97 & 3.54 \\
\hline 4. Could retreat & 4.63 & 23 & 40 & Liable for murder & 4.06 & 4.46 \\
\hline $\begin{array}{l}\text { 5. Could retreat from home } \\
\text { Believes deadly force is } \\
\text { necessary but: }\end{array}$ & 0.77 & 43 & 86 & Complete defense & 6.20 & 7.00 \\
\hline 6. Mistaken as to threat & 1.40 & 31 & 80 & $\begin{array}{l}\text { Complete defense } \\
\text { or mitigation }\end{array}$ & 5.89 & 5.31 \\
\hline $\begin{array}{l}\text { 7. Mistakenly believes } \\
\text { retreat not possible }\end{array}$ & 0.49 & 54 & 94 & Complete defense & 6.86 & 6.77 \\
\hline $\begin{array}{l}\text { 8. Actor provokes attack } \\
\text { Believes deadly force is not } \\
\text { necessary but: }\end{array}$ & 6.40 & 6 & 17 & Liable for murder & 5.11 & 4.31 \\
\hline $\begin{array}{l}\text { 9. Mistakenly believes } \\
\text { deadly force legal }\end{array}$ & 6.71 & 3 & 17 & Liable for murder & 2.74 & 3.20 \\
\hline
\end{tabular}

Liability Scale: $N=$ No criminal liability, $0=$ Liability but no punishment, $1=1$ day, $2=2$ weeks, $3=2$ months, $4=6$ months, $5=1$ year, $6=3$ years, $7=7$ years, $8=15$ years, $9=30$ years, $10=$ life, and $11=$ death.

Key to column heads:

(e) The amount of force the actor used was reasonable under the circumstances: 1=strongly disagree, 5=unsure, and $9=$ strongly agree.

(f) What is the maximum amount of force that someone should be able to use to protect themselves in this situation? $0=$ no force, 2 =risk of bodily injury, $4=$ =bodily injury, $6=$ serious bodily injury, $8=$ serious bodily injury with risk of death, and $10=$ death. 
beggar. Apparently, what to us seemed a trivial annoyance (being pestered by a beggar who persists in requesting money after he is initially turned down) led the subjects to see the pestered person as less blameworthy than the typical murderer - that is, the pestered person is seen as less blameworthy than one who actively seeks out another with the intention to kill. There is, unfortunately, the possibility that the respondents "read into" the case some degree of threat in the beggar's behavior or believed that the person who shot the beggar felt such a threat.

Let us consider this lower sentence further. As we mentioned, in the other scenario cases described elsewhere in this book, higher degrees of liability are assigned to persons who commit murders (averaging around 10, which scales to life imprisonment); thus, we would not conclude that our respondents take a particularly lenient view of murder in general. What the unforeseen lower sentence for killing the beggar suggests is that we examine, in future research, the minimum threat that people view as warranting a defensive response. It also may be that the contexts in which those threatening behaviors occur are important to the study respondents. A behavior that signals possible menace on a big-city subway platform may not be as menacing on a sunny small-town street. Moreover, our context is perhaps one that is perceived as dangerous by our respondents-a deserted city street at night. Regardless, our finding that some people consider the approach of a beggar (even under said circumstances) a mitigation for shooting that beggar seems alarming to us.

We turn next to the liability assignments given in scenarios 3 through 9. It appears that our respondents are generally telling us that a killing that has some claim to be carried out in self-defense, whether that claim is granted validity by the legal codes, should receive a mitigated punishment. The liability assignments in all of the noncontrol cases are lower than that given for the baseline case (scenario 1 ).

In these noncontrol scenarios, the general pattern suggests that assigned liability is a function of the seriousness of the threat to the attacked individual. (Appendix $B$ presents the text of the different scenarios.) Where the person knows that the attacker is unarmed and, thus, that deadly force is unnecessary (scenario 3 ), subjects impose liability of 6.66 ( 5.8 years). This is less, although only marginally significantly less, than the baseline case in which no threat (or a very ambiguous one) exists, suggesting that a person is judged increasingly less blameworthy as the degree of threat increases. As Figure 3.2 shows, our subjects appear to see a continuum of degree of liability based on the degree of threat; that is, importing data from other study scenarios in this book, we may conclude that a case of no threat (murder) ${ }^{1}$ is generally assigned a liability of 10 (life imprisonment); and, referring again to Table 3.1, killing the source of a trivial threat (row 1), 15 years; killing an unarmed attacker (row 3 ), 5.8 years; and killing an armed attacker (row 2 ), less than 1 day. While further studies should investigate the exact nature of this 
FIGURE 3.2 Liability Assigned for Defensive and Nondefensive Killing Scenarios

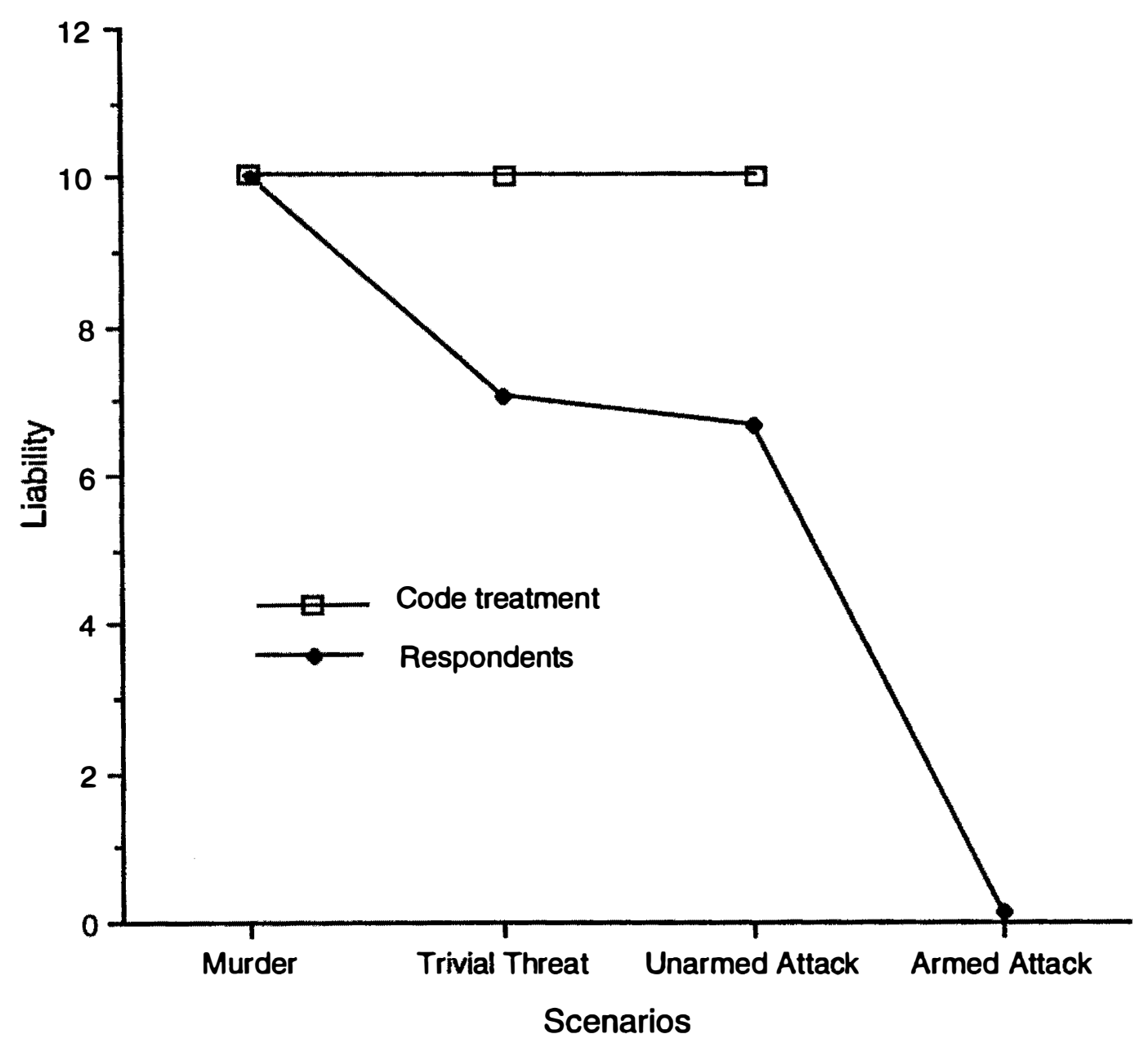

relationship, we already note a contradiction with the legal code. The legal doctrine adopts a simple cutoff. If the approacher threatens serious bodily injury, the attacked person is granted a complete defense. If less than serious bodily injury is threatened, murder liability is imposed. The Code treatment and our respondents' liability judgments are contrasted in Figure 3.2.

Furthermore, as the degree of the perceived threat increases, the amount of force our subjects authorize also increases. The subjects' views on the maximum force that they think permissible in the situation are in column $f$ of Table 3.1. In control scenario 2, when the knife-wielding individual attacks, our subjects judge that it is appropriate to respond with force that risks "serious bodily injury with risk of death," 7.83 on the force scale. In scenarios 5,6 , and 7 , the person is attacked by a man either wielding or thought to be wielding a knife; our respondents agree that the maximum force allowable in self-defense in these cases is also high, with judgments of 7.00, 5.31, and 6.77, respectively (column $f$ ). In the other cases, our subjects judge that the maximum force that would be appropriate in self-defense should be less than or equal to that which would cause bodily injury (but not serious bodily injury) to the attacker. Scenario 8, in which the person 
FIGURE 3.3 Liability as a Function of Maximum Force Allowed

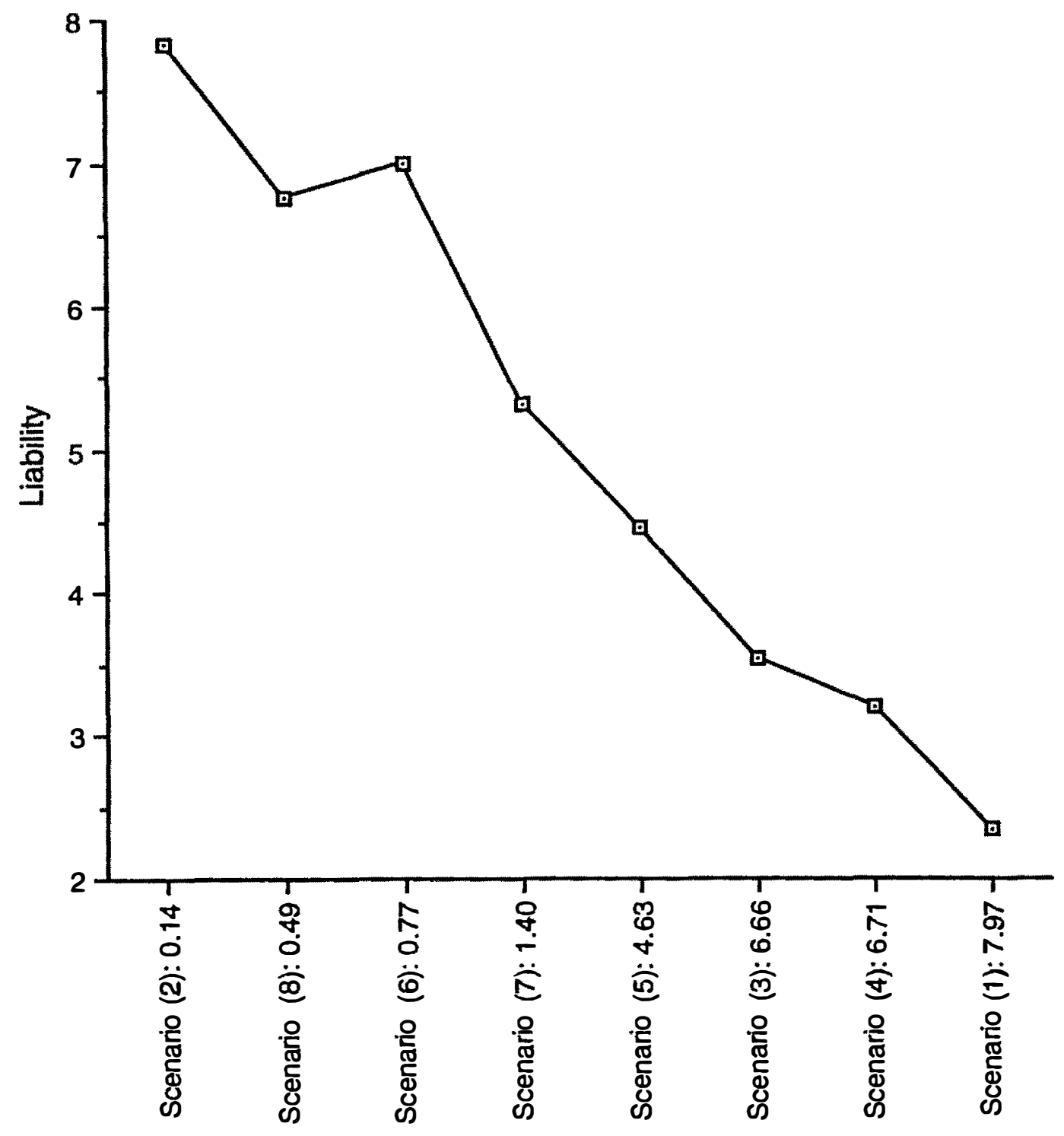

Maximum Force Permitted by Subjects in Such a Situation

kills an individual that he provoked into attacking him, is a complex case, which we will address later in this discussion. Note for now that the maximum force that the subjects deemed allowable is rated at 4.31 .

Notice, from Table 3.1, that these ratings of the maximum force allowable are consistent with the subjects' judgments of liability and (we would suggest) probably provide the basis for those judgments. To visualize this comparison, look at Figure 3.3. In it, we have ordered, along the horizontal axis, the scenarios in the order of the maximum force that our respondents would allow in self-defense (the maximum force is given along with the scenario identification), and along the vertical axis, the degree of liability assigned to the person who kills his "attacker." Note the close relationship. If our respondents judge that rather low 
amounts of force are appropriate in self-defense, then they assign the person who kills the "approacher" more severe sentences. If they judge that more force is allowable, they reduce the sentence to the individual who kills the attacker-until, in the final four cases, they tolerate responses that involve serious bodily injury to the attacker and give the defender quite low liability assignments. This suggests that the respondents are arriving at some global judgment-based on the set of facts they read-about what would constitute a reasonable action in the case, comparing the person's action and judging liability from the degree of discrepancy between the person's action and the "reasonable" action. Again, this view contrasts with the simple cutoff approach of current codes. Under the Model Penal Code, for example, only a threat of serious bodily injury or greater justifies the use of deadly force; a lesser threat justifies only the use of force short of deadly force.

We find an interesting code-subject discrepancy in scenarios involving possible retreat. Americans, stereotypically, "stand their ground," and our subjects seem to want them to even when the legal codes say they should not. That is, when one's use of deadly force is unnecessary because that person could safely retreat (Table 3.1's scenario 4), our subjects mitigate liability while the Code does not. As Table 3.4 , column $f$, reveals, subjects agree that the person could retreat, but as Table 3.1 (scenario 4, column a) reveals, the liability mean of 4.63 (9.6 months) reflects a considerably less severe sentence than the liability for murder that the current legal doctrine imposes. Apparently, some of our subjects are unsure about whether retreat should be required at all. In scenario 4,23 percent of our respondents give no liability; 40 percent give either no liability or no punishment. While a numerical majority appear to support the retreat rule, they support it as a basis for liability significantly short of what the Code assigns to that case, which is liability for murder.

Consistent with the subjects' equivocal support for the retreat rule, a large portion of our subjects agree with the Code's view that a person should not be required to retreat from his or her own home, even if he or she knows that he or she can do so safely (see Table 3.1's "retreat from home" case of row 5). Table 3.4 shows the respondents' ratings on the various dimensions of perception that we asked them about in regard to the self-defense cases. From Table 3.4 (column $f$ ), it is clear that they only rather grudgingly agree that retreat was possible. As in scenario 5 of Table 3.1, 43 percent give no liability in such a case. Similarly, a person who mistakenly believes that it is impossible to retreat (scenario 7) receives almost no liability $(0.49$, or less than 1 day in jail) from the respondents. It would be interesting to contrast this view with the views held by persons from other cultures.

Our subjects also agree with the codes in giving a defense to a person who incorrectly but honestly believes that use of deadly force is necessary (scenarios 6 and 7). This occurs both in cases in which the person is mistaken as to 
TABLE 3.4 Subjects' Perceptions of Self-Defense Cases

\begin{tabular}{|c|c|c|c|c|c|c|c|}
\hline Scenarios & $\begin{array}{l}\text { (a) } \\
\text { "Risk of } \\
\text { Bodily } \\
\text { Injury" }\end{array}$ & $\begin{array}{c}\text { (b) } \\
\text { "More } \\
\text { Force Than } \\
\text { Necessary" }\end{array}$ & $\begin{array}{c}\text { (c) } \\
\text { "Could Have } \\
\text { Safely } \\
\text { Delayed" }\end{array}$ & $\begin{array}{c}\text { (d) } \\
\text { "Intended } \\
\text { to } \\
\text { Shoot" }\end{array}$ & $\begin{array}{c}(e) \\
\text { "Believed } \\
\text { Force } \\
\text { Necessary" }\end{array}$ & $\begin{array}{c}(f) \\
\text { "Could } \\
\text { Retreat } \\
\text { in Safety" }\end{array}$ & $\begin{array}{c}\text { (g) } \\
\text { “Unaware } \\
\text { Could } \\
\text { Retreat" }\end{array}$ \\
\hline 1. Killing, no self-defense & & 7.51 & 7.57 & 6.63 & & & \\
\hline 2. Killing, self-defense & & 2.23 & 2.40 & 5.03 & & & \\
\hline $\begin{array}{l}\text { Knows deadly force is not } \\
\text { necessary because: }\end{array}$ & & & & & & & \\
\hline 3. Unarmed attacker & & 7.51 & 7.34 & 6.43 & & & \\
\hline 4. Could retreat & & 6.60 & 5.57 & 6.46 & & 6.23 & \\
\hline 5. Could retreat from home & & 5.37 & 4.77 & 6.11 & & 5.49 & \\
\hline $\begin{array}{l}\text { Believes deadly force is } \\
\text { necessary but: }\end{array}$ & & & & & & & \\
\hline $\begin{array}{l}\text { 6. Mistaken as to threat } \\
\text { 7. Mistakenly believes }\end{array}$ & & 5.66 & 5.51 & 5.83 & 6.71 & & \\
\hline retreat not possible & & 4.09 & 4.17 & 5.46 & & & 7.51 \\
\hline $\begin{array}{l}\text { 8. Actor provokes attack } \\
\text { Believes deadly force is not } \\
\text { necessary but: }\end{array}$ & 7.43 & 6.60 & 5.77 & 6.57 & & & \\
\hline $\begin{array}{l}\text { 9. Mistakenly believes } \\
\text { deadly force legal }\end{array}$ & & 7.69 & 7.26 & 7.17 & 4.49 & & \\
\hline
\end{tabular}

Key to column heads:

Statements (a) through (e) were responded to on a scale where: $1=$ "strongly disagree," $5="$ unsure," and $9=$ "strongly agree."

(a) The force the person used ... created a risk of causing serious bodily injury.

(b) The person could have effectively protected himself by using less force.

(c) The person could have effectively protected himself if he delayed the use of force.

(d) The person intended to shoot the person he shot.

(e) The person believed that the amount of force was justified/necessary to protect himself.

(f) The person could have avoided the threat by retreating out of his house in complete safety.

(g) The person was unaware that he could retreat. 
whether the attacker threatens serious bodily injury (e.g., as to whether he is armed-scenario 6) and in which the person is mistaken about whether safe retreat is possible (scenario 7). The former result suggests some respondent empathy for the person who must decide under difficult circumstances whether to shoot. The latter result, commented on before, is predictable, given the subjects' weak support for the retreat rule. As noted previously, many jurisdictions permit a defense only if the person's mistake is reasonable; an unreasonable mistake is grounds for murder liability. Other jurisdictions allow a mitigation for an unreasonable mistake. The scenario used in this study gave no facts to suggest that the mistake is culpable, and columns $e$ and $f$ of Table 3.1 suggest that the respondents see the use of a serious degree of force as acceptable in these situations. Thus the no-liability result seems consistent with the Code's complete defense for a reasonable mistake. One might speculate that the low liability scores, given in those instances in which the person's mistake might have been interpreted as culpable, suggest that the codes should give at least a mitigation for a culpable but honest mistake. A future study might test its subjects' reactions to various levels of culpability in making a mistake as to a legal justification.

It may be that the respondents are attempting to assess what a reasonable person would infer from the actions of the attacker and, therefore, the latitude of action that they will allow the defender. On this account, if the attacker commits certain actions, those may trigger an inference of significant, imminent harm by the attacked individual that leads him or her to respond with deadly force. This inference may be incorrect, but the attacked individual is given a great deal of leeway by our respondents in making it. Unless the inference is conspicuously egregious, the fact that it is made, and acted on, is largely the attacker's problem. Putting this another way, it is the privilege of the attacked individual not only to judge what force is sufficient to deal with the present level of force that the attacker is using but also to judge what level of force the attacker might escalate to in the immediate future. Fists may be all the force in play at the moment, but will knives or guns be next?

Our subjects also agree with the Code in rejecting a defense for a person who mistakenly believes that he is legally authorized to use deadly force against an unarmed attacker (scenario 9, Table 3.1). The liability mean of 6.71 (5.9 years) is not statistically different from that assigned to a person, using similarly unnecessary force, who does not believe that his use of deadly force against an unarmed attacker is lawful (scenario 3, 6.66; 5.8 years). This is an interesting result, and one that we will see again. It suggests that respondents believe that it is widely accepted that one should not kill an unarmed attacker. A mistaken belief that the law allows such an attack does not excuse it. Having said all of this, we should point out that future research, in which, for example, it is more clear that the person knew his conduct was unlawful, will be necessary to confirm these conclusions. 
In the scenario in which the person provokes the panhandler into an attack that requires defensive force (scenario 8 ), the respondents assign a high degree of liability to the provoker but the Code's liability even exceeds that. The provoked-attack liability scenario has a liability mean of 6.40 ( 4.6 years), which suggests that the subjects see clear blameworthiness in the provoker-but not of the level of a murderer (as the Code provides) and perhaps not even of the level of the person who kills upon a trivial threat $(7.97 ; 15$ years). (This last result, 7.97 -when compared to 6.40 -is only marginally significant.) Further research is necessary to illuminate the parameters of this complex issue. To guide that research, we can at least suggest what might be the components of the situation that people seek to assess when they assign liability to a person who in some sense provokes an attack and then uses deadly force in response. Intuitively, one would expect that if an individual attacks another in response to a mild provocation, killing the mildly provoking attacker would be seen as less warranted than if the provocation is more complete and violent.Here is the intuitive rule that we think is operating: If I say something to you that is only mildly provoking, and you then come at me with dagger drawn, I will be assigned relatively low liability for killing you before you kill me. My mild provocation does not warrant your overblown response; you are the primary cause of your attack on me. However, if my provocation to you was really quite intense, then I have some causal responsibility for your attack on me and bear some liability for killing you to head off your attack. Perceivers of these situations are likely to be attempting to unravel the familiar question of "who really started it" (Carpenter and Darley, 1978). There is also a question of what, exactly, the one who provokes the attack intends to do when counterattacked. If the respondents perceive, as in the formulaic cowboy movie, that the fast-drawing villain provokes the innocent, slow-drawing citizen into "drawing," with the certainty of outdrawing him and intending to kill him, then they see it as murder and are glad when the hero "does-in" the villain in the last reel. Fascinating questions lie here for future research.

\section{Study 5: Summary}

On the one hand, it appears that the subjects' judgments are complex, and in many instances they agree with the pattern of distinctions made in the Code. The subjects generally decline to punish in the scenarios in which the Code gives the person a defense (respectively, scenarios 2, 5, 6, and 7): Scenario 2, of course, is the paradigmatic case-deadly force used in response to an attack with a deadly weapon. The other scenarios in which the respondents generally decline to punish the person are those in which the person knows he could retreat in safety but is in his home; where he mistakenly but honestly believes serious bodily harm is threatened; and where he mistakenly but honestly believes that he cannot safely retreat. Similarly, the subjects impose significant liability in scenarios in which the Code would deny a defense (respectively, scenarios 3, 4, 8, and 9): where the 
person knows the attacker is unarmed; where he knows he can retreat in safety; where he provokes the attack to justify his subsequent use of force; or where the actor sees that deadly force is not necessary to repel the attack but, believing the law permits it, uses it anyway.

On the other hand, a second element in the patterning of our subjects' responses is evident - a tendency to assign lesser punishments than the Code. Our subjects and the Code disagree on the extent of liability that should be imposed in those cases in which the person either acts in self-defense but knows that deadly force is unnecessary (cases 3 and 4 ) or in which he provokes the attack (case 8). The subjects' disagreement with the Code is particularly striking in the case in which it would be possible for the person to retreat from the threat. While the Code denies a defense in this instance, leaving the person liable for murder, our subjects impose liability akin to manslaughter ( 5.8 years in jail) or, in the case of failure to retreat, something less (9.76 months). Apparently the subjects see a clear and significant distinction between an unjustified killing in self-defense and an intentional killing where no threat of attack exists. A self-defense provision that mirrors the subjects' views would mitigate liability for even unjustified killings in a self-defense setting.

The significant agreement that does exist between our subjects and the Code may be the result of community views manifesting themselves in the centuries of common-law development, upon which most of these rules are based. It may not be that the detailed rules are intuitive but rather that both the subjects' views and the Code's rules result from application of a few basic principles, such as the requirements that the defensive response be necessary and proportional. ${ }^{2}$ It also is possible that the rules of the legal code, which once may have been alien to the moral codes of the governed, over time became accepted moral principles. Morality can shape the law, but the law also can shape morality (Green, 1985).

\section{STUDY 6:}

\section{USE OF FORCE IN DEFENSE OF PROPERTY}

The criminal law typically allows a person to use force in the protection of property. As with self-defense, the force used must be necessary to protect the property, both in the amount of force used and in its timing; that is, no lesser force and no delay in the use of force would have provided adequate protection. The force used also must be generally proportionate to the threat. Thus, the use of deadly force generally is prohibited to protect property alone, even if such deadly force is the only means by which the property can be protected. As with self-defense, when a person makes a mistake as to the necessity for the use of force, he nonetheless may get a mitigation or defense, depending on the culpability level of his mistake. All jurisdictions give a defense for a reasonable mistake. Some give no defense for an unreasonable mistake; others give a mitigation in degree of liability. 
The illegality of using deadly force in protection of property is unequivocal: No mistake is grounds for a defense.

In this defense of property study, we tested the current defense of property rules against our subjects' assignment of liability in analogous defense of property situations. Subjects were given seven scenarios in which the person uses force to defend against an attempt to steal his motorcycle. One scenario presented a baseline case in which necessary, nondeadly force is used, which would receive complete exculpation under current doctrine. The other six scenarios presented variations in which the person deviates from the baseline case in one or more ways, typically in violation of one of the limitations on the use of force to defend property. The liability results are shown in Table 3.5. Notice that column $e$ contains the various liabilities assigned to the person who attempts the theft. As one would expect, the thief is assigned some liability, and it is roughly constant across the cases.

With respect to perceptions of the use of necessary nondeadly force (the baseline case results in row 1), our subjects agree that complete exculpation is appropriate. Of the respondents, 89 percent judge that no liability should be assigned to the property defender; the remaining 11 percent assign liability but no punishment.

Next, we examine scenario 2 , in which the force is labeled "questionably necessary." In this scenario, the description reads as follows: "Joe punches the man, believing at the time that it is necessary. Joe's wife begins to yell at Joe that the man was small and not very muscular and Joe probably could have scared him off with a yell. Joe later realizes that his wife was right." Here, too, the subjects imposed essentially no liability by the subjects on the property defender.

Table 3.6 contains respondents' perceptions of various aspects of the defenseproperty scenarios. Examining the ratings on the questions concerning whether more force than necessary was used (column $a$ ) and whether the force could have safely been delayed (column $c$ ), the respondents seem to give the benefit of the doubt to the defender in scenario 2 . That is, they are not convinced that the person used more force than was necessary or that the use of the force could have been delayed. Given that in this particular scenario the defender realizes only later that the force he used was not necessary, this seems a reasonable set of perceptions and (see Table 3.5) liability assignments.

In scenario 3, the owner has rigged a protective device to the garage door so that if anyone tried to break into the garage and steal the motorcycle, the device is triggered, firing a beanbag at the intruder. In this case, the thief breaks the lock on the garage door and opens it, and the device is triggered, breaking the thief's nose. Here we were beginning a probe of the reactions of our respondents to "spring guns" and "man traps," the use of which is significantly limited by law [MPC $\$$ 3.06(5)]. Their use is a complex area of the law because it is hard to predict the degree of harmful consequences of these devices for the thief or the nature of the existing threat when the device is triggered. Also, they can cause injury when no 


\begin{tabular}{|c|c|c|c|c|c|c|}
\hline Scenarios & Liability. & $\begin{array}{l}\text { (b) } \\
\text { \% No } \\
\text { Liability } \\
\text { (N) }\end{array}$ & $\begin{array}{c}\text { (c) } \\
\% \text { No Liability } \\
\text { or } \\
\text { No Punishment } \\
(N+0)\end{array}$ & $\begin{array}{c}\text { (d) } \\
\text { Model Penal } \\
\text { Code Result } \\
\text { for Defender }\end{array}$ & $\begin{array}{l}\text { Liability } \\
\text { for Thief }\end{array}$ & $\begin{array}{c}\text { (f) } \\
\text { Maximum } \\
\text { Force That } \\
\text { Sirould be } \\
\text { Permitted }\end{array}$ \\
\hline 1. Necessary force & 0.00 & 89 & 100 & Complete defense & 4.58 & 3.80 \\
\hline 2. Questionably necessary force & 0.00 & 77 & 98 & Unclear ${ }^{a}$ & 4.70 & 3.91 \\
\hline $\begin{array}{l}\text { 3. Necessary force applied by device } \\
\text { 4. No imminent threat (perceived }\end{array}$ & 0.19 & 77 & 93 & Complete defense ${ }^{b}$ & 5.11 & 3.91 \\
\hline as not immediately necessary) & 0.48 & 48 & 82 & Unclearc & 4.14 & 3.36 \\
\hline 5. More than necessary force by choice & 0.14 & 55 & 93 & $\begin{array}{l}\text { No defense; liable for } \\
\text { simple assault, a } \\
\text { misdemeanor }\end{array}$ & 4.05 & 3.41 \\
\hline \multirow{2}{*}{$\begin{array}{l}\text { 6. Deadly force, knowing not lawful } \\
\text { 7. Deadly force, mistakenly believing } \\
\text { it lawful }\end{array}$} & 2.56 & 21 & 46 & $\begin{array}{l}\text { No defense; liable for } \\
\text { aggravated assault, a }\end{array}$ & 5.39 & 4.32 \\
\hline & 2.63 & 18 & 48 & second-degree felony & 5.45 & 4.25 \\
\hline
\end{tabular}

Liability Scale: $\mathrm{N}=$ No criminal liability, $0=$ Liability but no punishment, $1=1$ day, $2=2$ weeks, $3=2$ months, $4=6$ months, $5=1$ year, $6=3$ years, $7=7$ years, $8=15$ years, $9=30$ years, $10=$ life, and $11=$ death.

Key to column heads:

(f) What is the maximum amount of force that someone should be permitted to use to protect his property in this situation? $0=$ "no force," $2=$ "risk of bodily injury, $4=$ "bodily injury," $6=$ "serious bodily injury," $8=$ "serious bodily injury with risk of death," and $10=$ "death."

aThis scenario was intended to present the case of a mistaken actor. Such an actor might get a defense under current law, especially if his mistake was reasonable; he might only get a mitigation if his mistake was not reasonable. In fact, the scenario was perceived as a case of necessary force, for which the actor would have a defense under current doctrine.

If the scenario had been perceived as the device creating a substantial risk of serious bodily injury, as was intended, there would be no defense. But no such risk was perceived by the subjects. See column $d$ of Table 3.6. In a case of no risk of serious bodily injury, a complete defense is available.

"An "imminent threat" was required by common law; modern codes such as the Model Penal Code require only that the "force used be immediately necessary." 


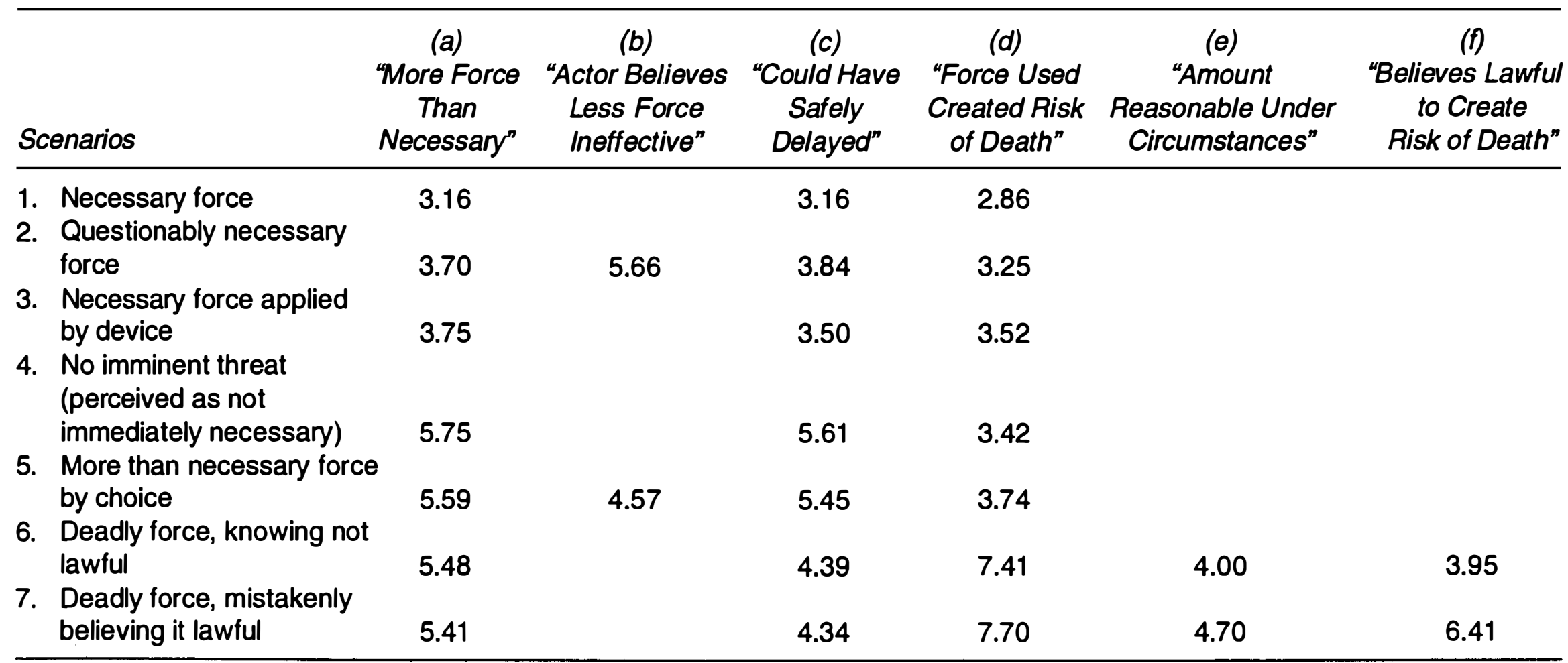

\section{Key to column heads:}

Statements (a) through ( $f$ ) were responded to on a scale where: $1=$ "strongly disagree," $5=$ "unsure," and $9=$ "strongly agree."

(a) The actor could have effectively protected his property by using less force than he did.

(b) At the time when the actor hits the man, the actor believes that less force would be ineffective to protect his property.

(c) The actor could have effectively protected his property if he delayed his use of force.

(d) The force that the actor used created a risk of causing the man's death.

(e) The amount of force the actor used was reasonable in light of the situation.

(f) The actor believes that he is legally entitled to use force that risks causing the thief's death. 
threat to person exists, because no one is present. Subjects seem to read this case as within the bounds of acceptability: They disagree that it was more force than was necessary (Table 3.6, column $a$ ) and do not agree that it created a risk of death (column $d$ ). Of the respondents, 93 percent assign no liability or punishment to the person who set the device. Futu re research ought to examine how respondents feel about setting more lethal traps for thieves.

Examining next scenarios 4 and 5, we find a continuation of the general pattern of lenient treatment of the person protecting his property. In case 4 , in which the force used in defense is described as not immediately necessary, 82 percent of the respondents still assign no punishment to the force user. (Briefly, the thief agrees to leave when Joe yells at him, but the thief makes it clear that he has an imprint of the keyhole and will return for the motorcycle. Joe resorts to force in order to retrieve the imprint.) In scenario 5, we sought to make it completely clear that the force used was knowingly more than was necessary: "Joe realizes that he can simply scare the man away by yelling at him. He nonetheless approaches the man and punches him in the face." Despite our efforts, even in this scenario 93 percent of the respondents impose no liability or no punishment on the property defender.

For each scenario, respondents were asked to indicate the degree to which they agreed with the statement that "the [person] could have effectively protected his property by using less force than he did" (column $a$ of Table 3.6). An examination of the respondents' ratings here suggests the thinking that may lie behind their rather permissive stance on property-defender punishment: They are not convinced that more force than necessary had been used. Thus, even when a scenario explicitly describes the force as unnecessary, the subjects generally are unconvinced. In scenario 5 , subjects' ratings on the necessity of the force used average 5.59 , less than one point above the scale midpoint of 5 (column $a$ ), indicating that they are unsure that the force was more than was necessary. It may be in this case that the subjects are taking the role of the person whose property is threatened and concluding that we cannot require that his cognitions be perfectly clear or his responses perfectly measured, when he is in the midst of the stressful circumstances of an attempted theft. Further, there may be an element of calculation that involves the value of the property at risk; a motorcycle is a relatively costly object, and a punch on the nose not too high a price for the potential thief to pay.

Consistent with the subjects' tendency to see nondeadly force as necessary is their general failure to impose liability even in those cases in which they see the force as possibly unnecessary. Even in the last scenario quoted above-where the subjects fall somewhere between uncertainty and agreement as to whether the amount of force used was unnecessary- 55 percent of the subjects think that no liability was appropriate and 93 percent think that no liability or no punishment was appropriate.

Summing up this initial look at the five scenarios involving nondeadly force, a considerable majority of our subjects would impose no liability in any of the sce- 
narios. Of the respondents, 82 percent or more would impose either no liability or no punishment. Overall, this might suggest that our subjects are not concerned with the many distinctions that the Code uses and that the subjects generally approve of the use of nondeadly force in the protection of property, whether necessary or not.

Examining the matter more closely, however, some evidence hints that subjects do take into account the necessity for the use of force in assessing the proper degree of liability. The two cases (in Table 3.6, column a) perceived as the weakest cases for necessity are scenarios 4 and 5, with average agreement ratings of 5.75 and 5.59, respectively, indicating slight agreement with the "unnecessary amount" manipulation check, as compared to means of 3.16, 3.70, and 3.75 for the other nondeadly force scenarios, which indicate disagreement with the statement that unnecessarily strong force was used. Scenarios 4 and 5 also have the lowest "no liability" percentages, 48 percent and 55 percent, respectively (see Table 3.5). But this seems at best weak support for the necessity principle, which is seen as fundamental to the legal doctrine. Recall that current doctrine treats the use of unnecessary force as a basis for denying any mitigation or defense to the property defender. Our respondents rather obviously treat it differently, as a factor determining liability. And the average liability of less than one day in jail ( 0.48 and 0.14 , respectively, Table 3.5) that they impose for using more than necessary force is considerably less than would be imposed by current legal codes, which would treat the case as one of simple assault with a maximum sentence of one year (MPC $\$ \$ 211.1$ and 6.08).

Rather than focusing on the necessity of the force, the subjects seem to rely more heavily on the reasonableness of the amount of force in light of the seriousness of the threat-what the doctrine calls the proportionality of the force-as a basis for determining liability. Where the aggressor makes a single threat to take property, as in the first five scenarios, the subjects see the "maximum amount of force that someone should be able to use to protect his property in this situation" as approximately constant (see Table 3.5, column $f$, ranging from 3.36 to 3.91 , where 4 = bodily injury). The amount of force that our subjects think ought to be permitted increases slightly in the remaining two scenarios, however, where the thief persists after repeated efforts by the owner to discourage him are unsuccessful (rows 6 and 7, 4.32 and 4.25). As we have noted, it would be interesting to determine in future research whether the maximum amount of force perceived as appropriate in defense would increase in relation to the value of the property defended. For example, if the individual was a store owner defending his goods, would subjects see a greater degree of force as reasonable than if he were only defending some inexpensive piece of property?

Our subjects' tendency to see (or claim to see) the person's use of force as necessary, despite statements in the scenarios to the contrary, does not appear to exist in the deadly force scenarios. The two deadly force scenarios (6 and 7) have the 
following core description: A thief is detected attempting to steal a motorcycle, and the owner attempts to get him to stop. The thief persists, and the owner gets a gun and shoots him. The respondents are told that the thief is wounded but not killed. Given the persistence of the thief in the face of several attempts to stop him, we thought the shooting portrayed force that at least some respondents might see as necessary, but it brought manipulation-check responses of 5.48 and 5.41 (Table 3.6), suggesting that our subjects as a group are leaning slightly toward agreeing that the force is unnecessary or are at best unsure that it is necessary. Our respondents (see column $f$ of Table 3.5) judge that force that causes bodily injury but not serious bodily injury is the maximum force appropriate to use on the persistent thief and that they agree (column $d$ of Table 3.6) that the actual force used, the gunshot, creates a risk of death, and therefore is, by inference, more than the maximum allowable force. This is confirmed by column $e$ of Table 3.6.

In these deadly force cases, the number of subjects who impose no liability drops to 21 percent and 18 percent. (This is a significant decrease in contrast with the nondeadly force scenario percentages.) The liability means correspondingly increase, from between 0.00 and 0.48 (less than 1 day) to 2.56 and 2.63 (about 5.6 weeks). ${ }^{3}$ Thus, the thief's greater aggression may justify the use of greater defensive force, but the use of deadly force correspondingly results in a considerable increase in liability. While the use of unnecessary force in defense of property is generally approved of by respondents, this principle has a limit: The majority of subjects think that the person's resort to use of a deadly weapon is unjustified. A majority of our respondents think it wrong to shoot the person attempting the theft of the motorcycle. Interestingly, they are not moved by being told that the person mistakenly thought that the shooting was lawful (scenario 7). This suggests that people see a clear moral issue here: One should know better than to shoot in defense of that sort of property.

These findings tend to support the Code's prohibition against the use of deadly force in defense of property, but we also must point out that there are vast differences between the way our respondents view the use of deadly force in defense of property and the way that such use of force is treated by the Model Penal Code. Indeed, almost half of the subjects ( 46 and 48 percent) would impose no punishment in the cases of deadly force in the protection of property: Also significant is the fact that the liability means of 2.56 and 2.63 imposed by the subjects represent - on average - a sentence of 5.6 weeks, not the 1- to 3-year minimum, 10year maximum sentence guidelines provided by the Model Penal Code.

Scenario 6 may be the most revealing of the seven cases in what it shows us about people's judgments:

Joe arrives home to find a man attempting to steal his motorcycle.

[Next are described a number of attempts by Joe to stop the thief, through which the thief persists in his attempts to steal.] While Joe believes that it may not be lawful to use a gun to prevent the theft of a motorcycle, he sees no other way to stop the 
man. He goes to his house just a few steps away, retrieves his gun, returns, and shoots the man. The man survives and is later taken into custody by the police.

The subjects indicate that the maximum amount of force that should be permitted to protect property in this situation is 4.32 (Table 3.5 , column $f$ ), or approximately enough force to result in bodily injury ( $4=$ bodily injury; $6=$ serious bodily injury; $8=$ serious bodily injury with risk of death). Additionally, the subjects clearly perceive Joe's conduct as creating a risk of death. Yet, despite Joe's failure to limit his conduct as the subjects would think appropriate, 46 percent of the subjects assign either no liability or no punishment. What of the remaining 54 percent who believe that some punishment is important? Do they impose the relatively severe sentence suggested by the codes? It turns out that they do not. About 75 percent of these subjects assign a punishment of less than one year. ${ }^{4}$ This strikingly differs from the Code's treatment of the offense; the Code treats it as aggravated assault, a second-degree felony with a maximum sentence of ten years.

\section{Study 6: Summary}

Even in those cases in which the force used in defense of property is unnecessary or disproportionate-according to legal codes-the vast majority of subjects impose no punishment. The subjects also show a tendency to interpret a person's conduct as necessary to defend his property even in instances in which such a conclusion is difficult to support on the objective facts. As with self-defense, the defensive nature of the person's situation appears to have a significant effect on the subjects' judgment. Even when the person's defensive response is knowingly improper-that is, he knows that the law does not justify his conduct-the subjects significantly reduce the person's liability. Again, the subjects appear to distinguish a person who improperly defends his property from a person who uses the same force in other than a defensive context. This argues in favor of providing reduced grades of liability for those who err in defending property against an attack. It remains a question for further research as to whether the value of the property being defended enters into the respondents' calculations.

If the legal code were modeled after the subjects' responses, it would give a complete defense for nondeadly force, necessary or not, used in the defense of property. The use of deadly force would be disapproved of but would result in low liability and punishment if the force appeared to be necessary (and the thief is not actually killed). ${ }^{5}$ In further research it would be important to address the question of what "philosophies" lie behind the judgments of individuals. Are there some individuals who believe that even deadly force is allowable in the defense of property? Does this belief reflect the view that the criminal justice system has become ineffective in defending property? The results may well be consistent with a public that is angry with what they see as the criminal justice system's failure to protect. "At the very least," the argument might go, "if the system will not protect 
my property, I should be permitted to do what is necessary [and perhaps more] to protect it myself."

\section{STUDY 7: \\ CITIZENS' LAW ENFORCEMENT AUTHORITY}

Citizens sometimes seek to exercise the authority of a law enforcement officer, as when they attempt to apprehend a person who has committed a crime against them. If the use of force is defensive in any way-for example, an aggressor is attacking them or attempting to take their property-a citizen can rely on a defensive-force defense, such as self-defense or defense of property, which frequently permits the use of greater force than would a citizen's law enforcement authority. If the use of force is not defensive, as when an offense is complete-for example, after a rape or after property damage has been caused - a citizen nonetheless has a right to use some degree of force to apprehend and restrain the offender [MPC $\$$ 3.07(1)].

Exercise of a citizen's law enforcement authority is subject to several limitations. A citizen is never justified in using deadly force to arrest an offender (unless he or she does so in assisting a peace officer and meets other special conditions) [MPC $\$ 3.07(2)(b)$ ]. A person may use nondeadly force only to the extent that it is immediately necessary to effect a lawful arrest. If a citizen is mistaken in some respect-for instance, about whether the person he or she is attempting to arrest is the actual perpetrator of the crime-that citizen may nevertheless get a defense if his or her mistake is reasonable. If it is unreasonable, some jurisdictions deny any defense or mitigation while others permit a mitigation. In the latter jurisdictions, if the citizen recklessly or negligently injures an innocent person, for example, the citizen may be liable for an offense of recklessness or negligence, as the case may be $[$ MPC $\$ 3.09(3)] .^{6}$ The Code does not alter the degree of nondeadly force permissible according to the seriousness of the offense for which the arrest is made; in all cases, the force must be just that which is necessary to effect the arrest.

In the citizens' law enforcement authority study, we sought to test the current doctrine's rules on such authority against the community's views. Subjects were presented with scenarios involving the use of deadly and nondeadly force by the victim to restrain an offender after a rape and after a property damage offense (setting the victim's car on fire). Notice that in both cases the offense is already complete at the time force is used; thus, we are not dealing with cases of self-defense or defense of property. The deadly force scenarios depict the victim as shooting the fleeing offender with a handgun and killing him; in the nondeadly force scenarios, the victim uses a stun gun that temporarily immobilizes but does not inflict lasting injury on the offender. In some scenarios, the person stuns or kills the offender and in others the person stuns or kills an innocent person that she mistakes for the offender. The subjects were asked, as usual, to determine how 
much liability the restraining person should receive, if any. They were also asked how much force a person in such a situation should have been able to use (column $e$ of Table 3.7) and whether the actual force used created a risk of death (column f). The results are shown in Table 3.7.

Notice first that the subjects saw the differences between the use of the stun gun and the handgun as we had wished. They agreed (column $f, 7.92$ on the average) that the person's use of the handgun creates a risk of death (not surprising, since they were told that the person shoots and kills the fleeing offender), and the person's use of the stun gun does not create a risk of death (2.83 on the average).

Please look next at the liability judgments. First, observe the patterning of the liability assignments in the four cases in which the citizen uses force to apprehend the individual who actually committed the crime (scenarios $1,3,5$, and 7). While the difference in liability assigned to the individual who uses deadly force (scenarios 1 and 5) is slightly higher ( 0.21 and 2.60; respectively, less than 1 day and 5.6 weeks) than the zero liability assigned to the person who uses nondeadly force (scenarios 3 and 7), what is most striking, as we noted in the previous study, is the tendency of our subjects to assign very low degrees of liability no matter what degree of force is used. The most dramatic difference between our subjects and the Code is in the deadly force scenarios. A strong majority (65 percent) would allow the use of deadly force by the citizen to apprehend the rapist-or at least would not punish such conduct. If we add to this group the respondents who find the defendant guilty but would impose no punishment, we include 90 percent of our respondents. The Code, in contrast, denies a defense (or a mitigation) and thereby holds the person liable for murder. Only in the case of the use of deadly force to apprehend an individual who has damaged property do we see any meaningful assignment of liability by a majority of respondents (67 percent); apparently, the use of force that has the potential to kill the offender in this particular instance exceeds the respondents' perceptions of the allowable level of force. Still, the average liability imposed for the same case, 2.60 , translates to a sentence of 5.6 weeks for an act that the legal code would treat as murder-a vast difference.

Does this pattern of results change in the scenarios in which the restraining person stuns or kills an innocent milkman instead of the actual person who committed the crime? No-the liability ratings do not change very much at all. Examine the four cases in which the person mistakenly uses force to apprehend an individual who did not in fact commit the crime (scenarios $2,4,6$, and 8 ). Look ahead now to Table 3.10 and notice, in column $d$, that the respondents judge that the person is unaware of the possibility of making this mistake. The person is not, therefore, seen as lashing out at anybody in the vicinity; the force is directed at the individual whom the person thinks committed the crime. Figure 3.8 compares the liability results in the mistaken-identity cases to the matched cases in which the person apprehends the correct individual. Examining this figure, we see that the respondents deal with the cases of mistaken identity by assigning liability 


\begin{tabular}{|c|c|c|c|c|c|c|}
\hline Scenarios & Liability & $\begin{array}{c}\text { (b) } \\
\% \text { No } \\
\text { Liability } \\
\text { (N) }\end{array}$ & $\begin{array}{c}\text { (c) } \\
\% \text { No Liability or } \\
\text { No Punishment } \\
(\mathrm{N}+0)\end{array}$ & $\begin{array}{c}\text { (d) } \\
\text { Model Penal } \\
\text { Code Result }\end{array}$ & $\begin{array}{c}\text { (e) } \\
\text { Maximum Force } \\
\text { That Should } \\
\text { Be Permitted }\end{array}$ & $\begin{array}{c}(f) \\
\text { "Force Used } \\
\text { Created Risk } \\
\text { of Death" }\end{array}$ \\
\hline \multicolumn{7}{|l|}{ Rape_Deadly force: } \\
\hline 1. Actual offender & 0.21 & 65 & 90 & Liable for murder & 7.55 & 7.87 \\
\hline 3. Actual offender & 0.00 & 83 & 100 & Complete defense & 6.85 & 2.92 \\
\hline 4. Mistaken identity & 0.35 & 30 & 83 & Complete defense ${ }^{a}$ & 6.49 & 2.82 \\
\hline \multicolumn{7}{|l|}{$\begin{array}{l}\text { Property destruction- } \\
\text { Deadly force: }\end{array}$} \\
\hline 5. Actual offender & 2.60 & 33 & 45 & Liable for murder & 4.39 & 8.08 \\
\hline 7. Actual offender & 0.00 & 70 & 100 & Complete defense & 4.07 & 2.67 \\
\hline 8. Mistaken identity & 0.62 & 23 & 80 & Complete defense $^{a}$ & 4.00 & 2.90 \\
\hline
\end{tabular}

Liability Scale: $N=$ No criminal liability, $0=$ Liability but no punishment, $1=1$ day, $2=2$ weeks, $3=2$ months, $4=6$ months, $5=1$ year, $6=3$ years, $7=7$ years, $8=15$ years, $9=30$ years, $10=$ life, and $11=$ death.

Key to column heads:

(e) What is the maximum amount of force that a person should be permitted to use to detain an offender in this situation? $0=$ no force, $2=$ risk of bodily injury, $4=$ bodily injury, $6=$ serious bodily injury, $8=$ serious bodily injury with risk of death, and $10=$ death.

(f) The force used was likely to cause death or bodily injury: $1=$ "strongly disagree," $5=$ "unsure," and $9=$ "strongly agree."

aThis assumes that the actor was not reckless as to injuring an innocent person. If the individual was reckless, the person could be liable for assault under MPC $\S 3.09(3)$ and 211.1(1). 
FIGURE 3.8 Effect of Mistake on Liability for Exercise of Citizens' Law Enforcement Authority

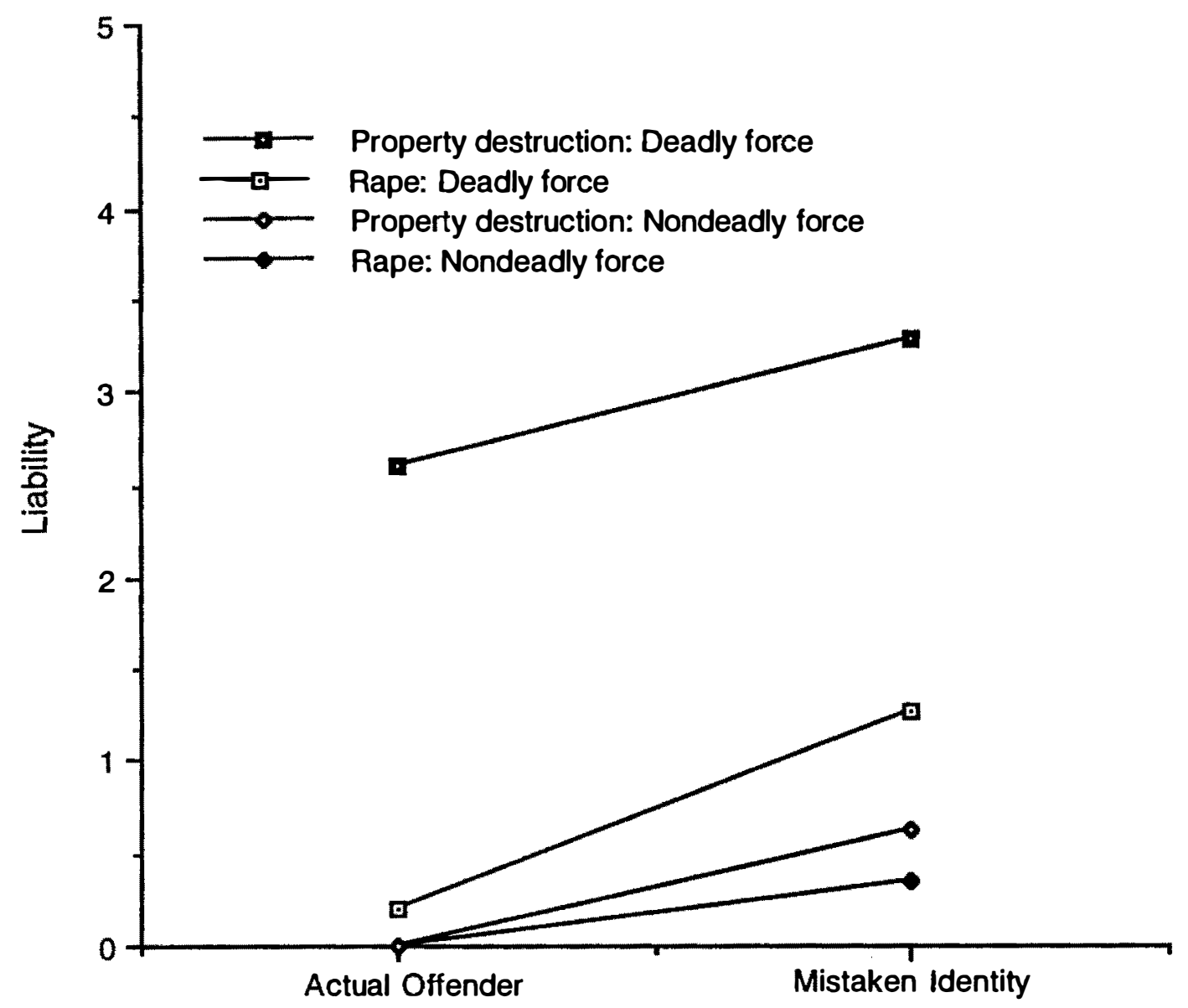

Person Apprehended

judgments that are slightly higher than the matched cases in which no such mistake occurs.

The Code's treatment of mistaken-identity cases does not match that of our subjects in several important respects. On the one hand, the Code does give a defense to the person who mistakenly injures an innocent person with nondeadly force, ${ }^{7}$ and a majority of the subjects would impose no punishment in such a case ( 83 percent in the rape arrest, 80 percent in the property destruction arrest). ${ }^{8} \mathrm{On}$ the other hand, a vast difference exists between the Code and our subject-community in the mistaken deadly force scenarios (2 and 6). Here the Code permits no defense ${ }^{9}$ and imposes liability for murder. But the number of subjects who would impose no punishment (column $c$ of Table 3.7 ) is substantial-68 percent in the rape case and 43 percent in the property destruction case. The no-punishment percentages are not dramatically different between the mistaken-identity and no-mistake deadly force scenarios (68 percent versus 90 percent in the rape arrest scenarios, 43 percent versus 45 percent in the property damage arrest scenarios), but the percentage of subjects who would impose no liability (column 
$b$ ) is significantly lower where the restraining person has mistakenly killed an innocent bystander ( 13 percent versus 65 percent in the rape arrest scenarios, 8 percent versus 33 percent in the property destruction arrest scenarios). One interpretation is that our subjects disapprove of the mistaken killing, and the person's conduct is judged to warrant the formal disapproval of the legal system (in the form of a "guilty" verdict) but not to warrant a prison sentence. We further discuss this "liability but no punishment" response-by now familiar to the reader-in Chapter 7 of this book.

Our respondents' low-liability ratings of the person in the mistaken use of deadly force scenarios are striking. Figure 3.9 presents this graphically; in analyzing it, one should bear in mind that the legal code would treat the deadly force cases as murder and assign a liability of approximately 10 . Only in the case in which the person mistakenly kills an innocent person in an attempt to arrest the offender who set fire to her car does a majority of subjects (57 percent) impose punishment. Even in this case, however, the respondents' liability mean suggests that the punishment imposed is relatively minor-3.27 (3.2 months) - considering that an innocent person is mistakenly killed. This is considerably less severe than the potential life (or death) sentence that a person could receive for the same accidental murder under the Code. In our scenarios, the mistake is what arguably might be described as "reasonable"; the person is at least not egregiously wrong in assuming that the person whom she harmed was the actual perpetrator. In future research, the plausibility of the case of mistaken identity should be varied, and we would expect that at some point this variation would make a difference. In the present case, however, it is only the combination of mistaken identity and the application of deadly force that receives any substantial penalty-and this is still nowhere near the penalty that would be given by the legal code.

What can we learn-from the patterns of the subjects' perceptions of the cases-that might reveal the grounds for their relatively lenient judgments? Three sets of perceptions stand out. First, given that the perpetrator is fleeing, respondents deem that immediate action is required to apprehend him-otherwise he will escape arrest (see Table 3.10, column $a$ ). Second, and particularly in the cases with the fleeing rapist, no less harmful action on the victim's part would successfully apprehend the perpetrator (column $b$ ). What the respondents clearly see is the dilemma that we intended to create: A perpetrator of a crime is fleeing and will escape unless the victim uses the only resource at her disposal to stop him, which is the gun. Third, notice, as we mentioned before, that the subjects always judge that the victim is quite unaware of the risk that she has mistakenly misidentified the individual whom she shoots as the true perpetrator of the crime (column $d$ ). These three perceptions, taken together, suggest that the victim of the crime is seen by the respondents as reacting reasonably to the event.

Recall the Code's treatment of the force allowable as it relates to the seriousness of the offense committed. The Code gives the same liability for use of force in the 
FIGURE 3.9 Effect of Use of Deadly and Nondeadly Force on Liability for Exercise of Citizens' Law Enforcement Authority

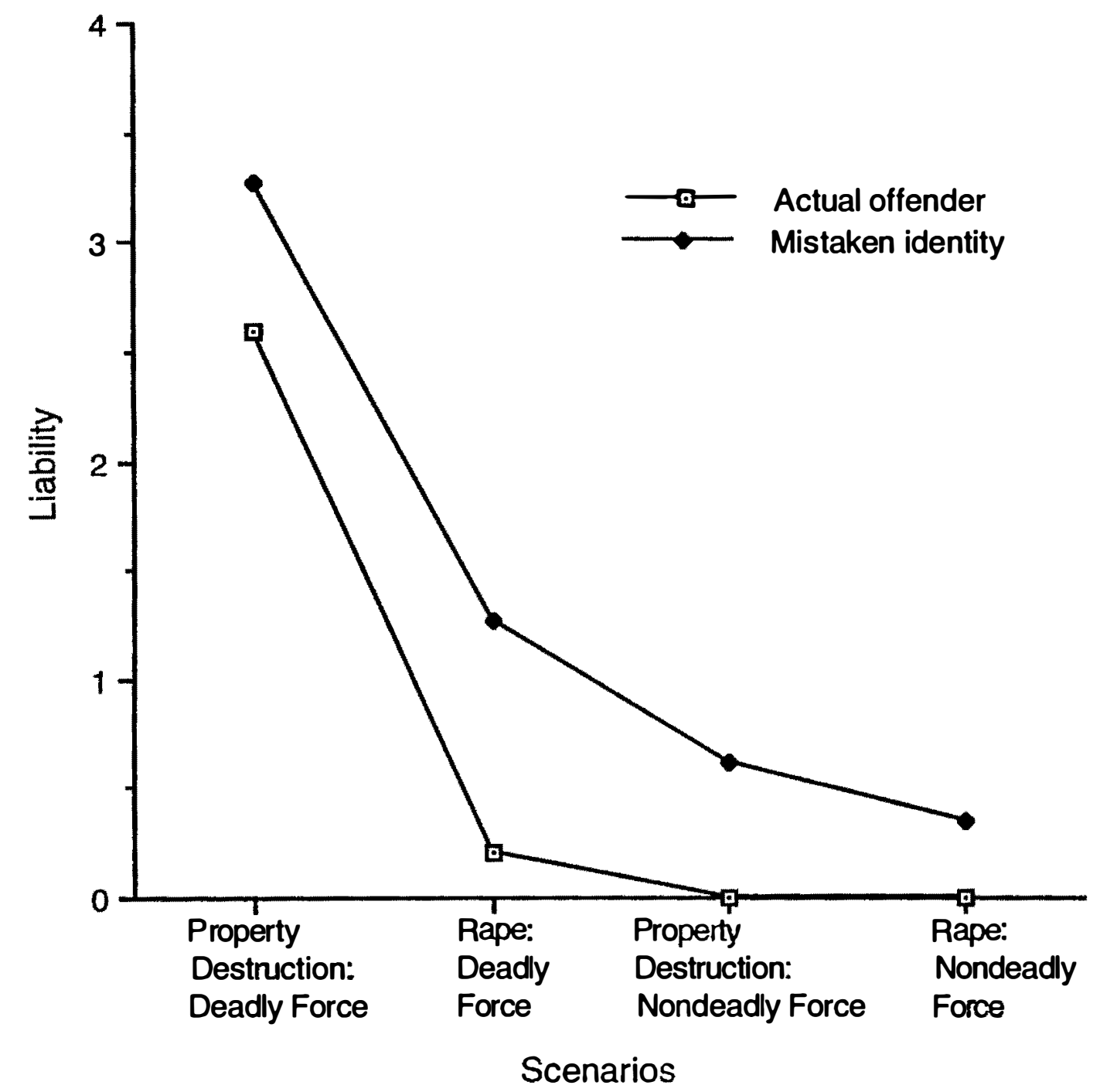

rape scenarios as it gives for use of the same force in the property destruction scenarios, suggesting that the Code does not find it appropriate to allow relatively greater latitude to a citizen apprehending an individual who has committed a relatively more serious crime. As is shown by their ratings of the maximum force allowable in the various cases (Table 3.7, column $e$ ), our respondents deeply disagree. The subjects approve the use of greater force for arrest after the moreserious rape offense than after the less-serious property damage offense ( $p<$ $.001) .^{\bullet}$ After cases of rape, the average maximum force our subjects would permit is 6.94 (with $6=$ serious bodily injury and $8=$ serious bodily injury with risk of death); after setting fire to a car (the property destruction case), the average maximum force our subjects would permit is 4.10 (with $4=$ bodily injury). These results suggest that our subjects would have the law vary the degree of force permitted according to the seriousness of the underlying offense. The subjects would 
TABLE 3.10 Subjects' Perceptions of the Exercise of Citizens' Law Enforcement Authority

\begin{tabular}{lcccc}
\hline & $\begin{array}{c}\text { (a) } \\
\text { "Immediate } \\
\text { Action } \\
\begin{array}{c}\text { Required } \\
\text { to Detain" }\end{array}\end{array}$ & $\begin{array}{c}\text { (b) } \\
\text { "No Less } \\
\text { Harmful } \\
\text { Means } \\
\text { to Detain" }\end{array}$ & $\begin{array}{c}\text { (c) } \\
\text { "Intended to } \\
\text { Shoot the } \\
\text { Person } \\
\text { Shot" }\end{array}$ & $\begin{array}{c}\text { (d) } \\
\text { "Aware of } \\
\text { Risk of } \\
\text { Mistaken } \\
\text { Identity" }\end{array}$ \\
Scenarios & & & & \\
\hline Rape-Deadly force: & 7.62 & 6.62 & 7.74 & 3.08 \\
1. Actual offender & 7.42 & 5.57 & 3.20 & 3.12 \\
2. Mistaken identity & & & & \\
Rape-Nondeadly force: & 7.40 & 7.32 & 7.82 & 3.20 \\
3. Actual offender & 7.41 & 7.15 & 2.97 & 3.03 \\
4. Mistaken identity & & & & \\
Property destruction- & & & & \\
Deadly force: & 6.41 & 4.58 & 6.82 & 3.62 \\
5. Actual offender & 6.27 & 4.70 & 3.50 & 3.17 \\
6. Mistaken identity & & & & \\
Property destruction- & & & & \\
Nondeadly force: & 6.69 & 6.26 & 7.46 & 3.16 \\
7. Actual offender & 6.87 & 5.97 & 4.10 & 3.37 \\
8. Mistaken identity & & & & \\
\hline
\end{tabular}

Key to column heads:

Statements (a) through (d) were responded to on a scale where: 1="strongly disagree," $5=$ "unsure," and $9=$ "strongly agree."

(a) If the victim did not act immediately, she would not have been able to detain the offender.

(b) There was no less harmful way, given the facts in this scenario, for the victim to successfilly detain the offender.

(c) The victim intended to shoot the person she shot.

(d) Before she shot, the victim was aware of a significant risk that the person she was about to shoot may not be the offender.

authorize something between serious bodily injury and risk of death to effect the arrest of a rape of fender but only bodily harm for arrest of an offender who causes property damage.

\section{Study 7: Summary}

To summarize our general findings on force in citizen arrests: The subjects agree with the Code's defense for a citizen's use of nondeadly force to effect an arrest. They disagree, however, with the Code's position that a citizen may not, independent of a law enforcement officer, use deadly force to ef fect an arrest. Most of our subjects would approve the use of deadly force to arrest a fleeing rapist. A large 
minority would take the same view even if the offender is fleeing from a property damage offense.

In general, the subjects are much more forgiving than the Code of a person's mistakes in using deadly force to effect a citizen's arrest. The Code imposes murder liability if the apprehending person kills an innocent person. A strong majority of the subjects, in contrast, impose no punishment even in the case in which the citizen kills an innocent person in trying to stop a fleeing rapist. Only in that case in which an innocent person is killed in an attempt to stop an offender fleeing from a property damage offense does a (bare) majority of our subjects judge punishment to be appropriate and, even then, liability is a few months rather than the murder liability that the Code provides. ${ }^{11}$ As the foregoing study demonstrates, the difference in views between the rape and property damage cases reveals that many subjects take into account the seriousness of the offense in judging the amount of force permissible to make an arrest-while the Code does not.

We are surprised by these results. Although intuitively we expected that our respondents might judge the use of force by citizens to apprehend criminals more leniently than does the legal code, we did not expect the overwhelming magnitude of the differences we found. We had expected that the use of deadly force would be more widely condemned in cases where, as here, the damage is already done and the force is being used aggressively (rather than defensively) to arrest the offender. This seems especially true where only damage to property is involved, but though our respondents do assign more liability to that case than to others, the liability assigned is very low.

Given these results, future research should test the generality of the leniency that the subjects display. Intuitively, one would expect that there must be limits on what sorts of mistake will generate these lenient patterns of liability. Surely one cannot egregiously mistake innocents for criminals and kill them with little or no liability. Furthermore, in this study's scenarios, the respondents could have believed that the person's primary goal in shooting the offender was to apprehend him rather than to kill him as deserved punishment. What if it were established instead that the arrester's primary purpose was otherwise? Would such a scenario receive equally lenient treatment? Finally, our offenders were fleeing. Do people believe that the legal system would be successful in eventually apprehending the perpetrator? Do those people who believe that the police will not be able to apprehend the criminal believe that it is more acceptable for the victim to shoot the perpetrator as a kind of victim-administered vigilante justice? From the perspective of the legal code, whether the criminal justice system will catch the offender is an irrelevant factor, but it may not be irrelevant to the community.

\section{CHAPTER SUMMARY}

We have now examined community views on three cases in which an individual has a justification for the use of force: when the force is used in self-defense, in de- 
fense of property, or to apprehend offenders fleeing from crimes they have committed. In all of these studies, the community judges that these justifications are more compelling than the legal codes are willing to grant. Respondents frequently assign no liability in cases to which the code attaches liability. Even when respondents assign liability, they typically assign considerably less punishment than would be suggested by the legal codes. This discrepancy is least evident in the justifications provided by claims of self-defense. In defense of oneself, the Code allows force, even deadly force, to be used in a number of cases. The differences between community standards and criminal codes become increasingly apparent when we examine what people think is justifiable in defense of property-and even more apparent in the cases involving a citizen who uses force to apprehend a criminal fleeing a crime or to apprehend a person thought to be a criminal fleeing a crime. Community standards, as evidenced by our respondents, tolerate the use of more force than the Code permits and assign lesser sanctions to the use of force-even in the instances in which our subjects judge that some blame accrues.

What can explain this sharp contrast between community standards and criminal codes? One possible accounting is that criminal codes are formulated with the often implicit presupposition that there is a reasonably effective criminal justice system in place. In the assumptive world of the code drafters, people who commit crimes have a high likelihood of being caught, convicted, and punished with due severity. But we know that many individuals do not believe this is true of the real world of the 1990s. Our subjects may believe that the criminal justice system is not likely to apprehend criminals, convict them when it apprehends them, or justly punish them when it convicts them. Our subjects also may believe that the criminal justice system is failing in its role of protecting citizens. Our discrepant results may stem from a general belief that when the criminal justice system does a poor job in punishing offenders, it is appropriate for individual citizens to do more in defense of both self and property as well as in law enforcement. The more ineffective the system is seen to be, the more people may be willing to let victims take matters into their own hands.

If this is the explanation for our results, it is a sad and troublesome one. The strength of the differences between community standards and legal codes that we found would indicate, at a minimum, that large segments of the population are deeply dissatisfied with the criminal justice system. These observed discrepancies may illustrate one of the "hidden costs" to policies that fail to provide adequately funded police forces or to court systems that fail to punish blameworthy offenders.

We are conducting further research to correlate individual attitudes about the effectiveness of the criminal justice system with judgments on what uses of force are appropriate in defense of both self or property or to apprehend those who commit crimes. However, one result is already clear: A code that seeks to mirror the community's views would have to broaden the Model Penal Code's justifica- 
tions and to ameliorate its treatment of unjustified conduct in a justification context. One suspects that in the actual operation of the criminal justice process, specifically when juries choose to acquit or refuse to indict or when prosecutors choose to reduce charges through plea bargains, these community judgments are registered. Still, should the legal codes be modified to match these community standards or at least to move in their direction? We find that an extraordinarily complex question, one to which we propose an answer in Chapter 7. 


\section{4}

\section{Doctrines of Culpability: When Is One's Violation of a Legal Rule Blameworthy?}

Once we have determined what we want our legal code of conduct to be (the subject of Chapters 2 and 3), we need to answer the question of when liability should or should not follow a code violation. Even if a person violates one of the criminal law's rules, it does not follow that liability is appropriate. The condemnatory nature of criminal law requires that inadvertent and unavoidable violations not be punished. If a person's violation is blameless, that individual ought to be free from liability even though he or she may well have caused the harm or evil prohibited by the doctrines of criminalization. Furthermore, liability is properly reserved for violations of sufficient seriousness committed with sufficient culpability to justify condemnation as criminal. Chapters 4 and 5 examine the criminal law's and the community's views on this issue of the minimum requirements for liability.

The law tests for adequate blameworthiness in two ways. First, it requires proof that the person's violation did not occur by virtue of blameless accident or mistake. This is achieved by requiring the prosecution to prove a person's culpability-purpose, knowledge, or recklessness (or occasionally negligence)—as to each element of an offense. As a second test, the law provides the person with the opportunity to raise various defenses-such as insanity, immaturity, duress, or involuntary intoxication - that suggest that, even if a person had the required culpable state of mind, the individual nonetheless is not responsible for his or her violative actions. In this chapter, we discuss the studies we conducted that concern the first kind of minimum requirement, the culpable state of mind. In Chapter 5, we assemble and discuss the studies that concern the second blameworthiness issue, excuse defenses.

To assure the minimum level of blameworthiness, the law requires proof of a person's culpability as to each element of an offense. Thus, the "intruder" in your basement is criminally liable only if he knows it is another's house that he is entering. If, because all of the row houses are identical and he just moved in next door, he enters your basement garage honestly believing it to be his own, his tres- 
pass may be a violation of the rules of conduct but may not be a sufficiently culpable violation to merit the condemnation of a criminal conviction.

As we mentioned earlier, modern criminal codes classify a person's culpability with regard to the circumstances or results that make his conduct criminal into one of four broad categories: purpose, knowledge, recklessness, or negligence. A person can bring about an outcome "on purpose," meaning that he or she fully intends that the particular consequence will happen. For example, I may set a bomb, hoping and intending to injure the people in a particular area. Alternately, the injury can be brought about knowingly but not purposefully. When I blow up a safe to steal the contents, I may know that the blast will injure people on the adjacent floors, but it is not my purpose to do so; all things being equal, I would prefer that no one would be injured. Alternatively, I may only be reckless as to the blast injuring others. That is, I may be aware of a risk of causing injuries but disregard the risk. Finally, I may be unaware of a risk that people may be injured but should have been aware - a reasonable person would have been aware-in which case the law judges me negligent as to causing the injuries [Model Penal Code (MPC) \$2.02(2); Robinson and Grall, 1983].

Generally, a minimum of recklessness as to each objective element is required for criminal liability, given the rather severe penalties that the system imposes-as compared to the civil justice system. Thus, for example, a person must be aware of a substantial risk that his or her conduct may obstruct a highway or that the property he or she is taking belongs to another or that the garage the person is entering is not his or her own-in order to incur criminal liability. This preference for recklessness as the normal minimum culpability required for criminal liability is expressed by provisions, such as the Model Penal Code's, that "read in" recklessness whenever an offense definition is silent on the required culpability as to an offense element [MPC $\$ 2.02(3)$ ].

Several of our previous studies have touched on culpability issues. For instance, in Study 1 we discovered that a person who forms a settled intent to commit a crime is assigned some liability. Study 2 found that when a person's purpose is to kill another, even though the action taken runs only a slight risk of bringing about a minor harm, our respondents judge the person to be highly culpable. These findings give us some preliminary indications that culpability is not only a prerequisite for liability but also a powerful determinant of the degree of liability. We will have more to say about this later in this chapter, as well as in Chapter 6 (in which we take up issues of of fense grading).

\section{STUDY 8: OFFENSE CULPABILITY REQUIREMENTS AND MISTAKE/ACCIDENT DEFENSES}

The definition of an offense typically requires that a person's conduct cause a specified harmful result or that the conduct be performed under specified circumstances that make it harmful or evil. Offense definitions are constructed from 
these three kinds of objective elements - conduct, results, and circumstances [MPC $\$ 1.13(9)]$. A result element might be something like the requirement in arson that a building be damaged. A circumstance element might be the requirement that the building be a dwelling and that it belong to another person (specific required characteristics of the nature of the damage) or the requirement in rape that the intercourse occur without the consent of the victim or the requirement in "statutory rape" that the partner be underage (an existing circumstance at the time of the conduct). A conduct element might be the requirement of intercourse in rape or of setting a fire in arson. In some instances, the definition of an offense does not require a specific kind of conduct. Homicide offenses prohibit conduct of any kind that causes a death. Property destruction offenses frequently require only that the person engage in some conduct-any conduct - that causes the prohibited damage.

Satisfaction of all of the objective elements of an offense definition is required for liability for the offense. Burning a dwelling that is your own property is not arson. Having intercourse with another who consents is not rape. Of course, such conduct may render a person liable for another offense, if the conduct satisfies the elements for that other offense. Intercourse with someone who consents is not rape but may be statutory rape if the person is underage.

In addition to the objective elements of an offense definition, modern codes require proof that a person have a specified culpability level as to each objective element of an offense [MPC $\$ 2.02(1)$ and (3)]. That is, it is not enough for criminal liability that a person's conduct caused destruction of another's dwelling or that a person had intercourse with another without consent. The person must be shown to have been culpable as to the fact that the property belonged to another (and even that the property was a "dwelling," if that is an objective element of the offense) or that the person was not consenting to intercourse.

Just as all objective elements must be proven to establish liability, so too must each culpability requirement as to each objective element be proven. Where a required culpability element is not proven, the person is given a defense frequently called a mistake defense, especially where the missing culpability concerns a circumstance element [MPC $\$ 2.04(1)$ ]. That the person made a reasonable "mistake" as to the partner's age, for example, means that the person did not have the culpability of negligence as to the partner being underage that some statutes require for statutory rape. In those cases in which a person lacks the required culpability as to a required result, in contrast, ordinary language might refer to the case as one of "accident." For example, when a person has no reason to be aware that his storage of a friend's improperly labeled goods creates a risk to his neighbor's house, he is faultless as to causing damage to the neighbor's house if the goods turn out to be dangerous chemicals that explode when improperly stored. The reasonableness of the person's conduct in causing the "accident" means that the offense's requirement of negligence as to causing damage is not satisfied. 
As one can imagine, the process of drafting a criminal code requires thousands of decisions as to the level of culpability that should be required as to each objective element of each offense. Each decision determines the kind of mistake or accident that will provide a defense to the violation. The drafters must determine what minimum level of culpability should be required as to each element of each offense. By what process and under what guiding principles should these decisions be made? Should a person's liability be increased if he or she has a greater culpability than the minimum required?

Our culpability requirements study sought to determine the community's views of the appropriate level of culpability that should be required for various kinds of elements of various kinds of offenses. Subjects were given scenarios containing instances of "unconsented-to" sexual intercourse, statutory rape, and property damage offenses involving damage to a dwelling or to unimproved property. The property damage offenses have a clear result element, while the rape offenses have "circumstance" elements-lack of consent and age-that are central to liability. Some of the property scenarios focus on the person's culpability as to causing the harmful result; others focus on the person's culpability as to the fact that the property belongs to another.

The six base scenarios-mistake as to causing damage to a house, mistake as to causing damage to unimproved property, mistake as to ownership of the house damaged, mistake as to ownership of the unimproved property damaged, mistake as to lack of consent to sexual intercourse, mistake as to age of the underage partner-were each presented in four variations in which the level of culpability of the person's mistake varied-among knowledge, recklessness, negligence, and faultlessness. ${ }^{1}$ In this culpability study, unlike in some of the others we have conducted, we informed the respondents that the action was either knowing, reckless, negligent, or faultless rather than giving them circumstances and hoping that they inferred the violator's proper state of mind. For instance, in the case of property damage in which we wanted our subjects to perceive the person to be faultless as to the property being that of another, we told the respondents that the person was told by his lawyer that the property is his. In the corresponding negligence case, respondents were told that, although the person does not realize that title to the property has not yet come to be his, a reasonable person would realize this. (Because we specified these matters directly, and because these respondents had so many cases to judge, we omitted asking them the questions about how they perceived the various elements of the case. Research carrying these topics further might give more subtle information about culpability and might include the manipulation-check questions.)

The liability results of our respondents for each of these twenty-four variations are contrasted with those of the Model Penal Code in Table 4.1. The table gives the complete results of the study and is not easy to follow. Therefore, we also will present several figures that clarify various aspects of the data. 
Within each of the six scenarios, the differences in liability assignments due to the different levels of culpability suggest the general importance of the assessment of culpability in the assignment of criminal liability and punishment. This result emerges very clearly in Figure 4.2, which graphs liability assignment as a function of the person's level of culpability.

Subjects perceive the four variations of each scenario as presenting distinguishable cases in which liability and punishment increase as the manipulated level of culpability increases. The consistent slopes of the lines graphing the six cases make this very clear. Furthermore, the patterns of liability in Figure 4.2 suggest a special significance in the distinction between recklessness and negligence (that is, between conscious versus inattentive risk-taking). This can be seen by the fact that the slope of the line connecting the reckless and negligent cases is always more sharp than the slopes of the lines connecting the other cases. This effect on the subjects' liability assignment of the reckless-negligent distinction would seem to support the Model Penal Code's special treatment of recklessness as the normal minimum culpability requirement [MPC $\$ 2.02(3)$ ].

However, a further examination of Figure 4.2 suggests a result that is not always in accord with penal codes. The difference between the average liability assigned by our respondents for reckless and knowing culpability suggests that the higher culpability, knowing, might properly be reflected in an offense definition that grades the knowing violation one grade higher than the reckless violation. (Each unit on the liability scale represents a difference in punishment that commonly is equal to one offense grade. $)^{2}$ The Model Penal Code treatment of offenses, shown in column $d$ of Table 4.1, sometimes but not always makes grading distinctions according to the reckless-knowing distinction. In the case of damage to the neighbor's house, knowingly causing the damage is a second-degree felony although recklessly causing the damage is only a third-degree felony, a grading similar to the ones that our respondents imposed. However, in both the damage to unimproved property and rape cases, in which the Code does not assign a different level of liability to the knowing and reckless commission cases, our respondents would do so. The responses of our subjects, if modeled in the code, would assign a higher degree of liability to the knowing versus the reckless commission of all offenses.

In fact, on examination, the Code's differing grading of the culpability levels for the various offenses generates more inconsistencies with our subjects' tendency to have culpability alter such grading in all offenses. Look first at the Code's treatment of various levels of culpability as to causing damage (Table 4.1, scenarios 1 and 2, column $d$ ). The Code's treatment of knowingly and faultlessly causing damage to a dwelling tracks that imposed by our subjects. A knowing violation is one grade higher than that for a reckless violation; a faultless violation is exempt from liability (Table 4.1, scenario 1). The Model Penal Code scheme deviates from the subjects' view in that it fails to lower liability for cases of negligent 
TABLE 4.1 Liability for Mistake/Accident
(a)
(b)
(c)
(d)

Scenarios:

Element of Offense

$\%$ No Liability

and Actor's Culpability Liability Liability Punishment

Model Penal

Code Result

1. As to causing damage

to house:
a. Knowing
6.21
0
0 2nd-degree felony
[§220.1(1)(a)]
b. Reckless
$5.08 \quad 0$
10
3rd-degree felony
c. Negligent
2.228
[\$220.1(2)(b)]
d. Faultless
1.2530
55
3rd-degree felony ${ }^{b}$
[§220.3(a)]
$75 \quad$ No liability

2. As to causing damage to unimproved property:
a. Knowing
5.54
0
3 Misdemeanor ${ }^{a}$ [\$220.3(a)]
b. Reckless
$4.31 \quad 3$
18
Misdemeanor ${ }^{\mathrm{a}}[\S 220.3(\mathrm{a})]$
c. Negligent
1.75
15
d. Faultless
$0.95 \quad 38$
65
Misdemeanor ${ }^{\mathrm{a}}$ [\$220.3(a)]
83 No liability

3. As to house belonging to another:
a. Knowing
$5.77 \quad 0$
3
2nd-degree felony [\$220.1(1)(a)]
b. Reckless
$5.31 \quad 0$
3
3rd-degree felony
c. Negligent
3.620 [\$220.1(2)(b)]
d. Faultless
$3.26 \quad 8$
28
No liability
38 No liability

4. As to unimproved property belonging to another:
a. Knowing
4.92
3
10
Misdemeano $r^{\mathrm{a}}[\S 220.3(\mathrm{a})]$
b. Reckless
4.49
13
3.10
3
38
Misdemeanor ${ }^{\mathrm{a}}$ [§220.3(d)]
c. Negligent
$2.44 \quad 10$
50
No liability
d. Faultless
No liability

5. As to victim's lack of consent in rape:
a. Knowing
6.60
5
8 1st-degree felony
b. Reckless
$5.55 \quad 3$
[\$213.1(1)(a)]
c. Negligent
$3.82 \quad 13$
d. Faultless
$0.26 \quad 78$
1 st-degree felony [§213.1(1)(a)]
90 No liability 
TABLE 4.1 (continued)
(a)
(b)
(c)
(d)

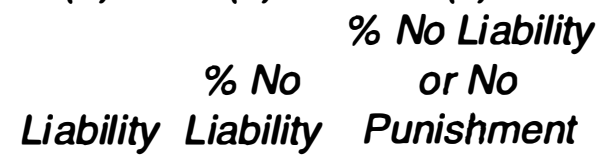
Model Penal
Liability Liability Punishment
Code Result

Scenarios:

Element of Offense and Actor's Culpability

6. As to victim being underage in statutory rape:
a. Knowing
3rd-degree felonyc
[§213.3(1)(a)]
b. Reckless
3rd-degree felony
c. Negligent
[§213.3(1)(a)]
d. Faultless
$0.51 \quad 65$
88
3rd-degree felony
[§213.6(1)]

Liability Scale: $\mathrm{N}=$ No criminal liability, $0=$ Liability but no punishment, $1=$ 1 day, $2=2$ weeks, $3=2$ months, $4=6$ months, $5=1$ year, $6=3$ years, $7=7$ years, $8=15$ years, $9=30$ years, $10=$ life, and $11=$ death.

${ }^{a}$ Assumes property damage between $\$ 100$ and $\$ 5,000$.

bAssumes property damage in excess of $\$ 5,000$.

${ }^{\mathrm{C}}$ Assumes that the defendant is at least 18 years old (4 years older than the 14-year-old victim).

damage as compared to cases of reckless damage. Indeed, it imposes the same degree of liability (third-degree felony) for negligent violations as for reckless violations, contradicting its own general tendency to draw the line between reckless and negligent culpability.

The Code's treatment of analogous cases of damage to unimproved property (Table 4.1, scenario 2) is also divergent from our subjects' views. As above, a negligent violation is a basis for liability under the Code, while the subjects would considerably reduce the liability of the person in that case. Knowing and reckless violations are not distinguished in the Code; they are treated the same as a negligent violation. They are distinguished by our respondents, as the line in Figure 4.2 marked "causing damage-property" makes clear.

The Code's scheme also is divergent from our subjects' views in its treatment of violatons that involve mistakes as to ownership (Table 4.1, scenarios 3 and 4 ). The Code gives no liability in cases of negligent and faultless mistake as to ownership; our subjects give liability-albeit low liability—as also is shown in Figure 4.2.

Turning to an examination of the rape cases (Table 4.1, scenarios 5 and 6), what can be said about our respondents' perceptions of the two rape scenarios? Note first the lack-of-consent case in Figure 4.3. Our respondents' views (as represented in this figure) also diverge in several respects from the Code's treatment of mistake as to consent in rape. Our subjects treat the degree of culpability as a 
FIGURE 4.2 Liability as a Function of Culpability Level

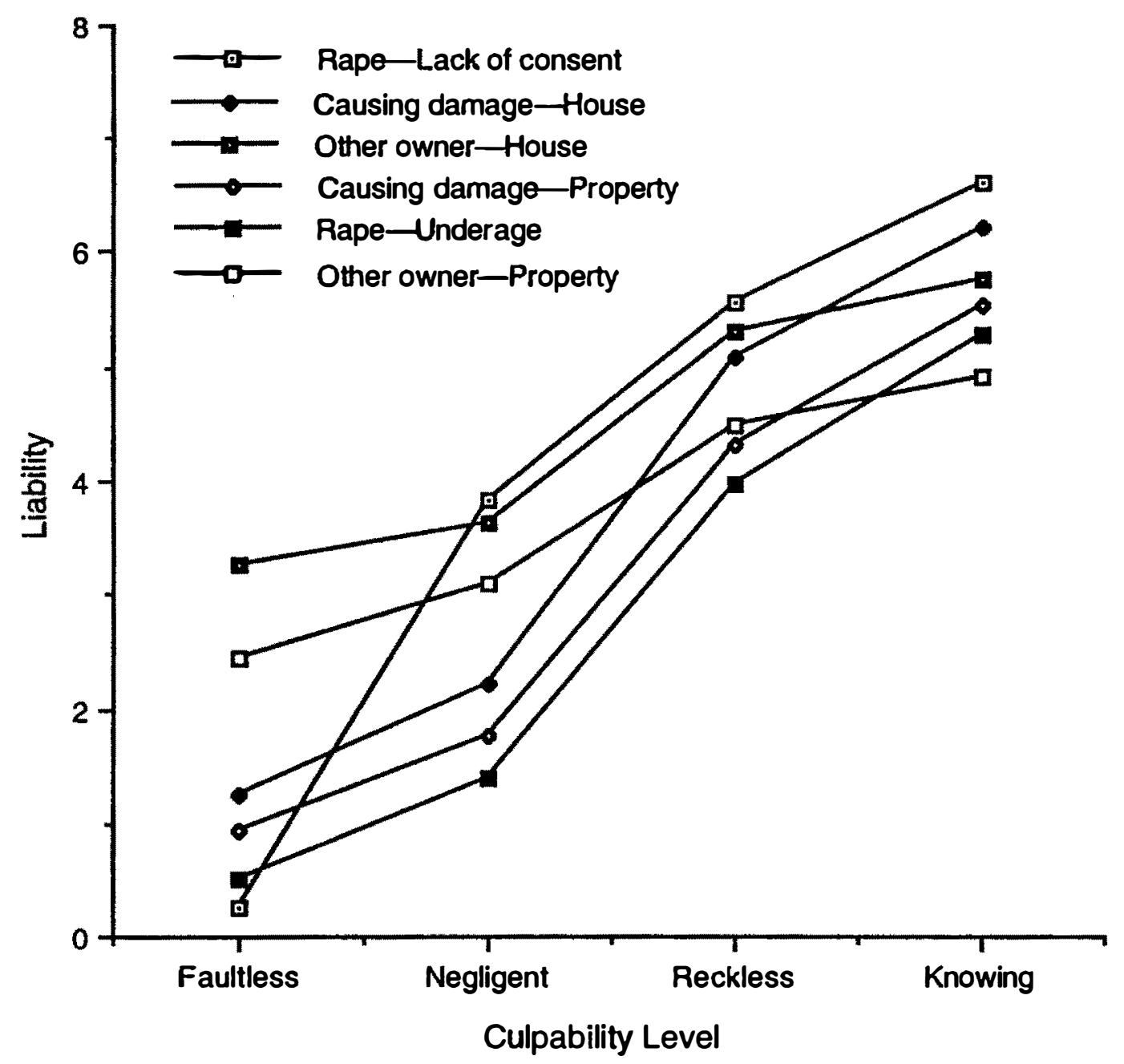

graded consideration, assigning a higher degree of liability as the offense progresses from negligence with respect to consent, through recklessness, to knowing. In contrast, the Code (Table 4.1, column $d$ ) imposes no liability for a negligent mistake, while the subjects' liability mean (column $a$ ) is 3.82 (5.2 months). The Code does not distinguish reckless and knowing errors, grading both as first-degree felonies; the subjects impose greater liability for a knowing error, 6.60 ( 5.4 years), than for a reckless error, 5.55 ( 2.2 years).

A more exaggerated form of this difference appears in the liability patterns for statutory rape, the case in which the victim is described as being under the statutory age of consent. The Code treats knowing, reckless, and negligent errors as to the victim's age as the same grade. Our subjects make significant distinctions between them all. The majority of subjects ( 73 percent) would impose either no liability or no punishment where the person is negligent as to age (Table 4.1, scenario $6 c$, column $c$ ), but the Code treats this as a third-degree felony.

The rape results reveal that the subjects tend toward setting different minimum levels of culpability for the two different cases. In statutory rape, a majority of the 
FIGURE 4.3 Liability as a Function of Culpability as to Different Offense Elements: Rape and Statutory Rape

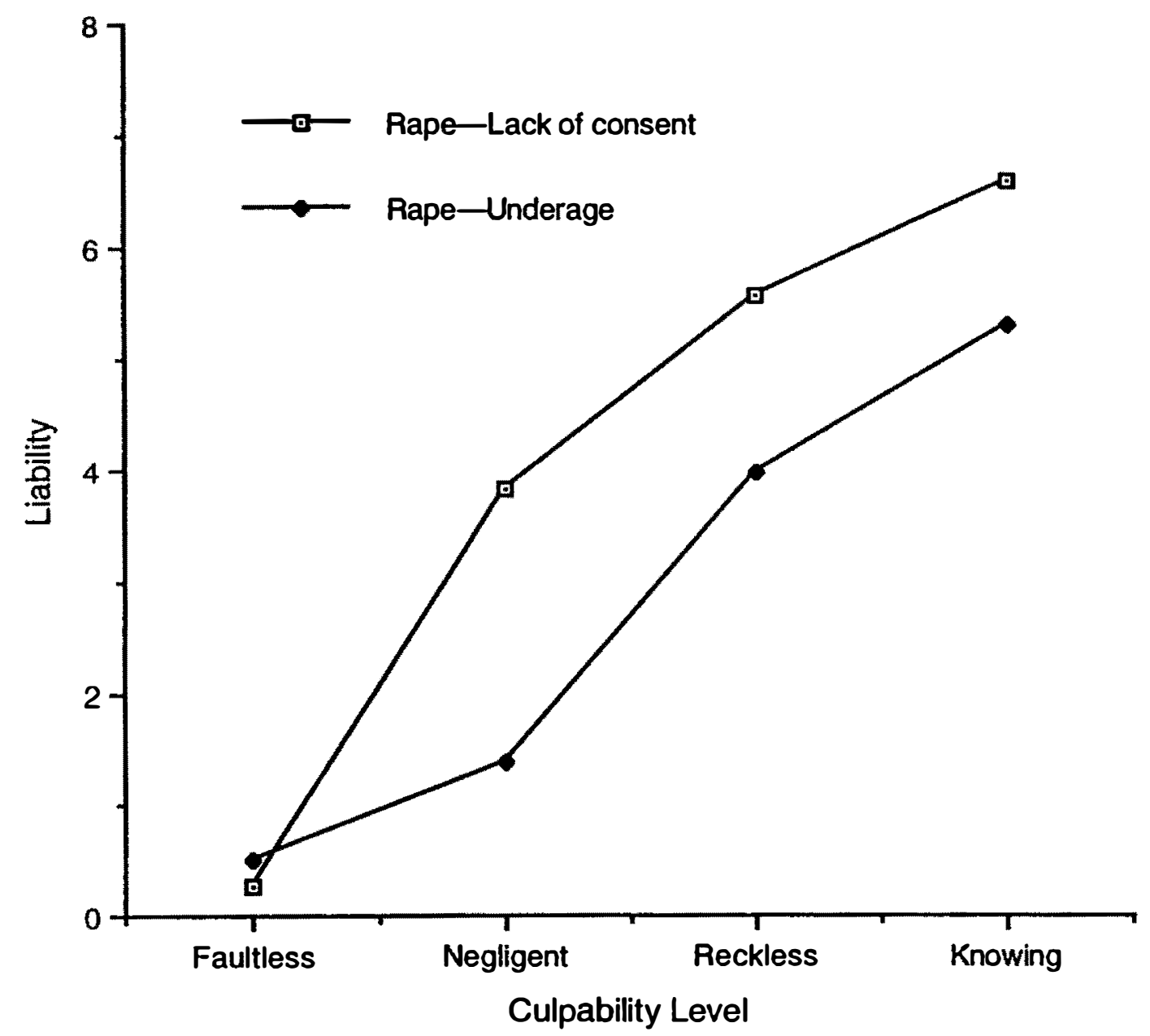

subjects impose no punishment on a person who is faultless or negligent as to the victim's age. In rape, in contrast, only faultlessness as to the victim's lack of consent draws no punishment from a majority of subjects; negligence as to lack of consent is no defense in the view of most subjects. This suggests that the subjects perceive the minimum culpability requirements of these two offenses somewhat differently, and intuitively one sees why they make the particular distinctions that they do.

If one were to draft a statutory rape provision using the intuitions contained in our respondents' judgments, one would grade the offense as a continuous function of the degree of culpability of the offender, rather than-as the Code currently does-as a dichotomous function, with negligent and higher degrees of culpability all assigned a third-degree felony grade.

Many of the foregoing results can be summarized as follows: Our results generally support the Code distinction that draws a sharp line between reckless and negligent commission of an offense. However (and frequently counter to the Code), our respondents also distinguish between knowing and reckless commission and between negligent and faultless commission. They assign differing liabil- 
FIGURE 4.4 Liability as a Function of Culpability as to Different Offense Elements: Damage to House

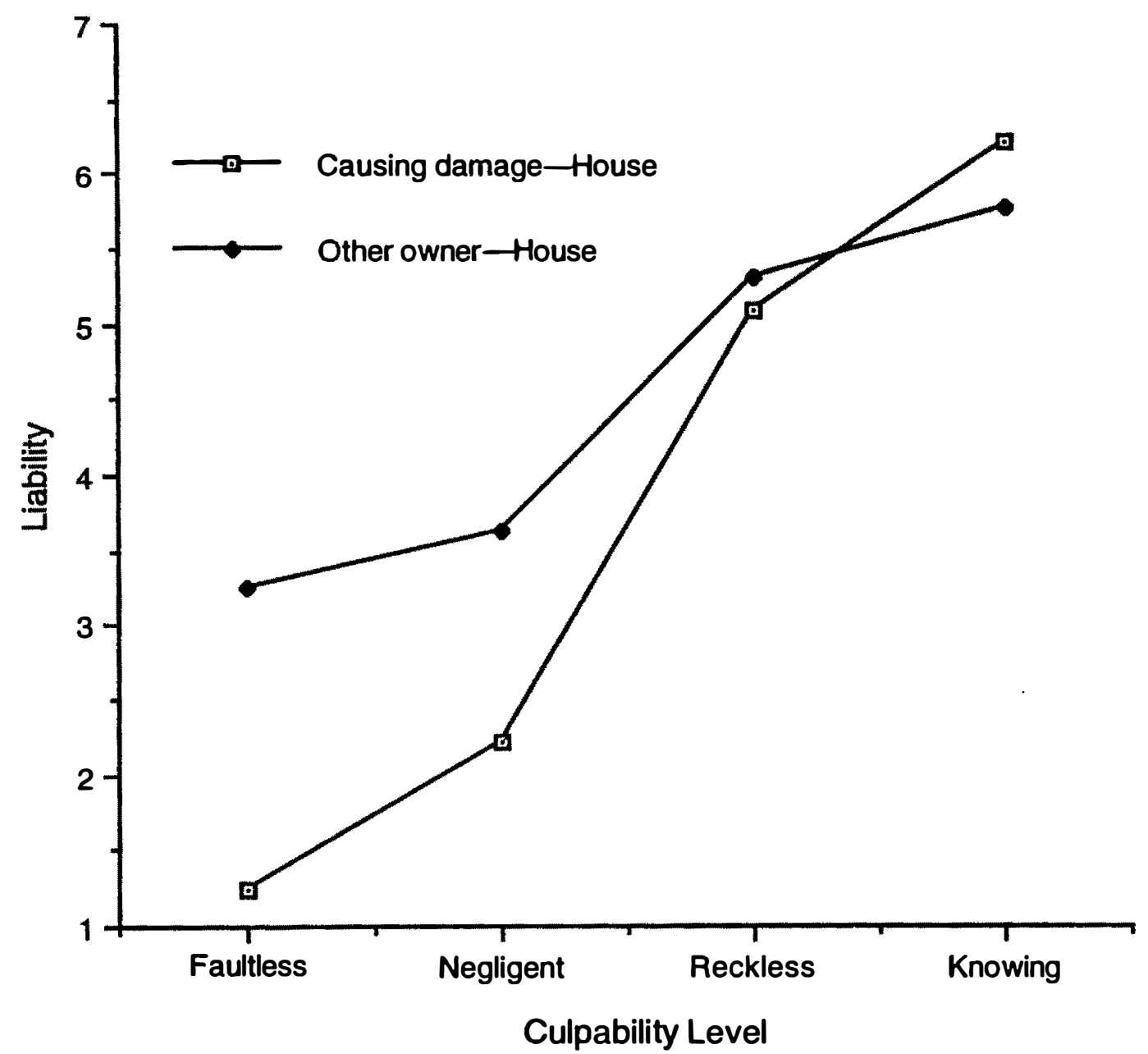

ities, in other words, to all of the different levels of culpability. This strikes us as an important result, but a somewhat predictable one; it is the result that we would have intuited. But certain of our other results confront us with a data pattern that we did not expect (or, at least, did not expect to be so strong in effect as to be evident from our data). If confirmed in further research, it would reveal an important code-community disagreement.

Evidence of the disagreement is shown in Figures 4.4 and 4.5. In them, we have graphed liability for damaging a house and for damaging unimproved property. In each of those cases, we had two culpability elements pertaining to the same of fense. In Figure 4.4, liability as a function of culpability is graphed for both the element of culpability as to causing damage and the element of culpability as to the property belonging to another-in this case a house that is owned by another. (Recall that the person has some reason to believe that he himself has bought the house.) Figure 4.5 displays liability as a function of the analogous elements of culpability as to damage to and ownership of unimproved property. Notice that, in 
FIGURE 4.5 Liability as a Function of Culpability as to Different Offense Elements: Damage to Unimproved Property

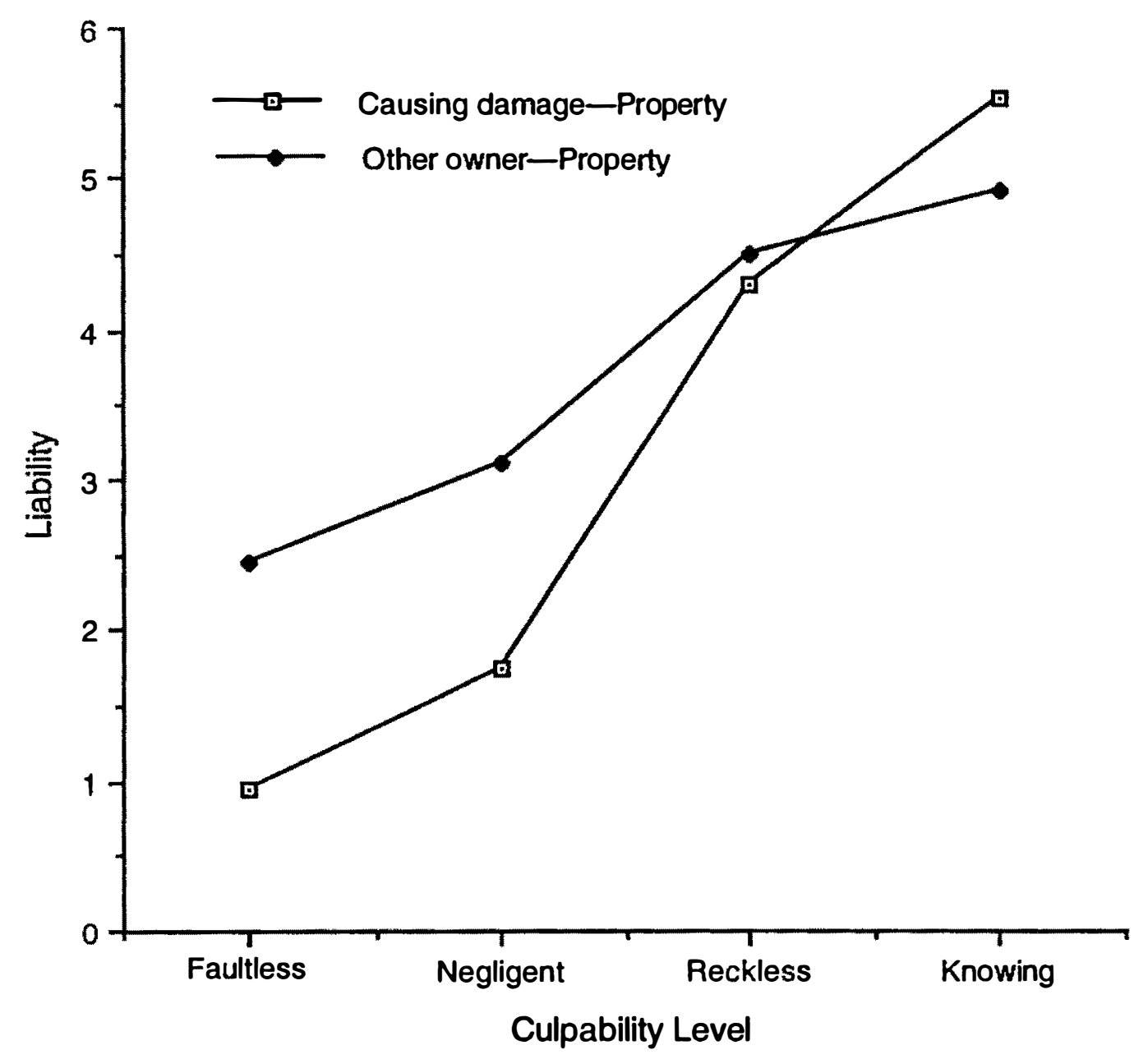

each graph, the line graphing liability as a function of culpability as to the property belonging to another is flatter in slope than is the line graphing liability as a function of culpability as to causing damage. What this means is that in each instance, where the culpability as to ownership is varied, the range of liabilities, 5.77 (2.6 years) to 3.26 (3.2 months) for the house and 4.92 (11.4 months) to 2.44 (4.4 weeks) for property, is noticeably less than the range of liabilities when the culpability as to damage is varied, 6.21 (3.8 years) to 1.25 ( 4.9 days) for the house and 5.54 (about 1.5 years) to 0.95 ( 1 day) for property. This suggests that the person's culpability as to causing damage is a stronger determinant of his liability, in our respondents' minds, than is his culpability as to another's ownership. ${ }^{3}$ This seems to give objective evidence of the somewhat vague feeling shared by many criminal law practitioners and scholars that some objective elements within an offense are different in effect and importance than others. While both "causing damage" and "property of another" - and culpability as to each-are required elements of the damage offenses, culpability as to "causing damage" and culpability as to "prop- 
erty of another" appear to play different roles in the determination of liability and punishment. "Causing damage" appears to be a primary determinant, a "core" element, while "property of another" appears to be a more "collateral" element, which establishes a minimum background condition. We will discuss the implications of this further in the summary of this study herein below.

One last result is worthy of note. Elsewhere in this book (in Chapter 6), we comment on the task of the comparative grading of offenses. Here we would point out that the respondents saw the various offenses we described to them in this study as differentially serious in nature. The differences in elevation between the lines in Figure 4.2 illustrate a pattern that makes good intuitive sense. Look simply at the treatment of the various crimes committed knowingly. As one might expect, the rape scenario in which another person is harmed shows the highest liability, 6.60 (5.4 years) for knowing culpability, followed by the scenario of damage (in which people might be endangered) to a dwelling, 6.21 (3.8 years). Damage to unimproved property, 5.54 (2 years), and consensual intercourse with a minor, 5.28 ( 1.6 years), are viewed as slightly less-serious offenses.

\section{Study 8: Summary}

The culpability requirements study sought to determine the community's views of the degree of liability that ought to be assigned to various levels of culpability required for different kinds of elements for three kinds of offenses. Culpability elements of offenses serve two distinct functions: defining the minimum requirements for liability and distinguishing different grades of a single offense. The research results give some insight into how the subjects would have each function performed.

We take up our most interesting finding first. In setting the minimum requirements for liability and also in grading offenses, it appears that some culpability elements are considerably more significant than others. For example, in an of fense of causing damage to property, a person who is faultless or only negligent as to causing the damage (while knowing it is another's property) receives no punishment from a majority of our subjects. In the cases in which the person is faultless or negligent as to the property being that of another (while knowing that he is destroying the property), in contrast, a majority would impose punishment. Our respondents seem to be suggesting that, at least in the specific case of storing potentially dangerous material, which was the way we manipulated elements in these scenarios, the person needs to recognize an obligation to assess the danger potential of what is being stored. It is of some concern (though a lesser degree of concern) that the person figure out who owns adjacent property. A sturdy component of common sense commends itself to our attention here: A person first needs to figure out the damage-causing potential of his or her actions. To whom, exactly, the potential damage might occur is an important but secondary question. Thus, in formal terms, we would suggest that the person's culpability as to the po- 
tential for causing damage is more influential on the subjects' decision to impose liability than the person's culpability as to the property being that of another. The same pattern is seen at the high-culpability levels; higher culpability as to causing damage increases punishment significantly more than higher culpability as to the property being that of another (Table 4.1, scenarios 1 through 4 , columns a through $c$ ).

This pattern suggests the need to distinguish between elements when defining the minimum requirements for liability. If one were to follow our subjects' intuitions, the minimum culpability as to causing damage may properly be set higher than the minimum culpability as to knowing whether the property belonged to another. Moreover, differences in levels of culpability as to causing damage should make a larger difference in the liability grading of an offense than culpability as to ownership. This illustrates one of the dangers of a provision such as Model Penal Code $\$ 2.02(4)$, which applies a stated culpability term in an offense to all objective elements. It tends to apply the same culpability requirement to both "core" elements_such as causing damage_and "collateral" or "background" elements-such as ownership by another.

But what constitutes a core element as opposed to a collateral element? The research results suggest that this is not an easy question. The results reveal different patterns of weighing culpability elements, depending on the circumstances of the crime. These are complex considerations that merit further investigation.

With respect to the second function of culpability requirements - distinguishing grades within the same offense (as in homicide)-our subjects appear to make significant liability distinctions on this basis across the range of culpability levels. The difference in the respondents' assigned punishment for a person who is knowing and one who is reckless frequently is greater than what constitutes the difference between offense grades in American criminal codes. Also, our respondents generally distinguish between the other levels of culpability as well; they generally assign increasing levels of liability as the level of culpability rises from negligent, to reckless, to knowing. As we have suggested, these patternings of liability assignments significantly differ from those provided by the Model Penal Code. First, few offenses in the Code, other than homicide, contain grades dependent upon culpability level. ${ }^{4}$ Indeed, most offenses are not defined to have more than a single grade. This may have been an attempt by the Code to preserve the sentencing discretion of judges. The fewer the grades of an offense provided in the Code, the greater the flexibility of the judge to rely on distinctions of his or her own choosing in imposing sentence. The shift to more articulated sentencing rules in the thirty-plus years since the drafting of the Model Penal Code may suggest that it is time to have the Code make more distinctions in grading offenses. Certainly degrees of an offense based on the person's level of culpability would provide a refinement that would better mirror the community's liability and punishment judgments. If code drafters want the criminal code to follow community 
views, it would be useful to do studies of this sort-to determine where the community sets the minimum culpability levels for different elements of different offenses and whether increased culpability over these minimums ought to give rise to a higher grade of liability. ${ }^{5}$

\section{STUDY 9:}

\section{CULPABILITY REQUIREMENTS FOR COMPLICITY}

Liability for complicity requires that a person assist another in the commission of an offense. The precise nature of the conduct requirement of assisting is examined in the objective requirements of complicity study in Chapter 2. In addition to this objective requirement, current doctrine requires that a person have a defined culpable state of mind as to providing such assistance in commission of the offense.

Just as criminal liability is inappropriate for an inadvertent commission of an offense, so too is liability inappropriate for one who indvertently assists another in the commission of an offense. Thus the Model Penal Code requires that, at the time of assisting the perpetrator, the accomplice must be acting "with the purpose of promoting or facilitating the commission of the offense" [MPC $\$ 2.06(3)(a)$ ]. A proposal to require "knowledge" rather than "purpose" was rejected by the full membership of the American Law Institute (the Institute). The requirement of "purpose" was judged preferable and was said to continue the long-standing common-law rule.

However, the phrase "purpose of promoting or facilitating the commission of the offense" is ambiguous on an important point. Does the very demanding "purpose" requirement apply only to the person's culpable state of mind as to assisting ("promoting or facilitating") the perpetrator's conduct, or does it apply as well to all elements of the substantive offense, such as "purposeful" with respect to the prohibited results of the person's conduct? If it applies to all elements of the substantive offense, the effect is dramatic, for it makes complicity very difficult to establish, essentially limiting it to cases in which the accomplice intended not only the offense conduct to occur but also intended any required results to occur or circumstances to exist. For example, statutory rape typically requires no more than negligence as to the partner being underage. When a person purposely assists conduct that in fact constitutes statutory rape, can that individual be defended by claiming that he or she only thought it probable (reckless) that the partner was underage but did not know or did not necessarily intend that the partner was underage? If complicity liability requires purpose as to all off ense elements, anything less than purpose as to the partner being underage will provide a defense in this case. For another example relating to a result element, the offense of endangerment requires that the perpetrator be at least reckless as to creating a risk of death. When a person purposely assists conduct that constitutes endangerment (dumping hazardous chemicals near a playground, for example), can that person be defended by 
claiming that he or she knew that, by assisting such conduct, a risk of death would be created but that he or she did not necessarily intend such a risk to be created? If complicity liability requires purpose as to all offense elements, anything less than purpose as to creating the risk of death will provide a defense in this case.

This was the ambiguity at issue in Etzweilerv. State ${ }^{6}$ for example, where the defendant was charged as an accomplice to a killing caused by a drunk driver. The defendant clearly had "purposely" assisted his drunk friend to engage in the conduct consisting the offense, driving; he gave his drunken friend the keys to his car. It was not clear, however, that Etzweiler was "purposeful" or even "knowing" as to his conduct creating a risk of death. At most, one might conclude that, by giving car keys to his obviously intoxicated friend, Etzweiler was "reckless" as to the resulting death; that is, at the time of giving the keys, he was aware of a substantial risk that a death could result.

The justices of the New Hampshire Supreme Court in Etzweiler disagree over the proper interpretation of the state code's "purpose" requirement for complicity, which was modeled in large part on the Model Penal Code. A majority of the court holds that the purpose requirement has the effect of elevating all culpability requirements of the homicide definition to purposeful for the accomplice. Thus, while manslaughter normally requires only recklessness as to causing a death, complicity in manslaughter requires that the accomplice be purposeful as to causing the death (even murder liability requires only knowing as to causing death). Some common-law cases came to a similar view that the culpability requirements for complicity in an offense are "elevated" over those of the substantive offense itself. Other common-law cases essentially came to the view of the dissenting judges, which is as follows.

The dissenting justices in Etzweiler conclude that complicity's purpose requirement only requires that the complicit individual be purposeful as to assisting the perpetrator's conduct - that is, purposely giving the friend the car keys with the intention of allowing him to drive the car. The culpability requirements of the substantive offense-recklessness as to causing death, for manslaughter-are not elevated to purpose for complicity liability. Under the latter view, a person can be an accomplice to manslaughter by purposely assisting another to engage in conduct that the accomplice is aware creates a substantial risk of causing death (i.e., the accomplice is reckless as to causing death). The Model Penal Code drafters make it relatively clear that they support this "no-elevation" view, at least with respect to result elements as in Etzweiler [MPC $\$ 2.06(4)$ ]. The complicity culpability requirements study sought to test the subjects' views on the importance to liability of an accomplice's culpability as to assisting and culpability as to the elements of the substantive offense.

Six scenarios presented variations on the Etzweiler situation. The study involved the same core description of an individual who makes his car keys available to an intoxicated friend. The two individuals arrive at the plant where they 
work. Because the friend is intoxicated, the other individual is driving. The intoxicated friend announces his plan to borrow the car to race home to change clothes before work. The area through which he will drive is crowded with workers arriving for their shift at the plant. In some cases, we describe the nonintoxicated individual as sure that his drunk friend will kill people if he drives; in other cases, the sober person is only aware of the possibility that his drunk friend might kill people. Thus, we attempted to make clear that the state of mind of the complicit individual was knowing or reckless as to causing the death that we described as ensuing, an element that we intuited was likely to be an important one to our respondents. The drunk obtains access to the car keys, heads home, and kills two workers just arriving through the factory gate.

We manipulated the description of the circumstances of the drunk's obtaining the car keys from his friend to create the perceptions that the accomplice is either purposeful, knowing, or reckless as to his drunk friend taking the car to drive while intoxicated. In the purposeful case, the sober friend willingly hands the drunk friend the keys. In the knowing case, he first urges the drunk friend not to drive, then reluctantly hands over the keys. In the reckless case, he refuses his drunk friend but then leaves the keys in a place where his friend can find them, even though it crosses his mind that the friend might take them.

The results of the study are presented in Tables 4.6 and 4.7. In Table 4.6, we include the liability assigned to the accomplice. In Table 4.7, we present the respondents' perceptions of the accomplice's and the perpetrator's states of mind with respect to the various elements of the situation.

We will examine some general aspects of the data patterns. Notice first the commonsense result (Table 4.6, column $a$ ) that the liability of the individual who drives while drunk and kills others is high; translated into years, the sentence is from eleven to fourteen years. This is as we would expect. The perpetrator, while drunk, is not so drunk that he cannot pressure the accomplice to give him the keys, make his way to the car, start it up, and drive off. As column $i$ of Table 4.7 indicates, the respondents see the driver as somewhere between unaware and aware that his driving has a substantial chance of killing somebody. Second, notice that the driver's liability is constant through all scenarios; it is not affected by variations in the state of mind of the accomplice, and again this is as we would expect. Third, note that in each instance, the liability of the accomplice (column $b$ ) is significantly less than that for the perpetrator. This is a second instance of a patterning of results that we saw in Study 3-that accomplices are given a significant discount in liability as compared to the perpetrator. The doctrine, remember, holds an accomplice liable at the same grade as the principal.

We examine next the questions that enable us to see how the respondents perceive the accomplice's state of mind in the different scenarios (columns $g$ and $h$ ). Respondents give their answers on a 4-point scale, with "4" indicating a rating of "purposeful," "3" a rating of "knowing," and "2" a rating of "reckless." (See the 
TABLE 4.6 Liability as Related to Culpability Requirements for Complicity

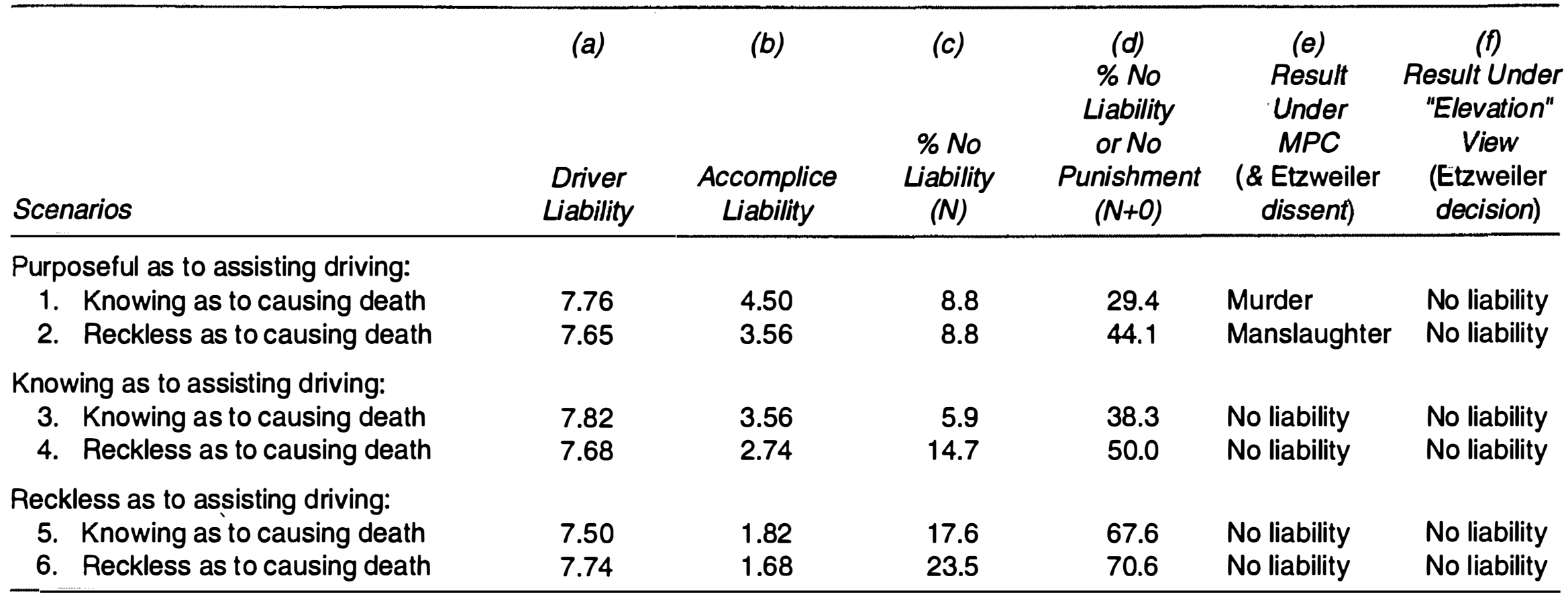

Liability Scale: $N=$ No criminal liability, $0=$ Liability but no punishment, $1=1$ day, $2=2$ weeks, $3=2$ months, $4=6$ months, $5=1$ year, $6=3$ years, $7=7$ years, $8=15$ years, $9=30$ years, $10=$ life, and $11=$ death. 
TABLE 4.7 Subjects' Perceptions as to Culpability Requirements for Complicity

\begin{tabular}{|c|c|c|c|}
\hline Scenarios & $\begin{array}{c}\text { (g) } \\
\text { Accomplice's } \\
\text { State of } \\
\text { Mind as to } \\
\text { Driving }\end{array}$ & $\begin{array}{c}\text { (h) } \\
\text { Accomplice's } \\
\text { State of } \\
\text { Mind as to } \\
\text { Causing } \\
\text { Death }\end{array}$ & $\begin{array}{c}\text { (i) } \\
\text { Perpetrator's } \\
\text { State of } \\
\text { Mind as to } \\
\text { Causing } \\
\text { Death }\end{array}$ \\
\hline \multicolumn{4}{|l|}{ Purposeful as to assisting driving: } \\
\hline 1. Knowing as to causing death & 3.09 & 2.59 & 1.29 \\
\hline 2. Reckless as to causing death & 3.21 & 1.97 & 1.26 \\
\hline \multicolumn{4}{|l|}{ Knowing as to assisting driving: } \\
\hline 3. Knowing as to causing death & 2.82 & 2.47 & 1.29 \\
\hline 4. Reckless as to causing death & 2.59 & 2.00 & 1.32 \\
\hline \multicolumn{4}{|l|}{ Reckless as to assisting driving: } \\
\hline 5. Knowing as to causing death & 2.21 & 2.24 & 1.29 \\
\hline 6. Reckless as to causing death & 2.03 & 1.91 & 1.35 \\
\hline
\end{tabular}

State of Mind Scale: 1 =negligent, $2=$ reckless, $3=$ knowing, and 4=purposeful.

Key to column heads:

(g) State of mind as to driving:

1. The accomplice was unaware of a substantial chance that the driver would drive the car.

2. The accomplice was aware of a substantial chance that the driver would drive the car.

3. The accomplice was practically certain that the driver would drive the car.

4. The accomplice hoped or wanted the driver to drive the car.

(h) State of mind as to causing death:

1. The accomplice was unaware of a substantial chance that the driver would kill someone.

2. The accomplice was aware of a substantial chance that the driver would kill someone.

3. The accomplice was practically certain that the driver would kill someone.

4. The accomplice hoped or wanted the driver to kill someone.

(i) Perpetrator's state of mind as to causing death:

1. The driver was unaware of a substantial chance that he would kill someone.

2. The driver was aware of a substantial chance that he would kill someone.

3. The driver was practically certain that he would kill someone.

4. The driver hoped or wanted to kill someone. 
key to Table 4.7 for the full description of the questions.) Look first at the numbers in column $g$ for scenarios 1 and 2. Respondents see the accomplice as closer to knowing ( 3.09 and 3.21 , with $3=$ knowing) than to purposeful as to having the friend drive the car, where we hoped the accomplice would be perceived as purposeful, ${ }^{7}$ and slightly below knowing in the knowing scenarios ( 3 and 4$)-(2.82$ and 2.59). The reckless scenarios ( 5 and 6 ) are perceived about as we had wished (2.21 and 2.03).

Examine next the question concerning the accomplice's state of mind with respect to the killing that eventuated (column $h$ ); there one sees a similar effect. The reckless scenarios $(2,4$, and 6$)$ are perceived about as we had intended, 1.97, 2.00, and 1.91 , respectively, with $2=$ reckless. The knowing scenarios are perceived as intermediate between knowing and reckless $(2.59,2.47$, and 2.24$) .{ }^{8}$ This last result is mildly troublesome; it means that the dimension of variation that we thought was most important, which was the state of mind with respect to the killing, was not perceived by our subjects as varying across the full range that we had desired. Keep this in mind as we interpret the data; found differences in liability scores are likely to be of a lesser magnitude than they might otherwise have been if the full range of perceived culpability had been achieved.

As can be seen from the graph of the results in Figure 4.8, the punishment assigned to the accomplice is affected by his state of mind, both with respect to the degree of deliberateness that he shows in giving his friend the car keys when he knows it is his friend's intention to drive and with regard to what he knows about the risk that his friend's driving creates. The line labeled "purposeful" is the line graphing the liability assigned to the accomplice who plans that the friend will take the car keys and drive. The line labeled "knowing" is the line graphing the results for the accomplice who knows that the drunk will take the keys and drive; the "reckless" line shows the liabilities assigned to the accomplice who recklessly disregards the known risk of the other driving. Note also the increase in liability assigned, particularly at the "purposeful" and "knowing" levels of assisting the perpetrator to drive, to the accomplice who is "knowing" with respect to the driver's causing death, as opposed to only "reckless."

Statistical analyses confirm what the figure reveals: First, the accomplice is judged more liable if his conduct in turning over the keys is purposeful with respect to assisting his friend's driving (although recall that the respondents see it as intermediate between purposeful and knowing), less liable if his action is knowing as to assisting, and least liable if his conduct is simply reckless in that respect $[F(2,64)=18.20, p<.01]$. Second, the accomplice is held more liable if he is knowing (although recall that the respondents see the accomplice as intermediate between knowing and reckless) rather than merely reckless with respect to the risk of killing others $[F(1,52)=10.97, p<.02]$. The figure hints that the accomplice's state of mind with respect to the risk of killing another becomes less important when he is only reckless with respect to giving the perpetrator access to 
FIGURE 4.8 Liability as a Function of Accomplice's Culpability as to Resulting Death

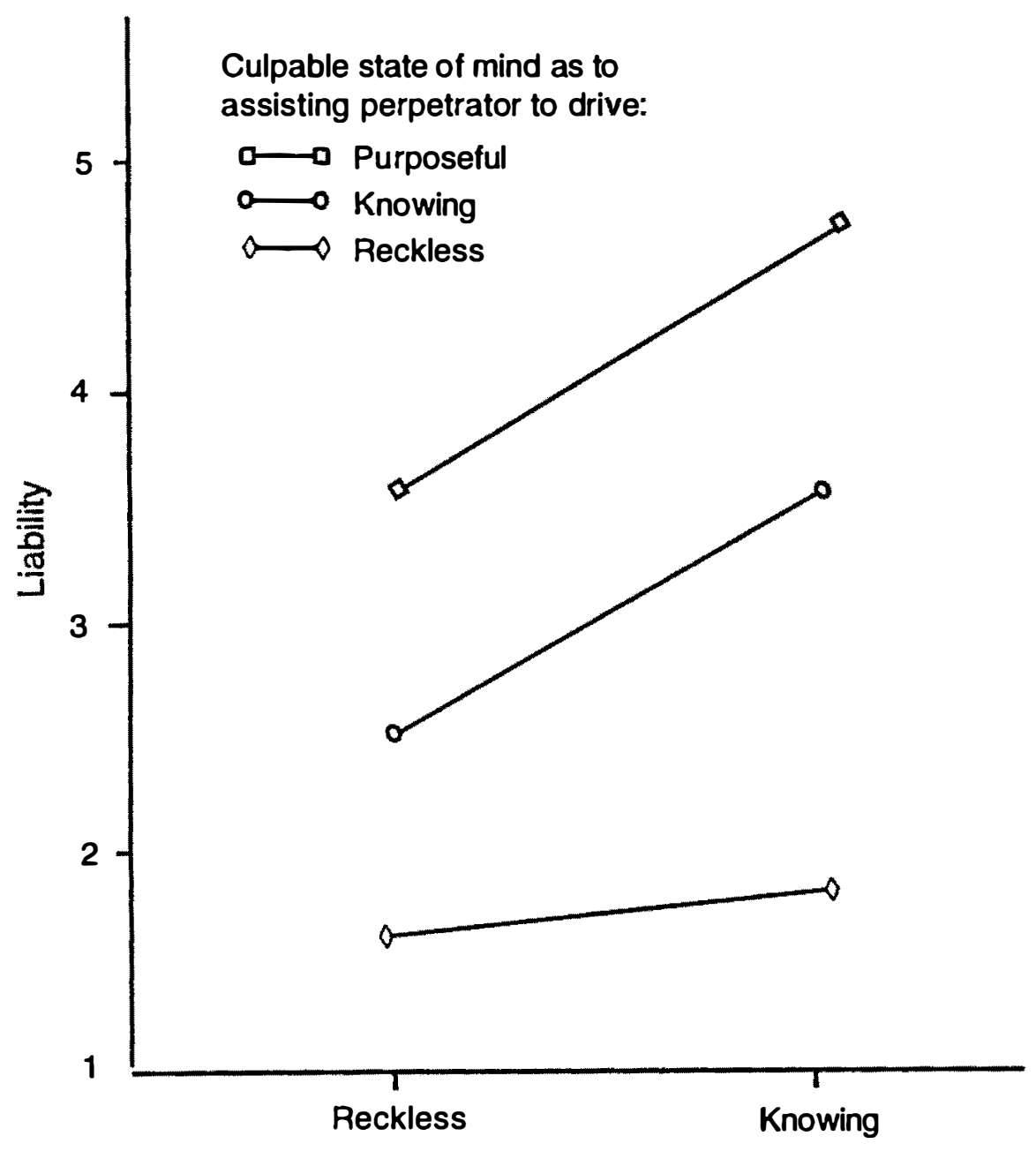

Culpable State of Mind as to Causing Death

the car keys, but the statistical analysis that tests the reliability of that difference does not reach significance. Further research might examine this possibility.

At the higher levels of culpability with respect to assisting, the magnitude of the two effects looks about the same. Being knowing versus only reckless as to causing a death causes a difference of about one grade in both categories, and the state of mind with respect to assisting the perpetrator also causes a difference of about one grade. Recall that we had a prediction about the relative magnitude of these two effects; we thought that culpability with respect to causing death, ignored by the Code, would be the more major determinant of liability among our respondents. But recall also that we have a possible reason why this might not show up in our results: Our manipulation of culpability with respect to causing a death was not entirely successful, leading to a range restriction on that dimension. Given our subjects' one-grade-level difference that derives from only a slight difference in perceptions of culpability as to resulting death, one might speculate that the ef- 
fect of culpability as to death indeed has the strong influence that we predicted. But this conclusion will have to be tested by further research.

\section{Study 9: Summary}

First, and as we have seen previously, the respondents are making graduated, continuous judgments where the codes make dichotomous ones. Next, our subjects can and do see the difference between the two culpability issues that this study presented to them, and these two dimensions of culpability make a difference in their collective liability assignment. This suggests that both of these issues should be addressed within the legal provisions dealing with complicity liability.

Next, let us consider how our results bear on the various formulations of the doctrine. To do this, recall our discussion of the interpretation of the requirement of "purposefulness." In one (the "elevation") view, the accomplice needs to be purposeful as to bringing about the prohibited result; in this case our accomplice would need to be purposeful (a rating of 4) in bringing about the eventual outcome of death. As column $h$ of Table 4.7 shows, not even our highest three "knowing" cases $(1,3$, and 5) meet this criterion-and yet significant liability is assigned to the accomplice in each of those three cases. (These three cases are shown as the upper ends of each of the three lines in Figure 4.8.) Obviously, our respondents do not hold the interpretation (as do the majority justices in Etzweiler) that purposefulness with regard to causing death is essential for liability. In fact, they do not even require knowledge for liability; they assign significant although reduced criminal liability to an accomplice who is merely reckless-not even knowing - with respect to the death that eventuated (the lower ends of each of the three lines in Figure 4.8, or cases 2, 4, and 6 of Table 4.7). However, notice also that the accomplice's state of mind about the death, when it is reduced from knowing to reckless, does cause our respondents to assign noticeably less punishment. (This is shown by the liability difference between the opposite ends of each of the three lines in Figure 4.8.)

The subjects' stark disagreement with the "elevation" view is shown in Table 4.6; that view (column $f$ ) would assign liability in none of the cases we presented to our subjects-yet the subjects assign liability in all cases. Subjects are assigning punishments to accomplices who are knowing or even only reckless with respect to the criminal outcome in instances in which the elevation view would assign no liability. From the point of view of our respondents, the culpability requirement as to result should not be elevated to purposeful as the Etzweiler majority and others would require; instead, the offense should be graded according to the degree of culpability that the accomplice shows.

Even the "nonelevation" view of the Model Penal Code (column $e$ )-that the accomplice need merely be purposeful with respect to assisting the conduct that in fact causes the death-does not entirely accord with our subjects' judgments. Ac- 
complices who knowingly-rather than purposefully-commit the act of assistance draw punishment (scenarios 3 and 4 of Table 4.6) that corresponds to more than 4 months and 6 weeks, respectively. Accomplices who merely recklessly assist (scenarios 5 and 6) draw reduced but still significant sentences from our respondents-about eleven days and nine days, respectively. ${ }^{9}$

Remember that our respondents do not see our "purposeful" cases as being completely purposeful. Although we were not altogether successful in producing cases that the subjects interpreted as creating accomplices who are completely purposeful with respect to causing death, that variable nevertheless makes a considerable difference in the liabilities that our subjects assign. This result suggests that the variable might emerge as even more determinative of liability assignments of respondents in future studies (that leave no doubt as to purposefulness). If this proves to be the case, then it strengthens the argument for recognizing culpability as to causing death as the primary determinant of complicity liability.

From the point of view of our respondents, the Code is wrong to set "purpose" as the minimum requirement for culpability as to assisting the conduct. The results support a tentative draft proposal that was voted down by the full Institute that would have required only "knowledge" as the minimum requirement for assisting the conduct (see earlier discussion at the beginning of Study 9). Further, even if only knowledge was required as to assisting the conduct, the Code would differ from our respondents' judgments because it would exclude liability in cases of recklessness as to assisting the conduct. Finally, our respondents would also view the Code deficient, as a grading matter, because it fails to adjust grade according to culpability level.

So, our subjects assign liability (although reduced liability) in knowing and reckless cases of assistance, and the Code does not. What might explain this difference? One rather speculative explanation is that the legal code seems to begin by taking for granted that the central question is whether the accomplice should be regarded as committing the same offense as that with which the perpetrator is charged. In other words, is the crime committed by the "assister" the same as the crime committed by the perpetrator? Not surprisingly, the Code sets quite high standards for a "yes" answer to that question. Judging by the reduced liability ratings that they give, our subjects do not ask themselves the same question. They do not ask themselves in this study: "Is the accomplice guilty of manslaughter?" They instead express the view that an individual who contributes to the commission of a crime by another deserves some punishment. The more purposeful that contribution-both in terms of facilitating the actions of the perpetrator and being aware of the perpetrator's criminal purposes-the higher the liability incurred. But, even when the accomplice is merely reckless in his or her contributions to the offense, some liability is incurred, although eventually it may result in nothing more than a condemnation rather than incarceration.

There are some hints that legal code drafters have recognized this point. Some states have created an offense called "criminal facilitation" that punishes the ac- 
complice at a lower level than is assigned to the perpetrator of the offense, but this "facilitation" also requires less in the way of culpability. Such a "facilitation" provision would approximate the liability pattern assigned by our respondents.

\section{STUDY 10: VOLUNTARY INTOXICATION}

When a person voluntarily becomes intoxicated and, in that state and as a result of it, commits an offense, the assignment of liability is complicated by two competing factors. On the one hand, because of his intoxicated state, the person may not be aware of the nature or consequences of his conduct. For example, the individual's conduct may create a risk of causing another's death but because the person is intoxicated, he is unaware of the danger. This absence of awareness of risk normally would bar liability for reckless homicide (manslaughter) because recklessness requires such awareness. In the first study in this chapter, we confirmed the importance of such culpable state of mind requirements to a finding of blameworthiness. On the other hand, that the person voluntarily became intoxicated makes it less clear that he should gain a mitigation for the resulting lack of a culpable state of mind; many would say that the person should not benefit from a self-imposed dysfunction of this sort. Obviously, the issue is a complicated one.

Current criminal-law doctrine typically responds to this dilemma with the following rule: If a person is culpable as to becoming intoxicated, that person will be treated, for the purposes of assessing liability, as if he were aware of a risk (i.e., "reckless" as to an offense element) - even though, because of the state of intoxication, the person is in fact unaware of the risk. A fixed minimum requirement of culpability as to becoming intoxicated ["negligence" in Model Penal Code $\$$ $2.08(5)(\mathrm{b})]$ thus establishes whether a person falls under the rule that imputes awareness of risk (recklessness) to the person. This means, for example, that a person who negligently becomes intoxicated and thereafter kills another (with no culpability as to the killing at the time because of the person's intoxication) will be held liable for reckless homicide (manslaughter) under the Model Penal Code.

Given this approach by current law, the primary focus of inquiry in investigations and trials is on whether the person has the minimum required culpability as to becoming intoxicated. A higher culpability as to becoming intoxicated-recklessly, knowingly, or purposely-does not increase the person's liability. Nor do different levels of a person's pre-intoxication culpability as to committing the offense have a bearing on his liability. In concrete terms, this means that a person may be only negligent as to becoming intoxicated but that the law will impute recklessness to him or her-even recklessness as to causing death. The liability here may seem more than is deserved.

At the same time, an individual who (for one reason or another) intentionally desires to harm another, gets intoxicated, and does so, is given the same liability treatment as an individual who has no desire to harm another but gets intoxicated and does so accidentally. This seems counterintuitive to us; an individual 
who has some reason to know that he might be violent when intoxicated would seem to have more reason to avoid getting intoxicated-and perhaps such a person warrants more condemnation if he does get intoxicated and commits the crime.

The voluntary intoxication study sought to test the subject-community's support for the rule that, as long as the minimum of negligence as to becoming intoxicated is met, a fixed level of culpability - that of recklessness-will be imputed to a person who lacks a culpable state of mind because of voluntary intoxication. The study also sought to test whether some instances exist in which the respondents judge that the level of culpability imputed under the rule should be higher or lower than the "recklessness" provision of the present law. Specifically, we examined the case suggested by the previous example, in which-before becoming intoxicated-individuals have various levels of culpability as to causing another's death while intoxicated.

We speculated that a person's pre-intoxication level of culpability as to the offense elements (causing another's death) would be seen as properly influencing the intoxicated offender's liability. That is, as a person's pre-intoxication culpability as to the offense increases, so too would the degree of liability assigned to him. A person who has no reason to think that he might cause a death while intoxicated (this is where the conditions are labeled "faultless as to causing a death") would, we speculated, be given less liability than a person who becomes intoxicated while aware of a risk that he might cause a death while intoxicated (reckless), and that person in turn would be given less liability than a person who becomes intoxicated intending and hoping to cause another's death (purposeful). In commonsense terms, a person who is aware that he becomes violent when drunk ought to avoid becoming drunk in the first place.

Current doctrine, as we said before, does not take account of a person's pre-intoxication culpability as to causing harm; the law focuses only on the pre-intoxication culpability as to becoming intoxicated and on the culpability as to the offense elements at the time of the conduct constituting the offense. ${ }^{10}$ This strikes us as odd; we speculated that a person's pre-intoxication culpability as to the offense would have the greatest effect on our subjects' assignment of liability and that culpability as to becoming intoxicated would have less effect and further that the latter probably would not operate simply as the minimum-level requirement that current doctrine gives it.

In this study, we presented subjects with two control scenarios containing cases of a purposeful and a reckless unintoxicated killing, which would be murder and manslaughter, respectively, under current law. We then presented nine test cases that varied the person's pre-intoxication culpability as to becoming intoxicated and the person's pre-intoxication culpability as to causing a death while intoxicated. In each scenario, the person is described as sufficiently drunk so that he 
lacks awareness of the consequences of his conduct at the time of the killing. $\mathrm{He}$ is-at the time of the killing, therefore-only negligent with respect to the killing, but the legal codes will impute to him recklessness as to causing the death. Thus the code treatment of all of these cases is alike: manslaughter.

A few comments on the scenarios will be useful. The core of the scenario described an individual who is angry with his roommate for attracting the affections of the individual's girlfriend. In the control murder scenario, included to determine what liability the respondents would assign to an act of murder involving no intoxication, the roommate returns home and the perpetrator beats the roommate, who later dies from the beating. The liability assigned here is 9.54 , between a 30-year sentence and life imprisonment (see Table 4.9). In the control recklesskilling scenario, he plans only to severely beat his roommate but not to kill him. He beats him, this time with a lead pipe about the head, and the roommate later dies from the beating. Again, no intoxication is involved. The liability assigned here is, on the average, thirty years in prison-high compared to some of the other study cases we report. It is almost certainly higher because beating another individual with a lead pipe about the head is an action that is highly likely to cause death. In the comparisons below, it is well to remember that the sentence assigned to this manslaughter also is relatively high. In future research it would be worthwhile to create a reckless killing case that involves an act that is less certain to bring about death."

A closer description of the various noncontrol scenarios is in order here. When the scenarios involved pre-intoxication purpose to kill, the person plans to kill his roommate and gets drunk while waiting to do so. In the pre-intoxication recklesskilling scenarios, the person plans only to severely beat his roommate. In the faultless killing scenarios, the person is angry with his roommate but plans no assault on him and does not kill the roommate; instead, he kills a friend with whom he is drinking. As for his culpability as to becoming intoxicated, in the scenarios presenting purposeful intoxication, the perpetrator drinks in order to get intoxicated. In both the reckless and negligent culpability conditions, he is taking medication for a back condition. In the reckless scenario, he thinks that alcohol might interact with his medication to make him severely intoxicated, but he drinks anyway. In the negligent condition, he never reads the warning label on his medication and is unaware of any possibility that the medication will react with alcohol to produce severe intoxication, although the warning label clearly states this. In both of these latter conditions, when the person drinks, the medication interacts with the alcohol and he gets very drunk, whereas the alcohol alone would not have produced such an effect.

Before examining the liability results, let us examine how our respondents actually perceived the various kinds of culpability that we intended to create. Notice first the three rightmost columns $d, e$, and $f$ of Table 4.9. These tell us how the 


\begin{tabular}{|c|c|c|c|c|c|c|}
\hline Scenarios & Liability & $\begin{array}{c}\text { (b) } \\
\text { \% No } \\
\text { Liability } \\
\text { (N) }\end{array}$ & $\begin{array}{c}(c) \\
\% \text { No Liability } \\
\text { or No } \\
\text { Punishment } \\
(\mathrm{N}+0)\end{array}$ & $\begin{array}{c}\text { (d) } \\
\text { Culpability } \\
\text { as to } \\
\text { Intoxication- } \\
\text { Pre-intoxication }\end{array}$ & $\begin{array}{c}\text { (e) } \\
\text { Culpability } \\
\text { as to } \\
\text { Killing- } \\
\text { Pre-intoxication }\end{array}$ & $\begin{array}{c}(f) \\
\text { Culpability } \\
\text { as to Killing } \\
\text { at Time } \\
\text { of Killing }\end{array}$ \\
\hline \multicolumn{7}{|l|}{ Controls: } \\
\hline 1. Purposeful killing & 9.54 & 0 & 0 & & & 1.71 \\
\hline \multicolumn{7}{|l|}{ Pre-intoxication purposeful killing: } \\
\hline 3. Purposeful intoxication & 9.89 & 0 & 0 & 1.59 & 1.07 & 1.83 \\
\hline 4. Reckless intoxication & 9.78 & 0 & 0 & 2.37 & 1.37 & 1.96 \\
\hline 5. Negligent intoxication & 9.46 & 0 & 2 & 3.26 & 1.28 & 2.17 \\
\hline \multicolumn{7}{|l|}{ Pre-intoxication reckless killing: } \\
\hline \multicolumn{7}{|l|}{ Pre-intoxication faultless killing: } \\
\hline 9. Purposeful intoxication & 8.38 & 0 & 2 & 1.65 & 4.29 & 3.80 \\
\hline 10. Reckless intoxication & 8.02 & 0 & 4 & 2.50 & 4.39 & 3.80 \\
\hline 11. Negligent intoxication & 7.89 & 0 & 7 & 3.57 & 4.52 & 3.91 \\
\hline
\end{tabular}

Liability Scale: $\mathrm{N}=$ No criminal liability, $0=$ Liability but no punishment, $1=1$ day, $2=2$ weeks, $3=2$ months, $4=6$ months, $5=1$ year, $6=3$ years, $7=7$ years, $8=15$ years, $9=30$ years, $10=$ life, and $11=$ death.

Key to column heads:

(d) Culpability as to intoxication, pre-intoxication. Before becoming intoxicated, the actor:

$1=$ wanted to become intoxicated.

2 = was practically certain that he would become intoxicated.

3 = was aware of a substantial risk of becoming intoxicated and most people would have been aware of the risk.

4 = was not aware of a substantial risk of becoming intoxicated but most people would have been aware of the risk.

5 = was not aware of a substantial risk of becoming intoxicated and most people would not have been aware of the risk. 
(e) Culpability as to killing, pre-intoxication: Before becoming intoxicated, the actor-

$1=$ wanted to cause the death.

$2=$ was practically certain that he would cause the death.

$3=$ was aware of a substantial risk of causing the death and most people would have been aware of the risk.

$4=$ was not aware of a substantial risk of causing the death but most people would have been aware of the risk.

5 = was not aware of a substantial risk of causing the death and most people would not have been aware of the risk.

(f) Culpability as to killing at the time of the killing: At the time of his conduct constituting the offense, the actor-

$1=$ wanted to cause the death.

$2=$ was practically certain that his conduct would cause the death .

$3=$ was aware of a substantial risk that his conduct would cause the death and most people would have been aware of the risk.

4 = was not aware of a substantial risk that his conduct would cause the death but most people would have been aware of the risk.

5 = was not aware of a substantial risk that his conduct would cause the death and most people would not have been aware of the risk. 
subjects perceive the various kinds of culpability that we thought relevant to their judgments. Column $d$ contains mean responses to the statements concerning how culpable the individual is as to getting intoxicated-that is, how deliberately he goes about getting drunk. The element of the story that we included about getting intoxicated had the desired effect to some extent. When we described the individual as purposefully setting about getting drunk, the subjects accurately see this as more purposeful than the individual who only recklessly sets about getting drunk. The individual who negligently sets about getting drunk is seen as even less purposeful than the individual who recklessly sets about getting drunk. However, the differences are not as extreme as we would have liked. In the cases in which we described the individual as purposeful, for instance, the subjects see the person as between purposefully and knowingly getting drunk (the average is 1.68, where 1 = purposeful and $2=$ "practically certain that he would become intoxicated"). We will say more about the implications of this later.

In column $e$, we present the subjects' ratings of the degree to which they see the perpetrator as purposeful as to killing the eventual victim before getting intoxicated. As we had wished, in the story in which the perpetrator is described as having formed a plan to kill the other, the perpetrator is always seen as highly premeditative as to the killing, less so (substantially aware) when he only plans to beat the other (reckless), and not at all planful when the stories describe him as having no intention of killing another. In column $f$, we indicate the degree to which the subjects see the perpetrator as purposeful in killing the other at the time that the killing takes place. The results indicate that subjects see differences in intentionality here, when we would have preferred this to have been a constant, approaching 4.0 (where $4=$ unaware of a risk of causing death). This creates a complexity that we will discuss later.

As we next examine the data on liability assignments from the various experimental conditions (column $a$ of Table 4.9), note first that all of the assignments of liability are consistently high; the lowest liability score (7.89) translates to a sentence of 14.2 years. In retrospect, we would suggest that a person who beats another about the head with a lead pipe is an individual whom people are going to be enthusiastic about incarcerating — and the generally high scores reflect that.

Next, we examine the differences in liability judgments caused by the variations in the different kinds of culpability - a task facilitated by Figures 4.10 and 4.11. The differences between the liability assigned to the various cases that differed with respect to the purposefulness of causing the death before becoming intoxicated are statistically significant $(p=.01)$, suggesting that the subjects see a person's pre-intoxication culpability as to causing a death as a significant and important determinant of liability. The importance of the differences that pre-intoxication culpability makes is shown in Figure 4.11.

Also confirming this is the fact that liabilities assigned in the reckless and faultless cases of pre-intoxication culpability are statistically significantly lower than the results in the control murder scenario, while the results in the purposeful case 
FIGURE 4.10 Liability as a Function of Pre-Intoxication Culpability as to Killing

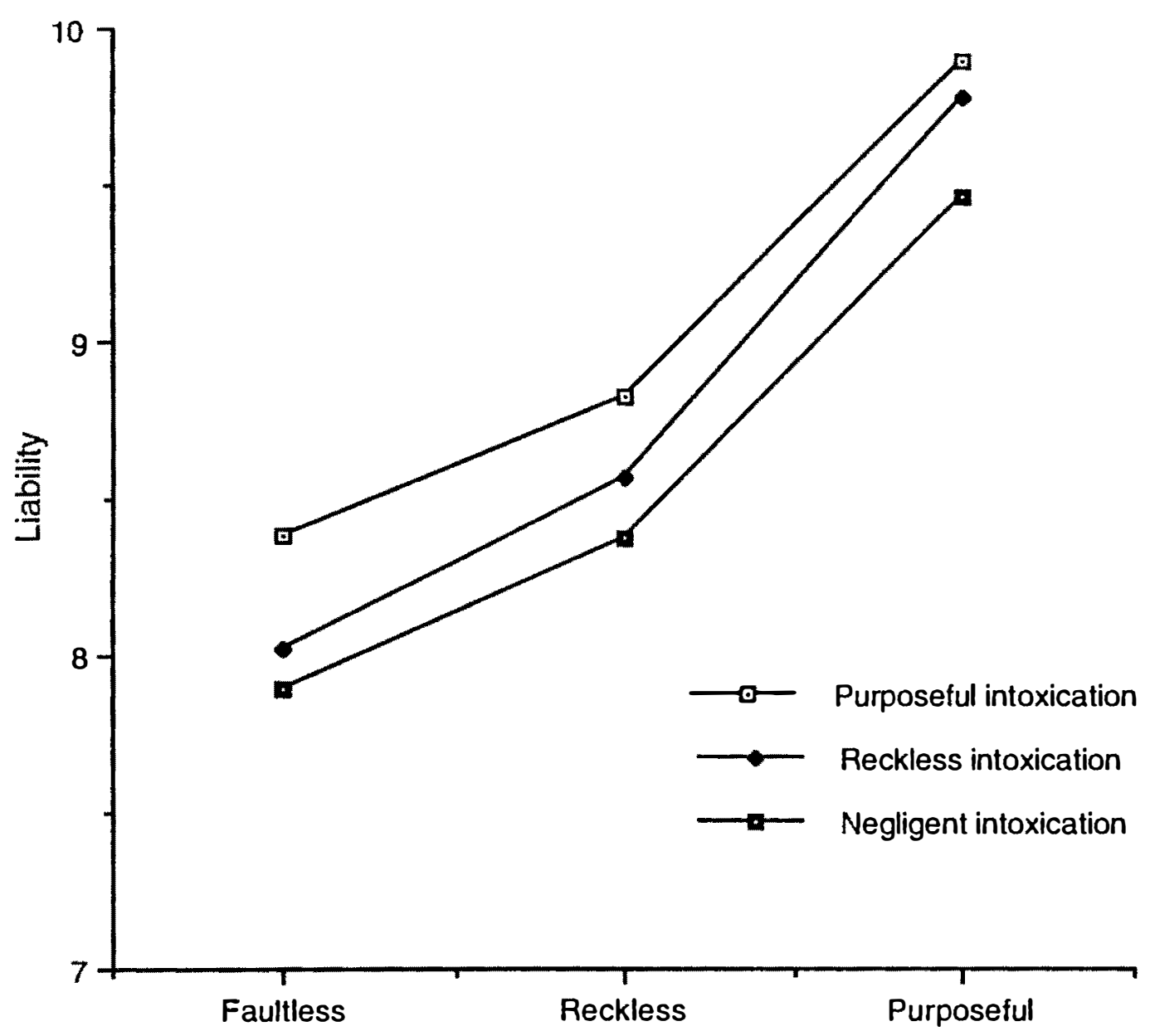

Pre-Intoxication Culpability as to Killing

(scenarios 3, 4, and 5 of Table 4.9) are not. (These numbers are pooled across the three levels of purposefulness with respect to intoxication.) This suggests that the subjects see the case of pre-intoxication purpose as similar to murder but view the cases of pre-intoxication recklessness and faultlessness as less serious than murder. Suggesting a similar conclusion, the liability ratings assigned to the person who plans to kill the roommate and then purposefully gets drunk while waiting to do so are statistically significantly higher than the results for the manslaughter control; two of the three liability assignments in the reckless cases are not statistically different from the manslaughter control; and all of the liability assignments in the faultlessness cases are statistically significantly lower than the manslaughter control.

All this suggests that the subjects see a pre-intoxication purpose to kill another, followed by a deliberate attempt to get drunk, followed by killing the other, as more serious than manslaughter; they see pre-intoxication recklessness as similar to manslaughter; and they see pre-intoxication faultlessness as less serious than manslaughter. In sum, a person's pre-intoxication culpability as to causing death 
FIGURE 4.11 Liability as a Function of Pre-Intoxication Culpability as to Becoming Intoxicated

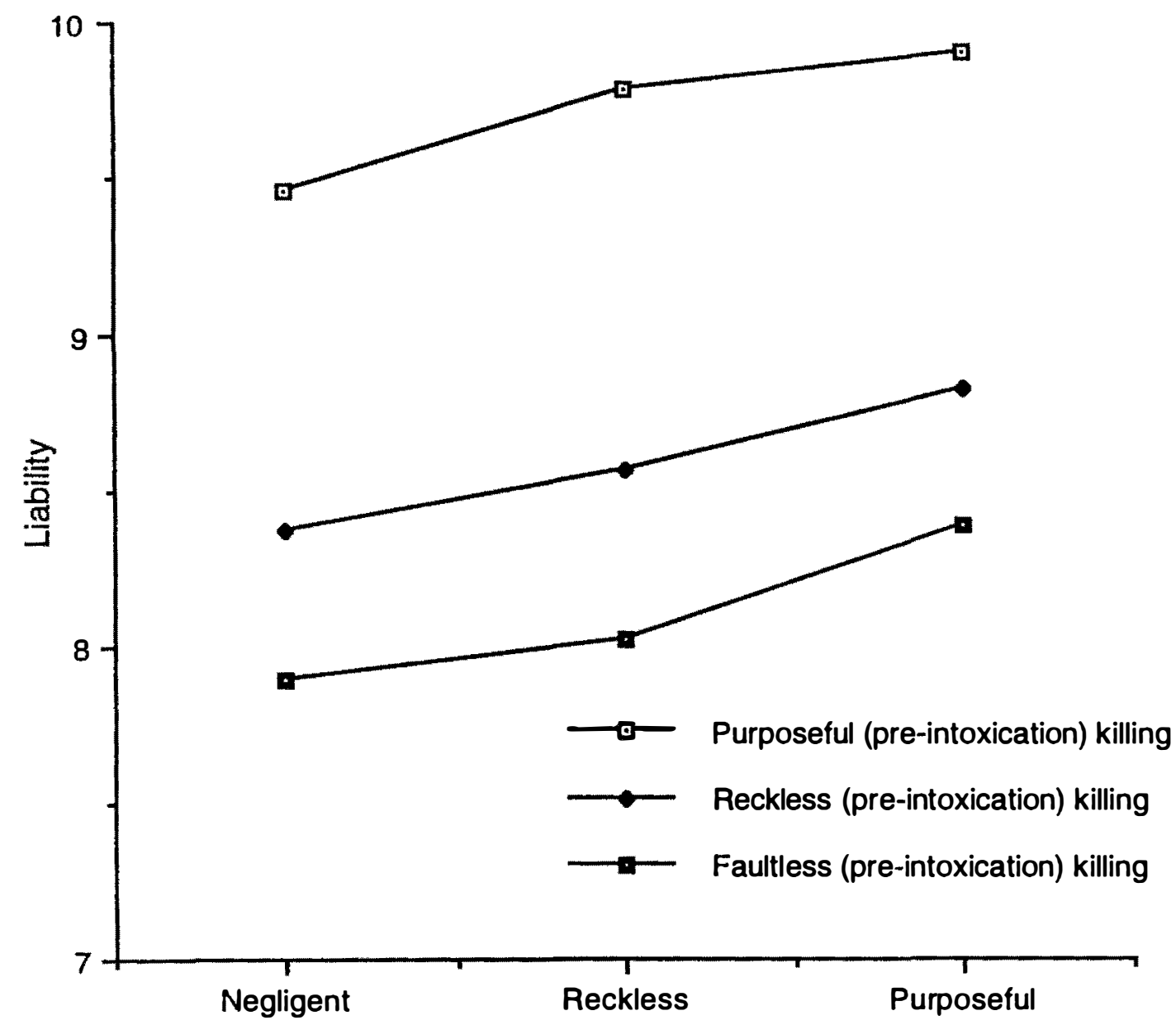

Culpability as to Becoming Intoxicated

is not only a highly influential determinant of liability but, indeed, is viewed by our subjects as being similar in effect to a person's culpability as to causing death at the time of the offense in the nonintoxication (control) cases.

The liabilities assigned in the "faultless" killing scenarios (represented by the "faultless killing" line of Figure 4.11) might strike the reader as high. But consider the facts. In those variants of the scenario the person, upset with his roommate, goes out with friends and drinks. One of his friends assists him home and the person "loses control and starts striking [the friend] with a lead pipe. [The friend] later dies from the beating." The preexisting condition of anger is likely to affect the subjects' judgments here; one should not drink when in a hostile state. Also, and again, those who beat people about the head with a lead pipe are persons whom we want to incarcerate. Still, the person who is nonnegligent (i.e., faultless) as to causing a death before his intoxication is given less liability than our manslaughter case; the average sentence is about twenty years. It is, however, still a substantial amount. 
Recall that the legal codes place considerable emphasis on the person's culpability for getting intoxicated. What are our subjects' judgments about that dimension of variation? They were told that the perpetrator, awaiting the return of his roommate, becomes intoxicated either deliberately or recklessly, or he drinks and is unaware that it will interact with the medication he is taking, and so becomes drunk negligently. As Figure 4.11 shows, this makes a difference in the liability judgments of the respondents in the way that one would expect $(p=.051)$, but the difference is of a lesser magnitude than the difference caused by the pre-intoxication culpability as to the killing, a fact that is revealed by the flatter slopes of the lines in Figure 4.1 1. Look again at Figure 4.10, which displays the person's liability as a function of the degree of culpability represented in his pre-intoxication plans to kill another. Obviously, as the steepness of the slopes of the lines suggests, preintoxication culpability is a more major determinant of the respondents' assignment of liability than is culpability as to getting intoxicated.

Still, the statistically reliable effect for culpability as to getting intoxicated suggests that the subjects see a person's level of culpability as to becoming intoxicated as a small but relevant factor in determining the person's liability for a death caused while drunk. The subjects do perceive that the person's intoxication comes about either purposefully, recklessly, or negligently (as their responses in column $d$ of Table 4.9 indicate). Our respondents moderate their sentences slightly, depending on the level of this culpability, but are not much moved by these distinctions.

This minimal adjustment of sentences is still worth noting, given that our subjects do not see the person's culpability as to being intoxicated in the various conditions as differently as we would have hoped. Examine the ratings of the cases in which we expected the subjects to perceive the person as negligent with respect to getting drunk - the cases in which the medication he took for back problems interacted with the alcohol to cause the drunkenness. Instead of negligence, the subjects saw the person as reckless, perhaps reasoning that anyone who is taking medications must be aware of at least a risk of serious intoxication through interaction of medication and alcohol. In these cases $(5,8$, and 11 of Table 4.9), the average culpability as to intoxication rating is 3.48 (column $d$ ), meaning that the person is seen as between being aware of the risk and not aware, but most persons would be aware of the risk.

Even though range-restricted, the alteration of liability judgments caused by the person's level of culpability for getting intoxicated is inconsistent with the doctrine's treatment of a person's culpability as to becoming intoxicated as a simple "trigger" - a minimum requirement - rather than as a liability factor. It is true that the legal code would impose similar liability for manslaughter in all of the scenarios, given that all of our actors are at least negligent with respect to becoming intoxicated, while our subjects grade the punishment as a close function of the specifics of the circumstances. In a broader sense, however, the results gen- 
erally fit with the code's rule. All of the persons are at least negligent with respect to getting intoxicated, and all are assigned sentences within one grade of that assigned to the individual in the control scenario who commits manslaughter. The generally high level of liability assigned to all appears to support the doctrine's selection of negligence (rather than recklessness, for example) as the trigger point for the attribution of liability equivalent to manslaughter. ${ }^{12}$

Concerns that negligence as to becoming intoxicated might be too low a level on which to impose liability cannot be perfectly tested in this study since the respondents see the person we tried to portray as negligent as about midway between negligent and reckless (Table 4.9, column $d$ of scenarios 5, 8, and 11). Still, they impose significant liability on a person whom they see as near negligentwho lacks awareness of the consequences of his conduct at the time of the killing. This suggests to us that negligence is not seen by our respondents as too low a level to set as a requirement for liability.

We previously indicated that we would need to say something about our subjects' perceptions of the culpability of the person as to causing death at the time of the killing, and we turn to that topic now. Returning to the results in Table 4.9, notice the data on the culpability of the person as to causing death at the time of the killing (column $f$ ). In scenarios 3,4 , and 5 , an interesting set of attributions emerges for the perpetrator who had previously planned to kill his roommate and then became intoxicated for whatever reason. Note that the average score for culpability at the time of the killing for these cases hovers around 2, meaning that the respondents see the person in each of these cases as being knowing with respect to killing the roommate at the time of the killing, even though the perpetrator was described as so drunk that "at this point [he] could barely stand. His thought processes and vision are severely impaired." Although we expected that the subjects would see this individual as less aware of the consequences of his actions, and thus less culpable as to causing death at the time of the killing, what the respondents may be suggesting with their high ratings of purposefulness makes psychological sense: If I plan to kill somebody, and then get drunk, my intent is preserved almost no matter how much the drink impairs my motor, thought, and perceptual systems. Furthermore, the subjects see people as being able to cling to their central intentions under these conditions and assign punishments that are as high as when the people commit the act without drinking. Future research will need to determine whether it is possible to separate these two kinds of culpability in the minds of perceivers.

\section{Study 10: Summary}

In the subjects' view, the factor that is highly determinative of liability is the person's pre-intoxication culpability as to committing the offense. A person who be- 
comes intoxicated-purposefully, recklessly, or negligently-and at the time of becoming intoxicated is purposeful as to causing death is treated by the subjects as a murderer and, as we already mentioned, is seen as having a highly culpable state of mind as to the killing at the time the person causes the death. A person who is reckless as to whether he will cause a death (as shown by his plans to severely beat another individual), becomes intoxicated either purposefully, recklessly, or negligently, and while intoxicated beats and kills the other, is assigned liability similar to one committing reckless homicide (manslaughter). In the faultless cases, the person, upset because his roommate stole his girlfriend, drinks with friends and beats and kills the friend who helps him home. He too receives quite high sentences, although ones that are diminished from the reckless and purposeful cases.

These results suggest that the differences between our respondent's moral intuitions and most codes are occasionally different, but not as different as in some other studies that we have considered. Certainly, the codes' position is consistent with the subjects' view in the cases in which a person culpably intoxicates himself and, before his intoxication, has no purpose as to causing another's death. Such an offender is treated as liable for manslaughter by most codes and treated nearly so by our subjects.

The major code-community difference arises in the consideration of the person's pre-intoxication degree of culpability as to causing death. It makes a great deal of difference to our respondents and none whatsoever in the codes. For instance, when a person is purposeful as to causing death before he becomes intoxicated, the subjects would impose liability for murder although each of the codes' voluntary intoxication provisions imposes liability only for manslaughter. That is, the codes, counterintuitively, do not discriminate the case of the individual who is purposeful about killing another bef orehand and then gets drunk and kills from the case of the individual who has no such pre-intoxication purpose. But, as one of us has suggested in another work, the codes do not prevent a prosecutor from using - as the basis for homicide liability - the person's conduct in becoming intoxicated and his culpable state of mind as to causing death at that time (Robinson, 1985). Such a theory of prosecution would produce the murder liability that the subjects impose. ${ }^{13}$

Higher culpability than negligence as to becoming intoxicated generally has some but not a major effect in increasing the liability assigned by our subjects; however, such higher culpability is given no such effect in the legal codes. Apparently, culpability as to getting intoxicated is only slightly a determinant of degree of liability but serves mainly to provide a fixed minimum requirement for liability in the legal codes. Codes could be altered to give a slightly higher degree of liability for greater culpability in becoming intoxicated, or such a consideration could be taken into account as a factor in sentencing. 


\section{STUDY 11: INDIVIDUALIZATION OF THE OBJECTIVE STANDARD OF NEGLIGENCE}

The Model Penal Code's culpability distinctions-distinguishing among being purposeful, knowing, reckless, and negligent as to causing a result or as to the existence of a circumstance-have been confirmed by several of our studies as reflecting decreasing levels of blameworthiness as perceived by our respondents. All other things being equal, as the level of a person's culpability decreases, so too does the level of assigned liability. The higher culpability levels-purposeful, knowing, and to a lesser extent reckless-focus primarily on the person's conscious state of mind as to causing the harm-desiring, knowing, and risking it, respectively. The lowest level of culpability, negligence (and recklessness to a lesser extent), relies not on a person's conscious wrongdoing but rather on a person's need to pay adequate attention to whether his conduct creates an unacceptable risk of harm. This means that judgments about a person's negligence must involve a different sort of consideration than judgments of purposeful or knowing harm-doing; such judgments must consider what a person "should" have known or reasoned out. A person parking a car on a hill should think of the possibility of the car overcoming its brakes and rolling downhill; a person shooting at a deer in a backyard should realize that the bullet could hit something other than the deer.

In these negligence cases in which the person may have no consciousness of the circumstances or consequences that make his or her conduct criminal, the law assesses the person's blameworthiness by comparing his or her attention (or inattention) to that of a "reasonable" or "prudent" individual in the same circumstances. The reasonable, prudent individual knows that cars sometimes roll and bullets carry. It is for this reason that, within legal circles, negligence is said to be based on an objective standard, rather than on the subjective inquiries into this particular person's exact state of mind that would be characteristic of inquiry into higher culpability levels.

Thus, a person's unawareness of the risks of harm that his action creates is culpable if a "reasonable person" would have been aware of those risks. Obviously, the phrase "reasonable person" does not give a precise standard. Rather, it provides a jury or judge with a mechanism for thinking about whether the person is blameworthy. The reasonable person is not the average person, statistically. Rather, the term necessarily represents a composite of those traits that the community sees as making up a person who is perceived as reasonable. That is, it embodies the community's judgment of how the prototypical person can properly be expected to behave, not necessarily a prediction of how the average person actually would behave (an inquiry that would leave the standard of care hostage to the percentage of sociopaths in the community). Nor is the reasonable-person standard the same for every person and for all situations. Modern criminal codes 
ask a jury to imagine a reasonable person in the actor's situation. Would the reasonable person have been unaware of the risk $k_{\triangleleft}$ as the person was? Momentarily, we will further detail what kinds of circumstances and characteristics are taken into account in imagining the reasonable person "in the actor's situation."

The judgments of improper risk-taking can be relatively refined. For example, in the case of driving, some driving may be negligent while other driving is not. A person may well drive in a manner that creates a greater risk than is acceptable. Even if the driver is not conscious of the unjustified risk he or she is creating-for example, the driver did not look at the speedometer to ascertain speed and did not notice the "school zone" signs and the children just getting out of school-the driver nonetheless may be blamed for inattentiveness to the risk he or she creates. A reasonably careful_driver would have been aware of the risk; therefore, the inattentive driver should have been aware. His or her failure to be attentive to the circumstances is judged to be blameworthy and an adequate basis for criminal liability.

The criminal and civil aspects of the legal system divide the responsibility for the punishment of negligence in an interesting way. Not every deviation from the reasonable-person standard is sufficiently condemnable to merit criminal liability. Unlike civil liability, where the issue is who among the parties should suffer the pecuniary loss that has occurred, criminal liability is not appropriate simply because a harm has occurred and the defendant caused it by conduct that was not entirely reasonable. Criminal negligence requires a sufficient degree of unreasonableness to merit condemnation. Thus, the Model Penal Code requires proof that the person's risk-taking is a "gross deviation" from the standard of care of a reasonable person. Therefore the criminal justice system, which is set into action by representatives of society rather than of the injured party and which has at its disposal society's most severe penalties, deals with those cases of negligence in whic! the negligent action is grossly out of line with societal standards. Less-flagrant cases can be pursued within the civil justice system, in which the penalties normally involve financial recompense for the damages done.

These aspects of criminal negligence are relatively well accepted and clearly expressed in the statutes and cases. One final aspect is more problematic: Early legal tests defined the negligence standard in purely objective terms-or so it was thought. The particular characteristics of the person-whether he or she was unusually stupid or distracted-were irrelevant. But there has also been a tradition of uneasiness with the absolute application of this standard; it seems to many commentators to be unrealistic and unfair to some violators. The mentally retarded or physically handicapped person, for example, presents a relatively obvious case of one who cannot meet a fixed objective standard that the vast majority of persons can meet. To impose criminal liability on such persons when it is beyond their ability to meet the objective standard is to violate the primary princi- 
ple that criminal liability ought to be imposed only in those instances in which the person is blameworthy for the violation. One cannot be condemned for failing to do something that one is incapable of doing.

In response to this very fundamental problem, some modern codes seek to partially individualize the objective reasonable-person standard. The person is held to the standard of a reasonable person possessing attributes modified to reflect some attributes of the defendant that may make it difficult for him to meet the objective standard. Thus, the mentally handicapped person, judged under the standard of the reasonable person similarly handicapped, would not be held liable for failing to perceive a risk that a person with such a mental handicap could not reasonably have been expected to perceive in the same circumstances. Yet the handicapped individual might be held liable, despite his or her handicap, for a failure to perceive very obvious and serious risks that someone like him or her could be expected to perceive and avoid.

The weakness in this policy lies in the difficulty of determining which characteristics ought to be recognized as potentially altering the reasonable-person standard. Mental retardation might be an easy and obvious reason to reduce our expectations of a person, but what of the parent upset over recent news of a child's death? Should our expectations be adjusted for a person's age, gender, cultural background, religious beliefs, or genetic makeup? At some point, individualization of the objective standard runs the danger of rendering it a subjective standard that every person will meet because we have so individuated the reasonable person as to make him or her identical to the specific individual. Even a callous egomaniac will be judged nonnegligent if his failure to perceive risks to others is judged by the standard of an equally callous and egomaniacal reasonable person. Even more complicated considerations also arise. For example, if we are to recognize factors that lower our legal expectations, should we similarly recognize factors that raise our expectations? Should smarter, stronger, more coordinated people be held to a higher standard because, with the same effort, they can do better than the average person?

A similar challenge arises in judging a person's recklessness. A person may be aware of a risk he or she creates yet disregard that risk as reasonable under the circumstances. The standard of culpable recklessness must determine whether a person acts reasonably when he disregards a given risk. Again, the system must ask what circumstances and characteristics of the person it is fair to superimpose upon the reasonable person in creating a standard by which to judge the blameworthiness of the person's disregard of the known risk. Are these circumstances and characteristics of a person different from those that are properly taken into account when judging the reasonableness of a person's failure to perceive a risk in the category of negligence?

Neither the Model Penal Code nor the existing literature gives a coherent theory for determining which characteristics or attributes of a person ought to be 
used to individualize the reasonable-person standard and under what circumstances. Indeed, the Model Penal Code drafters essentially admit that the matter is beyond their current ability to sort out. The Code allows judges and juries to make an ad hoc determination of which attributes to consider. The Code does so by providing that a person is to be judged by the standard of care of a reasonable person "in the actor's situation":

There is an inevitable ambiguity in "situation." If the person were blind or if he had just suffered a blow or experienced a heart attack, these would certainly be facts to be considered in a judgment involving criminal liability, as they would be under traditional law. But the heredity, intelligence or temperament of the person would not be held material in judging negligence, and could not be without depriving the criterion of all its objectivity. The Code is not intended to displace discriminations of this kind, but rather to leave the issue to the courts [MPC $\$ 2.02$, comment 4,242 (1985)].

In the present study, we sought to begin the inquiry into which attributes ought to be taken into account in judging either a person's failure to be aware of or his conscious disregard of a risk. Because no existing literature or case law proposes a general theory or principle that can be tested, this study attempts the very preliminary step of identifying attributes that might be seen by people in the community as either mitigating or aggravating criminal negligence liability. From this initial sampling, it was hoped that the responses might show a pattern that could be used to develop hypotheses and that those hypotheses might then be tested in subsequent studies.

The methods we used in this study were somewhat different from the ones to which the reader has become accustomed. Subjects were first asked to assign liability and punishment to each of three base scenarios, each of which presented a situation of risk: a commission resulting in death, an omission resulting in death, and an omission resulting in property damage. The commission resulting in death (scenario 1) involves a hunter who, in a remote wilderness area, shoots into the bush at a noise he hears and kills another hunter, earning a liability rating of 3.98 , or about 6 months in jail. In the omission resulting in death (scenario 2), a caretaker of a child pays insufficient attention to symptoms of the child's illness and fails to seek medical attention for the child, who dies. This was assigned a liability of 4.82, or between 10 and 11 months in jail. The omission resulting in property damage is depicted by an apartment house owner who does not maintain the property well, and thus it catches fire. This scenario (case 3 of Table 4.12) drew an average liability rating of 2.61 , or 5 to 6 weeks in jail. Notice the subjects' responses (in column $d$ ) to the question about whether the incident occurred because of something the person did (row 1) or failed to do (row 2). Obviously, the two acts of omission were seen as omissions. The act that we labeled "commission" was rated nearer an act of omission (Table 4.12, case 1, column $d$ ); this rating puzzled us until we talked to some who read the case who said that they 
TABLE 4.12 Liability and Culpability in Core Cases

\begin{tabular}{|c|c|c|c|c|c|}
\hline Scenarios & Liability & $\begin{array}{c}\text { (b) } \\
\text { \% No } \\
\text { Liability } \\
\text { (N) }\end{array}$ & $\begin{array}{c}\text { (c) } \\
\% \text { No } \\
\text { Liability } \\
\text { or No } \\
\text { Punishment } \\
(N+0)\end{array}$ & $\begin{array}{c}\text { Commission } \\
\text { or } \\
\text { Omission? }\end{array}$ & $\begin{array}{c}\text { Culpability } \\
\text { Level }\end{array}$ \\
\hline $\begin{array}{l}\text { 1. Commission: } \\
\text { Death } \\
\text { 2. Omission: }\end{array}$ & 3.98 & 2 & 32 & 1.73 & 4.00 \\
\hline $\begin{array}{l}\text { Death } \\
\text { 3. Omission: }\end{array}$ & 4.82 & 5 & 29 & 2.00 & 3.87 \\
\hline Property damage & 2.61 & 7 & 44 & 2.02 & 4.07 \\
\hline
\end{tabular}

Liability Scale: $\mathrm{N}=$ No criminal liability, $0=$ Liability but no punishment, $1=$ 1 day, $2=2$ weeks, $3=2$ months, $4=6$ months, $5=1$ year, $6=3$ years, $7=7$ years, $8=15$ years, $9=30$ years, $10=$ life, and $11=$ death.

Key to column heads:

(d) Please indicate whether you think the incident occurred because of: 1 = something the actor did.

2 = something the actor failed to do.

$3=$ some cause unrelated to the actor's conduct.

(e) At the time of the incident, the actor:

1 = wanted the other to die.

2 = was practically certain that his action (or inaction) would cause serious injury or death.

3 = was aware of a substantial risk of serious injury or death.

4 = was not aware of a substantial risk but should have been.

5 = was not aware of a substantial risk and a reasonable person would not have been aware of such a risk.

thought the hunter "had failed to take proper precautions," which was what they were rating rather than the act of shooting. Given this, we will continue to use the "commission" label for the case. Now notice the culpability-level ratings (column e). They hover around " 4 ," which was a rating of "was not aware of a substantial risk but should have been." This suggests that our respondents saw the cases as instances of negligence-as we had hoped.

Each subject then was asked to consider whether each of fourteen "actor characteristics" would make a difference in the liability they had assigned to the base scenarios. ${ }^{14}$ The fourteen actor characteristics were selected from those that were thought to be most likely to give some kind of reaction-either mitigating or aggravating. Frequently, the characteristics included the two extremes of a single continuum - for example, lower and higher than average intelligence, subnormal and advanced training, and youthfulness and old age. Subjects were asked to indi- 
TABLE 4.13 Factors in Individualization of Negligence Standard

\begin{tabular}{lccc}
\hline & \multicolumn{3}{c}{ Scenarios } \\
\cline { 2 - 4 } Actor Characteristics & $\begin{array}{c}(a) \\
\text { Commission: } \\
\text { Death }\end{array}$ & $\begin{array}{c}\text { Omission: } \\
\text { Death }\end{array}$ & $\begin{array}{c}(c) \\
\text { Omission: } \\
\text { Property Damage }\end{array}$ \\
\hline 1. Old age & -0.3 & -0.4 & 0.0 \\
2. Advanced experience & 0.6 & $1.6^{\star}$ & $1.8^{\star}$ \\
3. Genetic irregularity & -0.5 & $-0.9^{\star}$ & $-0.7^{\star}$ \\
4. Upbringing (knowledge) & $1.5^{\star}$ & -0.2 & -0.3 \\
5. Below-normal intelligence & -0.2 & $-1.4^{\star}$ & $-0.7^{\star}$ \\
6. Religion (knowledge) & 0.2 & -0.2 & 0.0 \\
7. Above-normal intelligence & 0.6 & $0.8^{\star}$ & 0.6 \\
8. Upbringing (environment) & $0.7^{\star}$ & -0.3 & -0.1 \\
9. Lack of knowledge (culture) & -0.3 & $-1.7^{\star}$ & $-1.0^{\star}$ \\
10. Substandard education & -0.4 & -0.3 & -0.2 \\
11. Cultural norms & $-0.8^{\star}$ & -0.1 & -0.5 \\
12. Recent upset & -0.4 & -0.4 & -0.5 \\
13. Religion (norms) & 0.2 & 0.0 & -0.1 \\
\hline
\end{tabular}

*These items are statistically significantly different $(p<.05)$ from the liability assigned to the person who did not have the named condition.

Note: The characteristic of "immaturity" is not included in this table's analysis.

cate for each variation whether, if the person possessed this characteristic, they would alter the punishment assessment they gave in the base scenario. A ninepoint scale allowed subjects to indicate less liability (1), no change (5), or more liability (9). Table 4.13 needs to be analyzed differently than the other tables that we have presented. A rating that hovers around 0 means that the respondents, on average, did not believe that that characteristic either lowered or raised the liability assigned to the person in the original case. Ratings that differ from 0 by about 0.7 are reliably different from 0 , meaning that a rating of -0.7 or lower indicates a tendency on the part of the respondents to want to lower the liability assigned to the negligent individual in that case, and a rating of +0.7 or higher indicates that the average respondent believes that possession of that characteristic warrants an assignment of more liability.

Before we look at the ratings, we need to briefly explain how we created the specific stories that the subjects based their judgments on. The specifics of the story that we created, for example, in the lack of cultural knowledge characteristic scenarios, for example, needed to vary depending on whether the story was about a failure to perceive a child's illness or the precautions to keep a building from burning. Similarly, different upbringings would cause the actor to know little about hunting or child care. Our case writers simply tried to create individuating information that fit the general category and that seemed to them to be both 
plausible and a reasonable stimulus for individuation. For these reasons, the labels that we have assigned the various conditions creating the different cases are rather approximate ones, and we will therefore interpret our results with considerable tentativeness.

Looking at Table 4.13, we first note that subjects do not often give ratings that deviate far from zero; that is, they rarely find that a particular characteristic is a reason to sharply increase or reduce the liability they assigned to the perpetrator in the original scenario. That is, in several instances of individuation, our respondents changed their ratings both far enough and systematically enough to produce a statistically reliable difference from their original ratings. (We have placed an asterisk by those scores to call them to your attention.) Given that we created the stories in ways that we thought might have some influence on our respondents' individuations, this is an interesting fact. Our respondents, like code drafters, seem cautious about individuating the objective standard of negligence.

However, in several instances the subjects do individuate. The results suggest that some actor characteristics, according to our subjects, do affect a person's liability for inattention to risks. In each scenario, two or more characteristics showed statistically significant differences in each direction from the "no change" point on the scale, or "zero" ( 0 ). In the hunter scenario (Table 4.13, column $a$ ) on the one hand, an individual whose upbringing (characteristic 4) was such as to make him knowledgeable about hunting was judged more liable for shooting at a noise in the bushes. On the other hand, an individual whose cultural norms (characteristic 11) do not include care with guns is judged as less negligent. For the apartment house owner (Table 4.13, column $c$ ), the characteristic of coming from a cultural background in which persons have little or no knowledge of the risks of particular materials catching fire caused respondents to reduce liability; however, having advanced experience at building care increased it.

Our respondents saw a number of factors as increasing or mitigating liability in the case of the child caregiver who failed to take the child in for medical attention (Table 4.13, column $b$ ). This makes sense if we note that that case is a more complex one than the other two, involving recognizing "warning signs" of the infant's distress. Immaturity, below-normal intelligence, genetic irregularity, and a lack of knowledge of children all are characteristics that decrease liability. Having aboveaverage intelligence or past experience with children-and still failing to get medical treatment for the infant-increases liability.

But which individuating characteristics do our respondents give weight to across the three base scenarios? This is a difficult generalization to infer from the data. ${ }^{15}$ We would tentatively suggest the following: In each of the cases, having relevant experience with the situation is seen as increasing liability for behaving negligently within it; and having a genetic defect, below-normal intelligence, or a culturally established lack of knowledge about the hazards often reduces liability. But the results suggest that the characteristics appropriate for individuating the 
reasonable-person standard vary with the factual situation, confirming the code drafters' assessment that this is a complex problem and suggesting that perhaps they were right to leave this to the ad hoc determination of courts. Further study may reveal a pattern to the kind of characteristics judged influential on liability in different kinds of situations. Or perhaps the jurisprudential literature will develop a hypothesis that can be tested.

\section{Study 11: Summary}

In several ways, the study's results do give us some meaningful insights. The results confirm that some individuation of the objective standard is consistent with the community view. Also, they suggest an answer to the question of whether individuation ought to increase as well as decrease our expectations of persons. Our subjects clearly believe that it is appropriate to elevate the standard of care required of an experienced person and, occasionally, of a person who is above average in intelligence as well.

Furthermore, although the Code drafters in the official commentary concerning standard of care of a reasonable person in the "actor's situation" specifically exclude the characteristics of "heredity" and "intelligence" as reasons to lower the standard, our respondents occasionally use information about these characteristics-genetic irregularity and below-normal intelligence-to reduce the liability they assign. One might think that, within the legal system, given that it generally is left to the juries to decide on the particular ways that they will individuate the reasonable-person standard, these cases of reduced liability can be accommodated. Unfortunately, this is not entirely true. It is the judge who decides whether evidence of a particular characteristic will be allowed to be introduced into evidence, so jury intuition on this point is not a safeguard, because the jury may never hear about such seemingly relevant factors. The fact that the Code's official commentary specifically excludes low intelligence as an individuating factor is particularly troublesome for this reason. A judge may well feel bound to follow the commentary and exclude such evidence, while our respondents report that it is a factor on which they would individuate the standard. Were the court system willing to individualize the objective standard of negligence to the degree reflected in these results, it would be possible to call the jury's attention to the general possibilities of individuation, perhaps even using these specific examples.

\section{CHAPTER SUMMARY}

In our study of the culpability requirements for various offenses, we discovered, first, general community confirmation of the law's tendency to make a major differentiation between reckless and negligent commission of an offense. Our subjects make major differences in their liability assignments depending on whether the individual is reckless with respect to the various elements specified as relevant by the code or merely negligent. However, unlike the standard treatment of the 
codes, which with the exception of homicide generally assign no higher liability for an offense committed knowingly or purposefully than for one committed recklessly, our subjects do assign higher liability for higher culpability than recklessness. Our subjects also distinguish recklessly committed offenses from negligently committed ones but, unlike the general code treatment, sometimes assign significant liabilities to negligently committed offenses. In general, to model our respondents' judgments, code drafters should consider more frequently having their codes make a distinction in the grade of the offense depending on the degree of culpability of the offender, rather than dichotomizing judgments between only two particular levels.

Of course, it is possible that judges accomplish one of these results in their sentencing decisions, by giving longer sentences to individuals who they see as filling the requirements for purposeful commission over and above knowing commission. However, given the current tendency to move toward more articulated sentencing rules that remove discretion from judges, it strikes us that it might be better to have this result included in code formulations-or at least embodied in sentencing guidelines - rather than being left to the discretion of the individual judge. Also, since cases of negligent commission in current code treatment typically do not trigger liability, these cases do not reach trial, and our respondents judge that they should.

A similar result emerged when we examined the culpability requirements for complicity. The codes set purposefulness as to assisting as the minimum requirement for complicity, but our respondents are willing to assign liability to a person who knowingly_or even recklessly_assists. Our respondents assign different and lower levels of liability as the culpability level decreases, which again suggests that the community would support a difference in grading of the offense depending on the degree of culpability.

For the cases of voluntary intoxication that we presented to our respondents, we found a pattern of judgments that was broadly consistent with the legal treatment of the cases in one respect. Codes commonly use negligence as the trigger point for the attribution of liability, and so do our subjects, thus supporting the codes' adoption of that standard rather than one triggered by a higher degree of culpability. However, our respondents are considerably influenced by the degree of pre-intoxication culpability that the person had with respect to commission of the offense, while codes, counterintuitively, do not consider that factor.

A person is negligent if he or she disregards possible risks that a reasonable or prudent individual would consider. Traditionally, codes have treated this as an objective standard not to be varied as a function of, for instance, the lower intelligence of the person whose conduct is being judged. However, some modern codes have moved in the direction of individualizing the standard, based on some of the characteristics of the charged individual, but have not provided a coherent theory of how to determine which individuations should be taken into account. Instead, 
judges (and, to a lesser extent, juries) are allowed to determine what attributes of the person should be considered. Without a theory to test, we conducted a study that was to some extent a "fishing expedition," seeking to discover what attributes our subjects considered to be appropriate grounds for individualization of the reasonable-person standard. As the reader will recall, the results were complexand instances of both lowered and raised standards were found. This suggests that the modern trend toward individualizing the objective reasonable-person standard has support among the community. The absence of an obvious pattern tends to confirm the practical need to leave the individualizing determination to ad hoc judgment with little principled guidance. At the same time, the dangers inherent in this lack of a guiding principle are illustrated by the Model Penal Code commentary's exclusion of a specific characteristic - below-normal intelligence-that our subjects believe is relevant in assessing the appropriate degree of liability. Because judges control the evidence that a jury will hear, jurors may never know of characteristics or circumstances that might alter their assessments of liability. 


\section{5}

\section{Doctrines of Excuse: When Is One's Rule Violation Blameless?}

That a person satisfies the culpability requirements of an offense (discussed in Chapter 4) typically will be enough to establish the blameworthiness for one's rule violation that makes criminal liability appropriate. Nonetheless, this presumption of blame may be rebutted by showing that, at the time of the offense, the perpetrator had a "disability" that excuses the person from responsibility for the offense. A person may be excused through any of the general disability excuse defenses-insanity, immaturity, involuntary intoxication, or duress. ${ }^{1}$ An insane arsonist, for example, may have intended to burn the building (a culpability requirement of arson), yet the offender's insanity may render him or her blameless for the offense. While assumptions of sanity, maturity, sobriety, and absence of coercion normally are correct and applicable in most cases, in the unusual case a person may have a disability-insanity, immaturity, involuntary intoxication, or coercion-and its effects may be such that he or she cannot reasonably be expected to have avoided the criminal violation.

The class of excuses that we address in this chapter are called "disability excuses" because society's reduced expectations for the conduct of the person come from some sort of disability or abnormality of the person. We have seen hints of these reduced expectations in previous studies, notably the study on the individuation of standards for negligence (Chapter 4, Study 11) in which our respondents were willing to require lowered standards of care from individuals whose characteristics gave them various disadvantages. Another class of excuses, "mistake excuses," look not to a person's abnormality but, on the contrary, to the normalcy (or reasonableness) of that persons' mistake as to an aspect of the circumstances that, if the mistake holds true, would render the conduct noncriminal. (In Chapter 3, we discussed several examples of this kind of excuse relative to justification defenses. For example, we saw that a person who uses deadly force on an attacker whom he or she mistakenly believes threatens him or her with deadly injury is granted a def ense by our respondents.) Future research might examine other mistake excuses, such as those given to the following: (1) a person who violates a law 
when that law has not been made reasonably available to the public; (2) a person who violates a law because he or she reasonably relies on what proved to be an official misstatement of the law; and (3) a person who makes a mistake as to the criminality of his or her conduct after making a diligent effort to ascertain the law. ${ }^{2}$

We begin our examination of disability excuses with one of the most frequent points of contact between psychology and the law: the insanity defense.

\section{STUDY 12: INSANITY}

Previous psychological research has probed many questions about the insanity defense, but two seem particularly germane to our interests. The first question is dealt with in surveys focusing on people's estimates of the fairness and effectiveness of the insanity defense as an instrument of public policy. These surveys have proven quite useful in comparing attitudes toward the insanity defense across different segments of the general population. For instance, Pasewark and colleagues have used this approach to compare laypersons' and legislators' estimates of how frequently defendants enter an insanity plea (Pasewark and Pantle, 1979; Pasewark and Seidenzahl, 1980). They found that while legislators' estimates of the frequency of cases of the insanity plea were substantially more conservative (i.e., fewer) than those of lay community members, both groups vastly overestimated the frequency and the success rate of insanity pleas. This overestimating tendency has been confirmed in more recent studies; people generally assign a much greater role to the insanity defense than it truly plays in the workings of the criminal justice system (Hans, 1986; Steadman and Braff, 1983). This finding is interesting in the present study, in that it suggests that most respondents, concerned not to overapply the defense themselves, will be relatively reluctant to grant validity to mental illness as a reason for excusing offenders from criminal liability.

Surveys and experiments that attempt to discover lay definitions of insanity constitute the second approach that previous researchers have applied to the study of the insanity defense. These studies have focused on the implications of lay definitions of insanity for the decision-making processes of juries. One conclusion has been that instructing jurors in simulated trials to apply different legalcode tests of insanity makes remarkably little difference in the verdicts that jurors ultimately reach (Finkel, 1988; Finkel, Shaw, Bercaw, and Koch, 1985). This suggests that various individuals hold their own views of what constitutes insanity and that they do not modify these views in the direction of code formulations, even when instructed to do so during their participation in simulated trials. In other words, lay definitions of insanity appear strong enough to override the specifications of the legal code in determining the Not Guilty by Reason of Insanity (NGRI) verdict. 
One study has tested lay understandings of legal definitions of insanity directly (Hans and Slater, 1984). This survey was conducted in the week following the announcement of an NGRI verdict in the case of John Hinckley, Jr., the man who attempted to assassinate President Ronald Reagan in 1982. During this week, Americans were exposed to unprecedented amounts of information and debate about the insanity defense. Consistent with previous research, Hans and Slater found that the majority of their respondents were still unable to accurately report the legal test for insanity that was being applied to Hinckley. ${ }^{3}$ A substantial proportion of respondents $(23 \%)$ volunteered the definition: “Didn't know what he or she was doing" (Hans and Slater, p. 107).

From our point of view, the interesting question is: Do ordinary persons spontaneously use standards for judging mental illness that are in rough accord with those that the legal system suggests are relevant? This question is not answered by the research cited above. What distinctions, then, are made by standard legal codes? Within the legal system, mental disease or defect can affect a person's criminal liability either (1) by negating (i.e., making it impossible for the prosecution to prove) a culpable state of mind that is required by the definition of the offense charged or (2) by satisfying the conditions of a general insanity defense. The latter, the general insanity defense, operates without regard to the elements of the offense charged. If the conditions of the general insanity defense are met, the person escapes criminal liability, whatever the offense. Rather than focusing on the person's actual state of mind as to the offense elements, the general insanity defense focuses on the person's general capacity for normal mental and emotional functioning. ${ }^{4}$ In this study, we test the similarities and differences between community standards and the provisions of the general insanity defense.

The common law recognized an insanity defense under what is called the McNaughten test, which provides a defense if one was laboring under such a defect of reason due to mental disease that one did not know the nature or quality of the act one was doing or, if one did in fact know about the act, one did not know that what one was doing was wrong. ${ }^{5}$ The test focuses exclusively on the person's cognitive (as opposed to control) dysfunction and requires a very high, if not absolute, degree of loss of function. The person must "not know" either the nature of his conduct or that it is wrong. In contrast, the cognitive dysfunction prong of the Model Penal Code's more modern formulation (called the "ALI test" because the American Law Institute authored the Model Penal Code) sets a somewhat lower standard of dysfunction: It requires only that the person lack "substantial capacity" to "appreciate" the criminality or wrongfulness of his conduct [MPC $\$$ 4.01(1)]. The Code's language permits the defense upon less dysfunction; cognitive function only need be impaired, not absolutely lost.

Many jurisdictions adopting the McNaughten test have added an alternative ground of exculpation: Even if one knows the nature of what one is doing and that it is wrong, one nonetheless is excused if he or she has lost the power to avoid do- 
ing the act in question to such a degree that one's free agency is at the time destroyed. ${ }^{6}$ This introduces the possibility of a defense based on a pure control dysfunction, with a person's cognitive functioning intact. Like McNaughten, however, this "irresistible impulse" test, as it is called, is stated as absolute in its demands. One must have no power to control one's conduct, and one's free agency must be "destroyed." Under the control prong of the Model Penal Code's ALI test, in contrast, one need only lack "substantial capacity" to conform one's conduct to the requirements of law [MPC $\$ 4.01(1)$ ]. Absence of control is not required for the Code's defense; substantial impairment of control is sufficient.

These distinctions-cognitive versus control, and complete loss versus substantial impairment of function-represent the major distinctions among the most common American formulations of the insanity defense. Some jurisdictions still use just the McNaughten test-requiring high cognitive dysfunction. Some adopt McNaughten and add the irresistible-impulse test as an alternative ground of defense-thus requiring either high cognitive or high control dysfunction. The Model Penal Code's ALI test has been adopted in many jurisdictions. It requires only substantial impairment of either cognitive or control functioning. Some jurisdictions, such as the federal system, have recently dropped the control-function prong of ALI and kept the cognitive-function prong. Rather than reverting to McNaughten entirely, they have retained the ALI test's substantial impairment approach. ${ }^{7}$ Public disillusionment and dissatisfaction have led a few jurisdictions to drop the insanity defense altogether. ${ }^{8}$

The following insanity study sought to determine whether our subjects would give a general defense because of a person's insanity, whether they recognize the validity of the cognitive versus control distinction that the doctrine uses, and which of the tests, if any, best reflects their views. In the core of the story we presented to the subjects, an individual (who is characterized with various details that suggest insanity) picks up an object that is nearby, such as a baseball bat, a mallet, or a rock, and hits another person with it, killing that other person. Because the writers of these cases wanted to make the mental dysfunction of the person vivid, they created scenarios that differed from one another in several ways. What we will need to look at carefully, therefore, are the respondents' perceptions of the kind and degree of mental dysfunction experienced in each case.

When we examine the subjects' perceptions of the degree and kind of insanity that was conveyed by the scenarios, we discover that their perceptions are somewhat different than we had expected them to be. ${ }^{9}$ The cases and the way our respondents perceived them are shown in Table 5.1.

The cases are numbered as they will appear in the next table, which is why the numbers run from 4 through 7 rather than beginning with 1 . Columns $a$ and $b$ show the subjects' ratings of the degree to which the perpetrator suffers from a substantial or complete control dysfunction. Columns, $c, d$, and $e$ report their perceptions of the degree of cognitive dysfunction. The questions on cognitive 
TABLE 5.1 Respondents' Perceptions of Cognitive and Control Dysfunctions

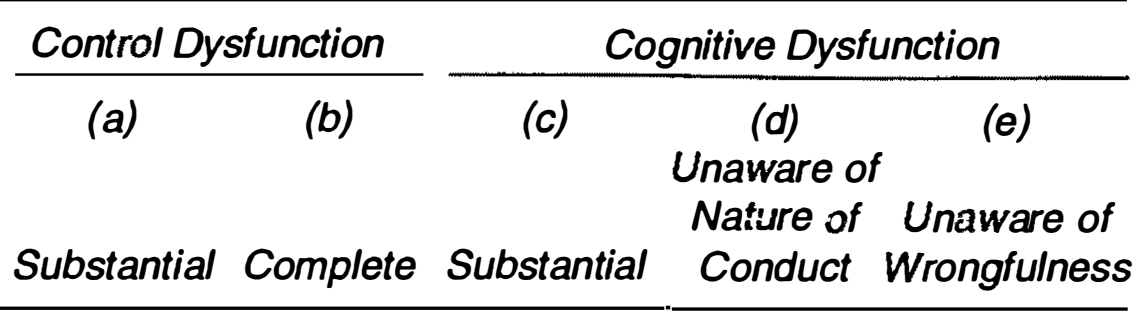

Suggested

Scenario Label Substantial Complete Substantial Conduct Wrongfulness

4. High control, low cognitive

7.58

7.39

3.05

2.76

2.71

5. High control, low cognitive

6.61

2.95

2.50

2.74

6. Medium control, high cognitive

4.47

4.74

7.68

7.97

7.58

7. Low control, high cognitive

3.79

3.89

6.82

3.29

6.68

The questions asked whether the respondent $1=$ "strongly disagreed," $5=$ was "unsure," or $9=$ "strongly agreed" that the actor had a substantial or complete control or cognitive dysfunction. The exact questions are shown in Table 5.4 and correspond to each of the five lettered columns of this table. The questions tabulated here are the common-language formulations.

dysfunction are more numerous because, as we noted about cognitive dysfunction, the legal doctrine distinguishes between cognitive dysfunction of two sorts: First, one may be unaware of the nature of one's conduct (unaware that the thing one is hitting is a person) and second, even if one is aware of the nature of the conduct, one may be unaware of the wrongfulness of the conduct (unaware that hitting another is wrongful). Therefore, we included questions about both of these sorts of cognitive dysfunction.

The results indicate that respondents are well able to distinguish cognitive from control dysfunction, a fact that lends some support for the use of this distinction by the doctrine. As can be seen from the scenarios in rows 4 and 6 , we were generally successful in creating perceptions of high dysfunction, whether cognitive or control. Subjects perceived the case in row 5 as being a case of high control dysfunction; and perceived the case in row 6 as having a fairly high degree of cognitive dysfunction. Looking at these degree-of-dysfunction ratings, one is struck by the fact that we have two conditions in which the control dysfunction is judged to be high and the cognitive dysfunction moderately low (scenarios 4 and 5) and two conditions in which the cognitive dysfunction is judged high and the control dysfunction low or moderate (scenarios 6 and 7). Therefore, in our analyses of liability judgments, we will treat each member of each pair as to some extent a replication of the other member of the pair, although trying to remain sensitive to the differences between the pair. (These are the scenario descriptions of this study and are represented in the "suggested label" columns of Tables 5.1 and 5.2.) 
TABLE 5.2 Liability as Related to Insanity

\begin{tabular}{|c|c|c|c|}
\hline Suggested Label & Liability $^{a}$ & $\begin{array}{c}\text { (b) } \\
\% \text { No } \\
\text { Liability } \\
\text { (N) }\end{array}$ & $\begin{array}{c}\text { (c) } \\
\text { \% Civil } \\
\text { Commitment }\end{array}$ \\
\hline \multicolumn{4}{|l|}{ Control Conditions: } \\
\hline 1. Murder & 10.42 & 0 & \\
\hline 2. Self-defense & 0.11 & 79 & \\
\hline 3. Mistaken identity & 7.79 & 0 & \\
\hline \multicolumn{4}{|l|}{ Experimental Conditions: } \\
\hline 4. High control, low cognitive & $1.89(19 \%-8.29)$ & 81 & 81 \\
\hline 5. High control, low cognitive & $3.00(34 \%-9.25)$ & 66 & 66 \\
\hline 6. Medium control, high cognitive & $0.64(8 \%-5.67)$ & 92 & 92 \\
\hline 7. Low control, high cognitive & $1.65(16 \%-9.00)$ & 84 & 84 \\
\hline
\end{tabular}

Liability Scale: $\mathrm{N}=$ No criminal liability, $0=$ Liability but no punishment, $1=$ 1 day, $2=2$ weeks, $3=2$ months, $4=6$ months, $5=1$ year, $6=3$ years, $7=7$ years, $8=15$ years, $9=30$ years, $10=$ life, and $11=$ death.

${ }^{a}$ Civil commitment cases are included as 0 in calculating these means. The numbers in parentheses indicate the percentage of respondents who assigned criminal liability and, of those, the average liability they assigned.

Before we leave Table 5.1, one more result is worth interpreting. The two different aspects of cognitive dysfunction have a complex relation with each other. As we previously noted, one can be aware of the nature of one's conduct but unaware of the wrongfulness of the conduct. It looks like this is the way that our subjects treat this situation, as the doctrine suggests. Scenario 7 is perceived by them as being a case in which the person is aware of the nature of his conduct (column $d$ ) but unaware of the conduct's wrongfulness (column $e$ ). As column $c$ shows, our respondents agree that this individual has a substantial degree of cognitive impairment. Note that if one is unaware of the nature of one's conduct that one will of course be unaware of its wrongfulness, but not the reverse. The two categories of awareness - of the nature of the conduct and of its wrongfulness-are serial in relation rather than alternative.

Next, we will examine Table 5.2. The liability results again are shown in columns $a$ and $b$, and there is one additional feature in column $a$ that we will explain in a moment. Before we examine the liability ratings for the mental illness cases, a note on the comparison cases is in order. The comparison (control) cases are scenarios 1,2 , and 3 . The murder case (row 1) involves a person who, because he is angry at another, goes to that person's house and bludgeons him to death, a straightforward murder, and we notice (in column $a$ ) that it commands a sentence of somewhere between life imprisonment and the death penalty. The selfdefense control case (row 2) shows the liability assigned to a convenience store 
owner who defends himself from a knife-wielding robber by pulling a nightstick from under the counter and striking the robber, who is lunging at him with a knife. The robber is killed. This seems a straightforward case of self-defense to us and, judging by their slight liability assignment, to our respondents as well. The third control case (row 3) involves again a convenience store owner who chases a robber, loses him, and misidentifies another individual as that robber. The lookalike individual and the owner get into a fight, the owner uses the nightstick that he is carrying, injures the look-alike, and the individual eventually dies from the injuries. The liability assigned to this case is high. This indicates the respondents' views about the wrongfulness of a mistake as to what the store owner thinks is justified force. The subjects' response is notable because the mistake is in some sense similar to the sorts of mistakes that the mentally dysfunctional persons make in the experimental cases.

Notice that a new column, $c$, appears in this table, containing the percentage of subjects who assign civil commitment to the perpetrator. In the real world, the choice facing judges and juries in insanity cases is not simply criminal liability or no criminal liability. A special verdict of not guilty by reason of insanity is available where an insanity plea is made, and this disposition generally leads to civil commitment, not to immediate release into society. Because of this fact, we gave subjects the option to recommend this course of handling the mental illness cases and even to suggest a term of the civil commitment. ${ }^{10}$ We gave them this option as a way of assuring that those who are concerned about community safety more than anything else would feel that the civil commitment system would provide this assurance and that they need not impose criminal liability on someone who they thought might not deserve it in order to assure the community's safety. Notice that many of our subjects (66 percent or more) choose this civil commitment option (Table 5.2, column $c$ ). The ability to specify not just civil commitment but also a term of years thus makes the civil option equally effective at protecting the community as the criminal option. Thus, those who give the criminal option would be those who are doing so because they believe that the person really deserves the condemnation and punishment of criminal conviction.

The first result to notice from these various liability-judgment comparisons is the global one. Perpetrators who are judged to be suffering from a high degree of dysfunction, whether that dysfunction is of the cognitive or conduct-control sort, are normally not assigned criminal liability. In other words, our subjects do grant validity to a defense of insanity and sharply reduce the liability assigned to a person who commits a crime while mentally ill; in making this judgment, our subjects are in general accord with the way that the criminal codes treat such cases. Typically, more than 70 percent of our respondents assign no criminal liability to such cases.

This result has special implications for the current controversy over whether the insanity defense should excuse only those cases of cognitive dysfunction or if 
control-dysfunction cases also should be provided a defense. Recall that the federal system, as well as several states following its lead, recently has reverted to a cognitive-only test, denying any defense for a control dysfunction. Our respondents would disagree with this change. In scenario 4 , which is perceived as showing high control and low cognitive dysfunction, 81 percent of the respondents impose no criminal liability, and in scenario 5, similarly perceived, 66 percent impose no liability. Scenario 7, perceived as the reverse (low control and high cognitive), has about the same number of respondents giving no criminal liability (84 percent). This suggests that both cognitive and control dysfunctions can support an insanity defense. This conclusion is supported as well by the results in scenario 6 . Where medium control and high cognitive perpetrator characteristics are perceived, 92 percent of subjects give the defense, noticeably more than the 84 percent who give the defense in scenario 7 for low control and high cognitive traits. Control dysfunction can support a defense; the greater the perceived control dysfunction, the greater the likelihood of a defense. Of course, these respondents do judge that civil commitment is appropriate for the insane individual; they do not wish to release the perpetrator into the community. Indeed, were we to graphically illustrate the length of the period of confinement recommended by the respondents-without respect to whether it was civil or criminal confinement-we would see that the time period of incarceration recommended was reasonably constant across cases. Our respondents seem to be making a complex judgment here. As is reasonably well understood in legal circles, there are a number of reasons why one incarcerates a person: because the person is blameworthy and deserves the sentence is one; to incapacitate the person so that no further crimes will be committed is another. (The latter is how one might treat a maneating tiger, were one to stray into the legal system. One would recognize that it is in the nature of tigers to eat men; so, one would not morally condemn the tiger for doing so. But exactly because it is in the nature of tigers to do so, one would lock the tiger up so that it would not have the opportunity to eat more men.) What our respondents wish to happen, given the alternatives presented to them, is to punish the noninsane perpetrator with a prison sentence and to incapacitate the insane perpetrator for a long period of time ${ }^{11}$ in a place that, within our system, may look remarkably like a prison.

Return now to the criminal liabilities (Table 5.2, column a) assigned to the cases in which we depicted possibly insane persons bringing about death. The number not in parentheses is the normal liability assignment; that is, the average liability assigned by all respondents, treating those who assigned no liability, no liability or punishment, or civil commitment as assigning a criminal liability of zero.

The corresponding numbers in parentheses show the average criminal liability assigned by those who assigned criminal liability. (To make the reader's task easier, we have included two numbers. The first is the percentage of respondents who as- 
signed criminal liability. The second is the average liability assigned by those persons. So, for instance, in case 4 , we see that 19 percent of the respondents assigned criminal liability in that scenario, and their average liability score was 8.29.) This new "average liability" number is a different statistic than we have previously included in our tables, and it is informative in this context because it reveals that those subjects (a minority of respondents in each case) who do not exculpate the offender for reasons of insanity judge that quite high sentences are appropriate. Additionally, notice that this is true for all of the insanity cases (4 through 7). Even within this minority group, however, liability ratings varied: Slightly more respondents assign criminal liability to the two high-control-dysfunction cases than to the two high-cognitive-dysfunction cases, and the average liability that they assign is higher. Further research will need to be done to determine both the persistence and importance of these differences and the degree to which they will transcend the specifics of the scenarios that we created for each case.

Having examined the liability scores related to the insanity cases, we address one more issue in this study - the respondents' understandings of the legal code's wordings of the various formulations of the insanity defense. (See Tables 5.3 and 5.4, which together explain our subjects perceptions in this regard.) For each scenario, we asked our respondents to estimate the degree to which the individual in the scenario fits the various formulations of the insanity defense, and we did this in two ways: First, we presented our subjects with our best commonsense translation of the legal code concept (Table 5.4, column $a$ ); and second, we also gave them the exact wording of the legal code formulation (Table 5.4, column $b$ ). For example (in insanity case 2 ), we asked the degree to which the respondents agreed with the statements that the perpetrator "did not realize that striking the [victim] with the baseball bat was wrong" and that the perpetrator "was laboring under such a defect of reason [due to mental disease] that he did not know that what he was doing was wrong."

Table 5.3 shows the average responses of our subjects to these questions and, more important, shows the correlations between the pairs of equivalent questions (that is, between the common and legal language formulations). The correlations (column $c$ ) are generally high, averaging 0.86 in scenario $4,0.85$ in scenario 5, dropping to 0.58 in scenario 6 , and returning to 0.84 in scenario 7 . We interpret these high correlations to mean that, in this context, the subjects saw the paired statements as having about the same meanings. This conclusion of the essential interchangeability of the two forms of the statements is supported by the general close agreement between the average scores on each of the two equivalent questions. (The comparison across rows between columns $a$ and $b$ shows this. ${ }^{12}$ ) This suggests that, on the one hand, it would not be wrong in the criminal justice system to use the ordinary language formulations of the questions that the jurors are instructed to decide in determining whether a specific individual meets the legal criteria for insanity. On the other hand, it also suggests that the people to whom 
TABLE 5.3 Respondents' Perceptions of Cognitive and Control Dysfunction: Agreement with Common and Legal Language Formulations

\begin{tabular}{|c|c|c|c|c|c|}
\hline Scenario & & $\begin{array}{l}\text { Dimension of } \\
\text { Perceived Dysfunction }\end{array}$ & $\begin{array}{c}\text { (a) } \\
\text { Common } \\
\text { Language } \\
\text { Agreement }\end{array}$ & $\begin{array}{c}\text { (b) } \\
\text { Legal } \\
\text { Language } \\
\text { Agreement }\end{array}$ & $\begin{array}{c}\text { (c) } \\
\text { Correlation* }\end{array}$ \\
\hline $\begin{array}{l}\text { 4. High } \\
\text { control, low } \\
\text { cognitive }\end{array}$ & $\begin{array}{l}1 . \\
2 . \\
3 .\end{array}$ & $\begin{array}{l}\text { Unaware of nature of } \\
\text { conduct } \\
\text { Unaware of wrongfulness } \\
\text { Substantial impairment of } \\
\text { appreciation of } \\
\text { wrongfulness } \\
\text { Complete loss of control } \\
\text { Substantial impairment } \\
\text { of control }\end{array}$ & $\begin{array}{l}3.05 \\
7.39 \\
7.58\end{array}$ & $\begin{array}{l}3.29 \\
7.13 \\
7.47\end{array}$ & $\begin{array}{l}0.86 \\
0.94 \\
0.86\end{array}$ \\
\hline $\begin{array}{l}\text { 5. High } \\
\text { control, low } \\
\text { cognitive }\end{array}$ & $\begin{array}{l}1 . \\
2 . \\
3 .\end{array}$ & $\begin{array}{l}\text { Unaware of nature of } \\
\text { conduct } \\
\text { Unaware of wrongfulness } \\
\text { Substantial impairment of } \\
\text { appreciation of } \\
\text { wrongfulness } \\
\text { Complete loss of control } \\
\text { Substantial impairment } \\
\text { of control }\end{array}$ & $\begin{array}{l}2.95 \\
6.61 \\
7.29\end{array}$ & $\begin{array}{l}3.21 \\
6.42 \\
6.84\end{array}$ & $\begin{array}{l}0.86 \\
0.83 \\
0.83\end{array}$ \\
\hline $\begin{array}{l}\text { 6. Medium } \\
\text { control, } \\
\text { high } \\
\text { cognitive }\end{array}$ & $\begin{array}{l}1 . \\
2 . \\
3 .\end{array}$ & $\begin{array}{l}\text { Unaware of nature of } \\
\text { conduct } \\
\text { Unaware of wrongfulness } \\
\text { Substantial impairment of } \\
\text { appreciation of } \\
\text { wrongfulness } \\
\text { Complete loss of control } \\
\text { Substantial impairment } \\
\text { of control }\end{array}$ & $\begin{array}{l}7.68 \\
4.74 \\
\\
4.47\end{array}$ & $\begin{array}{l}7.50 \\
4.42 \\
4.61\end{array}$ & $\begin{array}{l}0.48 \\
0.34 \\
\\
0.57 \\
0.68 \\
0.85\end{array}$ \\
\hline $\begin{array}{l}\text { 7. Low } \\
\text { control, } \\
\text { high } \\
\text { cognitive }\end{array}$ & $\begin{array}{l}1 . \\
2 . \\
3 .\end{array}$ & $\begin{array}{l}\text { Unaware of nature of } \\
\text { conduct } \\
\text { Unaware of wrongfulness } \\
\text { Substantial impairment of } \\
\text { appreciation of } \\
\text { wrongfulness } \\
\text { Complete loss of control } \\
\text { Substantial impairment } \\
\text { of control }\end{array}$ & $\begin{array}{l}6.82 \\
3.89 \\
\\
3.79\end{array}$ & $\begin{array}{l}7.16 \\
3.63 \\
4.26\end{array}$ & $\begin{array}{l}0.89 \\
0.85 \\
0.95\end{array}$ \\
\hline
\end{tabular}

Note: The exact wordings of these questions are shown in Table 5.4. Question 1 is tabulated in column d of Table 5.1, question 2 in column $e$, question 3 in column $c$, question 4 in column $b$, and question 5 in column $a$. Respondents were asked whether they $1=$ "strongly disagreed," $5=$ were "unsure," or $9=$ "strongly agreed" with the common and legal language formulations that correspond with each of the five dimensions of perceived dysfunction for each of the four scenarios presented here.

*All of the correlations shown in column $c$ are statistically significant $(\rho<.05)$. 
TABLE 5.4 Key to Table 5.3-Questions for Common and Legal Language Formulations

Dimension of Perceived Dysfunction (a)

Common Language Formulation (b)

Legal Language Formulation
1. Unaware of nature of conduct the actor did not realize that he was striking the tenant with a baseball bat.

2. Unaware of wrongfulness

3. Substantial impairment of appreciation of wrongfulness

4. Complete loss of control

5. Substantial impairment of control
Because of mental illness, the actor did not realize that striking the tenant with a baseball bat was wrong.

Because of mental illness, the actor's ability to understand the wrongfulness of his conduct was substantially impaired.

Because of mental illness, the actor lacked any ability to stop himself from striking the tenant with the baseball bat.

Because of mental illness, the actor's ability to stop himself from striking the tenant with the baseball bat was substantially impaired.
The actor was laboring under such a defect of reason due to mental disease that he did not know the nature or the quality of the act he was doing.

The actor was laboring under such a defect of reason that he did not know that what he was doing was wrong.

As a result of mental disease or defect at the time of his conduct, the actor lacked substantial capacity to appreciate the criminality or the wrongfulness of his conduct.

Because of the duress of mental disease, the actor had so far lost the power to avoid doing the act in question, as that his free agency was at the time destroyed.

As a result of mental disease at the time of his conduct, the actor lacked substantial capacity to conform his conduct to the requirement of the law.

we gave these scenarios, and by extension, jurors, are able to understand and apply the somewhat ponderous legal wordings of the various formulations of insanity as well. This does not contradict the findings of other research (discussed at the beginning of this study) that showed that people were unable to reproduce the legal system definitions of insanity.

\section{Study 12: Summary}

Recall our discussion of the treatment that would be given to each case by various formulations of the current law. Let us for the moment assume that the typical 
judgments in every insanity scenario are of "not guilty," as in fact they are. If this is assumed, interestingly, both the formulation of insanity contained in the Model Penal Code and the formulation under the McNaughten-irresistible-impulse test accurately fit the pattern of our respondents' judgments, and the formulations of the McNaughten rule and the recently passed federal statute do not match the respondents' judgments. Specifically, the last two formulations do not grant a defense when the person is laboring under a control dysfunction, even though our respondents do see control dysfunction as establishing a defense of insanity. Thus, the two formulations that grant validity to the insanity defense based on either a cognitive or a control dysfunction are the ones that best match the judgments of our respondents. Further, the subjects were able to distinguish cognitive from control dysfunctions, lending some support for the use of this distinction by the doctrine. As the history of the doctrine might predict, cognitive dysfunctions appear to provide persuasive excuses to more of the subjects than do control dysfunctions.

Further examination of the data suggests, rather tentatively, one more conclusion. Examine again the degree of our subjects' agreement with the substantial impairment dysfunction statement for scenarios 6 and 7 (column $c$ of Table 5.1). Although the subjects are in strong agreement with those dysfunction statements, they are by no means in total agreement with them. We would suggest that this supports the Model Penal Code's formulation of the cognitive dysfunction rule, which requires only that the person lack "substantial capacity" to appreciate the criminal wrongfulness of his conduct. This accesses the defense when cognitive functioning is impaired-rather than totally lost-a judgment with which our respondents seem to be in accord. In further research, we will test whether a cognitive dysfunction that respondents judge as establishing a lack of substantial capacity to appreciate the criminal wrongfulness of one's conduct is sufficient to cause those respondents to grant the insanity defense.

Further research also will be necessary to provide more support to the conclusions we have drawn from this study. Since our respondents perceive all of the cases as containing a high level of either control or cognitive dysfunction, further testing is necessary to determine what degree of each dysfunction is required before support for the insanity defense appears. It would also be useful to determine whether respondents use the defense in an essentially dichotomous way, granting it standing as a complete defense after it rises above a certain level, or if they would continuously scale their liability judgments to the degree of dysfunction that they detect. The former is the process that most closely matches those contained in all of the legal formulations.

There is a great deal of controversy about the insanity defense in our society. As we noted, many individuals feel, probably inaccurately, that the defense is used too often and has the effect of "letting off" many blameworthy persons. Given this is so, it is worth noting that a strong majority of our subjects still excused a 
person who bludgeoned his victim to death if they judged that perpetrator as being genuinely dysfunctional because of mental illness. It may be that much of the controversy about the insanity defense is generated in circumstances in which the average reader of the publicity about a case sees the perpetrator as having only a modest degree of dysfunction-not enough to trigger the defense-whereas the jurors see the same degree of dysfunction as sufficient to trigger the defense. Still, we should also note that those minorities of the respondents who did find criminal liability appropriate assigned quite lengthy sentences.

\section{STUDY 13: \\ IMMATURITY AND INVOLUNTARY INTOXICATION}

As our discussion of the previous study on insanity has suggested, when one commits an offense under the influence of some significant dysfunction of one's capacity to control one's conduct or to understand the nature of one's conduct, the criminal law frequently recognizes an excuse that provides a defense. In addition to mental illness, the law excuses for dysfunctions that arise from either involuntary intoxication or immaturity (or, as we shall see in the next study, from duress).

Current legal codes typically use a person's chronological age (although there is considerable debate over the exact age that divides maturity from immaturity) as conclusive evidence that the person is too immature to understand or control the harmful and criminal nature of his or her conduct [MPC $\$ 4.10$; Robinson, 1984, $\$ 175]$. Our study sought to test the subjects' willingness to excuse persons because of their immaturity, as evidenced by their chronological age. A "control" harm was described, and then the same harm was described as having been committed by an individual of various ages. No other information accessing an excuse was given, so if respondents gave lesser sentences to the younger offender, they did so solely because of the differential inferences they drew from the offender's age.

The defense of involuntary intoxication in legal theory works through mechanisms similar to those used for the defenses of insanity and immaturity, as described in the previous study concerning insanity. In Chapter 4 , we discussed the legal theory relating to voluntary intoxication. If a person voluntarily becomes intoxicated, that person's intoxication has a limited effect in mitigating his or her liability. In those cases in which a person's intoxication is involuntary, however, liability may be eliminated or mitigated in two ways, parallel to those seen for mental illness. First, the resulting dysfunction from involuntary intoxication may provide a defense if it negates a culpable state of mind required by the offense definition. Second, the condition may excuse the violator if it satisfies the conditions of the general involuntary intoxication defense, notwithstanding that the elements of the offense are satisfied. Those conditions typically are analogous to the conditions required by a jurisdiction's particular formulation of the insanity defense [MPC $\$ 2.08(4)$; Robinson, 1984, $\$ 176$ ]. As with insanity, the most com- 
mon defense formulations use the McNaughten test, the McNaughten-irresistible-impulse test, or the ALI test. The differences among these tests arise from the distinctions between cognitive and control dysfunction and between loss versus impairment of function, as described in the previous study.

In this study, we attempt to see the degree to which our respondents agreed with the immaturity and involuntary intoxication defenses recognized by the legal doctrine, as well as the degree to which these two defenses are based on similar underlying mechanisms of exculpation. To examine community views on the general involuntary intoxication defense and its effect on a person's liability, subjects were given five homicide scenarios intended to present a person who suffers from the following dysfunctions, respectively: high control only, high cognitive only, low control only, low cognitive only, and low cognitive plus low control. To examine community views on the doctrine's immaturity defenses, three scenarios presented cases in which the person engages in similar conduct under similar circumstances (but without being under the influence of any intoxication). In these cases, it is the person's age that is varied, from 10 to 14 to 18 years of age. ${ }^{13}$ Finally, there was a control comparison case to establish the penalty these respondents would give to the perpetrator of a similar homicide who suffered from no dysfunction.

In the control case and the three age-related cases, the core scenario is this: Two brothers have a history of antagonism. After an argument, one waits until the other is asleep and then kills him by dousing him with kerosene and setting him on fire. In the involuntary intoxication scenarios, the respondents were told that the cause of the involuntary intoxication is an unexpected interaction between two medications that the person is taking: one to control long-term pain and the other described as an over-the-counter drug for treatment of a cold. (By describing it as an over-the-counter medication, we attempted to create the perception that people would regard it as generally safe and unlikely to enter into side-effect interactions with other medications.) The prescribing physician had not mentioned the possibility of drug interaction side effects, and the person had not thought to ask about them. The core of these stories had the involuntarily intoxicated person killing his brother by suddenly dousing him with kerosene and setting him on fire. We manipulated the kind and degree of the resulting dysfunction both by a description of the person's resulting mental experiences and the later testimony of a physician about what dysfunction the particular drug interaction would cause. Thus, we attempted to create perceptions that the involuntary intoxication experienced by the person brought about high or low cognitive or control dysfunctions. Our respondents' liability judgments regarding these scenarios are in Table 5.5.

Look first at the five scenarios ( 2 through 6 ) that involve involuntary intoxication. We consider these cases first because they are more closely analogous to the insanity cases of the previous study. For these cases, the civil commitment of the 
TABLE 5.5 Liability as Related to Immaturity and Involuntary Intoxication

(a)

\begin{tabular}{|c|c|c|c|c|}
\hline Scenarios & Liability ${ }^{a}$ & $\begin{array}{l}\text { \% No } \\
\text { Liability } \\
\text { (N) }\end{array}$ & $\begin{array}{c}\% \text { No Liability } \\
\text { or No } \\
\text { Punishment } \\
(\mathrm{N}+\mathrm{O})\end{array}$ & $\begin{array}{c}\% \text { Civil } \\
\text { Commitment }\end{array}$ \\
\hline \multicolumn{5}{|l|}{ Control: } \\
\hline $\begin{array}{l}\text { 1. Murder } \\
\text { Involuntary intoxication: }\end{array}$ & 10.42 & 0 & 0 & \\
\hline 2. High control & 5.00 & 7 & 44 & \\
\hline 3. High cognitive & 3.84 & 23 & 52 & \\
\hline 4. Low control & 6.19 & 0 & 26 & \\
\hline 5. Low cognitive & 6.83 & 0 & 20 & \\
\hline $\begin{array}{l}\text { 6. Low control and } \\
\text { cognitive } \\
\text { Immaturity: }\end{array}$ & 6.93 & 7 & 20 & \\
\hline 7. 10-year-old & $4.84(53 \%-8.94)$ & 47 & 47 & 47 \\
\hline 8. 14-year-old & $6.66(77 \%-8.77)$ & 23 & 23 & 23 \\
\hline 9. 18-year-old & $8.70(90 \%-9.26)$ & 7 & 10 & 7 \\
\hline
\end{tabular}

Liability Scale: $N=$ No criminal liability, $0=$ Liability but no punishment, $1=$ 1 day, $2=2$ weeks, $3=2$ months, $4=6$ months, $5=1$ year, $6=3$ years, $7=7$ years, $8=15$ years, $9=30$ years, $10=$ life, and $11=$ death.

${ }^{a}$ Civil commitment cases are included as 0 in calculating these means. The numbers in parentheses indicate the percentage of respondents who assigned criminal liability and, of those, the average liability they assigned.

perpetrator was not an option that made sense within the judicial system and, therefore, was not given to our respondents as an option. First, and obviously, the sentences are greatly reduced from the control case of murder (as is revealed in column a). Second, both cognitive and control dysfunction appear to support a defense. This is similar to the conclusion of the insanity study. Third, statistical analysis reveals that the high and low dysfunction cases differ reliably: The high dysfunction scenarios $(2$ and 3$)$ receive lower criminal liabilities $(p<.05)$ than the low dysfunction scenarios $(4,5$, and 6$)$. The type of dysfunction-cognitive versus control-is not found to produce reliable differences. The interpretation that arises from this, then, is that people do assess cases of involuntary intoxication in terms of the degree of dysfunction that such cases bring about, and those perceptions of the dysfunctions cause respondents to reduce the liability they assign to the perpetrator.

Before taking this conclusion at face value, we need to look at the respondents' actual ratings of the degree of dysfunction brought about by the different scenarios (shown in Table 5.6). As column $b$ indicates, the respondents certainly see the person in all of these scenarios as being intoxicated by the drug. They see him 
TABLE 5.6 Subjects' Perceptions of Immaturity and Involuntary Intoxication Cases

\begin{tabular}{|c|c|c|c|c|c|c|c|c|}
\hline Scenarios & $\begin{array}{l}\text { (a) } \\
\text { Age }\end{array}$ & $\begin{array}{c}\text { (b) } \\
\text { "Intoxicated" }\end{array}$ & $\begin{array}{c}\text { (c) } \\
\text { "Intoxication } \\
\text { Involuntary" }\end{array}$ & $\begin{array}{c}\text { (d) } \\
\text { "Unaware } \\
\text { of Actions" }\end{array}$ & $\begin{array}{c}(e) \\
\text { "Unaware of } \\
\text { Wrongfulness" }\end{array}$ & $\begin{array}{c}(f) \\
\text { "Understanding } \\
\text { Impaired" }\end{array}$ & $\begin{array}{l}(g) \\
\text { "Not Able", } \\
\text { to Stop" }\end{array}$ & $\begin{array}{l}\text { (h) } \\
\text { Ability to Stop } \\
\text { Impaired" }\end{array}$ \\
\hline \multicolumn{9}{|l|}{ Involuntary intoxication: } \\
\hline 2. High control & & 7.19 & 6.13 & 3.77 & 3.87 & 4.90 & 6.03 & 6.42 \\
\hline 3. High cognitive & & 7.90 & 6.52 & 7.00 & 7.10 & 7.13 & 6.74 & 7.10 \\
\hline 4. Low control & & 6.90 & 6.03 & 3.71 & 3.55 & 5.13 & 4.74 & 5.58 \\
\hline 5. Low cognitive & & 8.26 & 8.45 & 6.39 & 7.10 & 8.00 & 6.84 & 7.39 \\
\hline $\begin{array}{l}\text { 6. Low control and } \\
\text { cognitive }\end{array}$ & & 6.42 & 5.97 & 4.06 & 4.32 & 5.48 & 4.58 & 8.19 \\
\hline \multicolumn{9}{|l|}{ Immaturity: } \\
\hline 7. 10-year-old & 10.19 & - & - & 2.58 & 2.90 & 3.61 & 2.58 & 3.35 \\
\hline 8. 14-year-old & 14.13 & - & - & 1.74 & 1.90 & 2.42 & 2.00 & 2.19 \\
\hline 9. 18-year-old & 17.87 & - & - & 1.39 & 1.32 & 1.39 & 1.42 & 1.48 \\
\hline
\end{tabular}

Key to column heads:

All statements were responded to on a scale where: $1=$ "strongly disagree," $5=$ "unsure," and $9=$ "strongly agree."

(b) The actor was drug intoxicated at the time he performed the offense.

(c) The actor, if drug intoxicated, was not responsible for being drug intoxicated.

(d) Because of drug intoxication, the actor did not realize that he was committing the offense.

(e) Because of drug intoxication, the actor did not realize that committing the offense was wrong.

(f) Because of drug intoxication, the actor's ability to understand the wrongfulness of his conduct was substantially impaired.

(g) Because of drug intoxication, the actor lacked any ability to stop himself from committing the offense.

(h) Because of drug intoxication, the actor's ability to stop himself from committing the offense was substantially impaired. 
as comparatively less intoxicated in scenario 6, and since that involves low degrees of dysfunction, that is appropriate. Moreover, as column $c$ indicates, our subjects agree-somewhat grudgingly - that the offender is not responsible for being drug intoxicated in all of these scenarios.

Next, let us look at the individual scenarios and see what conclusions we can draw from them. The information in columns $d$ through $h$ tells us how these cases are perceived in terms of cognitive and control dysfunctions, with columns $d$ through $f$ relating to cognitive dysfunction and $g$ and $h$ relating to control dysfunction.

In the high control dysfunction case (row 2), respondents agree that the individual is tending toward being unable to stop (column $g$ ) and is also impaired in his ability to stop (column $h$ ). They also see the individual as being moderately cognitively aware; that is, they tend to disagree that he is unaware of his actions (column $d$ ), that he is unaware of the wrongfulness of those actions (column $e$ ), and that his ability to understand the wrongfulness of his actions is substantially impaired (column $f$ ). In this condition, it is reasonable to say that the respondents perceive that the individual has a modest degree of cognitive impairment and a higher degree of control dysfunction; in other words, that scenario is not inaccurately described as a "high control, low cognitive dysfunction" case. Persons perceived to have that level and kind of dysfunction by our subjects get a considerable reduction in sentence; certainly as compared to the control case of murder but also as compared to the low dysfunction cases. However, the liability rating of 5 ( 1 year in jail) is some distance from the sentence of no liability that many of the legal codes would give to an individual who has that dysfunction. Still, our respondents grant some considerable degree of validity to a defense based on a control dysfunction, which suggests that the legal codes that include a control prong in their formulations accurately represent community standards.

Look next at scenario 3, in which we attempted to create perceptions of a high cognitive dysfunction (an unawareness of the meaning or the wrongfulness of the harmful actions) and a low degree of control dysfunction. The respondents' ratings of the two statements on unawareness and the third on whether the individual is impaired in his ability to understand the wrongfulness of his actions all are high; clearly the case is perceived by our respondents, as intended, as one of high cognitive dysfunction. But the high ratings on the questions about whether the individual is able to stop the wrongful act indicate that the respondents see this case as one of high control dysfunction as well as one of high cognitive dysfunction. This means that, in this study, we were even less successful in creating a clear case of high cognitive dysfunction coupled with low control dysfunction than we were in the insanity study discussed previously. (Recall that it was demonstrated in that study that subjects do considerably reduce sentences for individuals who have high cognitive and moderate control dysfunctions.) Notice here that this individual receives a low liability rating of 3.84 (about 5.5 months in prison), which 
is the lowest sentence given in this study's various cases of involuntary intoxication. This makes sense, since the respondents see this individual as impaired on both of the prongs of the defense.

The fact that the present case of high cognitive dysfunction was also read by our respondents as having a high control dysfunction may tell us something interesting about their "theories of mental dysfunction." Intuitively, a person who is thinking so oddly as to be unaware of the wrongfulness of killing somebody may be seen by the respondents as not able to stop the action because he or she sees no moral need to stop it. To put it another way, one who is unaware of one's own actions and their wrongfulness has a cognitive dysfunction that may be seen by the respondents as also creating a control dysfunction. A similar pattern showed up in our insanity cases, in which the individual who is seen as highly cognitively dysfunctional is also seen as having a substantial although not complete control dysfunction (Table 5.1, case 6). Again, future research will need to examine the generality of this inferential pattern of individuals; it may not always occur. For instance, it might be an inference based on the particular disability or the substance that brought about the voluntary intoxication in this case. Still, the fact that it also occurred, although to a more moderate degree, in the insanity case suggests that this inference pattern might be general.

In the three involuntary intoxication cases in which we intended to communicate various kinds of low dysfunction levels (Table 5.6, rows 4 to 6), we notice that the respondents in fact perceive those cases as involving moderate levels of dysfunction of a rather generalized sort. Specifically, the descriptions of scenarios 4 and 6 caused the respondents to perceive a moderate degree of both control and cognitive dysfunction (columns $d$ through $h$ ). Intuitively in keeping with this, they do reduce the sentences given to those individuals as compared to the control case of murder (Table 5.5, case l-sentence of 10.42, above life imprisonment) or the case in which an 18-year-old, nonintoxicated individual committed the same act (case 9 , liability of 8.70 , or more than 25 years in prison). But the sentences are by no means minor ones, ranging around five years in prison, and relatively few respondents ( 20 to 26 percent) assign no liability or no punishment in these cases.

We should mark one anomaly that we cannot currently explain. In the "low cognitive" impairment scenario (5), the respondents perceive that individual as having a considerable degree of both control and cognitive impairment-yet gave that individual a relatively high sentence. Further research will be needed to clarify this finding. It is possible that the subjects saw something in the specifics of our description that led to this odd result.

Still, with some tentativeness, we can derive one conclusion relevant to code drafters. Our respondents seem to analyze involuntary intoxication cases as analogous to those of mental illness; the subjects use the same concepts of control and cognitive dysfunction that they employ for analyzing mental illness. This sup- 
ports the common practice of providing analogous conditions of exculpation in the general involuntary intoxication and insanity defenses.

It strikes us that some general comments may be in order on the exact circumstances that we created for the core scenario of the involuntary intoxication cases. Recall that the individual is taking a long-term drug for the control of pain, has not been warned by the physician as to the possibility of side effects, and takes an over-the-counter cold remedy that, in interaction with the pain medication, triggers the mental dysfunction. This case seems fairly far toward the involuntary end of a voluntary continuum that we will now suggest. Briefly, that continuum represents what a sensible person should know about what might happen to his or her mental state as a consequence of certain actions. Our actor, it seems to us, is relatively justified in not realizing in advance that the particular drug combination would produce mental dysfunction. He is, in other words, in a state of high dysfunction for involuntary reasons. Our previous study on voluntary intoxication showed what happens when the intoxication is more voluntary.

What can we conclude from our respondents' judgments of liabilities and associated perceptions of the immaturity cases? (Refer again to Table 5.6, scenarios 7 , 8 , and 9, which vary the control, or murder, case only as to the the age of the person.) Notice, first, the "age" column $(a)$ of the table; clearly the readers notice and can accurately report the age of the different persons in the scenarios. Also, columns $d$ through $h$ list respondents' perceptions as to the degree of awareness that the person has about the consequences and the wrongfulness of his actions. In general, these results tend to suggest that the youngest person is seen as comparatively less aware of the wrongfulness and likely consequences of his actions. He is less aware-but by no means unaware-all of the ratings stay well on the "aware" side of the scale midpoints.

Next, notice the civil commitment factor (column $d$ of Table 5.5). For the cases involving underage perpetrators, we asked whether the respondents would recommend some alternative, nonprison form of dealing with the offender, as is sometimes available in the juvenile criminal justice system. Notice that some of our respondents do indeed recommend this form of treatment for the underage offender; the younger the offender, the higher the percentage of those recommending civil rather than criminal commitment. For the 10 -year-old person, almost half of the respondents recommend this form of treatment.

Next notice the liability ratings assigned to the differently aged persons (Table 5.5, column $a$ ). Again, as in the previous study, the first number is the average liability assigned by all respondents, factoring in zero $(0)$ for those who selected the civil rather than the criminal commitment option; the parenthesized numbers report the percentage of respondents imposing criminal liability and, of those, the average sentence they would impose. Relatively severe sentences are given, and age makes little difference in this. This surprises us, and we would like to see if this result holds up in future research. However, tentatively, we will interpret it: The 
younger the perpetrator, the higher the percentage of respondents that would recommend that person to receive treatment that is alternate to criminal incarceration; however, for the majority of respondents who see criminal sentences as appropriate, youth does not decrease the duration of the sentence. Two possible interpretations strike us: The majority sees criminal incarceration as an appropriate vehicle for reform of the young individual, and they think that a long time in prison will accomplish this; or they see him as being just as incorrigible as an older offender would be, and they want to lock him away for a good long time. We suspect the latter.

As we mentioned in the introduction to this study, the treatment of juvenile offenders within the legal system is a topic of current discussion and controversy. Although our subjects are willing to assign some degree of cognitive and control impairment to 10- and 14-year-old youngsters, it may be that stronger inferences about impairment, or the lack of it, would be made from a consideration of the facts and circumstances of other particular acts of wrongdoing than those we have devised for this study. There may be instances in which a 10-year-old is judged both perfectly capable of being aware of the wrongfulness of a specific action and quite able to maintain the self-control necessary to avoid committing it. There also may be some instances in which an 18-year-old is seen to act without this awareness. If so, then some examination of these issues within the context of a trial might be the preferred procedure for judging the validity of the application of this defense.

\section{Study 13: Summary}

Our involuntary intoxication scenarios involved an interaction between a prescribed and an over-the-counter drug; one would want to have cases about other forms of involuntary intoxication before coming to any firm conclusions. That said, involuntary intoxication does seem to be judged by our respondents according to principles similar to those used for the general defense of insanity. However, our respondents are noticeably less willing to treat involuntary intoxication as a complete defense; it mitigates liabilities, but the liabilities assigned are still reasonably high. Further research is needed to determine whether this is the case in all instances of involuntary intoxication or if this was specific only to the cases we created.

The younger the offender, the higher the percentage of our respondents who recommend that the offender be treated in some alternative to the normal criminal justice system. However, for any of a number of reasons that we have discussed, those who would require that the offender be retained in the criminal justice system are willing to give that person, despite the age factor, sentences of more than twenty years. Much depends, we suspect, on the degree of rationality that the respondents attribute to the offenders, and that may not correlate well with the age of the offender. Much remains to be explored in further research on 
this topic, and we notice that the criminal justice system is in a somewhat unsettled state with regard to the treatment of youthful offenders as well.

\section{STUDY 14:}

\section{DURESS AND ENTRAPMENT DEFENSES}

In legal codes, another defense, duress, exculpates a person whose conduct otherwise would create liability. In duress, unlike in the insanity, immaturity, and involuntary intoxication defenses, the focus is not directly on the dysfunction caused but on the external pressures on the individual that might create reasons why he or she engaged in the otherwise punishable conduct. These pressures normally arise from the improper actions of other people and create such a force that even a reasonably resolute person, subject to those pressures, might succumb to them and violate a law. The bank manager who lets the burglars into the bank vault after hours because the burglars have kidnapped his family (and he believes that they will harm his family if he does not let them in) is an example of an individual who acts under coercion. The external pressure may cause coercion that, in turn, one might guess, causes an impairment of control analogous to the impairments excused under insanity or immaturity defenses. Statutes typically require that the force exceed a given level and reach a level of sufficient coerciveness to render the person blameless, before a defense is available. Frequently the definition of that level involves the familiar legal fiction of the "reasonable person." Under the Model Penal Code, for example, the force must be such "that a person of reasonable firmness in [the actor's] situation would have been unable to resist" (MPC $\$ 2.09$ ).

The case of the "entrapped individual" is sometimes thought to share a similar philosophical grounding; an individual who would not otherwise have committed the criminal act is led by abnormal circumstances into doing so. The possibility of entrapment arises when an agent of the government somehow lures or entices an individual into committing a crime. At the highest level of generalization, the entrapment doctrine gives a person a defense if a government agent induces or persuades that person to commit the offense. But as intuition would lead one to expect, entrapment statutes typically have additional limitations and restrictions that are taken into account. The defense is limited to instances of improper entrapment by a police officer, typically undercover; the same inducement by a private individual is not grounds for a defense. The inducement or persuasion of entrapment is not as compelling as the coercion typical of duress and does not seem to so clearly exculpate the acting individual.

The entrapment defense is almost unique to the United States, and there is a great deal of variety among different U.S. jurisdictions in defining it. The debated differences center around defining it in an appropriately limited way. Two general approaches are common. What may be called the "subjective formulation" of entrapment requires both that the person be induced to commit the offense by the 
police agent and that the person is not otherwise predisposed to commit the offense. Thus, under the subjective formulation, a career drug dealer cannot get an entrapment defense-even if the transaction was induced or encouraged by a government agent-because the dealer's previous transactions demonstrate predisposition.

Note that, somewhat counterintuitively, the subjective formulation of the entrapment defense does not have a specific requirement for the amount of pressure or enticement that was brought to bear on the person. As long as the person is not predisposed to commit the offense, any amount of pressure or inducement that successfully causes the person to commit the offense will provide a defense. The subjective approach focuses on both the police and the accused and requires two conditions for the defense to be successful-improper police conduct (conduct that would have caused a person not otherwise predisposed to do so to commit the offense) and no predisposition on the part of the defendant.

One 'senses that some competing policy considerations may be trading off within this formulation. On the one hand, one does not want the police to go around inducing criminal acts among citizens not otherwise predisposed to commit these acts. On the other hand, one recognizes that having undercover police officers purchase drugs or otherwise induce illegal transactions is sometimes necessary for catching career criminals. Letting off career criminals is too high a price to pay for deterring police entrapment practices, hence the exclusion (from the subjective formulation of the entrapment defense) of persons "predisposed to commit the offense."

A second common approach of entrapment defenses is what may be called the "objective formulation." Under this approach, the focus excludes whether the defendant was predisposed to commit the offense and focuses exclusively on the propriety of the government agent's conduct. Of course, the subjective approach also focuses on one aspect of the police officer's conduct-Is the conduct such that it would cause a person not predisposed to commit the offense to do so? The difference, however, is that the objective approach does not ask, in addition, whether the defendant was in fact predisposed.

A career drug dealer may get an entrapment defense under the objective formulation if the government agent's conduct is "improper." What conduct is "improper"? Under the Model Penal Code (which uses such an objective formulation), for example, a government agent acts improperly and may generate an entrapment defense for an offender if the agent induces an offender to commit an offense by: "(a) making knowingly false representations designed to induce the belief that such conduct is not prohibited; or (b) employing methods of persuasion or inducement that create a substantial risk that such an offense will be committed by persons other than those who are ready to commit it" [MPC $\$$ $2.13(1)(a)$ and $(b)]$. 
Note that the objective formulation seems somewhat more inconsistent with people's intuition. The first clause of the statute requires only that the false representation be designed to induce a belief that the conduct was not prohibited. The second clause requires only that the methods create a risk of inducing a person not ready to commit the offense to commit the offense. Thus, the statute does not require that the actual offender be brought to the belief that the action is legal or that the offender actually be persuaded or induced to commit the offense. That is, the defendant need not actually be induced by the agent; the person need only have committed the offense in response to certain actions on the part of the agent. For instance, a government agent may tell a habitual drug dealer that it is not illegal to sell a certain sort of drug. The dealer may know full well that it is illegal and yet escape liability for the act of selling the drug under the objective formulation of the defense because of the agent's knowingly false representation.

It may be apparent by now that the entrapment defense is not, strictly speaking, an excuse that exculpates the accused. It permits the person to escape from liability but does so for a variety of reasons relating to fairness and deterring governmental overreaching rather than the defendant's lack of blameworthiness. This is true of the subjective formulation as well as the objective formulation. No minimum coerciveness of the inducement is required. Nor is the defense available if the person succumbs to inducement from a private citizen-even under circumstances where the same inducement from a government agent would evoke a defense.

This study tested cases involving both duress and entrapment. First, we sought to determine whether the subjects would recognize a duress defense for coerced conduct and, if so, how much coercion would be required to evoke the defense. Second, and considerably more tentatively, we explored the related questions of entrapment. We sought to determine whether our subjects would recognize a defense under the various conditions of entrapment suggested by different formulations of the defense. That is, we sought to determine whether the subjects would see entrapping conditions as exculpating the person or, alternatively, whether they might reduce the person's liability because they saw mitigating if not exculpating conditions. We sought to examine as well whether the respondents' views correspond better with one or the other of the two formulations of the entrapment defense.

In this study, we gave subjects both duress scenarios with varying levels of coercion and entrapment scenarios with and without predisposition of the offender, with and without improper inducement by a government agent, as well as variations substituting a private citizen for the agent. The core story involved an individual who agrees to transport eight ounces of cocaine for another individual. We asked the respondents to tell us the degree to which they saw the person as being personally disposed to commit the crime that he commits, to rate the amount of 
coercion they saw exercised on the person, to judge whether a person of reasonable firmness would be coerced or induced to commit the same offense, and to indicate the degree of impropriety of the inducements that are held out to the person in committing the crime, as well as to assess the punishment that the person deserves, if any. Table 5.7 contains the respondents' judgments.

As to the duress defense, notice first that in the control scenario (row 1), in which the person commits the crime of transporting cocaine with no degree of duress or inducement, the liability our subjects imposed is 5.52, corresponding to a sentence of approximately 2 years. For contrast, take the most extreme duress case, that of high coercion (row 2) next. In this case an individual with no prior record transports the cocaine for an individual who threatens to kill his family if he does not do so. This high-coercion duress scenario gave liability results that are much lower than the control case, suggesting that the respondents see a considerable mitigation in this case; the average liability they assigned (column $a, 2.29$ ) is a sentence of 3.8 weeks. Notice also that 50 percent of the subjects assign no punishment to the offender.

As the degree of coercion decreases (the low-coercion case of row 3), the subjects assign a liability that is between that of the high-coercion and the control cases (3.65, corresponding to 4.4 months in jail). An examination of the distribution of the results provides no evidence of bimodality, which would have supported a "threshold" notion of coercion. It appears that here, as in other cases we have examined, the respondents are making continuous judgments of liability for cases in which the legal system imposes a threshold concept by requiring a fixed minimum coercion for a complete defense. Our respondents see degrees of coercion; the legal system sees either coercion or no coercion.

Examine next the ratings on the perceptions of the coercion cases (columns $d$ through $h$ ). In the case of high coercion, respondents are in agreement that the coercion is indeed high (column $d, 8.21$ on a scale in which $9=$ extreme coercion), and they are in agreement with the statement that it is sufficient coercion to cause any reasonable individual to succumb to it and commit the offense (column $e$ ). (But notice that the extent of the agreement is not strong, 6.31-where 5 $=$ unsure and $7=$ agree. Respondents mention such options as reporting the threat-making individual to the police.) Our case of low coercion, which involves a person smuggling cocaine because he would lose his job as a truck driver otherwise, is assessed by our subjects as a moderate to high coercion case (column $d$, 6.29-where $9=$ extreme coercion), and they are generally unsure whether it is enough coercion to get a reasonable person to commit the offense (column $e$, 4.88 , or quite near the "unsure" response). This suggests, in future research, cases of very low coercion be included to test the lower limits of the respondents' perceptions. There may be cases in which subjects recognize that some degree of pressure has been exerted yet do not grant the def ense of coercion. However, note that in one sense the pattern of results takes us in the opposite direction-to con- 
TABLE 5.7 Liability and Subjects' Perceptions as Related to Duress and Entrapment

\begin{tabular}{|c|c|c|c|c|c|c|c|c|}
\hline Scenarios & (a) & $\begin{array}{c}\text { (b) } \\
\% \text { No } \\
\text { Liability } \\
\text { (N) }\end{array}$ & $\begin{array}{c}\text { (c) } \\
\% \text { No Liability } \\
\text { or No } \\
\text { Punishment } \\
(N+0)\end{array}$ & $\begin{array}{c}\text { (d) } \\
\text { Amount } \\
\text { of Coercion }\end{array}$ & $\begin{array}{c}\text { (e) } \\
\text { "Reasonable } \\
\text { Person } \\
\text { Coerced" }\end{array}$ & $\begin{array}{c}(f) \\
\text { "Predisposition" }\end{array}$ & $\begin{array}{c}\text { (g) } \\
\text { "Improper } \\
\text { Inducement" }\end{array}$ & $\begin{array}{c}\text { (h) } \\
\text { "Reasonable } \\
\text { Person } \\
\text { Induced" }\end{array}$ \\
\hline $\begin{array}{l}\text { 1. Control- } \\
\text { no duress or } \\
\text { inducement }\end{array}$ & $5.52^{\mathrm{a}}$ & 0 & 3 & - & - & 5.58 & - & - \\
\hline $\begin{array}{l}\text { Duress scenarios: } \\
\text { 2. High coercion } \\
\text { 3. Low coercion }\end{array}$ & $\begin{array}{l}2.29^{c} \\
3.65^{b}\end{array}$ & $\begin{array}{l}9 \\
3\end{array}$ & $\begin{array}{l}50 \\
24\end{array}$ & $\begin{array}{l}8.21 \\
6.29\end{array}$ & $\begin{array}{l}6.31 \\
4.88\end{array}$ & $\begin{array}{l}2.32 \\
3.68\end{array}$ & $\begin{array}{l}8.09 \\
7.53\end{array}$ & $\begin{array}{l}6.32 \\
4.82\end{array}$ \\
\hline $\begin{array}{l}\text { Entrapment scenarios } \\
\text { 4. No prior } \\
\text { record-agent } \\
\text { 5. Prior record- } \\
\text { agent } \\
\text { 6. No prior } \\
\text { record-buddy }\end{array}$ & $\begin{array}{l}2.44^{c} \\
6.24^{a} \\
3.50^{b}\end{array}$ & 21 & 50 & 7.62 & 6.06 & $\begin{array}{l}2.79 \\
6.91\end{array}$ & $\begin{array}{l}8.18 \\
6.03\end{array}$ & $\begin{array}{l}5.91 \\
4.50\end{array}$ \\
\hline
\end{tabular}

Liability Scale: $N=$ No criminal liability, $0=$ Liability but no punishment, $1=1$ day, $2=2$ weeks, $3=2$ months, $4=6$ months, $5=1$ year, $6=3$ years, $7=7$ years, $8=15$ years, $9=30$ years, $10=$ life, and $11=$ death.

Key to column heads:

Statements (e) through (h) were responded to on a scale where: $1=$ "strongly disagree," $5=$ "unsure," and $9=$ "strongly agree."

(d) How much coercion (i.e., pressure or force) did the actor feel, from the accomplice, to commit the offense? ( $1=$ no coercion; $9=$ extreme coercion).

(e) The amount of coercion (i.e., pressure or force) from the accomplice on the actor would have been enough to cause a reasonable person in the actor's situation to commit the offense.

(f) The actor is generally inclined to commit an offense like this even if no one encouraged him to do so.

(g) The accomplice used methods of persuasion or inducement on the actor, to get him to commit the offense, that were improper.

(h) The accomplice used methods of persuasion or inducement on the actor, to get him to commit the offense, that would have caused a reasonable person to commit the offense.

Note: Superscript letters indicate significance at the $p<.05$ level by a Newman-Keuls test. Matching superscripts indicate means that are not statistically significantly different from each other. Means are compared within columns only. 
sider what degree of coercion is necessary to completely exculpate the defendant. Even our actor who experiences high coercion receives no punishment from only 50 percent of the subjects. This puzzles us, because the facts described in this scenario appear to be highly coercive-the respondents see them as highly coercive-and yet the offender does not receive complete exculpation.

Still, the degree of coercion that our subjects perceive as operating on the person makes a difference in the liabilities that our respondents assign. There is a second line of evidence that coercion makes a difference to our respondents. Look within the low-coercion condition (scenario 3); specifically, at the perceptions of whether a reasonable person would have been coerced in to committing the crime (column $e$ ). The extent to which the average subject judges that the degree of coercion would cause a reasonably firm individual to succumb to the pressure and the degree of liability assigned to the off ender correlate strongly. (Beta $=-0.48$, $\mathrm{F}(1,32)=9.62, p=.004$, with the negative sign indicating that the lesser the degree of coercion that the respondent sees exerted on the person to commit the criminal act, the longer the sentence he or she imposes on the offender for committing the act.)

We next look at the psychologically more complicated situation of entrapment to see if we can discern a pattern in the respondents' judgments. In scenario 4 , the driver, who has no prior record of an offense, is approached by an undercover government agent who was previously acquainted with him in the Navy. The driver is put under pressure by the agent to transport drugs. Scenario 5 is the same, except the respondents were told that the person has had prior convictions for transporting drugs. ${ }^{14}$ The liabilities assigned to the two cases are significantly different; the liability assigned to the person with the prior record is as high as (indeed, higher than) the liability assigned to the individual who commits the act with no inducement (control-case 1). Compare this result with that suggested by the objective formulation, which relies solely on the propriety of the conduct of the government agent. Quite clearly, the objective formulation does not accord well with our subjects' intuitions. For the objective formulation, the past convictions are irrelevant; what is critical is that the government agent approached the person and, in some sense, "lured" him into the behavior. Yet for our respondents, prior convictions are critical; the individual with a prior record is assigned a mean sentence of about four years, exceeding that assigned to the perpetrator in the control case; in contrast, the individual with no prior record is assigned a sentence that is sharply lower (between four and five weeks in prison).

The reason for this difference is probably found in the respondents' perceptions of the degree to which the criminal act resulted from the predispositions of the person. (Refer to column $f$ in which subjects were asked whether they agree that "the [individual] is generally inclined to commit an offense like this even if no one encouraged him to do so.") When the person has a prior history of similar offenses, the respondents interpret the person's current criminal action as springing from his predispositions (they agree with the statement that the action is due 
to the person's general inclinations), and they tend to think that the coercion would not have worked with a reasonable person (column $e$ ); they judge the criminality of the person accordingly. In contrast, when the person is a first-time offender (case 4 ), the coercive force of the inducements provided by the agent is seen as much more potent, and the assigned liability is accordingly reduced. These results are psychologically interesting: The discovery of prior convictions has caused our respondents to see that entrapment scenario quite differently from the others.

This is not to say that there is no concern that government agents are involved in the inducement process or are acting improperly. In cases identical in every other respect, a slightly greater mitigation of liability is given in the case of inducement by a government agent ${ }^{15}$ (case 4 ) than by a friend of the person (case 6 ), and the percentage of respondents who assign no punishment in the former case (column $c$ ) is much higher. However, an examination of the various other ratings of the two cases suggests that this may not be due to the fact that the inducer is a government agent; instead it may be because, knowing that the inducements came from a government agent who can be expected to be more skilled at the "inducement game," the amount of the coercion contained in the inducement is judged by the subjects as being slightly higher, the degree to which a reasonably firm person would succumb to the inducement is rated slightly higher, and so on.

Whatever the source of this slight difference in the liabilities assigned in these two nearly identical cases, the finding tends to undermine the validity of the entrapment defense generally-both the objective and the subjective formulations. The defense is available only for inducement by a police agent, yet the subjects see the definition of police versus nonpolice source of the inducement as not a major determinant of liability.

Much about the objective formulation is untested in this study and awaits further research. For example, such research might create cases in which the government agent entrapped but was not perceived as having coerced the person or in which the government agent violated one of the objective formulation's specific prohibitions, such as telling the person that the action was not illegal.

The subjective formulation of entrapment is this: A person, who is not predisposed to commit the offense, is induced (not coerced, as in the duress defense) to commit the offense by a police officer with methods that would have induced a reasonable person to also commit the offense. On initial examination of our data, the subjective formulation of the entrapment defense corresponds better to the subjects' view than the objective formulation. Of our three entrapment cases, scenario 4 draws on average the lowest liability assignment from our subjects-2.44 ( 4.9 weeks) -and the person is perceived as not predisposed to commit the crime (column $f$ ). Further, subjects tend to agree that a reasonable person in the same situation would have been induced to commit the crime (column $h$ ). Scenario 5 , in which the person, who has a prior record, is seen as predisposed and the inducement tends to be seen as not sufficient to cause a reasonable person to com- 
mit the crime, draws a sentence higher than our no-inducement control case (scenario 1)! Further analysis confirms that the degree of perceived inducement matters. Within entrapment scenario 4 , we examined the correlation between the agent providing an inducement and the degree of liability our subjects assigned to the induced individual [Beta $=--0.49, \mathrm{~F}(1,32)=9.62, p=.004]$.

Note that even the subjective formulation of entrapment does not find support among the subjects as a defense. The individual with no prior record who is lured by the government agent into committing the crime gets a liability rating of 2.44 (about 5 weeks in jail). This assignment of some liability on the part of our respondents suggests that they do not believe that a complete defense should be available in entrapment cases (as provided for in current doctrine) but believe that only a mitigation is appropriate. Moreover, recall also that the subjective formulation, like the objective formulation, stresses the importance of the inducer being a police agent; however, our subjects give only minor weight to that distinction.

We are tempted to ask whether, in terms of community standards, there should be an entrapment defense at all. One of the questions that awaits further research is whether one might explain the entrapment mitigations found in this study as reflecting the subjects' assessment of the degree of duress-like coercion that existed in the entrapment cases. Some of our results suggest that the subjects may recognize entrapment as a defense only to the extent that it would give a defense or mitigation under a duress defense (albeit a duress defense altered to take account of degree of coercion and to give mitigations for coercion that does not exculpate). If this were so, then, if one were to reform the criminal-law doctrine to conform to the subjects' views, one would expand the duress defense to provide a mitigation (but not a complete defense) in cases of high to moderate coercion. Having done that, one might then abolish the entrapment defense as unnecessary.

\section{Study 14: Summary}

This study confirms the fact that people do mitigate and exculpate for coercion. If duress is perceived, liability is lowered. An individual who is under quite high duress to commit a crime receives a significant reduction in liability but does not, as we might have expected, receive complete exoneration. The frequent use of the "liability but no punishment" option suggests that our respondents want to make it clear that they are not condoning the conduct, but such disapproval of the conduct does not diminish their willingness to exculpate the person. Recall that unlike insanity, which has a special verdict that signals the reason for the acquittal, a duress acquittal under the current system leaves the message about the conduct ambiguous. Thus, one would expect more resort to this particular verdict of, essentially, "rule violation but no punishment," under cases of duress than in insanity cases. The use of this option by our respondents shows no ambivalence about exculpating the person, we suggest, but rather ambivalence about apparently approving the conduct. 
With respect to entrapment, we found that both of the standard formulations, which emphasize the importance of the inducement coming from a police agent as well as the particular conduct of the police agent, do not have much effect on the liability judgments of our subjects. Instead, our subjects give a mitigation in those cases in which they believe the person is strongly coerced and in which they believe a reasonably firm person would also be induced to commit the crime. Thus, if the community's view was to be followed, the entrapment defense would disappear as a separate defense and be subsumed under the duress defense.

\section{CHAPTER SUMMARY}

The issues that we have addressed in this chapter are perhaps broader in scope than in other chapters, and much about these doctrines of excuse remains to be explored. Still, some conclusions seem reasonably well established. The disability caused by mental incapacity is recognized by our respondents as a valid reason to exculpate a person. Formulations of mental incapacity that recognize both a control and cognitive deficit are the preferred ones; the respondents seem to judge that dysfunction of either type is a valid trigger for exculpation. The greater the dysfunction, the greater the likelihood of a defense. In addition, respondents seem satisfied with a substantial rather than a complete dysfunction as establishing exculpation.

Involuntary intoxication is analyzed in legal codes on principles similar to the ones used for the analysis of mental illness, and this seems appropriate to our subjects. Their responses show a similar pattern of liability for involuntary intoxication as for insanity: They recognize both cognitive and control dysfunctions as an excuse and the greater the dysfunction, the greater the likelihood of exculpation.

Duress scenarios, our data reveal, are recognized as providing at least a mitigation of liability for offenses, and the degree of mitigation is a function of the degree of coercion that the respondents see in the particular situation. Whether duress can provide a complete excuse-in the community's view-awaits further research. Code formulations of the entrapment defense require that it be given only when a police agent supplies the inducement that leads the person to commit the crime, and our respondents did not see the importance of this requirement. Instead, they seemed to judge these cases using considerations similar to the ones they used in the duress cases, leading us to consider the possibility that the entrapment defense might properly disappear as a separate defense and be subsumed under the duress defense.

We suggest that our respondents often deal with their complex judgments about many of these excuse cases by giving a response that signals that they do wish to disapprove of the conduct, but they do not wish to do more than symbolically punish the person. 


\section{6}

\section{Doctrines of Grading: What Degree of Punishment Is Deserved for One's Blameworthy Violation?}

A legal code's grading of the seriousness of a blameworthy violation appears in two forms: within offenses and between offenses. Within a general offense such as rape or theft, it is often the case that the code makes some distinctions about the differential seriousness of different kinds of rapes or thefts. Different levels of punishment are attached to these different intra-offense gradings. Also, different types of offenses are given different grades, reflecting the relative seriousness of rape as compared to theft, for example.

We have touched on the issue of grading within offenses already. The factors that establish the minimum requirements for criminalization and for liability, discussed in the previous chapters, provide the starting point for grading within an offense. They establish the requirements for the lowest grade of any given offense. The determination of higher grades of the offense then requires consideration of various other factors. Nearly all jurisdictions recognize several grades of homicide: negligent homicide, manslaughter (paradigmatically reckless homicide), and murder (intentional homicide). It is also common to distinguish even within these categories. Some jurisdictions may recognize two grades of murder and of manslaughter-first and second degree. Thus, first degree murder might be reserved for the most brutal forms of murder. Other offenses also have higher grades contained within their definitions, such as aggravated assault. Rape may have three or four grades-the term "rape" sometimes being used only in relation to the most serious of these grades.

A second sort of question involves what might be called "comparative grading" across different offenses. This requires judgments about the seriousness of a particular offense in comparison to other offenses. Murder intuitively seems a more serious offense than rape, which seems a more serious offense than theft, and so on, and the criminal codes recognize this by classifying murder as a higher grade 
of offense than rape and rape a higher grade than theft, with a corresponding classification of each of the grades within each general offense.

Questions of offense seriousness and grading have become more important of late because of the move to standardize sentences by creating sentencing guidelines that judges must follow when they sentence convicted criminals. Factors that were once left to be considered by the sentencing judge in a highly discretionary judgment of how much punishment ought to be imposed are now articulated and given defined weight under modern sentencing guidelines. So, offense-grading principles, historically important in constructing criminal codes, have become important in the sentencing context.

The criminalization doctrines identify many of the most important factors in assessing the degree of punishment a person deserves-and thus what we might call the comparative grading of the offense-because they define the harm or evil of the offense. Interestingly, they frequently have done so by appeal to human intuition, although others have suggested that comparative grading is derivable from some more logical, less intuitive, analysis. Regardless of presumed source, it usually comes out that human safety is more important than the safety of property; intercourse with a 9-year-old is a more egregious wrong than intercourse with a 16-year-old. Assessing the relative seriousness of an offense requires an assessment of the relative value of the full range of interests protected by the criminal law. Criminal-law theorists have only recently attempted to formulate principles for determining the relative seriousness of violations, having relied previously on appeals to shared intuitions within the culture (see, e.g., Feinberg, 1984; von Hirsch and Jareborg, 1991).

The grading task for the code drafters, then, is twofold: to distinguish among distinct grades of an offense, specifying minimal requirements for the crime, and specifying the circumstances that will produce a more aggravated version of that crime; and also to put these individual crimes into some comparative relationship of seriousness. Many of the studies reported earlier in this book give a hint at the kinds of factors that are relevant to these tasks.

First, the greater the seriousness of the harm caused, the higher the grade assigned to the offense. "Seriousness" can be an intuitive notion, and people can differ on how "serious" a particular off ense (like theft) is, but it is clearly a notion that occupies a central place in a person's grading of offenses. Crimes in which life is risked or lost consistently receive more severe sentences than what we cannot help referring to as "lesser crimes." As we saw in our study on offense culpability requirements (Study 8), people regard a sexual offense, in which an individual who did not consent to intercourse is raped, as more serious than setting fire to a dwelling (in which people could conceivably be harmed), and setting fire to a dwelling, in which a person could conceivably be harmed, as more serious than setting fire to a similar site that is uninhabited. Second, similar notions of seriousness define the grades within a category of offense. The risk-of-harm study (Study 
2), for example, showed that subjects increase liability as the extent of the harm risked increases.

The operating principle used to grade between and within offenses appears to be the same: The greater the harm caused or risked, the greater the liability, all other things being equal. In Study 15, a study concerning sexual of fenses, we show just how refined the community's judgments can be in distinguishing among actions judged to be of different seriousness. We also show that the general principle of "greater harm means greater liability" applies as well to offenses, such as many sexual offenses, that are defined in terms of the depravity of the conduct rather than the harmfulness of the results of those actions.

A second powerful influence in grading is the person's culpability level. Several studies in the previous chapters (and particularly Chapter 4) have demonstrated that greater culpability in producing a fixed level of harm generally means greater liability. For instance, recall that greater liability is assigned to the accomplice who has greater culpability as to the perpetrator's offense or as to assisting a perpetrator (Study 9). Also recall the greater liability assigned to the individual who purposefully sets out to become intoxicated before he kills another, as compared to the individual who only knowingly or recklessly does so (Study 10). In Study 16 , we refine that discussion with an investigation of felony murder, a doctrine frequently criticized as deviating from the normal principles of culpability. The study's results suggest that the subjects make relatively refined judgments about culpability.

A third influence on grading is the actual presence of the harm or evil of the offense and the strength of the person's causal connection to it. This is a related but distinct factor from the nature of the harm or evil noted previously. We said that, for instance, intentional killing is perceived as more serious than theft and is therefore graded more seriously. The point is that, within the realm of intentional killings, an actual killing is assigned more liability than an unsuccessful attempt to kill. The attempt study (Study 1) demonstrates this point. We refine this notion in this chapter by showing that resulting harm provides increased liability-but only if the harm is sufficiently causally connected with the person's conduct. In Study 17, we present subjects' reactions toward different causal connections to a resulting death, which indicate that the stronger the causal connection with a resulting harm, the greater the increase in liability because of that resulting harm. This result was signaled in the objective requirements of complicity study (Study 3). Complicity is a form of causing an offense perpetrated by another person. The complicity study suggested that the greater the degree of the accomplice's causal contribution to the offense, the greater the accomplice's liability.

A fourth contributor in setting a person's ultimate punishment is the number of offenses for which he or she is to be punished. Consider the example of a headline which reads, "Burglar Who Committed 20 Burglaries Finally Caught." Obviously whether the burglar actually did commit the twenty offenses requires judi- 
cial determination, but suppose the system determines that the burglar did. Somehow this must be reflected in the sentence that the burglar receives. This goes somewhat beyond the issue of offense grading, but it is an essential part of setting the general range of punishment- the goal of the grading determination. In Study 18, we investigate a few of the basic principles involved in determining the range of punishment for multiple offenses.

\section{STUDY 15:}

\section{THE SERIOUSNESS OF THE OFFENSE-SEXUAL OFFENSES}

One of the major tasks of a criminal code is to identify the most significant factors that affect the seriousness of a criminal action and to define offenses in a way that incorporates these factors. Our first study in this chapter examines the grading of offenses within the category of sexual offenses. We selected these offenses because, intuitively, some of the judgments encased within some legal codes on these issues seemed "out of kilter" with the ways that ordinary people seem to think about these offenses in the 1990s.

Sexual offenses, as they are defined by the Model Penal Code (MPC, or "the Code"), are defined and graded around several central distinctions. For example, forms of forcible intercourse generally are treated as more serious than forms of consensual but unlawful intercourse, such as consensual intercourse with an underage partner. Within each of these groups (forcible and consensual intercourse), the Code adds several grading refinements and it is here that we think that the Code may contradict community standards. Forcible intercourse is deemed less serious if the victim is a voluntary social companion on the occasion of the crime or previously permitted the person sexual liberties [MPC $\S$ 213.1(1)]. Forcible intercourse is judged to be still less serious (indeed, is not a sexual offense but only simple assault) if the aggressor and the victim are married $^{\prime}$ or living together as married [MPC $\$ 213.1(1)$ and (2)]. However, if the same forcible intercourse occurs between a homosexual couple living together as married, it is not judged to be as serious as rape, because the relationship between the parties is not given legal standing in the Code. ${ }^{2}$

Cases of consensual intercourse similarly are distinguished in seriousness according to several factors. Intercourse with a partner under the age of 16 ("statutory rape") or with a mentally retarded female who is "incapable of appraising the nature of her conduct" is judged less serious than forcible rape but more serious than consensual intercourse by a female with a retarded male or consensual intercourse with a person who is in the person's legal custody (such as a prisoner is to a jailer). It is a complete defense to several offenses, including statutory rape, that the victim previously engaged promiscuously in sexual relations with others [MPC $\$ 213.1(1)(\mathrm{a})]$ and (2)(b), 213.3(1)(a), 213.4(2) and (8), and 213.6(4)].

Our sexual offenses study sought to test the offense distinctions used in the Model Penal Code against the community's views by presenting a series of sce- 
narios, each of which embodies one of the Code's distinctions. In this study, those who wrote the different scenarios allowed the circumstances of the scenarios to vary more widely than has been the case in many of the other studies, because they wanted the cases to have some overall plausibility. Thus, occasionally a codecommunity difference that we will report may be due to differences in scenarios other than the ones that are central to the legal issues that we are pursuing. When that is possibly the case, we will comment on it. The results of the study are described in Table 6.1.

The control case of "straight" rape involves a woman who is followed as she leaves her health club, forcibly detained in a deserted parking lot, and forced to have sexual intercourse by a man who threatens to kill her if she screams or resists him. Our respondents gave this act (Table 6.1 , case 1 , column $a$ ) a liability rating of 7.84, which corresponds to 13.4 years in prison. Examine next the case of the rape perpetrated by an individual who was out on a date with the woman, returns with her to her apartment, and rapes her there, the "date" case (row 2). The forcible intercourse mitigation that the Code recognizes for a voluntary social companion appears only as a slightly lower liability mean for that scenario than the control scenario, 7.26 versus 7.84 (9.4 years versus 13.4 years, $p<.11$ ).

This interpretation of the difference is complicated by the fact that the readers perceive a higher, although not significantly different, degree of consent on the part of the woman to the intercourse in the date scenario and also attribute a higher degree of causation to her as well. (Examine Table 6.2, scenarios 1 and 2, columns $b$ and $c$ for these results.) In future research, a date rape versus a stranger rape comparison should attempt to create similar perceptions of consent and causation in both instances, and see if any reduction of sentence for the offender remains. ${ }^{3}$ Still, one can say of these results that, even if the subjects see greater consent in the date context, they see it as having only a slight effect on liability, not such that would seem to support the grading difference assigned to the two cases by the Code. It may well be that our perceptions of the meaning of accepting an invitation to a date may have changed from those held at the time the Code's drafters developed these rules. Perhaps the point to extract is that community standards can change over time, and legal codes might properly change with them. The hint of a discovered difference between the two cases, if it can be replicated in future studies, provides some support for the grading difference that the legal code assigns to the two cases, but even so the extent of the Code's difference in its treatment between the two (maximum of life for first-degree versus maximum of ten years for second-degree offense) is much more of a difference than is justified in the subjects' view.

In the next two cases, the rape occurs between people who have been cohabiting. The woman tells the man with whom she has been living (case 3) or to whom she has been married (case 4) that she is leaving him and does not want to see him anymore. The conversation takes place in their residence and she asks him to 
TABLE 6.1 Liability for Sexual Offenses

\begin{tabular}{|c|c|c|c|c|}
\hline Scenarios & Liability & $\begin{array}{c}\text { (b) } \\
\text { \% No } \\
\text { Liability } \\
\text { (N) }\end{array}$ & $\begin{array}{c}\text { (c) } \\
\% \text { No Liability } \\
\text { or No } \\
\text { Punishment } \\
(N+0)\end{array}$ & $\begin{array}{l}\text { Model Penal } \\
\text { Code Result }\end{array}$ \\
\hline \multicolumn{5}{|l|}{ Forcible intercourse: } \\
\hline 1. Stranger & $7.84^{a}$ & 0 & 0 & $\begin{array}{l}\text { 1st-degree felony } \\
{[\S 213.1(1)(a), \text { rape] }}\end{array}$ \\
\hline 2. Date & $7.26^{a, b}$ & 26 & 29 & $\begin{array}{l}\text { 2nd-degree felony } \\
\text { [§213.1(1)(a)\&(ii), } \\
\text { rape] }\end{array}$ \\
\hline 3. Live together & $6.27^{b, c}$ & 26 & 31 & $\begin{array}{l}\text { Misdemeanor } \\
\text { [§2.11(1)(a), } \\
\text { simple assault] }\end{array}$ \\
\hline 4. Married & $5.68^{c}$ & 53 & 66 & $\begin{array}{l}\text { Misdemeanor } \\
\text { [§2.11(1)(a), } \\
\text { simple assault] }\end{array}$ \\
\hline 5. Homosexual & $5.58^{\mathrm{c}}$ & 53 & 66 & $\begin{array}{l}\text { 2nd-degree felony } \\
{[\S 2.13 .2(1)(a),} \\
\text { deviate sex by force] }\end{array}$ \\
\hline \multicolumn{5}{|l|}{ Consensual intercourse: } \\
\hline 6. Statutory & $2.29^{d}$ & 18 & 55 & $\begin{array}{l}\text { 3rd-degree felony } \\
\text { [§213.3(1)(a), } \\
\text { statutory rape] }\end{array}$ \\
\hline $\begin{array}{l}\text { 7. Statutory- } \\
\text { prior promiscuity }\end{array}$ & $2.39^{d}$ & 21 & 53 & $\begin{array}{l}\text { Complete defense } \\
{[\S 213.6(3)]}\end{array}$ \\
\hline $\begin{array}{l}\text { 8. Mentally } \\
\text { handicapped } \\
\text { female }\end{array}$ & $1.97^{d}$ & 34 & 63 & $\begin{array}{l}\text { 3rd-degree felony } \\
\text { [§213.1(2)(b), gross } \\
\text { sexual imposition] }\end{array}$ \\
\hline $\begin{array}{l}\text { 9. Mentally } \\
\text { handicapped } \\
\text { male }\end{array}$ & $1.37^{d}$ & 37 & 74 & $\begin{array}{l}\text { Misdemeanor } \\
\text { [§213.4(2), sexual } \\
\text { assault] }\end{array}$ \\
\hline 10. Female in jail & $1.82^{\mathrm{d}}$ & 37 & 63 & $\begin{array}{l}\text { Misdemeanor } \\
\text { [§213.3(1)(c), } \\
\text { seduction] }\end{array}$ \\
\hline
\end{tabular}

Liability Scale: $\mathrm{N}=$ No criminal liability, $0=$ Liability but no punishment, $1=$ 1 day, $2=2$ weeks, $3=2$ months, $4=6$ months, $5=1$ year, $6=3$ years, $7=7$ years, $8=15$ years, $9=30$ years, $10=$ life, and $11=$ death.

Note: Superscript letters indicate significance at the $p<.05$ level by a Newman-Keuls test. Matching superscripts indicate means that are not statistically significantly different from each other. Means are compared within columns only. 
(a) (b)

\begin{tabular}{|c|c|}
\hline $\begin{array}{l}\text { Ictor } \\
\text { rcedn }^{n}\end{array}$ & $\begin{array}{c}\text { "Victim } \\
\text { Consented" }\end{array}$ \\
\hline
\end{tabular}

Scenarios (b)

"ictim

$\begin{array}{lllll}8.18^{\mathrm{a}} & 1.37^{\mathrm{c}} & 1.82 & 2.55 & 1.47 \\ 8.13^{\mathrm{a}} & 1.87^{\mathrm{b}, \mathrm{c}} & 2.47 & 2.97 & 1.89 \\ 7.79^{\mathrm{a}, \mathrm{b}} & 2.32^{\mathrm{b}} & 3.95 & 2.97 & 2.87 \\ 7.82^{\mathrm{a}, \mathrm{b}} & 2.18^{\mathrm{b}} & 3.95 & 2.95 & 3.11 \\ 7.00^{\mathrm{b}} & 2.26^{\mathrm{b}} & 3.50 & 3.97 & 3.76\end{array}$

Forcible intercourse:
1. Stranger
2. Date
3. Live together
4. Married
5. Homosexual

Consensual intercourse:
6. Statutory
7. Statutory-prior promiscuity
8. Mentally handicapped female
9. Mentally handicapped male

$2.16^{\mathrm{C}}$

$2.26^{\mathrm{C}}$

$3.05^{\mathrm{C}}$

10. Female in jail

$$
\begin{aligned}
& 7.70^{\mathrm{a}} \\
& 7.63^{\mathrm{a}} \\
& 6.95^{\mathrm{a}} \\
& 7.08^{\mathrm{a}} \\
& 7.22^{\mathrm{a}}
\end{aligned}
$$

(d)

'Victim Should Have Struggled Moren

(e)

Victim Acted 'Victim Morally Capable of Inappropriately" Consent"

Key to column heads:

All statements were responded to on a scale where: $1=$ "strongly disagree," $5=$ "unsure," and $9=$ "strongly agree."

(a) The actor forced the victim to have sexual intercourse with him.

(b) The victim consented to have sexual intercourse with the actor.

(c) The victim's behavior caused the actor's actions.

(d) The victim should have struggled harder to prevent what happened.

(e) The victim acted in a way that is morally inappropriate.

(f) The victim was capable of meaningfully consenting to sexual intercourse.

Note: Superscript letters indicate significance at the $p<.05$ level by a Newman-Keuls test. Matching superscripts indicate means that are not statistically significantly different from each other. Means are compared within columns only. 
sleep in a different room or at a relative's home. Angered, the man comes into the bedroom, and they begin fighting. Then the story returns to the core, in which the man forces the woman to have sex and threatens to kill her if she screams or resists. Notice that the rejection of the man creates the possibility that the respondents would perceive the rapist as in the grip of an emotion, and perhaps they reduce the liability assigned for that reason. With that in mind, let us examine the results.

Notice first that the respondents agreed that in this forceable intercourse case, the man forced intercourse on the woman-but agreed less enthusiastically than in the stranger and date rape cases (Table 6.2, column $a$ ). They also perceive (column $b$ ) a low degree of consent on the part of the victim-but significantly more consent than in the stranger rape case. This may provide at least a partial account of why the subjects' liability means for stranger rape (column $a$ of Table 6.1, 7.84, or 13.4 years) and date rape (7.26, or 9.4 years) are noticeably higher than those for a couple living together $(6.27$, or 4.2 years) or for a married couple (5.68, or 2.4 years). But even with this possibility, the differences we found are not nearly so different as the Code provides when the aggressor and victim are married or living together: from first- or second-degree felony for rape of a stranger or date rape to a misdemeanor for forcible intercourse with a legal or common-law spouse (treated as simple assault, for which the maximum sentence is one year). This seems to us to suggest that a reexamination of the Code is in order.

If the Code regards forcible sexual intercourse between a couple who are married or living together as significantly less serious, this seems a judgment that is no longer in tune with the way people think. If the Code lowers the degree of the offense because the drafters were attributing an automatically higher degree of consent to the woman, this too seems inappropriate. Sadly, we have learned in the past few decades that spouses do batter, abuse, and rape their mates without regard for the lack of the victim's consent. The issue of consent is a judgment best left to the jurors who are privy to the details in each specific case.

The greatest difference between the Code's and the subjects' views of the forcible intercourse scenarios arises where the aggressor and victim are a homosexual couple living together. In this story (Table 6.1, case 5), the circumstances are the same as in the married couple story. One individual announces he wishes to end the relationship; angered, the other forcibly rapes him, threatening to kill him if he resists or screams. The subjects see the case as meriting essentially the same degree of punishment as that given in the case of forcible intercourse between a married couple ( 5.58 versus $5.68, p=n$ s). The Code, in sharp contrast, treats the married heterosexual case as a misdemeanor (simple assault), not a sexual offense at all, and the homosexual case as a serious sexual offense (deviate sexual intercourse by force), a second-degree felony. Clearly, a good deal of the reason for this lack of difference is that our respondents see the case of rape within marriage as much more serious than does the Code. A further reason is that our respondents 
are not assigning an increment in liability for the fact that the homosexual intercourse is "deviant" although the Code appears to. ${ }^{4}$

Disparities between the Code and the subjects also exist in the consensual intercourse scenarios. The two cases at issue here are the "statutory" and the "statutory with prior promiscuity" cases (Table 6.1, scenarios 6 and 7). In both, a 14-year-old girl initiates sexual intercourse with a 19-year-old boy. In the latter, she has a reputation for prior promiscuity. The Code gives a complete defense to the third-degree felony of statutory rape for the offender in the case of a victim's prior promiscuity, while the subjects see no significance in an underage victim's prior promiscuity ( 2.29 versus 2.39 , column $a$ ). The mean sentence in both cases is a bit less than four weeks, and more than half of the subjects would assign no punishment. The respondents' reasoning here seems clear. Given the specifics of the case (that the girl is 14, near the age of consent, and initiates the intercourse, that the boy is 19 , and that there is no suggestion of violence), the respondents do not regard the case as particularly serious whether or not there is prior promiscuity on the part of the girl. Notice that in these two scenarios-and these two only-the respondents tend to agree with the statement that the victim brought about the intercourse (column $c$ of Table 6.2). They also agree strongly that she had consented to it (column $b$ ); a sensible judgment, since they were told that the girl had initiated it. However, note the sharp difference in the relatively lenient sentence that our subjects assign (2.29, or 3.8 weeks in jail) and the third-degree felony liability (a five-year maximum) that the Code assigns in the case of the individual who has intercourse with a nonpromiscuous 14-year-old girl. As we said earlier, the respondents do not see this particular case of statutory rape as serious.

The Code classifies consensual intercourse with an underage female and with a mentally retarded female as the same grade, and the subjects also consider the latter (case 8) as approximately equal in seriousness to consensual statutory rape. (The liability difference between the two cases is not statistically significant.) Here it is important that we say more about the specifics of the mentally handicapped case. The degree of mental retardation or mental handicap is probably perceived by our subjects as mild, since the mentally retarded woman is described as able to attend physical therapy sessions at a local health club, and the case description makes it clear that the handicapped individual initiates the sex act with the man. Our respondents clearly perceived (column $b$ and $c$ of Table 6.2) that these circumstances, taken jointly, warrant the inference that the handicapped individual tends to play a causal role in bringing about the intercourse and certainly "consents" to the intercourse.

In these circumstances, the respondents do not view the male's participation in this case of intercourse as particularly blameworthy. This does not mean that people will never see intercourse with a mentally handicapped person as serious; another set of circumstances would probably lead to an inference of more serious wrongdoing. For instance, one would expect that a person who is extremely men- 
tally retarded would not be perceived as able to give meaningful consent to intercourse. However, the results do suggest that people are capable of making quite nuanced judgments in this area and resist seeing statutory rape or intercourse with a mentally handicapped person as always being as serious as a third-degree felony.

One obvious limitation on our results ought to be mentioned here; in our case of consensual intercourse with an underage person, the underage person is a 14-year-old teenager and is likely to be seen by the respondents as fairly adult in her decision-making capacities. Were the victim to be younger, one would expect that the subjects would see the offense in a more serious light. (So would the Model Penal Code; if the victim is less than 10 years of age, the Code moves the grade up to the same grade as for forcible rape of a stranger-first or second-degree felony [MPC $\$ 213.1(1)(\mathrm{d})]$. Similarly, the mentally retarded person also seems to be perceived as competent enough to give consent. However, the contradiction between our respondents' judgments on these two cases and the Code remains. The consensual statutory rape cases we presented-of the teenage girl or the mentally retarded individual-are cases that represent classes of cases that receive different treatment by our respondents than they are assigned by the Code. We will return to a discussion of what this suggests.

Turning to a comparison of cases 8,9 , and 10 , in the mentally handicapped male case (scenario 9), a female has sexual intercourse with a mentally handicapped male under the same circumstances as the previously described case in which the male has intercourse with a mentally handicapped female (scenario 8); and in the "female in jail" case (scenario 10), a female prisoner has sexual intercourse with one of the guards. The guard has supervisory responsibility over the woman, but there is no suggestion in the scenario that he has used his power to coerce the woman into intercourse (she consents to it). The Code finds differences between these three cases. Under the Code, consensual intercourse with a mentally retarded female is classed as a third-degree felony, while the same conduct with a mentally retarded male or with a person for whom the offender has custodial supervision is a misdemeanor. The subjects, in contrast, do not distinguish significantly between these three forms of consensual intercourse (mentally retarded male, mentally retarded female, and person in custody). Nor do they assign significant sentences to any of them; all persons receive a mean sentence of less than two weeks in jail, and approximately between two-thirds and threequarters of the respondents assign no jail term at all.

In these three cases, the respondents see the victim (or perhaps we should say the "victim") as giving consent to the intercourse. As an examination of the ratings in the "consent" column for these cases reveals, in all of these cases the respondents agree (Table 6.2, column $b$ ) that the "victim" has consented to the intercourse. An underlying issue here (that code drafters might raise) is the degree to which the consent is freely and competently given - that is, perhaps a reason- 
able person's interpretation of the perceptions of the perpetrator on this issue of consent. The legal code may treat other cases involving prisoners or mentally handicapped individuals differently because it regards those cases as involving a lower degree, or otherwise flawed case, of consent. If this is so, then code drafters might consider making the degree and quality of consent the explicit focus of the judicial inquiry rather than imputing different degrees of consent to the different categories of sexual offenses. Alternatively, this may be one of those cases in which there is a reasoned set of valid considerations for having the legal code contradict the intuitive judgments of respondents, in which case it would be useful to articulate those considerations.

Another important aspect of the results is that some major differences appear in punishment assignments between groups of our subjects. More specifically, the results reflect a dramatic disagreement in the amount of punishment imposed in the consensual intercourse scenarios. A majority of subjects would impose no punishment in any of scenarios 6 through 10 (see column $c$ of Table 6.1). Our examination of the distribution of punishment given by the subjects suggests two distinct camps of opinion among the subjects. While a majority of subjects impose no punishment, the subjects that do impose punishment impose liability in the 4 to 6 range ( $4=6$ months; $6=3$ years); no one in the study assigned punishment in the in-between range of 1 to 3 . One would have expected more sentences in this range if the distribution was of the typical normal curve pattern. ${ }^{5}$

Obviously, this finding arises mainly from the cases in which the lower liability assignments were made. This is one of the few times in our studies that we have found a relationship that suggests that subsets of subjects see the situation differently. The grounds for this result will need to be addressed in future research. One obvious hypothesis, that males and females are seeing the situation differently, seems not to be the case. ${ }^{6}$ A related possibility is that a small subset of our sample regards sexual congress with an underage or mildly retarded person as a scrious offense while most others do not. Further research is needed to understand this difference and the possible attitudinal sources of it.

\section{Study 15: Summary}

The results of the sexual offenses study suggest that the subjects agree with some of the distinctions contained in the Code but not others. Of the scenarios tested, all forms of forcible intercourse are viewed by the subjects as more serious than any form of unlawful consensual intercourse. The subjects do not, however, recognize the Code's significant reduction in liability for forcible intercourse with a social companion, nor do they provide as much reduction as the Code does for forcible intercourse with a spouse. The Code defines a marital-like relationship of a heterosexual couple as receiving a greater mitigation than our subjects would grant in the seriousness of forcible intercourse. Yet, at the same time, the Code disregards a marital-like relationship of a homosexual couple, treating the offense 
as if it is one between strangers, though our subjects would treat the case as analogous to that of a married couple. These differences between the Code and our subjects may reflect a change in public attitudes since the late 1950s, when the Code was drafted.

The subjects see as less serious than the Code does all forms of consensual intercourse, and most of the Code's distinctions in this area are not particularly significant to the subjects. In our respondents' view, consensual intercourse with someone under 16 years of age is seen as only slightly more serious than other forms of consensual intercourse. Contrary to the Code's rule, our subjects judge prior promiscuity of the underage partner as having no such mitigating effect, although there is the possibility that this is true because the sentence assigned the non-prior-promiscuity is so low as not to be much reducible. In the context of consensual intercourse as well, the distinctions that the Code uses-prior promiscuity of a statutory rape victim, female versus male mentally handicapped victim-and its more serious treatment of all forms of unlawful consensual intercourse may reflect public opinion as it was before 1962. More than three decades have passed since then, and public opinion has shifted. Even in the several years since this data was collected, state code reforms have nearly eliminated use of the Model Penal Code's spousal exception to rape as well as other traditional formulations of sexual off enses. Thus, state legislatures appear to have been sensitive to the changing public views revealed by these results and have reformulated their codes accordingly.

Another more complex explanation of the differences between the Code and the subjects' responses is that the Code standards were based on a mix of two considerations-first, assumptions about what the degree of consent was likely to have been, as inferred from the nature of the existing relationships between the two individuals; and second, notions concerning "a husband's rights" and the "unnaturalness" of any homosexual relationship. It would be useful, in future research, to see if individuals who differ on these attitudes also differ in their liability assignments to specific rape scenarios. But we would continue to suggest that it would probably be useful, to the degree to which codes were based on what seem to us to be outmoded notions, to revise the Code to reflect changes in community views. If codes are instantiating notions about what degree of consent is assumed to exist in different relationships, it might be better to deal directly with consent issues in the context of the specific trial rather than infer them from relationships.

Should the Code be drafted in terms of the ultimate issue of effective consent, rather than using substitutes for consent such as age, mental handicap, or position of power disadvantage? In an age in which sexual harassment is a commonplace issue, this is a remarkably timely question. Some might suggest that these objective substitutes are needed because a person uses them to know whether the partner is capable of, and in a position to, give effective consent. In 
this way, we avoid punishing persons who are honestly mistaken about effective consent. But an alternative approach to protect these same persons from liability is available: to rely on culpability requirements to exculpate for a mistake. To be logically consistent, however, this might mean that the culpability requirement would need to be restored for statutory rape, for example, from which it frequently has been removed.

We have offered the suggestion that community standards about sexual offenses may have changed over the past few decades. Not all offenses are likely to be the subject of significant changes in public opinion, but a mechanism ought to exist that will detect such changes and signal a need for code drafters to reexamine the offense definitions. This is one important function of increased social science research on community views of criminal liability and punishment.

\section{STUDY 16:}

\section{THE CULPABILITY OF THE PERSON-FELONY MURDER}

One person causes the death of another. As common intuition suggests, the legal codes concern themselves with exactly how this came about and assign different degrees of liability depending on the answer. Specifically, the standard grading differences among homicides tie the degree of liability to the level of a person's culpability as to causing the death. As is familiar to the reader by now, a person who purposely or knowingly causes a death is liable for murder; one who recklessly causes a death is liable for manslaughter; one who negligently causes a death is liable for negligent homicide; and the grade of the offense in each instance is diminished. ${ }^{?}$

When an accomplice is involved in the homicide, similar considerations of culpability are used. Specifically, the culpability level of a person who assists the principal (an accomplice) as to causing another's death is determinative of the degree of liability. Like the principal, an accomplice who is purposeful or knowing as to the homicide is liable for murder; one who is reckless is liable for manslaughter; and one who is negligent is liable for negligent homicide. ${ }^{8}$

But for a certain kind of homicide-when the homicide occurs during the commission of a felony - the consideration of either the principal's or the accomplice's degree of culpability abruptly stops; any homicide of this kind is considered to call for the penalties assigned for murder. Most jurisdictions have a special doctrine, called the felony-murder rule, that holds a person liable for murder, without regard to his level of culpability as to causing the death, if that person causes the death in the course of a felony. ${ }^{9}$ Thus, an offender's negligent killing that would otherwise be punished as negligent homicide is treated as murder if it occurs during a robbery. ${ }^{10} \mathrm{~A}$ second aspect of the felony-murder rule applies this aggravation of culpability to accomplices as well. Thus, an accomplice in a robbery is liable for murder, although he assists a principal who is only negligent as to the killing and is himself (the accomplice) only negligent as to such a death." 
Initially, one intuitively sees the point of this. Assume I am robbing a bank and fire a warning shot into the floor, but I have used such a powerful pistol that the shot ricochets and kills some innocent customer to my surprise. The force of the claim that I have committed a more serious offense than negligent homicide is clear. I have created a situation fraught with danger and should pay the price when the potential harm is realized. Still, one also understands why the case is still distinguishable from intentional killing (murder) in a way that suggests lower liability.

The felony-murder rule is still broader in some jurisdictions, and it seems to move even farther away from our intuitions. Some jurisdictions hold felons liable for a death caused by an innocent person who resists the intended felony. ${ }^{12}$ Thus, in the case in which a person who is being robbed draws a gun and accidentally kills an innocent bystander, the robbers are held liable for murder for the killing of the bystander by the robbery victim. A specific case will make the operation of the rule clear and also will help explicate why it causes us uneasiness. Two thieves have tunneled into a bank vault and are surreptitiously hauling away cash. Alerted by a silent alarm, two independent private security groups rush to the scene, each unaware of the other. In the confusion, a member of security force $A$ shoots and kills a member of security force $B$. The thieves, neither of whom are armed, are charged with murder. Now clearly, the thieves created the occasion for the accident and are in some very basic and central way responsible for the outcome, but it does not seem intuitively obvious that the right decision is to assign them the same penalty we would assign a thief who shoots the security guard.

In some jurisdictions, the rule goes yet farther. It has been applied to both killings of an innocent and killings of one of the felons. ${ }^{13}$ In this latter case, it is felony murder for the surviving robber if a robbery victim pulls out a hidden gun and kills one of the robbers in self-defense; that is, some jurisdictions hold surviving robbers liable for murder for the death of their fellow robber. Consider the case: I and my accomplice are stealing valuable property from a warehouse at night. A security guard approaches to apprehend us, and my accomplice unwisely attacks the guard while I cower in the corner. The guard shoots the accomplice, kills him, and I am charged with murder. Intuitively, this seems a bit severe.

It seemed severe to the Model Penal Code drafters as well. The Code drafters disapproved of the felony-murder rule, even in its most narrow form. They substituted an evidentiary presumption, rebuttable by the defendant, that if a killing occurs in the course of a felony, the felons are presumed to have caused the death "recklessly under circumstances manifesting an extreme indifference to the value of human life," which it defines as adequate culpability for murder [MPC $\S$ 210.2(1)(b)]. Commentators similarly criticize the felony-murder rule and have applauded the Model Penal Code's rejection of it. ${ }^{14}$ Finkel (1990) has provided a forceful analysis of the complexities and apparent contradictions in the various courts' holdings in the felony-murder matter, and the degree to which the felony- 
murder rule seems to contradict community sentiment. Both code drafters and commentators argue, in part, that the rule fails to accurately assess the felon's degree of blameworthiness. That is, they concur with what we would expect ordinary people's intuitions would be about the blameworthiness of the individualwho admittedly caused the state of affairs that led to the death but did so in ways that cause us to wish to distinguish that case from a prototypical case of murder.

Interestingly, this is one of the instances in which the code drafters and the commentators have had little effect on state criminal codes. The enduring popularity of the felony-murder rule is reflected in the fact that although more than over two-thirds of the states have recodified their codes to adopt the Model Penal Code's general structure, a majority have insisted on reinserting felony murder. Could this be because we misunderstand community standards about this issue? Does the community wish to impute the penalties for murder in the cases we have discussed? Or, might those legislators be wrong in believing that their constituents would insist on such a rule? Another perspective suggests itself. A broad felony-murder rule, while in some general sense unjust, is a useful additional deterrent that might make felons more careful during the commission of a felony, or better yet, might make them not commit the felony in the first place. Relatedly, it does give the prosecution a heavy weapon to bring into play during pretrial maneuvering on crimes in which a death has occurred; various individuals who have played some subsidiary role in a crime that has led to a death can be threatened with murder liability if they do not cooperate with the prosecution.

We will first examine the community view on the various possible instances in which the felony-murder rule could come into effect and then say more about the sources of the rejection of the Model Penal Code position.

Subjects in this study were presented with a variety of felony-murder scenarios and three control cases (Table 6.3). The control cases give us the baseline liability that our respondents assign for standard murder (scenario 1), for manslaughter (scenario 2), and for negligent homicide (scenario 3). The liability-punishment results in the felony-murder scenarios (cases 5 through 11) can then be compared to the three controls to determine which of those controls the subjects see each felony-murder scenario as more akin to, murder, manslaughter, or negligent homicide.

Look first at the control scenarios. In scenario 1 , an individual deliberately purchases a gun and kills his best friend, at whom he is angry. The respondents, not unnaturally, see this as a case of deliberate murder (the culpability rating in column $d$ is 1.64 , with $1=$ purposeful and $2=$ knowing) and assign an average punishment (column $a$ ) to the killer of between life imprisonment and death. When an individual recklessly fires a gun at a noisy and drunken party in a nearby house (case 2 ), the offender is seen by our subjects as reckless $(3.29$, with $3=$ reckless and $4=$ negligent) and deserving of a penalty of 9.08 , or approximately 30 years in prison. This, then, is the punishment we would expect if a person commits man- 
(a)

(b)

(c)

(d)

(e)

(f)

(g)

$\begin{array}{ccccc}\text { Principal } & \text { Accomplice } & \text { Defender Culpability Culpability Culpability } & \begin{array}{c}\text { Legal Treatment } \\ \text { Under Felony }\end{array} \\ \text { Liability } & \text { Liability } & \text { Liability of Principal of Accomplice of Defender } & \text { Murder Rule }\end{array}$

Scenarios

Liability

of Principal of Accomplice of Defender

Murder Rule

1. Purposeful killing

$10.39^{\mathrm{a}} \quad 10.39^{\mathrm{a}}$

1.64

3.29

4.00

Murder

2. Reckless killing

$9.08^{\mathrm{b}, \mathrm{c}, \mathrm{d}}$

$9.08^{\mathrm{a}}$

Manslaughter

3. Negligent killing

$4.58^{f}$

$4.58^{\mathrm{d}}$

Negligent homicide

4. Purposeful shooter, purposeful co-felon, owner victim

$10.11^{a, b} \quad 9.56^{a}$

1.43

1.54

Murder

5. Negligent shooter, negligent co-felon, owner victim

$8.78^{\mathrm{c}, \mathrm{d}} \quad 7.31^{\mathrm{a}}$

3.86

3.91

Murder

6. Purposeful shooter, Negligent co-felon,

owner victim

$10.08^{a, b, c}$

$6.92^{\mathrm{b}}$

1.76

3.83

Murder

7. Negligent shooter, purposeful co-felon, owner victim

$8.53^{d}$

$9.11^{\mathrm{a}}$

4.00

2.19

Murder

8. Purposeful but innocent shooter, purposeful co-felon, felon victim

(killed)

$5.25^{c, d}$

0.69

2.11

1.97 Murder*

9. Purposeful but innocent shooter, negligent co-felon, felon victim

$\begin{array}{lll}\text { (killed) } \quad 4.97^{\mathrm{d}} & 0.67\end{array}$

$\begin{array}{lll}\text { (killed) } \quad 4.97^{\mathrm{d}} & 0.67\end{array}$

3.71

2.11 Murder* 
10. Negligent but innocent shooter, purposeful co-felon, felon victim

(killed) $\quad 5.39^{\mathrm{c}, \mathrm{d}} \quad 0.51$ 1.89

11. Negligent but innocent shooter, purposeful co-felon, owner victim

Liability Scale: N=No criminal liability, $0=$ Liability but no punishment, $1=1$ day, $2=2$ weeks, $3=2$ months, $4=6$ months, $5=1$ year, $6=3$ years, $7=7$ years, $8=15$ years, $9=30$ years, $10=$ life, and $11=$ death.

Note: Superscript letters indicate significance at the $p<.05$ level by a Newman-Keuls test. Matching superscripts indicate means that are not statistically significantly different from each other. Means are compared within columns only. In addition, no subjects gave either No Liability (N) or Liability but No Punishment $(0)$. The columns indicating $(N)$ and $(N+0)$ have therefore been left out of this table, as all percentages were 0 . Culpability of principal (column $d$ ), accomplice (column $e$ ), and defender (column $f$ ) were scored on the following scale:

$1=$ The actor wanted to kill the victim (purposeful).

$2=$ The actor was practically certain that his conduct would cause the victim's death (knowing).

$3=$ The actor was aware of a substantial risk that the victim would be killed (reckless).

$4=$ The actor was not aware of a substantial risk that the victim would be killed but should have been aware (negligent).

$5=$ The actor was not aware of any substantial risk that the victim would be killed and a reasonable person in his situation would not have been aware of such a risk (faultless).

*Only under the broader forms of the felony-murder rule, where the rule is applied to killings by nonfelons. 
slaughter-the reckless killing of another person. ${ }^{15}$ When the person fails to check on whether the gun is loaded and accidentally kills a friend (case 3), the respondents judge that he should have been aware of that risk and therefore was culpably negligent (their culpability rating was 4 , and $4=$ negligent) and assign punishment of 4.58 (9.6 months). These controls provide reference points against which we can evaluate the sentences assigned in the various felony-murder cases.

We next examine the felony-murder cases. Looking back, we see that we created a number of cases in which the differences between them, which are critical to our analysis, are quite difficult for the reader to understand. (And in retrospect, conceivably, quite difficult for the writers to understand as well.) For that reason, we will walk through them in some detail. Begin with cases 4 through 7 , all of which share a common core. Two men set out to rob a liquor store, carrying guns. One or both of them plan to shoot the owner if he does not turn over the cash fast, or one or both do not plan to shoot the owner but simply plan to menace him with what they think is an unloaded gun. The owner is slow about turning over the cash, and one of the robbers, whom we have labeled the principal or "shooter," shoots him. This is true even if the principal did not plan originally to shoot the owner. To go on in a slightly tedious fashion, this creates four cases in which the principal does shoot the owner: The principal did or did not plan to shoot the owner and the accomplice did or did not plan to shoot the owner. In the cases in which the person, whether principal or accomplice, did not plan to shoot the owner, we thought that he would be perceived as negligent with respect to causing death and perhaps draw a reduced sentence. For all of these cases, the felonymurder rule grades the offense as murder.

Look at the liability results for cases 4 through 7 (column $a$ ). There are a number of questions that we can ask of these data. Let us start with a relatively simple one. In each case, the perpetrator, purposefully or negligently, is the one that shoots the owner; the accomplice does not. Does this perpetrator-accomplice distinction make a difference in liability assignments given by our respondents?

As Figure 6.4 reveals, it does. The figure is made by simply averaging the four sentences given to the perpetrator and the four given to the accomplice in the four symmetric cases of scenarios 4 through 7 . As can be clearly seen, the perpetrator receives a higher average sentence. The principal, even though he sometimes does not plan to do so, does pull the trigger and shoot the owner; the accomplice, even though he sometimes plans to do so, does not. The legal doctrine, in contrast, fails to recognize such a mitigation for an accomplice. Standard complicity rules, such as those in the Model Penal Code, hold the accomplice liable as if he were the principal; our respondents do not. This result is consistent with the "complicity discount" that we have seen in other studies, for instance, Study 3, Objective Requirements of Complicity (Chapter 2) and Study 9, Culpability Requirements for Complicity (Chapter 4 ). However, in a more global sense, our respondents and 
FIGURE 6.4 Liability as a Function of the Role of the Actor

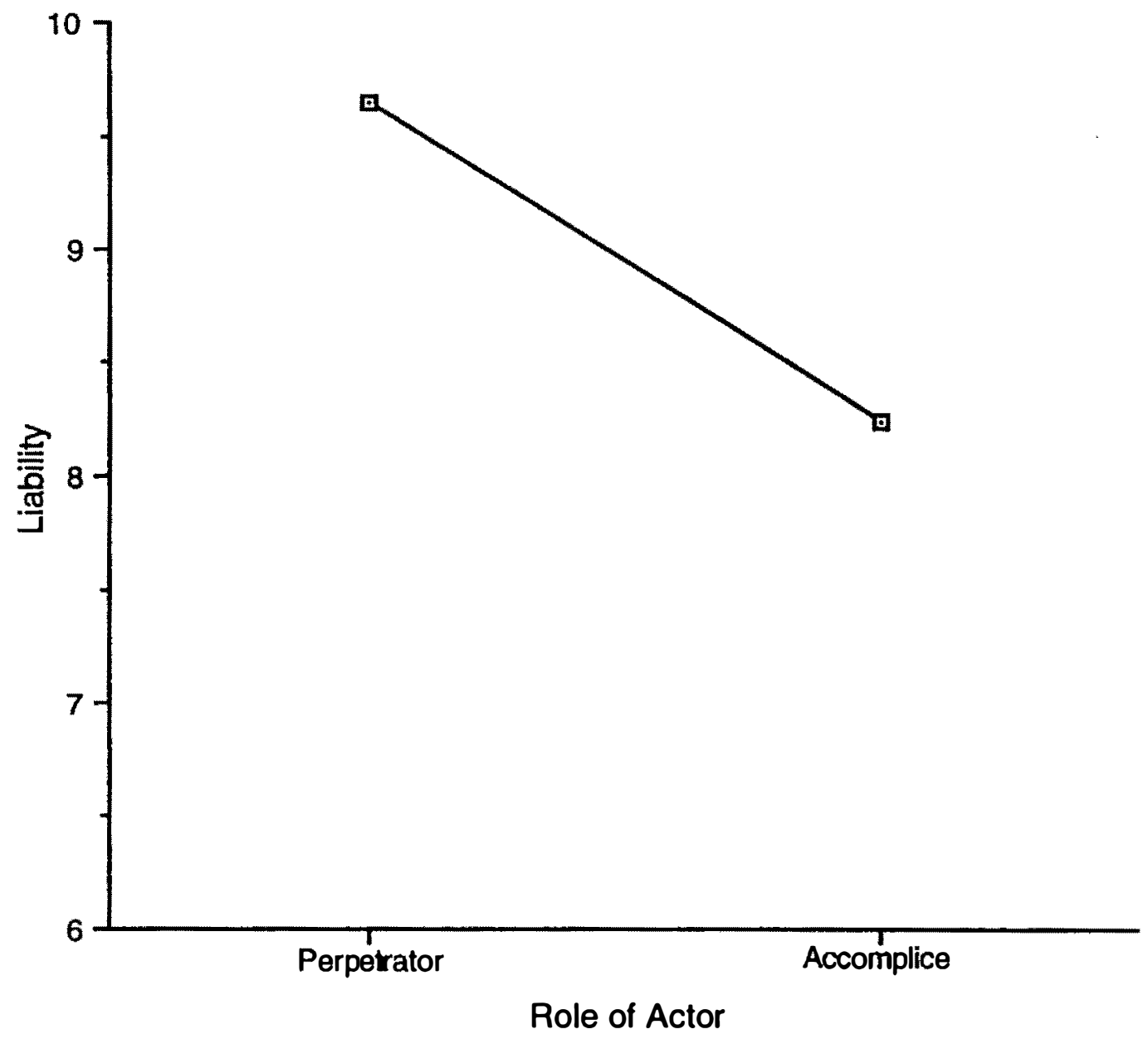

the various versions of the code are in accord: All give a very high sentence to both the principal and the accomplice.

A useful next question to ask is whether the state of mind as to causing death with which the two robbers enter the situation makes a difference to our respondents. Variations in the story made the accomplice or the principal either negligent as to the death because he had no plan to shoot or purposeful as to causing the death because he had plans to shoot. In Figure 6.5, we have simply averaged the liabilities assigned to those who plan to kill, whether perpetrator or accomplice, and those who do not.

Obviously, state of mind matters. Those who plan to kill receive higher average sentences than those who do not plan to kill.

Averages can be built up from more than one pattern of differences, and both Figure 6.4 and Figure 6.5 present averages. Thus, we need to look at the various cases that make up the averages, to see if anything is hidden by the averaging process. Figure 6.6 shows the results of the four cases that are averaged in Figures 6.4 
FIGURE 6.5 Liability as a Function of the State of Mind of the Actor as to Killing

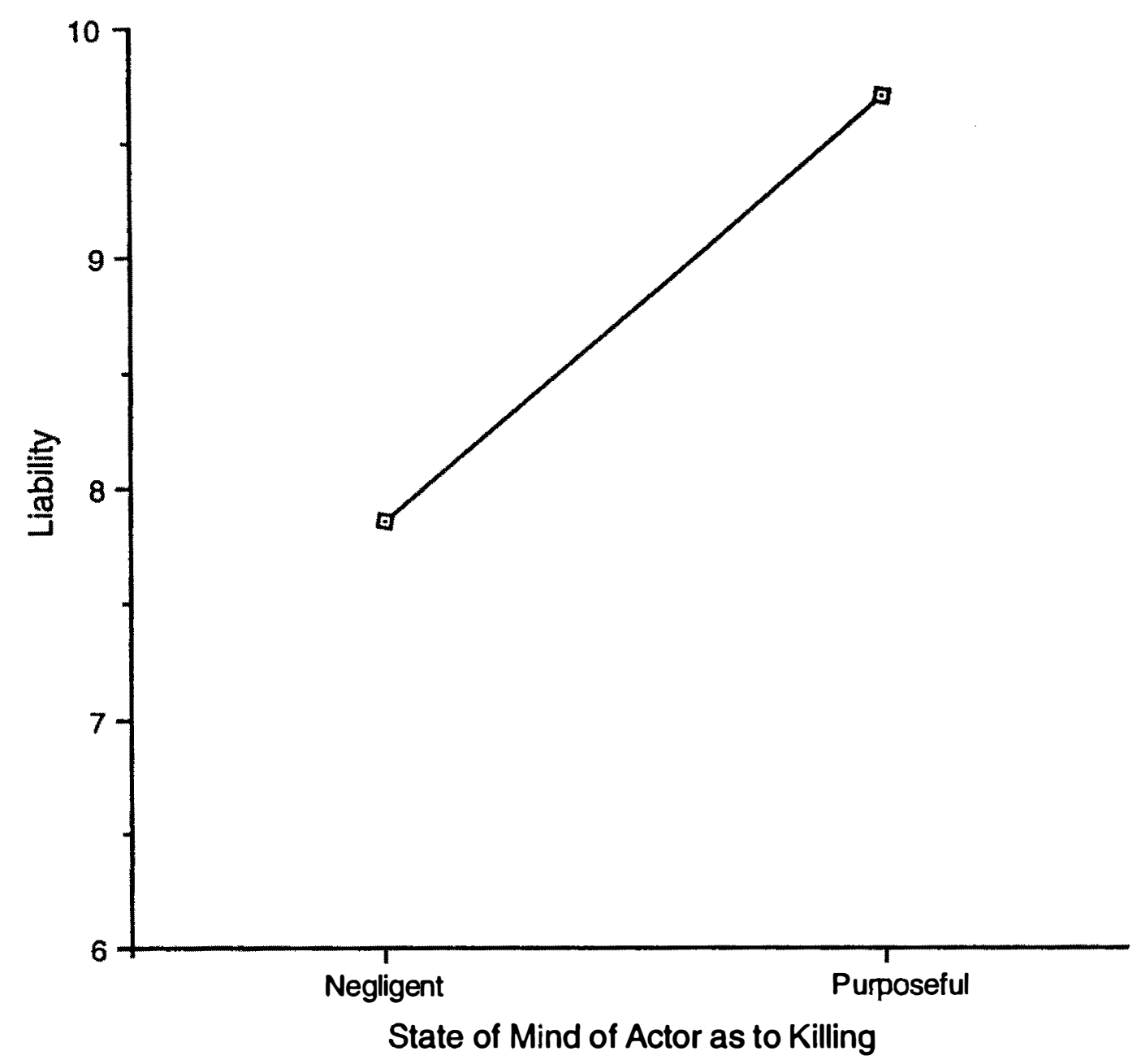

and 6.5. Our look can be mercifully brief, because the figure indicates that the individual cases are rated about as we would expect, based on the two rules we articulated: The shooter gets a higher liability than the one who does not shoot, and a person who plans to shoot gets higher liability than one who does not plan to shoot. In the figure legend, we first indicate whether the principal is purposeful or negligent with respect to the shooting and indicate second whether the accomplice is purposeful or negligent with respect to the shooting. Thus, for instance, the line labeled "Purp-Neg" is the one that charts the results of the case in which the principal plans to shoot and the accomplice does not (or scenario 6 of Table 6.3).

Three of the lines give a lower sentence for the accomplice, as we would expect from the joint operation of the two rules. The only case in which the accomplice draws a higher liability than the principal is the one (corresponding to scenario 7) in which the principal does not plan to shoot and the accomplice does plan to, which is the case in which we would expect this reversal to happen. This being the case, it is fair to summarize the results as follows: Respondents assign more liabil- 
FIGURE 6.6 Liability as a Function of Role and State of Mind as to Killing

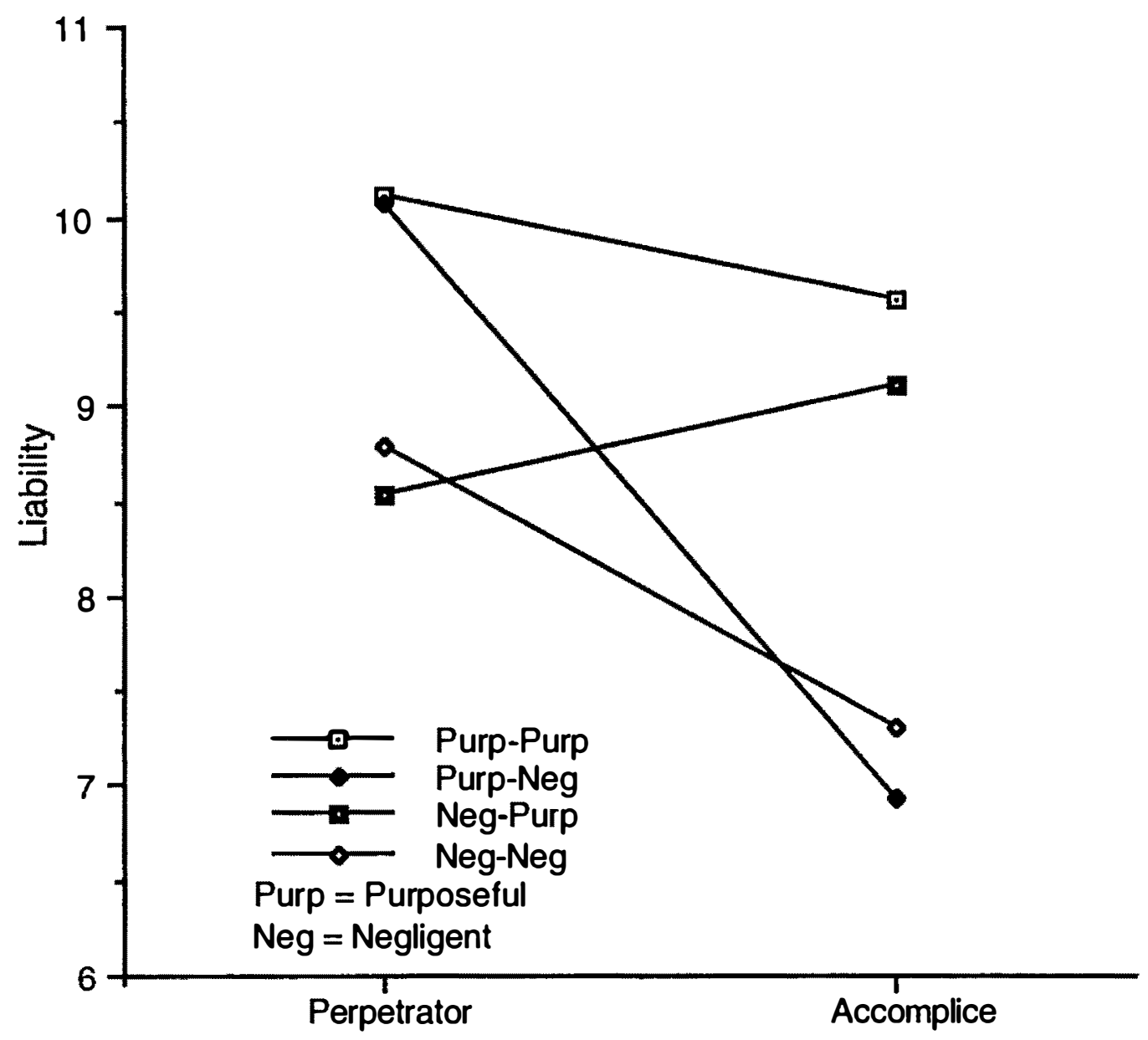

Role of Actor

ity to the principal than to the accomplice, probably reflecting a tendency to punish more heavily the individual who does the actual shooting. They also give less liability to a person-principal or accomplice-who they know does not intend to shoot if the store owner resists. These two effects, combined, give the accomplice who does not plan to shoot a considerable reduction in liability from the other cases. Finkel and his associates (Finkel and Duff, 1991; Finkel and Smith, 1993) have found similar effects. They demonstrated that, in a number of felonymurder scenarios, college student respondents assigned lesser sentences to accomplices than to felony-murder principals.

Recall a point that we have made before. It is worth noting that our scenarios were such as to give the respondents confidence in the belief that one of the robbers really does not intend to shoot. Subjects were straightforwardly told this in the scenario. Notice the culpability ratings in Table 6.3 (column $d$ for the principal, and column $e$ for the accomplice), which indicate that the subjects believed what they were told. Further, the culpability ratings do make a difference; they do predict the liability ratings assigned to the two individuals. An actual robber, try- 
ing to convince an actual jury of that lack of intention, might have considerable difficulty in doing so and therefore often may be treated as a purposeful murderer. Still, the pattern of responses of our respondents argues that the accused should at least have the chance to try to convince the jury concerning his intentions. More generally, this pattern of differences between the felony-murder rule and the subjects' responses echoes the commentators' criticisms of the rule and the Model Penal Code's rejection of it in its current form.

Here is how we would formulate the rule that might underlie our respondents' judgment. Notice that the penalties assigned the negligent persons were reduced-but not reduced to the level of the grade given the negligent individual who kills another while cleaning his gun. The baseline for negligent homicide is 4.58 (9.6 months), although the subjects' sentences for negligent felony-murder principals are 8.53 (22.5 years) and 8.78 (27.0 years) and for negligent accomplices are 6.92 (6.6 years) and 7.31 (9.4 years). These sentences are sufficiently greater than the baseline for a negligent killing to suggest that there is some support for the notion at the heart of the felony-murder rule-that a killing in the course of a felony ought to be punished more severely than it would be without the felonious context. This suggests that our subjects, like the state legislators, are assuming that committing an armed robbery for example, creates a risk of causing death of which the person must be aware. The data pattern suggests that, from our respondents' view, the felony-murder rule is on the right track but simply goes too far. The subjects would support a felony-murder rule that significantly aggravates negligent killings during a robbery but only to the level of manslaughter for principals and to something less than that for accomplices, not to the level of murder as the current doctrine does. In other words, they would support a "felony-manslaughter rule" with a standard "accomplice discount."

We now proceed to a discussion of cases 8 through 10. In these cases, a bystander to the robbery (the wife of the store owner), who is hidden from view, shoots and kills the principal felon. Since the principal felon is dead, the question we asked in these cases is what sentence should be given to the accomplice. As noted previously, some jurisdictions extend the felony-murder rule to impute to the surviving felon, as murder, killings committed by innocent persons defending against the felony. In case 8 , the wife purposefully shoots the principal, and the accomplice had planned to shoot the store owner if he did not respond quickly. In scenario 9, the wife purposefully shoots the principal, and the accomplice had not planned to shoot the store owner. In scenario 10 , the wife accidentally shoots the principal, and the accomplice had not planned to shoot. Given these facts, it is possible to intuitively order the cases. One might expect that the accomplice who had planned to shoot would get a higher sentence than the accomplice in either of the cases in which he had not planned to shoot, and that the purposeful choice of the wife to shoot might further lower the liability assigned to the accomplice. 
In fact, no such "intuitive" differences appeared. The subjects' liability assignments hovered around 5.20, a sentence of about 1 year for all cases, with no statistically significant difference among them. One way of saying what this means is that the subjects do not spontaneously impose the level of liability that the most extended form of the felony-murder rule provides in these cases. Intuitively, the respondents might condition their liability ratings on the fact that a bystander shoots the felon, and the respondents do not attempt to reason through the somewhat complex possible interpretations of the various intentions of the accomplice.

The lower level of respondent liability assigned to the accomplice in these cases of killings of the principal by an innocent does not differ significantly from the baseline for a negligent killing, 4.58 (9.6 months). It is possible (some would say, likely) that standard homicide grading would impose liability for negligent homicide in such cases. That is, it is likely that a jury would conclude that a robber who enters a store with his gun drawn is at least negligent as to causing a death (when one occurs) regardless of who shoots whom (i.e., the robber should have been aware of a substantial risk that such conduct could cause a death). If this is true, then the liability levels given by the subjects in cases of killings of co-felons by innocent bystanders may be obtained in settings in which the code is applied without the felony-murder rule. The rule is needed, in the subjects' view, only in cases of negligent killings of innocents by felons. Further, even in these cases the subjects would prefer that the rule only aggravate liability to manslaughter (reckless homicide) at most, and in most cases to something considerably less. ${ }^{16}$

Finally, let us examine the somewhat baroque case of scenario 11 , in which a bystander attempts to stop the robbery and clumsily shoots the owner of the store instead. In this case, although the felon is actually purposeful or knowing as to planning to cause a death, the subjects put his liability for the killing by an innocent of another innocent at 6.83 (6.2 years), significantly less than the liability for murder $(p=.01)$. Indeed, such liability is significantly less than the liability imposed on the purposeful accomplice in the analogous situation (scenario 7 in which a negligent principal kills the innocent owner, 9.11 ( $9=30$ years; $10=$ life $)$. The fact that the killing is actually done by an innocent person, not the principal or an accomplice, appears to matter a great deal to the subjects. ${ }^{17}$

\section{Study 16: Summary}

This study confirms that subjects, like current legal doctrine, aggravate the liability of a person who kills during a felony over what that liability would be if the offense did not occur during a felony. They punish a person's negligent killing during a robbery at a liability level similar to a reckless killing in a nonfelonious context. If one brandishes a gun during the course of a robbery, and it goes off accidently and kills an innocent, the subjects are not particularly sympathetic to the 
view that this is equivalent to accidentally discharging a gun and killing another. But according to our subjects, current doctrine goes too far, for it punishes such a negligent killing as if it were murder, although the subjects would prefer to punish it as manslaughter. So, the subjects would support a "felony-manslaughter rule."

The complicity aspect of the felony-murder rule reflects similar differences. Like the doctrine, the subjects punish the accomplice for more than negligent homicide when the perpetrator kills during a felony. But while the doctrine treats the accomplice exactly like a murderer, the subjects impose liability somewhat less than they would for manslaughter. The lesser liability of the accomplice is significant. It reflects the view of the subjects, manifested in several studies, that the accomplice generally deserves less liability than the perpetrator, all other things being equal. If the code were to adopt a standard "accomplice discount," felonymurder accomplices could remain within the rule; the accomplice would be held at some level of liability less than that of the "felony-manslaughter" perpetrator.

The vicarious aspect of the felony-murder rule-holding a felon liable for murder for a killing by the intended victim of the felon or by some other bystander-has even less support among the subjects than the aggravation and complicity aspects of the rule. Where the victim kills the principal felon, the liability imposed by the subjects on the surviving accomplice is not significantly more than that imposed for a negligent homicide and is far from the murder liability imposed on the accomplice by the felony-murder rule in some jurisdictions. (Also, under the felony-murder rule, the state of mind of the accomplice as to planning to kill does not seem to matter.) Where an innocent person is killed by the robbery victim, the accomplice's liability is slightly more than that for negligent homicide but is still nowhere near manslaughter liability. This result is likely under normal homicide grading; thus, the subjects would see no need for extension of the special rule to these cases.

To conclude, it is possible that a jury might reach the same conclusions as our subjects even without a felony-murder rule, by seeing culpability in the felon's creation of a situation in which the likelihood of a killing is brought about. It may be, as we suggested earlier, that it is this perception of blame for creating the dangerous situation that generates the subjects' responses. Such increased liability is possible if not likely under the normal graded-homicide offenses, and its likelihood is increased if the Model Penal Code's evidentiary presumption approach is used. The Code, recall, uses the fact of the felony as grounds to create a presumption of "recklessness manifesting extreme indifference to the value of human life," which is defined as sufficient culpability for murder; the defendant can rebut this presumption. One might suggest, on the one hand, then, that these results argue against the continuing need for a felony-murder rule. On the other hand, the results suggest that a form of a felony-murder rule might be unobjectionable-and, 
thus, if politically demanded, might be continued-if revised to better reflect the subjects' views, which call for lower liability levels.

A rule that mirrors the subjects' views would aggravate a negligent killing by a felon in the course of a felony to reckless homicide (manslaughter), not murder. No special complicity rule would be required; accomplices would receive the normal complicity discount, which varies with the level of the accomplice's culpability and degree of contribution. A felon might be liable for killings by an intended victim of the felony, at the level of negligent homicide, but not under a special rule for killings during a felony.

\section{STUDY 17: THE STRENGTH OF THE PERSON'S CONNECTION WITH THE PROHIBITED RESULT-CAUSATION REQUIREMENTS}

A person acts, intending a result that is prohibited, such as another's death. Through some chain of circumstances, the result intended occurs, but not exactly in the way intended by the person. Should we hold the person liable for that result? This situation is a familiar one to fans of courtroom drama. For example, I intend to kill Jones but only put him in the hospital with a minor wound. The hospital, due to some medical ineptness, causes Jones's death. Have I committed murder? In another example, I shoot at Jones and miss, but he dies of fright induced by the noise of the shot. Have I murdered him? Alternatively, and as a third example, intending to kill my rival, Smith, I administer a slow-acting poison to him. Before it acts, a third rival, Clark, bludgeons Smith to death. What is my liability? Philosophers have posed these and similar cases for generations, to explore the limits of moral sanctions; we posed some similar cases to a set of our respondents.

We begin by examining the current legal code. Current criminal-law doctrine typically imposes two requirements for a person to be held causally accountable for a prohibited result. First, the person's conduct must have been necessary for the result to occur: "It is an antecedent but for which the result in question would not have occurred" [MPC $\$ 2.03(1)(a)$ ]. Second, even if the person's conduct is a necessary cause ("but for" cause) of the result, the nature of the connection between the conduct and the result must be sufficiently close and direct; the result must not be "too remote or accidental in its occurrence to have a [just] bearing on the person's liability or on the gravity of his offense" [MPC $\$ 2.03(2)(b)]$. Where these two requirements-termed "factual cause" and "legal cause," respectively - are not met, a person cannot be held accountable for the result and, typically, is liable only for an attempt to commit the substantive offense (or, in some instances, has no liability ${ }^{18}$ ).

A "necessary cause" requirement is one formulation of factual cause. Another is a "sufficient cause" requirement. A cause is necessary if the result would not 
have occurred but for the cause. A cause is sufficient if, without additional assistance, intervention, or changed circumstances, it will cause the result. The traditional doctrinal position is to require the former (a necessary cause). During the Model Penal Code debate, it was argued that an alternative, less-demanding ground for causal accountability be permitted, requiring only that the cause be "a substantial factor in producing the result," 19 a formulation even less demanding in many ways than a sufficient-cause requirement. ${ }^{20}$ The members of the American Law Institute rejected the sufficient- or substantial-cause formulations, instead adhering to the traditional requirement of a necessary cause. ${ }^{21}$ This means that, in the case example in which I poisoned Smith but Clark bludgeoned him to death before the poison acted, I would not be liable for murder (but would be liable for attempted murder). Although the poison eventually would have killed Smith without additional assistance or intervention, and thus fits the definition of a sufficient cause, it was not a necessary cause: Smith would have died when he did from the beating by the subsequent person, even if he had never been poisoned. One goal of the causation study was to examine which of these two testsnecessary cause or sufficient cause-best represents the community's view of a prerequisite for causal accountability.

A second concern of the causation study was the effect of the strength of the relationship between a person's necessary cause and the prohibited result-the socalled legal-cause requirement. This is the question that arises, to refer to the first example described previously, when I set out to murder Jones but only wound him, and some other events (such as carelessness in the hospital) bring about Jones's death. The test of the legal-cause requirement in current doctrine is relatively vague: The result must not be "too remote or accidental in its occurrence to have a just bearing on the actor's liability." Yet much depends on the application of this standard, specifically, the difference between liability for the full substantive offense and liability for an attempt (or, in some cases, exoneration from all liability). The study sought to test various factors that might affect the community's liability judgment in such cases of potentially "remote" or "accidental" results. An identification of relevant factors, it was felt, might lead to formulation of a more specific standard or might guide decision-makers in applying the present vague standard.

In summary, the causation study sought to determine which of the two factual cause requirement tests-necessary cause or sufficient cause-best reflects the community's view of a prerequisite for causal accountability. A second goal was to examine the effect of the strength of the relationship between a person's necessary cause and the prohibited result-the legal-cause requirement.

We first presented respondents with two control scenarios that established liability baselines for a clear, direct, and immediate killing (scenario 1 of Table 6.7) and a failed attempted killing (scenario 2). The various other scenarios can then 
TABLE 6.7 Liability as Related to Causation

\begin{tabular}{llll}
\multicolumn{2}{c}{ Principal } & Second Actor or Accomplice \\
(a) (b) & (c)
\end{tabular}

Scenarios

Liability Legal Code Result

Liability Legal Code Result

1. Murder, control $9.89^{\mathrm{a}}$ Murder

2. Attempt, control $7.25^{\mathrm{e}}$ Attempted murder

8.89b Murder

3. Subsequent killer

$9.47^{\mathrm{a}}$

$8.75^{\mathrm{b}}$

Attempted murder

$9.89^{\mathrm{a}}$ Murder

4. Allergy

$8.33^{\mathrm{b}, \mathrm{c}}$

Murder

$7.97^{\mathrm{C}}$ Murder

5. Careless nurse

Murder or attempt (jury)

$7.58^{\mathrm{c}, \mathrm{d}}$ Murder or attempt (jury)

6. Accident on way to hospital

$8.03^{\mathrm{c}, \mathrm{d}}$

Probably attempted murder

7.36 d,e Probably attempted murder

7. Construction accident $7.36^{\mathrm{d}, \mathrm{e}} \quad$ Attempted murder

6.75 Attempted murder

Liability Scale: $\mathrm{N}=$ No criminal liability, $0=$ Liability but no punishment, $1=$ 1 day, $2=2$ weeks, $3=2$ months, $4=6$ months, $5=1$ year, $6=3$ years, $7=7$ years, $8=15$ years, $9=30$ years, $10=$ life, and $11=$ death.

Note: Superscript letters indicate significance at the $p<.05$ level by a Newman-Keuls test. Matching superscripts indicate means that are not statistically significantly different from each other. Means are compared within columns only.

be compared to the control cases to see if the assignment of liability in each instance is more akin to the case of causal accountability for murder or more akin to the case of no causal accountability, where only attempt liability is imposed. As this process suggests, we first examine the liability ratings for the two control scenarios, which establish boundaries within which the other cases can be interpreted. Examining Table 6.7, one sees that the liability assigned to the murder in scenario 1 is high (9.89, or just slightly less than life imprisonment). Second, notice that the attempted murder scenario drew an average sentence of 7.25 (9.4 years). This finding in itself is significant for the topic of this chapter, because it shows just how important the actual occurrence of the resulting harm is as related to the respondents' grading of liability.

Let us first look at the "factual cause" issue-the necessary- versus sufficientcause debate. In scenario 3, labeled "subsequent killer," the first person inflicts a wound sufficient to kill but, before the victim can die from this wound, the second person, unaware of the prior attack, shoots and immediately kills the victim. (This scenario is equivalent to the earlier example in which I poisoned Smith but 
Clark bludgeons him to death before the poison takes effect.) Recall that the necessary-cause requirement of the legal code is not satisfied in this scenario. The first person's conduct is sufficient to cause the death but is not necessary; the victim would have died exactly when he did from the conduct of the second person.

The subjects found the first person warranted a high degree of liability. The subjects impose liability upon the first person that is very close to that imposed in the direct-killing control case ( 9.47 versus 9.89). However, the liability that they impose is very different from that imposed in the attempt control $(9.47$, or 30 years to life, versus 7.25 , or 9.4 years, for the attempt control, with $p<.02$ ). Thus, where a person's conduct is sufficient to cause death but is not necessary for the death, the subjects impose liability only slightly less than that imposed for conduct that is both necessary and sufficient to cause death.

Obviously, the respondents are much closer to a formulation that treats either necessary or sufficient actions equally as examples of murder than they are to the code formulation in which one is treated as murder and the other as only attempt. But we also point out that column $e$ of scenario 3 (see Table 6.8) indicates that subjects were unclear that the act of the first person was not necessary for bringing about the death; instead, their mean rating (5.74) hovered around the neitheragree-nor-disagree point on the scale. Further research will need to see if the punishment equivalent to murder is given by the community for actions clearly seen as not necessary but sufficient to bring about death.

Consider next the "legal cause" requirement, which holds that the connection between the person's conduct and the result must be close and direct for liability to be incurred. Four scenarios (4 through 7 in Table 6.7) involving an attempted homicide were used to present various situations that we thought might raise legal causation issues. In all of these scenarios, two persons go to the victim's house to kill him. The first person shoots at the victim, either missing or only wounding him, while the second person serves as a lookout. The scenarios differ in the way in which the death of the victim ultimately results. In two scenarios, the death occurs when the man is being treated in the hospital. The victim dies from an unusual allergic reaction to a drug given during initial treatment of the wound (case 4). Alternatively, death results from the careless actions of a nurse during initial treatment (case 5). In a third case, death of the wounded individual results from a traffic accident that occurs while the victim is on the way to the hospital for followup treatment, and this occurs two months after the shooting (case 6). In the fourth case, the shooters miss their intended victim, and he flees from them. His death results from a construction-crane accident that occurs during his flight (case 7). The liabilities assigned to the persons in these cases are contained in Table 6.7, and the respondents' perceptions of the cases are listed in Table 6.8.

Let us deal with what is by now a familiar issue, which is the liabilities assigned to the perpetrator and to the individual who plays a lesser role in the incident. To 
TABLE 6.8 Subjects' Perceptions of Causation

\begin{tabular}{|c|c|c|c|c|}
\hline Scenarios & $\begin{array}{c}\text { (e) } \\
\text { "Actor's } \\
\text { Act } \\
\text { Necessary" }\end{array}$ & $\begin{array}{c}\text { (f) } \\
\text { "Actor's } \\
\text { Act } \\
\text { Sufficient" }\end{array}$ & $\begin{array}{l}\text { (g) } \\
\text { "Actor } \\
\text { Intended } \\
\text { Death" }\end{array}$ & $\begin{array}{c}\text { (h) } \\
\text { “Accomplice } \\
\text { Intended } \\
\text { Death" }\end{array}$ \\
\hline $\begin{array}{l}\text { 1. Murder, control } \\
\text { 2. Attempt, control }\end{array}$ & $7.86^{a}$ & $8.22^{a}$ & $\begin{array}{l}8.56^{a} \\
8.17^{b}\end{array}$ & $\begin{array}{l}7.75^{b} \\
7.92^{b}\end{array}$ \\
\hline $\begin{array}{l}\text { 3. Subsequent killer } \\
\text { 4. Allergy } \\
\text { 5. Careless nurse } \\
\text { 6. Accident on way to hospital } \\
\text { 7. Construction accident }\end{array}$ & $\begin{array}{l}5.74^{c} \\
7.20^{a, b} \\
6.91^{a, b} \\
4.37^{d} \\
6.34^{b, c}\end{array}$ & $\begin{array}{l}7.78^{a} \\
5.22^{b} \\
4.81^{b} \\
4.83^{b} \\
4.81^{b}\end{array}$ & $\begin{array}{l}8.31^{a, b} \\
8.08^{b} \\
8.08^{b} \\
8.03^{b} \\
8.11^{b}\end{array}$ & $\begin{array}{l}8.36^{a} \\
7.83^{b} \\
7.72^{b} \\
7.69^{b} \\
7.81^{b}\end{array}$ \\
\hline
\end{tabular}

Key to column heads:

All statements were responded to on a scale where: $1=$ "strongly disagree," 5 ="unsure," and 9="strongly agree."

(e) The victim's death would not have occurred but for the actor's conduct.

(f) The actor's conduct was by itself sufficient to cause the victim's death.

(g) The actor intended to kill the victim.

(h) The accomplice intended that the actor kill the victim.

Note: Superscript letters indicate significance at the $p<.05$ level by a Newman-Keuls test. Matching superscripts indicate means that are not statistically significantly different from each other. Means are compared within columns only.

test all of the complex causal connections we wanted to investigate, it was necessary to have two individuals involved in the commission of the act. The liability assigned to the second person, who functioned as lookout in the cases we will examine, in contrast to that assigned to the first person, gives us another chance to examine the effect of the criminal role on liability. To examine that, we have plotted the liabilities assigned to the perpetrator and to the lookout in Figure 6.9.

As this figure shows, the liability scores assigned to the perpetrator and the lookout are consistently quite different; the liability assigned to the individual who fulfills only the lookout function is consistently lower than that assigned to the major perpetrator.

This is consistent with the "accomplice discount" that we have seen in other studies. In these cases, in which the second individual serves only as a watchkeeping accomplice, the codes regard both as equally liable. Given the results that emerge so clearly from Figure 6.9 and the results of our two earlier complicity studies, the community standard is in significant disagreement with the codes, in that a lesser degree of liability (reflected in a lesser prison term) is given 
FIGURE 6.9 Liability for Perpetrator and Lookout in Causation Scenarios

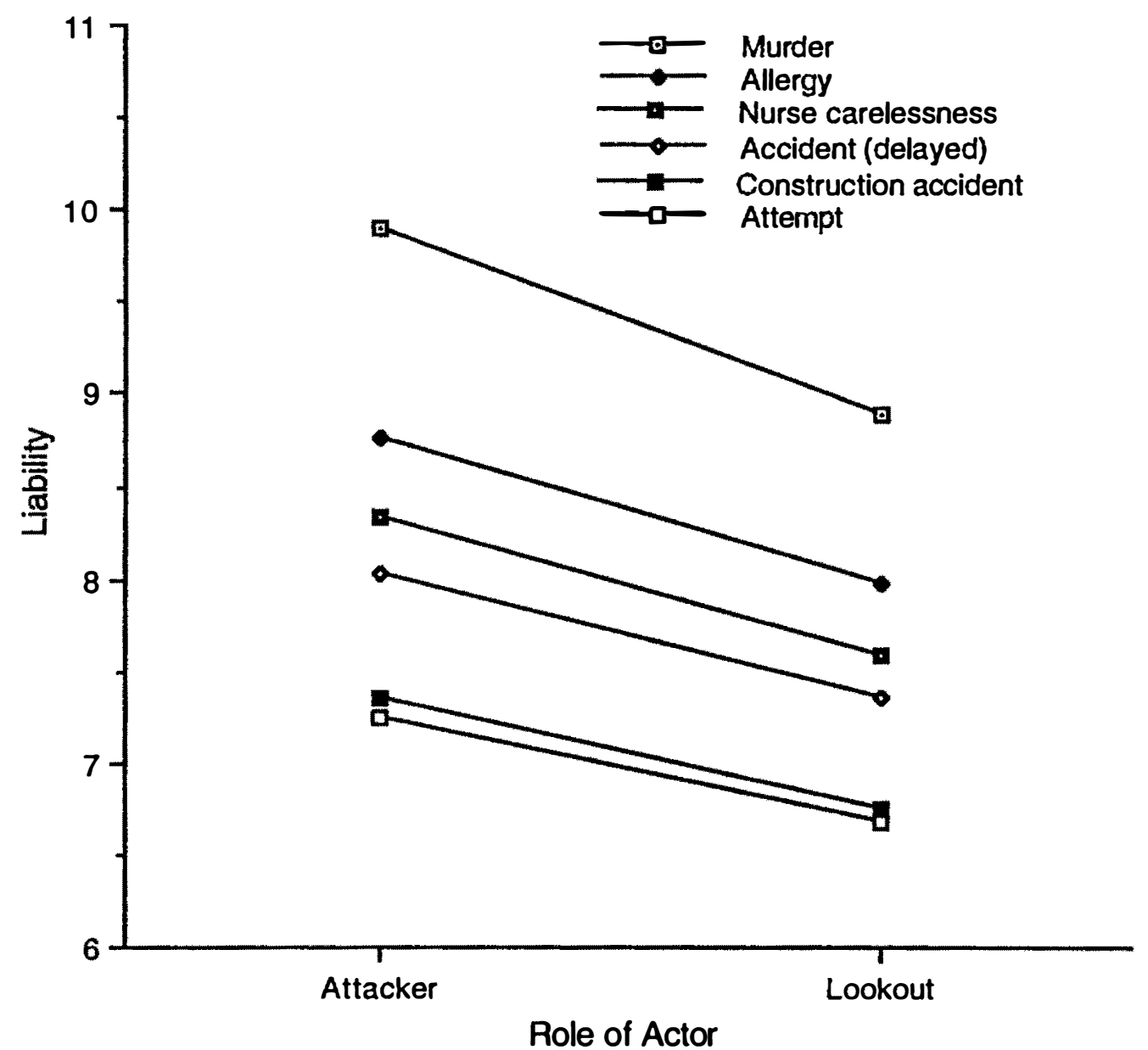

to the accomplice. Recall that some modern sentencing guidelines are moving in this direction; they assign reduced sentences to those who play lesser roles in crimes. ${ }^{22}$

Notice that we have omitted scenario 3 from the figure and this discussion. In that scenario, the second person, unaware of the first person's actions, steps in and kills the wounded victim. The killer, therefore, is not an "accomplice" but rather an independent perpetrator, who is appropriately assigned murder liability by our subjects.

Let us now look at the question of "legal causation." The point at issue here is whether and when an outcome of a chain of events is so remote, in any of the various senses of "remote," that the respondents do not see the perpetrator as having the normal accountability for the outcome, even if that was the outcome the perpetrator intended.

The drop in liability assigned to the complex causal scenarios (4 through 7 in Table 6.8) suggests that these scenarios include factors that discount a person's 
FIGURE 6.10 Liability as Related to Causation

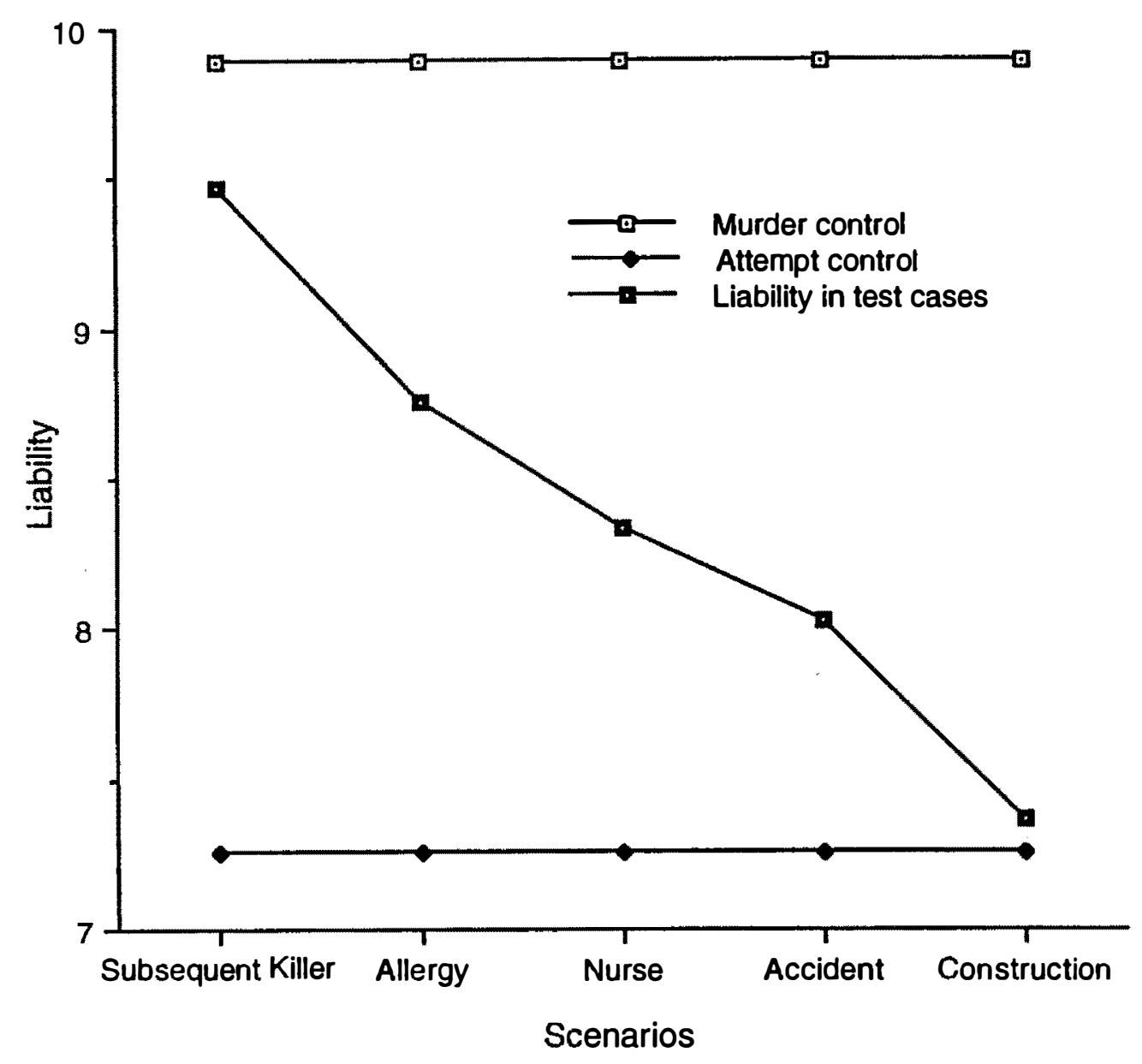

causal accountability for the resulting death. In Figure 6.10, we have attempted to examine this by contrasting the liabilities assigned to the principal in each of the four test scenarios. The top line in the figure shows the liability assigned by respondents to the case of murder, and the bottom line shows the liability assigned to attempted murder. What one would expect (according to the doctrine of legal causation) is that some of the scenarios should be assigned murder liabilities and others should coincide with the liability assigned to the attempt case. Obviously, our respondents' assignments do not mirror this expectation.

Factors that seem to make a difference include whether the risk that comes to fruition is one that commonly results from the conduct (compare allergic reaction-8.75, or 27 years - to construction accident cause-7.36, or 10.2 years); the presence of a subsequent volitional person contributing to the result (compare allergic reaction-8.75, or 27 years-to careless nurse-8.33, or 19.5 years); and the remoteness of the result in time and place from the person's conduct (see death by accident two months later when returning to the hospital for treat- 
ment-8.03, or 15 years) ${ }^{23}$ Further studies could establish the factors that contribute to a perception of remoteness and the relative effect of the different factors on liability. It may be that the subjects are reaching their judgments of liability via the mediating inference of remoteness-or some alternate reasoning model may be needed to explain their judgments. Further still, one may need a reasoning model that includes both remoteness of result and necessary-versus-sufficient causal contribution to the death.

Notice the pattern of the results in the figure. The liability of the perpetrator in each of the test scenarios, other than the construction-crane accident, is statistically significantly different than his liability in the murder and attempt control scenarios-lower than the murder liability but higher than the liability for attempted murder. This suggests that the subjects see the circumstances as reducing but not eliminating the person's accountability and liability for the death. In other words, the subjects see causal conditions as presenting a continuous rather than a dichotomous relationship with liability. The legal rules, in contrast, set causation as a minimum requirement, which when met establishes liability for the full offense (in this case, murder) and when not met defaults liability to that for a case of attempt.

Therefore, and as common sense suggests, the degree of perceived liability generally decreases in a graduated way as the causal connection between the person's conduct and the result becomes weaker. Furthermore, many of the factors that one might guess would add to a result's "remote or accidental" nature do serve to reduce the liability that the subjects impose. An unusual event, such as an allergic reaction to a drug during treatment, reduces liability. A subsequent person's carelessness reduces liability even further, as does a significant time delay between the conduct and the result. Notice also, however, that no simple rule summarizes our results; the construction accident takes place within minutes of the attempted murder, but receives lower liability assignments than do other scenarios in which the death-causing incident is much more delayed in time from the murder attempt. Therefore, unless the relevant factors (e.g., remoteness, accidentalness) and their interrelation can be more clearly explicated, it may be best for code drafters to leave this particular determination to juries, rather than attempt to codify it.

\section{Study 17: Summary}

As to the factual cause issue, our findings are inconclusive. Our subjects gave liability almost equal to murder in the sufficient-cause scenario, which would suggest that the codes' necessary-cause test was too limiting. But our analysis also suggests that the subjects were unclear as to whether the cause in that scenario was a necessary cause.

Our results did clearly suggest, however, that the extent of a person's liability is reduced as the result becomes more "remote or accidental" in relation to the per- 
son's conduct. This result is at significant variance with the current treatment in the modern codes. Subjects do not seem to conceive of the causation issue in the dichotomous way that the doctrine treats it. They do not see causal accountability as a yes-no issue but as one with a continuum of accountability. As a person's degree of accountability increases, so does his liability, from attempt liability up to liability for the full substantive offense. This is one of several examples of the current doctrine's tendency to treat continuous functions as dichotomous ones, an issue discussed further in the concluding chapter.

\section{STUDY 18:}

\section{PUNISHMENT FOR MULTIPLE OFFENSES}

Current law has some considerable difficulty in determining the appropriate range of punishment for multiple related offenses. If a single instance of theft deserves a punishment of $x$ amount, how much punishment is deserved if the offender is convicted of two identical but separate instances of such theft? Traditionally, judges sentence such an offender separately for each of the two offenses, then determine whether those sentences are to run concurrently or consecutively. Concurrent sentences are served at the same time; consecutive sentences are served one after the other. This leads to the odd result that a person who, for example, carries out two burglaries and gets a two-year sentence for each-to be served concurrently-serves only two years. Concurrent sentences are rightly criticized because they trivialize the second (and all subsequent) offenses. If consecutive sentences are imposed, our burglar would have his two sentences served one after the other, for a total jail term of four years. Consecutive sentences are criticized on the basis that two identical offenses by the same offender do not necessarily deserve twice the punishment as a single offense.

The theory behind this latter claim is somewhat unclear. It may stem in part from the fact that the punishment deserved for an offense is based only in part on the harm caused, such as the deprivation of the owner of his property. The person's willingness to violate the announced rules of society may be part of the foundation for punishment, and this factor is already taken into account in the sentence for the first offense. In any event, there seems to be some general sense that additional punishment is deserved for each additional offense but that the additional amount deserved is less than that for the first offense. There seems to be some feeling, in specific, that a third, fourth, fifth, or further offense ought to each give rise to additional punishment but that, in each instance, the amount of the punishment ought to be less than the additional punishment assigned for the previous offense. This multiple-offense discount notion is instantiated in the United States Sentencing Commission (USSC) guidelines. Each additional offense is punished, although with increasingly reduced penalties. (The Sentencing Commission guidelines use a formula that takes account as well of different seriousness levels of the different offenses, establishing the baseline with the most se- 
rious of fense and adding on penalties for additional offenses by considering offenses in their decreasing order of seriousness (USSC Guidelines Manual \$\$ 3D1.1-3D1.5.1). ${ }^{24}$

The "multiple-offense discount" may well describe what sentencing judges would like to do, but their options may be limited by the consecutive-versus-concurrent options we discussed earlier. (One somewhat manipulative way around this, reported by some judges, is to give the defendant more than the offense deserves on one or both of the counts, then have the sentences run concurrently.)

Given these competing models of multiple-offense sentencing, it seemed useful to have some empirical data on what ordinary people think on the issue; so, we set out to collect such data through this study. The multiple-offenses study sought to determine whether the subjects concur with the general notion of a multiple-offense discount in the sentencing of such cases.

The study also sought to investigate the significance of the time interval between multiple offenses (all of which occur before conviction for any one). We speculated that the closer in time the offenses occurred, the more the subjects would treat them as a single offense and, therefore, impose proportionally less increase in liability for each subsequent offense. The longer the period of time between the multiple of fenses, the more the subjects would be likely to treat them as entirely independent offenses deserving entirely independent, nonoverlapping penalties. It might even be the case that they would begin to see the offender as a habitual offender and assign harsher sentences for the second of fense than for the first. $^{25}$

The study also sought to determine whether the operative principles are different for offenses against a person, such as assault, than for of fenses against property, such as theft. One might speculate that offenses against property, where the harm can more easily be reduced to a monetary form, may well be thought of in those terms only. Sentences for multiple offenses against property might follow a principle of a simple accumulation of the monetary value of all the property taken. In other words, while two assaults may be viewed as entirely separate offenses for which a substantial add-on is appropriate for multiple violations, multiple theft offenses might be viewed as no different in seriousness than a single theft offense where the value of the property taken equals the sum of the values for the multiple offenses. This is the approach taken by the United States Sentencing Commission guidelines: If the nature of the harm of multiple offenses is such that it simply can be aggregated, as in theft or fraud, then the amounts are aggregated and treated as a single offense of this amount [USSC Guidelines Manual $\S$ 3D1.3(b)]. Thus, the guidelines take different approaches to aggregatable and nonaggregatable offenses. They suggest a very different patterning of additional penalties for multiple theft offenses than for multiple assault offenses. Even the treatment of theft, the aggregatable offense, does not really give full value to each additional dollar of theft, since the grading of theft itself provides a discount for each additional dollar stolen, but they do ignore whether the total loss is caused 
by one theft or by many. That seems inconsistent with the general principle that every new offense should count for something additional —not just in recognition of greater harm but also in recognition of an additional violation of the legal rules. Nonaggregatable offenses such as assault, however, would be expected to generate more substantial add-on sentences.

Other possible hypotheses might suggest other patterns of multiple-offense sentencing. We thought it best first to do the study, and let its results guide further theorizing. We set up two sets of scenarios. In the core assault scenario, an individual who had been angered by a co-worker (or co-workers) at an of fice where he used to work returns to the office, armed with a baseball bat, and breaks several bones of the co-worker (or co-workers). In the core theft scenario, the thief, waiting until no one is around (and thus by inference avoiding needing to use violence on anybody who observes him) steals a 55-gallon-drum from a gas station to resell it (or steals several drums from several gas stations). ${ }^{26}$

To study the effects of the time interval between the multiple offenses, we created several cases in which two persons are assaulted or two drums are stolen, and the interval between the events is either nearly zero (the previously described scenarios), two weeks, or two years in length.

We asked our subjects, in other words, to read and retain the subtle differences in a good many cases. Luckily for us, they did. Table 6.11 indicates that subjects are reasonably accurate as to the number of individuals injured in the various assaults and the number of drums stolen in the various thefts (column $a$ ). The respondents also recognize the differences in the time intervals between the crimes, in the cases in which multiple crimes are committed (column $b$ ).

The liability results for this study are in Table 6.12. As with other tables that we have presented in which multiple comparisons are possible, it is difficult to extract them from the table. Perhaps the main points to extract from the table are that no respondent thinks that no liability is appropriate, and only very few assign liability with no punishment - and when this assignment is made, it is almost always in the theft cases.

As we said, the various comparisons we want to make are difficult to make from an inspection of the liability table alone. It seemed useful to present them in figures. Let us look first at the major question of this study, which involves the patterns of changes in liability when the number of offenses increases. In Figure 6.13 , we assemble for comparison all of the cases of theft or assault in which the multiple thefts or assaults occurred immediately one after the other.

First, notice that the liability assigned for any assault is always greater than that assigned for any theft $[\mathrm{F}(1,40)=127.88, p<.0001]$. This is exactly as we would expect from both intuition and the criminal code; harming another person is more serious than stealing an oil drum.

Notice, second, that both curves have the general property that both matches our intuition and is built into the federal sentencing guidelines for nonaggregatable offenses. The greater the number of offenses, the greater the sen- 
TABLE 6.11 Subjects' Perceptions of Multiple Offenses

\begin{tabular}{|c|c|c|c|c|c|c|}
\hline Scenarios & $\begin{array}{c}\text { (a) } \\
\text { Number } \\
\text { of } \\
\text { Offenses }\end{array}$ & $\begin{array}{c}\text { (b) } \\
\text { Time } \\
\text { Interval }\end{array}$ & $\begin{array}{c}\text { (c) } \\
\text { Threat } \\
\text { of } \\
\text { Harm" }\end{array}$ & $\begin{array}{c}\text { (d) } \\
\text { "Intended } \\
\text { to } \\
\text { Commit" }\end{array}$ & $\begin{array}{c}(e) \\
\text { "Likely } \\
\text { Future } \\
\text { Offense" }\end{array}$ & $\begin{array}{c}\text { (f) } \\
\text { "Likely } \\
\text { Past } \\
\text { Offenses' }\end{array}$ \\
\hline \multicolumn{7}{|l|}{ Single day-Assault: } \\
\hline 1. 1 victim & 1.00 & & 8.63 & 8.61 & 5.41 & 5.10 \\
\hline 2. 2 victims & 1.98 & 1.00 & 8.83 & 8.68 & 5.83 & 5.49 \\
\hline 3. 4 victims & 3.93 & 1.00 & 8.93 & 8.76 & 5.95 & 5.59 \\
\hline 4. 7 victims & 6.85 & 1.00 & 9.00 & 8.83 & 6.44 & 5.93 \\
\hline \multicolumn{7}{|l|}{ Single day-Theft: } \\
\hline 5. 1 item & 1.05 & & 2.05 & 8.68 & 5.22 & 5.24 \\
\hline 6. 2 items & 2.00 & 1.00 & 2.51 & 8.71 & 5.51 & 5.49 \\
\hline 7. 4 items & 3.88 & 1.00 & 2.41 & 8.61 & 5.90 & 5.76 \\
\hline 8. 4 items $/ 1$ victim & 1.46 & & 2.10 & 8.51 & 5.46 & 5.56 \\
\hline 9. 7 items & 7.02 & 1.02 & 2.66 & 8.66 & 6.05 & 5.95 \\
\hline \multicolumn{7}{|l|}{ Two-week interval: } \\
\hline $\begin{array}{l}\text { 0. Assault, } \\
2 \text { victims }\end{array}$ & 2.00 & 1.98 & 8.83 & 8.78 & 6.37 & 5.90 \\
\hline 11. Theft; 2 items & 2.05 & 1.97 & 2.52 & 8.57 & 5.92 & 5.90 \\
\hline \multicolumn{7}{|l|}{ Two-year interval: } \\
\hline 12. Assault, 2 victims & 2.00 & 2.98 & 8.85 & 8.83 & 6.71 & 6.27 \\
\hline 13. Theft, 2 items & 2.05 & 2.93 & 2.73 & 8.46 & 6.51 & 6.47 \\
\hline
\end{tabular}

Key to column heads:

Statements (c) through ( $f$ ) were responded to on a scale where: $1=$ "strongly disagree," 5="unsure," and 9="strongly agree."

(a) Number of crimes the actor committed: 1 to 10.

(b) Time interval between offenses: $1=$ less than a day, $2=2$ weeks, and 3=2 years.

(c) In the scenario above, there was physical harm or a threat of physical harm to persons.

(d) The actor intended to commit the offense.

(e) After his conviction, the actor is likely to commit other offenses in the future.

(f) The actor is likely to have committed other offenses in the past for which he has not been caught. 
TABLE 6.12 Liability for Multiple Offenses

(a) (b) (c)

$\begin{array}{lccc} & & \% \text { No Liability } \\ \text { Scenarios } & \text { Liability } & \text { (N) } & \text { or No Punishment }\end{array}$

Single day-Assault:

1. 1 victim

5.85

0

0

2. 2 victims

6.17

0

15

3. 4 victims

6.76

0

0

4. 7 victims

7.10

0

0

Single day-Theft:

5. 1 item

3.17

0

0

6. 2 items

3.95

0

5

7. 4 items

4.37

0

2

8. 4 items $/ 1$ victim

3.54

0

10

9. 7 items

4.68

0

2

Two-week interval:

10. Assault, 2 victims

6.41

4.10

0

0

11. Theft, 2 items

6.59

0

5

Two-year interval:

12. Assault, 2 victims

4.15

0

0

13. Theft, 2 items

Liability Scale: $\mathrm{N}=$ No criminal liability, $0=$ Liability but no punishment, $1=$ 1 day, $2=2$ weeks, $3=2$ months, $4=6$ months, $5=1$ year, $6=3$ years, $7=7$ years, $8=15$ years, $9=30$ years, $10=$ life, and $11=$ death.

tence grows $[F(1,120)=70.01, p<.001]$, but it does not do so in a linear fashion. Instead, it follows the general rule we discussed of adding a decreasing increment for each additional offense.

However, our results do not support the aggregation side of the United States Sentencing Commission guidelines approach. Under the guidelines, theft is aggregatable; assault is not. Under the guidelines, therefore, each additional theft would get even less additional increment; each would be treated as providing no more punishment than if the person took the two drums from the same gas station in a single theft. The sharp increase in sentence for the thief for the theft of the second drum suggests that subjects do not follow this rule. Future research, in which the scenarios might compare the theft of $x$ drums from different stations with the theft of $x$ drums all at once, will clarify this still further.

Turn now to the effect that a time delay between offenses has on the sentencing patterns of our respondents. Figure 6.14 shows us the effect of time delays between a first and a second offense on liability for the two offenses. (The figure 
FIGURE 6.13 Total Liability as a Function of Number of Offenses (no time delay)

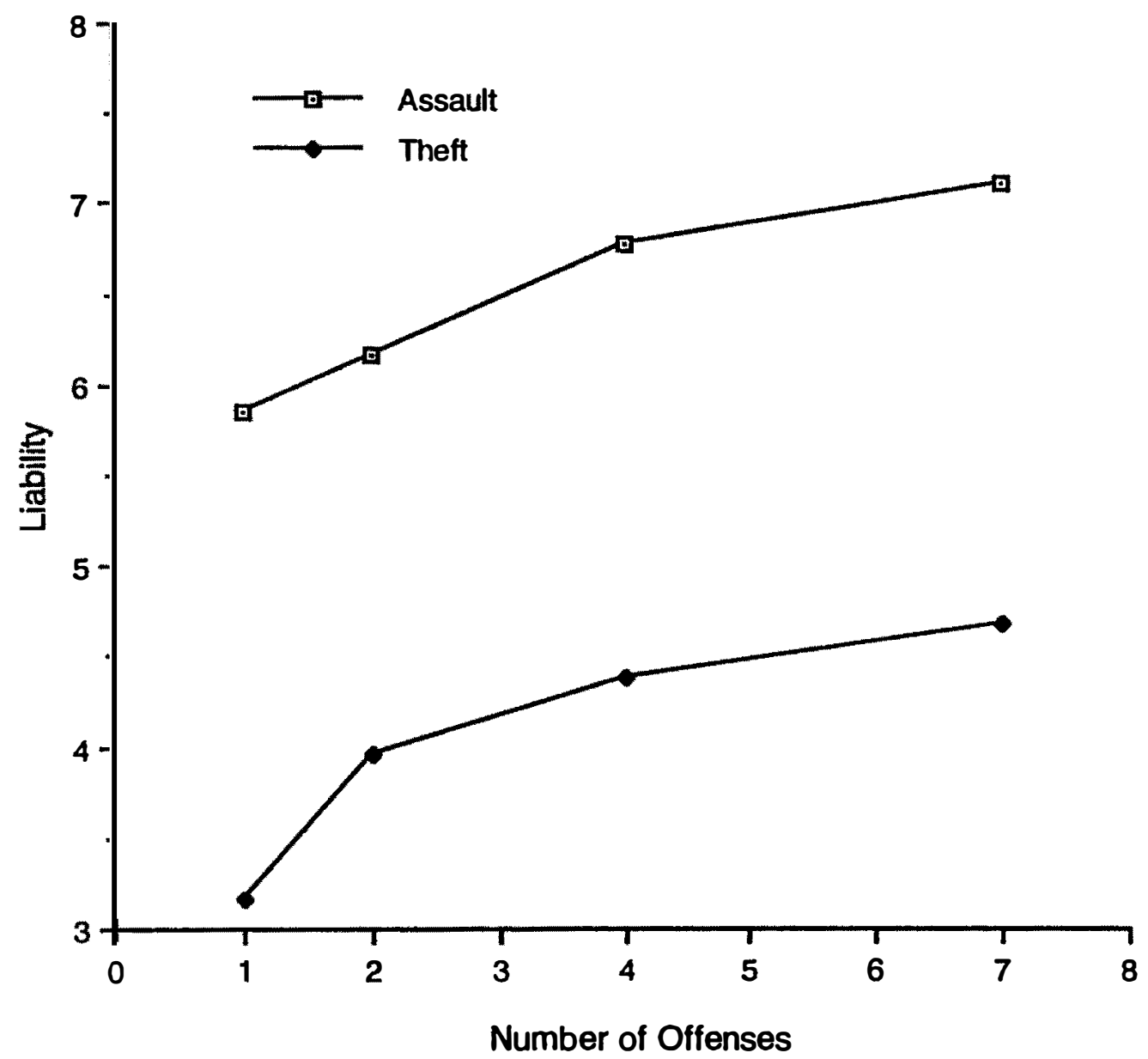

graphs the total liability for the two offenses.) As can be seen, the time delay does seem to make a difference; the longer the time between the two offenses, the more severe the sentence for the pair of them, and this is confirmed by the statistical test, $\mathrm{F}(2,78)=9.85, p<.001$. However, it is also important to note that, compared to many of the other differences we have found between scenarios in other chapters, the differences we have graphed in Figure 6.14 are not large or dramatic. Respondents assign only mildly more severe sentences the longer the delay between the incidents for which they are sentencing the individual. It may well be that this is because the longer the period of time between the multiple offenses, the more the subjects would be likely to treat them as entirely independent offenses deserving entirely independent, nonoverlapping penalties, as we suggested earlier. The best description of these results is this: increasing the interval between offenses slightly increases the liabilities assigned.

Why might this be so? A glance at Figure 6.15, in which we have illustrated the respondents' ratings of the likelihood of the person having committed previous offenses (from column fof Table 6.11) or the likelihood of the person committing 
FIGURE 6.14 Total Liability as a Function of the Interval Between Two Offenses

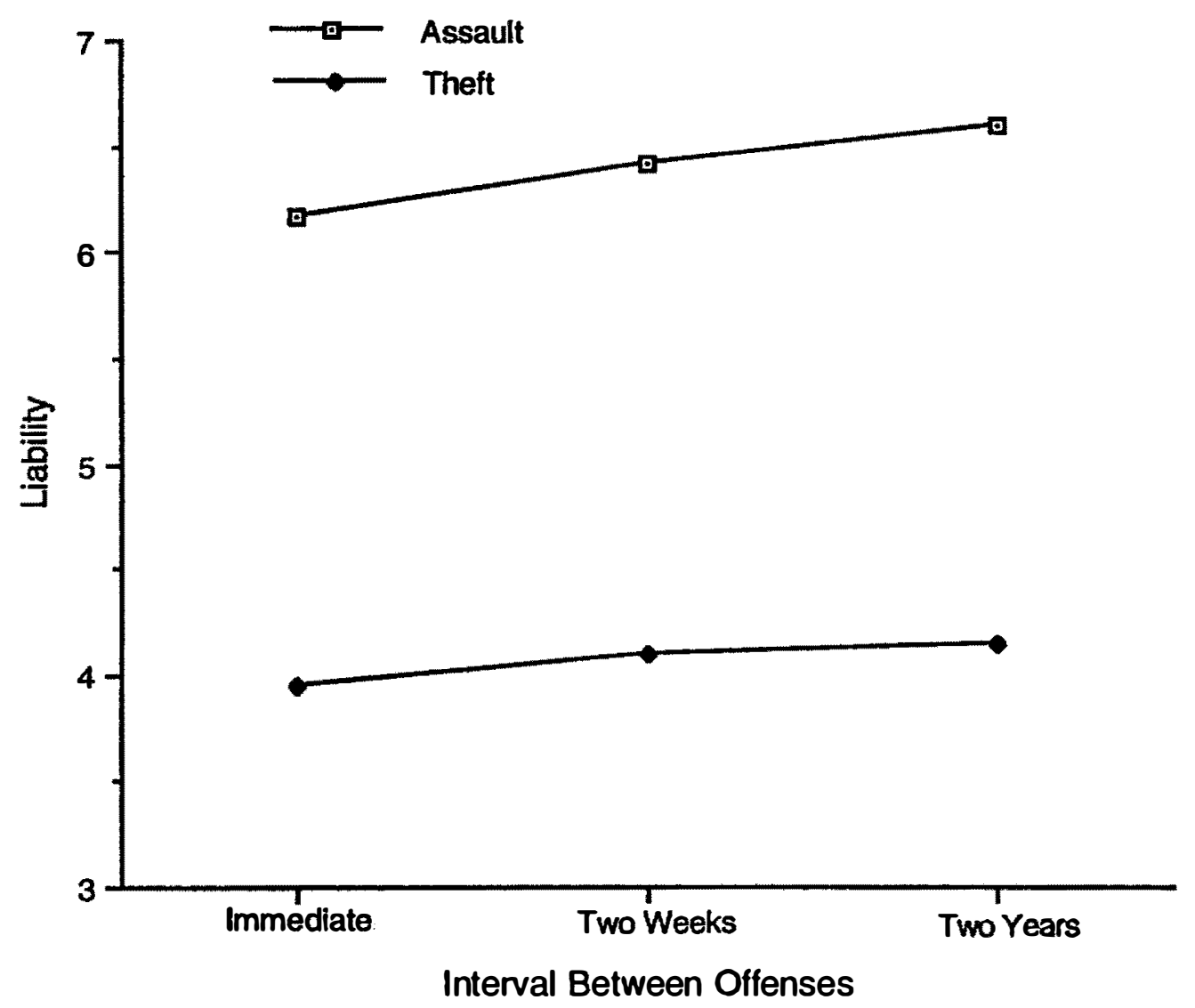

future offenses (from column $e$ of Table 6.11), suggests a mechanism that might be triggered by the delay between offenses and might be producing the increase in sentences. Respondents judge that it is much more likely that an individual who commits two assaults or two thefts separated by several weeks is more likely to commit similar assaults or thefts in the future (and to have done so in the past ${ }^{27}$ ) than an individual who commits two assaults or thefts immediately following each other. Further, an individual who commits two assaults or thefts over a period separated by two years is even more likely to act in a similar way in the future (and to have done so in the past).

It is clear that the respondents do what a great deal of research on person attribution processes suggests that they would, which is to treat information about a person's actions as providing information about his underlying dispositions (Jones and Davis, 1965; Kelley, 1967). In this instance, if a person does something once, a number of possible explanations are available for that action, including situational pressures rather than underlying dispositions. The thief of an oil drum could have been under some extraordinary pressure (for instance. needing medicine for his child) that caused him to steal; and the person who assaults another could have been assaulting a co-worker who harassed him. However, if the person 
FIGURE 6.15 Past and Future Likelihood of Committing Similar Offenses

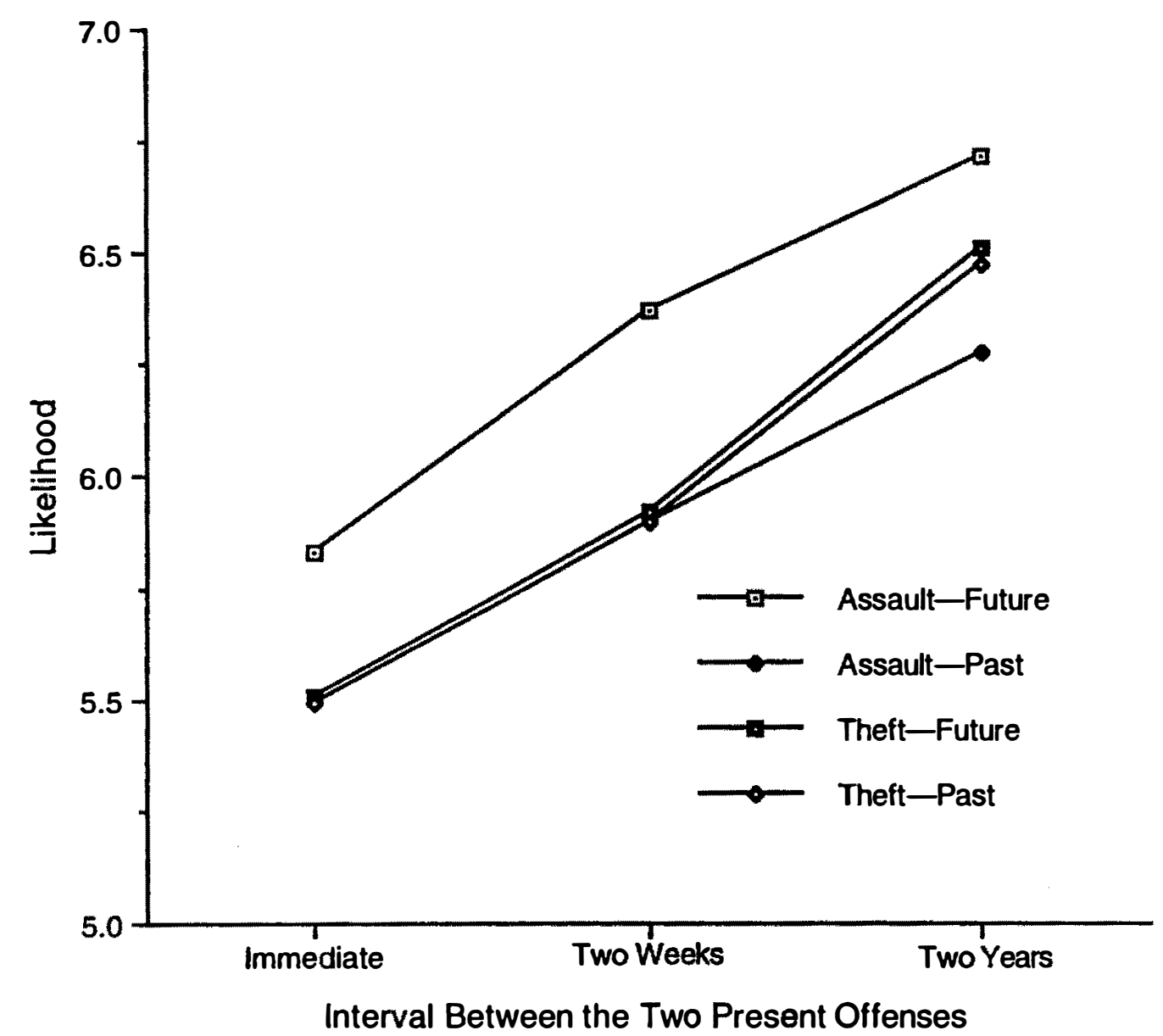

commits essentially the same act in different situations, then we are likely to conclude that the act is dispositional; that it reflects the true underlying personality of the person. So the observer will conclude, specifically, that the person is a thief or a habitually violent person. What the data pattern suggests is that the time separation between the two acts is read as suggesting that the two situations are in fact different.

\section{Study 18: Summary}

Our respondents do function the way that our intuition suggests and as the general, nonaggregated aspect of the federal sentencing guidelines articulate. They assign a more extended sentence for two crimes than for one but generally do not double the sentence that they assign for the first offense. They do not follow the strictly additive pattern characteristic of consecutive sentencing or the pattern of no increase in sentence that would be dictated by a concurrent-sentencing philosophy. Their sentencing pattern is in accord with the principle that we suggested earlier - that the punishment deserved for an offense is based only in part on the 
harm caused, such as the deprivation of the owner of his property. The person's willingness to violate the announced rules of society may be part of the foundation for punishment, and this factor is already taken into account in the sentence for the first offense.

Our respondents do not agree with the aggregational rules provided by the sentencing guidelines. Within those guidelines, theft is an aggregatable offense, and a number of thef ts of one item draws the same penalty as one theft of the same total number of items. Our respondents assign a sharply increased penalty to the second theft. In further disagreement with the sentencing guidelines, although slight differences emerged between the pattern of sentencing for multiple assault and multiple theft cases, the small variations do not suggest any major differences in our respondents' sentencing "philosophies" in those two kinds of cases.

What remains to be explored in future research are the conditions under which a pattern of multiple offenses leads respondents to move from a model in which each additional offense is punished, although with increasingly reduced penalties, to one in which the "habitual offender" concept comes into play. The latter may apply when an individual who has served a sentence for an offense repeats the crime. The "psychological logic" would then be that the sentence for the first offense did not deter the convict and a longer one is required. An alternative explanation is that, having once been officially sanctioned, greater punishment is called for with the second offense because the subsequent violation is a greater challenge to the authority of the criminal law. Yet one more explanation: We noticed that our subjects are making the inference that a person who commits the same sort of crime after a delay is predicted to be more likely to commit future crimes, and one might expect this to find its way into individuals' sentencing patterns. Subjects might be exercising the incapacitation function of punishment, locking away a person who is likely to commit future offenses. Future research could sort out some of these issues.

\section{CHAPTER SUMMARY}

In several of the cases we considered in this chapter, we found that our respondents' intuitions about the appropriate grading for different variants of offenses differ from those reflected in the legal codes. For instance, in sexual offenses, our respondents regard forcible rapes as generally of similar grades regardless of the existence of various kinds of prior relationship between the individuals involved, while the Code sharply conditions the offense grade as a function of prior relationship. With regard to felony murder, our respondents preferred a "felonymanslaughter rule" with a standard "accomplice discount" rather than the law's imposition of murder liability for all participants (and, in some jurisdictions, all variations of involvement by innocents and felons). When this or another community-code discrepancy was discovered, we commented on what principles of 
judgment might be underlying our subjects' responses, and we also discussed the implications of the discrepancy for code alteration, where we thought that a case could be made for consideration of that. With those discussions as background, we now turn to a consideration of the general implications of our subjects' responses.

In sum, it is clear that our respondents are in accord with the general tendency in the legal codes to distinguish grades of offenses within and between offenses. For instance, the subjects clearly distinguish different levels of sexual offenses, although not always exactly in the ways suggested by the legal codes. Interestingly, in the case of felony murder, in which, probably for policy reasons, the codes emphatically reject the idea of grading within felony murder and treat all cases as murder, our respondents do distinguish grades within that offense, assigning lower sentences to felons whose causal connection with the resultant death is more remote. Similarly, in the causation study, respondents grade different causal connections with a death differently, specifically assigning lower sentences to persons who intend to kill but do not succeed in directly doing so, although death eventuates by means of a later chain of events. The general notion of grading offenses is recognized as a basic and appropriate code function, both in the eyes of our respondents and in legal codes.

However, it is worth noting that the grading of offenses registered by our subjects is done in a somewhat different manner than codes generally accomplish such grading. The codes tend toward dichotomous grading: A botched attack on another's life, which through a chain of circumstances leads to that other's death, is either causally closely enough connected to the death (in which case it is murder) or not closely enough connected (in which case it is only attempted murder). In contrast, our respondents provide more continuous judgments; for instance, they judge that cases in which an attempted murderer's victim dies only through a chain of events after the attempt warrant a sentence lower than that for straightforward murder but higher than that for attempted murder. We will discuss the implications of this continuous grading further in the concluding chapter.

A different but related point is the tendency of some codes, including the Model Penal Code, to recognize too few categories of offenses-as compared to the refined intuitions of our respondents. Most jurisdictions have adopted a grading scheme that uses more than the five grades of the Model Penal Code ${ }^{28}$ but even eight or nine grades could not give expression to the rather nuanced judgments that we see our respondents make. The effect of this shortage of grades means that even in cases in which the codes properly identify a relevant mitigating or aggravating factor, they frequently must give it more or less effect in grading than it merits. Our respondents agreed with the Model Penal Code, for example, that absence of a prior sexual relationship aggravates liability for rape, but the Code's one-grade difference for those two cases - the minimum distinction it can make-significantly exceeds the difference in grade that our respondents would 
give. This argues for codes with more grades into which offenses can be categorized. ${ }^{29}$

The special problems of sentencing multiple offenses also suggest a structural change in current doctrine. Presently, multiple offenses typically are dealt with either by concurrent sentences, which impose no additional sentence for the second offense, or by consecutive sentences, which effectively double the penalty. Our respondents assign sentences for a second offense that add to but do not double the sentence for the first offense; and they continue this pattern for any further offenses. This approach matches at best one aspect of the United States Sentencing Commission guidelines, and the model provided by these guidelines may move the legal doctrine in this direction. 


\section{7}

\section{Conflict Between Community Views and Criminal Codes}

We now return to the question, which we raised at the beginning of the book, of the implications of discrepancies between legal codes and community standards, using the specific cases on which we have gathered evidence to illuminate the possible meanings of those discrepancies.

Recall our discussion in Chapter 1 regarding the importance of taking account of community views in formulating liability rules. Certainly, one cannot claim that the community's view is necessarily the morally correct view. As moral philosophers would note, the members of the community may well express views about proper punishment that they would find unfair if they themselves were to be judged by such views or that are in some other way unfair when examined from some rational moral perspective. Nonetheless, the community's disagreement with a liability rule may, at the very least, suggest that philosophers should scrutinize the analysis that leads them to a different formulation of the liability rule than community intuitions expect.

Community views have a more direct relevance, we argued, under a utilitarian justification for criminal-law rules, where the primary goal is the reduction of crime rather than the imposition of deserved punishment. The fear of the shame and stigmatization of criminal conviction is a powerful yet inexpensive deterrent, but its effectiveness depends on the established condemnatory value of conviction. The more past convictions correlate in the community's collective consciousness with morally condemnable conduct, the more likely that condemnation will attach with the conviction at hand. Thus, discrepancies between the criminal code and the community tend to undercut the condemnation of conviction and thereby lessen the effectiveness of condemnation as a deterrent threat.

Perhaps more important, recent empirical evidence suggests that the law's most powerful mechanism for gaining compliance lies not with the negative force of the deterrent threat but rather with the positive force of the law as arbiter of proper conduct. Most people obey the law not because they fear punishment but because they see themselves as persons who want to do the right thing. Again, discrepancies between the criminal code and the community tend to undercut the law's moral credibility and this, in turn, weakens the law's ability to dictate proper 
conduct. As the law's moral credibility decreases, so too does its power to set authoritative standards of conduct to which people are willing to conform.

Finally, the perceived "justice" of the system also is crucial to gaining the cooperation and acquiescence of those persons involved in the process (such as offenders, potential offenders, witnesses, and jurors). Greatest cooperation will be elicited in that situation where the system has greatest moral credibility. A system that is perceived as unjust is in danger of being subverted and ignored. On the one hand, it risks jury nullification and martyrdom that rallies resistance to its commands. On the other, it risks vigilantism.

Our conclusion is that the moral credibility of the criminal law is its single most important asset. Discrepancies between the code and the community have the potential to undercut the law's moral credibility and thereby its effectiveness. This can occur in either of two ways: by convicting morally blameless persons and by failing to convict morally blameworthy persons. The former may be more detrimental than the latter. That is, each time the criminal law convicts a blameless person, it calls into question, in some small way, the legitimacy of every other criminal conviction. As the number of blameless convictions increases, the credibility of each subsequent conviction decreases.

Where the criminal law fails to convict a blameworthy person, it may earn a reputation as being ineffective, but it does not as directly undercut the credibility of the convictions that do result. However, the criminal law's failure to criminalize certain conduct, which the community finds morally offensive, does call into question the moral judgment of the code drafters, which in turn may undercut the law's moral voice. Imagine for a moment that bestiality was decriminalized on the basis that no individual was harmed and that the prohibition infringed upon the individual's right of privacy (following the arguments that led to the decriminalization of consensual sodomy in many codes). A similar dynamic may occur where the law criminalizes the repugnant conduct but fails to punish violators of the prohibition, for reasons other than a lack of blameworthiness. One could conceive of many people losing faith in the moral judgment of the criminal law generally and reacting to it merely as a collection of rules rather than as a statement of moral wrongs. And this, in turn, we speculate, might reduce the criminal law's compliance power.

In the studies we have discussed in this book, we have sought out evidence for code-community discrepancies and frequently found it. However, we have not shown whether those discrepancies have the undercutting consequences we have suggested here. Is there any evidence that these discrepancies have the sorts of effects we suggest?

A number of studies have confirmed the existence of one of the relationships that we suggest, the one between an individual's disbelief in the morality of a particular law and his or her unwillingness to obey that law. Studies show that the 
degree to which people report that they have obeyed a law in the past and plan to obey it in the future correlates with the degree to which they judge that law to be morally valid (Grasmick and Green, 1980; Jacob, 1980; Meier and Johnson, 1977; Silberman, 1976; and Tittle, 1980).

There is less evidence for our other claim, which is that disbelief in the morality of one law eventually causes contempt for the legal code in general, or more accurately, those areas of the code that are concerned with the prohibition of activities that are not immediately and intuitively regarded as wrong. Tyler's recent (1990) Chicago panel study provides some indirect evidence on this point. The degree to which Tyler's subjects saw the legal authorities as having legitimate power predicted their willingness to obey various laws promulgated by those authorities. Thus, if people believe in the legitimacy of the authorities making the law, they are willing to believe that the laws that those authorities promulgate should be obeyed. Other studies find that a person's views about the legitimacy of the legal system and obligations to obey its laws correlate with that person's reports of engaging in lawbreaking activity (Sarat, 1977; Tittle, 1980). We would argue from this that when authorities promulgate what individuals consider an unjust law, individuals lose respect for the authorities and regard with suspicion the whole system of laws. When people report that they do not trust the "governmental system" or grant relatively little legitimacy to authorities, the evidence suggests that they are more willing to engage in violent social protest, rioting, aggressive political behavior, and use of violence for political ends. See Tyler's 1990 review of this evidence, pp. 33-35.

\section{WHEN CODE AND COMMUNITY AGREE}

With this introduction, one may ask whether we found cases in which any sort of code-community discrepancy exists. We did. But we also found many cases in which the code and the community seemed in harmony, and we begin by marking those cases.

The results of the studies confirm many aspects of current doctrine, including several important foundational principles upon which the doctrine is based. The legal system consistently asserts that the degree to which liability should follow a violation depends to a considerable extent on the culpability level of the person in violating the law. With this principle, stated at this broad level, our subjects were in agreement. The degree of a person's culpability for a violation, ranging from negligent through purposeful commission, made a difference in the penalties that our subjects assigned. This emerges most clearly from our Study 8, concerning offense culpability requirements, but also emerges indirectly in many other studies as well.

Further, our subjects recognized and granted validity to the various "excusing conditions" that are recognized in legal codes. For instance, debilitating abnor- 
malities in an offender's capacities (from mental illness, for example) can indeed serve to exculpate a person, even for the most serious offense. Still further, the studies found broad support for the recognition of justification defenses. If the person's conduct is justified in any of several ways that the law now recognizes, the subjects do not punish what normally would be an offense.

The studies also support many specific aspects of current doctrine, including provisions that have been criticized by some commentators. Causing a death during a felony is treated by the subjects as more blameworthy than causing the same death under otherwise similar circumstances. Negligence as to becoming intoxicated is accepted by the subjects as an adequate basis to impose liability for many offenses committed while intoxicated, as it is in many legal codes. When faced with a possibly insane person, people evaluate the degree to which that person shows both control and cognitive dysfuncion, which are the two dimensions that the legal codes mark as important. Further in accordance with the standards of judgment that the codes use, respondents make their liability judgments based on their perceptions of these dysfunctions.

\section{WHEN CODE AND COMMUNITY DISAGREE}

We turn next to the second set of cases, those in which the subjects' views conflict with current law. How can we characterize these differences in general? What issues do these differences raise for code formulation?

Our empirical research suggests factors currently used by the doctrine that are not relevant to the community's assessment of blameworthiness. The sexual offenses study, for example, reveals instances in which the Model Penal Code, which was drafted in the 1950s (and promulgated in 1962), no longer reflects community social mores. The subjects do not treat consensual intercourse with an underage partner as the very serious offense that the Code treats it as; they give no mitigation because of prior promiscuity of an underage partner, though the Code does; they do not give the significant mitigation to forcible rape that the Code gives where the victim is a voluntary social companion. Recall that if subjects see the violated individual as the nonconsenting victim of a sexual assault, they regard the act as incurring approximately equal liability whether or not a previous sexual relationship existed and the woman was on this occasion a voluntary social companion. This strikes us as an area in which the opinions of society have genuinely changed. In fact, current state codes now reflect this change in public opinion; most have recently dropped the spousal exclusion, voluntary social companion mitigation, and so on.

Research also can suggest factors that should be added to a code's assessment of liability. The culpability requirements study, for example, revealed that subjects impose significant increases in liability for a person's increased culpability over the minimum required for the offense by most legal codes. As the person moves 
from negligent to purposeful commission of the same offense conduct, our subjects assign greater punishment in response to this heightened culpability. Yet, with the exception of homicide and a few other of fenses, most codes typically define each kind of criminal conduct as an offense with a single grade, defined only by certain minimum culpability requirements, usually recklessness. If the code is to mirror community views, the culpability study suggests that offenses be defined to include multiple grades according to the person's culpability level. The specific suggestion here is that code drafters consider increasing the grade of the crime as a function of the culpability of the perpetrator-rather than using recklessness as the trigger for a single grade of offense.

Empirical studies have the potential to not only identify when an additional of fense element is needed but also to guide drafters in formulating the element, as in selecting the level of culpability to require as to which element. The culpability study illustrates that the subjects have specific views on what the minimum level of culpability ought to be and how much liability ought to increase for increases in a person's culpability. Recall that this judgment was a relatively complex one, with culpability as to different elements-for example, "core" elements versus "collateral" elements-having different effects.

In addition to identifying needed elements or setting culpability levels, empirical research can help choose between alternative formulations of an offense or even suggest new formulations or criteria. The attempt study, for example, challenges the Model Penal Code's formulation of the objective requirement for attempt. Though modern doctrine imposes attempt liability as soon as a person takes a substantial step toward commission of an offense, 77 percent of the subjects would impose no punishment in such a case. Instead, the subjects generally support the older common-law tests for attempt: All respondents would impose liability and punishment when a person has come close to committing the offense. The code-community discrepancy here is an interesting one, and one that raises pertinent issues in the debate. It may be that, given the current climate of worry about increased criminal activity, the code is moving in the direction of criminalizing relatively small steps toward the commission of crimes. Here, those interested in retaining the system's integrity should carry out this debate with maximal involvement of the public, so that the public can be put on notice that the code criminalizes conduct at an earlier point than the community intuitively would. This is important to protect the code's moral credibility; code drafters ought to make clear their reasons when their formulation conflicts with the community's views.

Earlier in this chapter, we remarked that, in Study 16, our respondents agreed with the code's tendency to treat a killing that occurs in the course of a felony as deserving more blame than the killing would in nonfelonious circumstances. Although this generally is true, our felony-murder study reveals that the common 
formulations of the rule do not reflect popular intuition. (Subjects tended to punish most accidental killings during a robbery as less serious than manslaughter, though many codes woud punish those killings as murder.) This makes all the more puzzling the rule's continuing political vitality despite its extensive criticism by scholars. Some aspects of the rule are clearly less popular with the subjects than others, suggesting a means by which the rule could be reformed. For instance, subjects do not follow the logic of assigning murder to the surviving robber when, during the course of the robbery, the wife of the store owner shoots and kills one of the robbers. A reconstruction of the rules to reflect this would be possible. Felony-murder could be retained for killings that directly result from the action of the perpetrator and perhaps his accomplices, given the utility of hold ing participants in the crime responsible for the actions of their fellow culprits. Alternatively, some might use the results to support abolition of the special rule in favor of reliance upon the usual homicide doctrines with the addition of certain evidentiary presumptions, as the Model Penal Code does but which most states have rejected. That is, if a death occurs during the course of a felony, the perpetrators would be presumed to have caused that death in a way that warrants a murder penalty, and it would be the task of the defense to rebut this presumption with evidence showing that the defendants' conduct, while reckless, did not manifest extreme indifference to the value of human life.

Another use of empirical research is to set or adjust the grades of offenses. For example, if the felony-murder doctrine is not to be abolished or reformulated, the research suggests that, at the very least, its liability grades should be reduced. A "felony-manslaughter rule" might be more appropriate.

A more fundamental grading issue is illuminated by the attempt study. Some codes, like the Model Penal Code, impose the same level of liability for an attempt as for the offense that is attempted; ${ }^{1}$ but a majority of codes provides a standard discount for attempt liability. The subjects support the majority rule here. ${ }^{2}$ This sheds some light on a dispute in the literature over people's intuitive notions as to whether actual resulting harm should increase liability. ${ }^{3}$ The attempt study also suggests that resulting harm does increase a person's deserved punishment-in the subjects' view-but that even liability for a completed offense sometimes is reduced if the person is able to undo the harm that has been done. This evidence has implications for the formulation and grading of all offenses, as well as doctrines of liability such as complicity; it suggests that codes ought to distinguish and punish more severely instances where the prohibited harm actually occurs or the prohibited conduct is actually consummated, as compared to instances where the harm or evil is only intended (but not carried to completion).

The studies also suggest different grading than current law for most of the doctrines that concern errors in justification. If a mistake as to a justification does not give a defense, it ought to at least mitigate liability, according to our subjects. 
The general area of justification for actions otherwise prohibited is an interesting one from the perspective of code-community clashes. Review for a moment our findings on the degree of force that the community finds appropriate to use in defense of self or property or to bring about a citizen's arrest. The shared theme here is the degree to which the average citizen can take the law into his or her own hands. Recall that our subjects were willing to approve the use of a good deal more force than the legal codes would permit, and the use of force in a good many more cases that the codes would allow.

We see several possible explanations for this. First, many of our subjects may see the criminal justice system as failing to keep its side of the social contractfailing either to apprehend criminals or to get them convicted when they are arrested or to keep them in jail when they are convicted. If this is the case, have they, therefore, reverted to a vigilante notion of justice, in which any individual is entitled to take almost any step to protect his or her property or person? To the degree that this is the case, it represents a complex problem for code drafters. To what degree can or should the code be formulated to represent people's views about a perceived or actual breakdown of the criminal justice system? This seems a particularly acute question for the case of force allowable in carrying out a citizen's arrest. Our subjects seem to be trying to convey the message that a person who uses a high degree of force in these circumstances, even unnecessary or disproportionate force, should receive only relatively minor punishment for doing so (in contrast to the codes' dichotomous, all-or-nothing assignment of liability). Again, what may be going on here is that subjects may perceive the existence of crisis within the criminal justice system. People may believe that our overtaxed police departments have a very low likelihood of apprehending a thief or that our court system has a very low likelihood of appropriately punishing the thief if apprehended. If respondents are thinking along these lines, they may believe that the violent acts of the theft victims are the only punishment a perpetrator is ever likely to receive and, therefore, that victims are appropriately empowered to deliver this punishment.

A second explanation of the results is this: People may rely on a different set of principles than those that we articulated from the legal code for judging appropriate defensive force. For instance, the legal code formulation seems to require some apparently complex calculations-on the part of the attacked person-about exactly what an attacker intends and about the minimum force sufficient to thwart those intentions. People may regard it as inappropriate to require such judgments of an attacked individual in what they perceive as a rapidly occurring and emotionally terrifying situation (such as an assault or a robbery).

The above cases raise the possibility that subjects would approve of alterations in the legal codes that decriminalize certain acts or reduce the liability assigned to those acts. However, we would remind the reader that, in other cases, our subjects 
seem to be calling for the criminalization or more serious treatment of actions that the codes do not criminalize or to which the codes assign relatively minor penalties. These studies suggest that new offenses be created or that liability be expanded from its current scope. The omission study, for example, reveals that about 80 percent of the subjects would impose liability for a person's failure to rescue a stranger when such can be done with no danger to the rescuer. Current doctrine, recall, imposes no duty to rescue in such a case and, therefore, imposes no liability for failing to do so, no matter how minor the inconvenience to the potential rescuer.

\section{LIABILITY REQUIREMENTS VERSUS LIABILITY FACTORS AND DICHOTOMOUS FUNCTIONS VERSUS CONTINUOUS FUNCTIONS}

Perhaps more dramatic than the comparison with any particular aspect of current doctrine are the rather clear findings that the process by which our subjects assess liability is different from the way in which the drafters of current doctrine conceptualize the issue. Where the doctrine treats a factor as setting a fixed minimum requirement for full liability, the subjects frequently see the same factor as aggravating or mitigating the degree of a person's liability and punishment. For example, while the doctrine treats complicity as a means of establishing full liability for the substantive offense, the subjects generally consider an accomplice to be less blameworthy than the principal and reduce the accomplice's liability accordingly. ${ }^{4}$ A similar general "discount" in liability is seen in cases of omission. Though the doctrine holds a person fully liable for the substantive offense if he or she satisfies the requirements of omission liability, the subjects significantly reduce a person's liability if he or she commits an offense by omission from what it would be if he or she committed the same offense by commission. ${ }^{5}$ Reacting intuitively, the community's views seem to us to be more rational than the code treatment here. In a failure to rescue case, the codes' assignment of no penalty to the stranger who fails to rescue and of a penalty equivalent to murder or manslaughter if certain complex conditions about the assumption of duty are met seem, respectively, too lenient and then too harsh.

The grading of attempt conduct further demonstrates this difference between the codes' and the respondents' treatment of liability. The codes define a particular point, during the preparation and conduct toward an offense, as the moment when liability attaches. The subjects, in contrast, see increasing liability as the person gets closer to committing the offense.

From the subjects' perspective, the codes' tendency to dichotomize signals a serious and pervasive flaw in current law. The doctrine more often than not sees a fact as either establishing liability or not or as giving a mitigation (or an aggravation) or not; a relevant fact in the case typically triggers application of a particular rule or subrule. The subjects, in contrast, frequently see a continuum of blame- 
worthiness and liability. A fact more frequently contributes to an increment or decrement in liability judgment than produces a complete assignment of liability or total escape from liability.

The notion of a liability continuum for some factors is acknowledged by current doctrine in some contexts. Codes typically are structured to impose greater liability for greater harm done, all other things being equal. Codes sometimestoo rarely from the subjects' perspective-vary the degree of a person's liability with his or her level of culpability. The codes' culpability spectrum is not a strictly continuous one, at least as it is defined in modern codes, with four discrete levels of culpability. It is, however, a practical and useful approximation of a continuum.

In most other instances, however, current doctrine fails to acknowledge continuums that the subjects clearly support. In complicity, for example, not only do the subjects give a liability discount to the accomplice, which the codes do not, but the respondents vary the extent of the discount with the extent of the accomplice's contribution to the offense. Similarly, in attempts, the extent of the attempter's discount will depend in part on how far he or she has gone toward completion of the offense. In omissions, the extent of liability depends on the degree of danger or inconvenience to the person who is to undertake the rescue.

In causation, liability varies with the strength of the causal connection between the person's conduct and the result. The law, in contrast, sets a maximum degree of tolerable remoteness between the person's conduct and the result-for instance, in time, place, or strength of causal chain. If this maximum amount is not exceeded, the person is fully accountable for the result. The subjects, in contrast, see degrees of liability according to the degree of remoteness.

Obviously, a criminal code cannot take account of the infinite continuum over which many factors may range. ${ }^{6}$ It is not unrealistic, however, to expect a code to recognize that these factors are relevant to determining liability-that is, to recognize some kind of discount-and to attempt a rough approximation of their varying effect. This can be done in the same way that modern codes approximate the harm and culpability continuums-by defining a few large categories for each of the most relevant factors. Such a rough approximation of a continuum generally is sufficient for the criminal code's role of indicating a range for the extent of punishment. More refined distinctions can be made in the sentencing process.

Is it not the case that all such distinctions could be reserved for the sentencing process? We suggest that it would be a mistake to push over to the sentencing process the responsibility to make such rough approximations of highly relevant factors, especially when such determinations can effectively be made by a code. First; as a matter of principle, the purposes supporting the legality principle, as well as modern notions of due process, prefer that the most significant determinants of liability be considered at the liability stage, where the jury can make the determination under the normal rules of trial procedure. To leave such determinations to the more discretionary sentencing stage is to devalue legality, the jury system, and 
due process unnecessarily. ${ }^{7}$ Second, at the level of practice, jurors are more likely to abide by their legal instructions to the extent that those instructions reach results that they regard as fair outcomes. To fail to have verdicts that match the general range of punishment deserved is to invite jury dissatisfaction and resistance.

\section{CRIMINAL LIABILITY WITHOUT PUNISHMENT}

In many of our studies, the subjects impose criminal liability on a person but then impose little or no punishment. ${ }^{8}$ Such is the subjects' view: (1) where the person is intent on crime but his conduct falls short of dangerous proximity of commission; (2) where the person satisfies the objective elements of an offense but is faultless as to one or another element; (3) where the person fails to rescue the stranger because of danger (or inconvenience); and (4) where the person mistakenly or improperly uses deadly force in self-defense, unnecessary force in protection of property, or excessive force or force against the wrong person in attempting to detain an offender.

This practice by subjects may seem somewhat odd. If the person's conduct is serious enough to merit the condemnation of criminal conviction, why should the person escape punishment? One explanation is that the subjects want to express their disapproval of the person's conduct but feel that the person is not sufficiently blameworthy to be punished for the conduct. If one takes a once-popular view among academics that the only role of the criminal law is one of deterring criminal behavior, this response by the subjects makes very little sense. Liability is taken as a judgment that application of deterrent punishment is appropriate, yet no such application is made. ${ }^{9}$ However, if one sees the criminal law as having dual roles (of both announcing rules of proper conduct and adjudicating violations of those rules) and, further, sees desert as the primary guide for assessing punishment, then this sort of judgment of "improper conduct, no punishment" makes more sense. It is the mechanism by which the subjects seek to achieve the sometimes conflicting functions of law: judging the propriety of the conduct as a signal to others in the future and judging the blameworthiness of the defendant at hand for his past violation.

Notice that, in each instance that "liability but no punishment" is given as a response, the person's conduct is arguably inappropriate although the actor is not held to be terribly blameworthy. In the omission cases, for example, in which an individual fails to rescue a drowning man although he could do so without great danger, our subjects often assign a verdict of "liability but no punishment." Here the subjects seem to be saying that this is conduct that they want to disapprove of, but the individual does not deserve a term in jail. The subjects use the condemnatory function of the legal system in a way that makes perfect sense if one sees that ordinary people take the legal code as having moral force to exert on the citizen. The respondents also seem to be saying that these sorts of behaviors are morally inappropriate, without feeling that the person is to be punished for the conduct. 
In doing so, they are acknowledging what has become one of the major messages of our discussion: that the legal code is seen as having moral force by the citizens of the state, and the legal code's moral force operates independently of its coercive force. For this reason, we suggest that code-community discrepancies have far more importance than the previous rather scant attention to the topic has given them.

Still, imposing criminal liability in such a verdict, in one sense, perverts the function of criminal conviction. If the person is not sufficiently blameworthy, why should he or she suffer the condemnation of a criminal conviction? The answer may be found in the limited options available in the criminal law. The law provides no opportunity, other than through criminal conviction, for a person's criminal conduct to be disapproved. The subjects are caught in a difficult situation. On the one hand, to decline to impose liability is to seemingly approve of conduct of which they in fact disapprove. On the other hand, to impose liability is to blame a person whom they see as not warranting the blame they hand out. The liability-but-no-punishment option may seem an attractive compromise in such a situation.

In the end, however, the liability-but-no-punishment option is just that-a compromise - rather than an accurate expression of the subjects' or jurors' feelings. The fact is that such a practice imposes criminal liability, albeit without punishment, on persons who do not deserve it. This is not only unfair to the person and unsatisfying to the subjects and jurors but also undercuts the effective operation of the criminal law. If the law's role is to exact justice, it fails in that function when an insufficiently blameworthy person is convicted. That no punishment is imposed only minimizes the extent of the injustice. Also, of course, when juries convict, they cannot control whether the judge will exercise the nopunishment option.

The difficult situation and the undesirable compromise arise because the criminal law has two important but distinct functions, each of which has its own special demands. These two functions-announcing public rules of conduct and assessing individual blame in adjudication of a violation-have very different doctrinal foundations. The rules-of-conduct function gives the general population ex-ante direction as to what they can, must, and must not do. The principlesof-adjudication function gives decision-makers (i.e., prosecutors, juries, and judges) guidance in assessing ex post the blameworthiness of an individual's violation of the rules. When the doctrine tries to serve both of these functions with the same provisions, one or the other of the functions suffers. In this instance, an offender is convicted to assure that the proper signals are sent to disapprove of the conduct - the rules-of-conduct function is satisfied-yet a blameless or insufficiently blameworthy offender suffers the condemnation of conviction-the adjudication-of-blame function is perverted. In other instances, the reverse perversion occurs. ${ }^{10}$ 
The solution to the subjects' dilemma and to the "perversion" of the law is to allow subjects and jurors to disapprove of the person's conduct without condemning the person. This requires the use of trial verdicts that allow a distinction between an acquittal based on approval of the person's conduct and an acquittal based on a person's blamelessness for admittedly improper conduct. The available trial verdicts might be: "no violation," "blameless violation," and "guilty" or "blameworthy violation" (see Robinson, 1990, pp. 766-767). In future research, one could allow for such verdicts from subjects and test the conditions under which they would use each.

\section{THE JURY AS A RESOLVER OF CODE-COMMUNITY CONFLICTS}

Is it possible that our elaborate focus on code-community comparisons misses the point? One could argue that we misunderstand the functioning of the legal system and ignore the presence of a mechanism within it that modifies the results produced by a mechanical application of the legal code where community standards would be seriously violated by formulaic application of the code. The mechanism, of course, is the jury. Juries have been known to produce verdicts that seem far from the ones that would be required by an exact application of the legal code, choosing instead, for instance, to find an individual not guilty of the of fense or guilty of a lesser offense that provides the reduced punishment that the jurors judge to be appropriate. Here we recall the case of "the subway shooter," Bernhard Goetz, who shot several persons whom he believed were beginning to mug him during his ride on the subway in New York. He was found not guilty of any serious charges even though his actions seemed to clearly violate what the code formulations allow in self-defense. Similarly, the rather inelastic code formulation of self-defense has been stretched to find persons innocent who would otherwise be found guilty under the code-for example, battered women who finally kill their abusive husbands.

Certainly, within the Anglo-Saxon legal system, the jury emerged with what is called "jury nullification" as one of their legitimate functions. Historically, this was not always the case; the jury was not always given leeway to make these sorts of adjustments. Early in the history of the emergence of the jury, there were cases in which the civil authorities, outraged at a particular verdict of a jury, threw the members of the jury in jail. But quite early in the development of the jury, jurors became immune from this kind of retrospective punitive evaluation of their verdicts (Green, 1985). This gave the jury the autonomy to refuse to find individuals guilty (even when the code would have found them guilty), or to find guilty unpopular individuals who were charged with offenses they might not have committed. Interestingly, Green's analysis of jury deliberations occurring in the twelfth century showed that jurors actually did use their nullification powers to find innocent various of their neighbors who had harmed or killed others in what 
the jurors regarded as acts of self-defense, even though the acts did not meet the stringent requirements that the legal code set up for legal self-defense.

The code requirements at that time were not dissimilar to what they are now, requiring that the attacker be threatening injury at the moment and that retreat from the attack be impossible. Facts damaging to the claim of self-defense, therefore, were that the attacker was wounded in the side or the back (since it would follow then that the attack could not have been in progress) or that the incident took place in an open field or some other location from which it should have been possible to flee the attack. Coroner's reports often attested to the awkward presence of these facts in specific cases. But during the jury deliberations (as inferred from the facts as they were described in the jury reports), wounds that the coroner had described as located in the back or side of the attacker were mysteriously relocated to the front-creeping wounds-and what were described as open fields were found to contain ditches, dikes, hedges, or other obstacles that made retreat from the attack more plausibly impossible. ${ }^{11}$ Juries have nullified the mechanical operation of the criminal code in the twelfth century, in the twentieth century, and no doubt every century in between. By doing so, they bring community standards to bear in a context that finally gives them no apparent role.

However, relying on the jury to nullify the normal operation of the legal code in cases of code-community discrepancies does not seem to us to be an entirely satisfactory mechanism for adjudicating differences. First, it is unlikely to consistently work in a way that provides fairness across cases. One jury, somehow aware of its power to nullify, does so. Another jury, unaware of its power to nullify, or more cowed by the authority of the court, does not. One of the accused goes to jail, the other goes free. ${ }^{12}$ What frequently happens is that this discrepancy, now personalized in the form of two individuals, is publicized, drawing attention to the unfairness of the legal system in a vivid and personal way. Second, as we have discussed earlier, for the legal code to criminalize certain actions that people regard as morally acceptable (even though juries at least sometimes do not convict) is to give a signal that damages peoples' respect for the legal code and, thus, likely impairs what we have called its moral credibility. Third, as pointed out by Green, if juries systematically provide this kind of "safety valve" function for the legal code, they reduce pressure for a change in the code that would move it in the direction of better rendering community standards (and thereby enhance its moral credibility). In the extreme case, they stultify code change.

Further, the jury's nullification ability is effective only as far as their power extends--in the assignment of liability. The jury's power only works in one direction; they can with their verdict minimize the extent of punishment that a person can receive, but they cannot ensure that a judge will sentence a person to the full punishment that their verdict calls for. Finally, and relatedly, many of the code positions that we have shown to conflict with community views are instantiated in sentencing-guideline systems. Most of what we have said about "missing dis- 
counts" and dichotomous rather than continuous treatment in codes applies equally to existing sentencing guidelines. Although judges who pronounce sentence might share the jury's desire to deviate from the formal demands of the code and might regularly have done so through the exercise of sentencing discretion, that possibility is reduced when sentencing guidelines have been articulated that deviate from community views. ${ }^{13}$ For all of these reasons, then, it seems preferable to us to have community standards reflected in legal codes when it is appropriate to do so.

Our argument has been a long one, and it seems useful to draw some elements of it together as a conclusion. In doing so, we will emphasize what we think the implications are for those who are involved in legal code drafting.

Drawing on both empirical social science research and various theories of the justification of punishment, we suggested that code-community conflicts, if they are to exist, would have various corrosive consequences on the general respect that ordinary citizens have for the criminal justice system and, therefore, their willingness to obey the law. Next, via a set of scenario experiments, we demonstrated that, frequently, such discrepancies do exist. The moral intuitions of ordinary persons and the rules formulated in legal codes frequently clash in ways that seem very important to us.

We suggest that the implications of this for code-drafting groupsare as follows. First, we would urge that various alternative formulations of code provisions under consideration by code drafters or legislators be subjected to the sort of empirical scrutiny represented by our experimental procedures. We suggest, specifically, that social science research of the sort we have illustrated in this work be an explicit part of a code-drafting process and that social scientists be included among the parties involved.

The research process need not be complex or time-consuming. Representative samples of subjects could be drawn in advance from the state or other jurisdiction that was to be governed by the proposed legal code. Once the specific alternate code provisions were clear, the social scientists could quickly design scenarios that would test the community intuitions about the alternative possibilities instantiated in the proposed versions.

Second, how would these empirical results play into the drafters' deliberations? A number of possibilities exist. Frequently, if one examines the minutes of the deliberations of code-drafting groups, one finds that they intend to base the code provisions under discussion on the intuitive standards of justice of the community. If this is so, then disagreeing factions among the code-drafting group are often disagreeing about the moral intuitions of the community. Certainly, in that case, the empirical findings, particularly if they result from experimental designs that the disagreeing factions have agreed on in advance, should be of considerable utility in resolving the controversy. Nevertheless, one or more factions may be pressing for the consideration of other reasons for preferring a specific code for- 
mulation than one reflecting the moral intuitions of the community. If so, suppose our sort of empirical research reveals that the proposed formulation is in some way at significant odds with the community's view. Then, such conflict ought to be taken into account in debating the provision and, if the counterintuitive provision is finally adopted, community education about the provision would be required.

In fact, two kinds of education are necessary. First, the community should be informed that the counterintuitive provision is the one that the lawmakers chose to adopt and therefore people should govern their behavior accordingly. Otherwise, since individuals generally tend to assume that code provisions match their moral intuitions, they will be uninformed about the possibilities of transgressing the law. ${ }^{14}$ Second, the public needs to be informed about the reasons why the code deviates from moral intuitions in order to avoid the lessening of respect for the criminal law that would otherwise result when some violation of it is publicized, causing the community to become aware of it in what could be explosive circumstances. In other words, when a counterintuitive provision of the legal code is put into effect, the community needs to be informed about the provision and persuaded of its validity.

Certainly, social science has a role to play here as well. Research could determine not only what sorts of explanations of the new code provision would make people most aware of the code, but also what sorts of explanations would make them most convinced of the necessity of the provision.

Our attempt, then, has been to persuade the reader of the value of a certain kind of research in the formulation of legal codes and to demonstrate what the beginnings of such research projects would entail. 


\section{Appendix A: \\ Research Methodology}

In this appendix, we discuss several related technical matters that we believe will be useful to the reader attempting to evaluate the weight to be given to the findings that we report. We begin by placing our research design in a more general social science context and then discuss the strengths and weaknesses associated with that design. Finally, we turn to what proves to be a quite complex question: When can it be said that there is a consensus among our individual respondents in their treatment of cases? This brings us again to a discussion of the role of community views in drafting legal codes.

\section{OUR RESEARCH DESIGN IN CONTEXT}

In a good many ways, our present research method resembles what Rossi and Nock (1982) refer to as a "factorial survey." As they report, the method of factorial survey was designed to gain an empirically based understanding of people's judgments in various domains. Basically, it asks people to judge a number of cases and then analyzes the pattern of judgments across cases in order to determine the judgmental principles that the people are using.

The factorial survey method combines elements from experimental psychology with those of survey sociology. From experimental psychology one takes the notion of the balanced multivariate experimental design and from sociology the method of sample survey procedures. Subjects are presented with a number of cases to judge, and these cases differ on the various factors that the researchers think might make a difference to the respondents. The cases are arranged so that the different factors are varied orthogonally, enabling an assessment of the independent contribution of the different factors to the final judgment. Because a reasonable sample of respondents is surveyed, it is possible to determine to what degree the judgment structure is a shared one and to what extent it differs between individuals in the sample.

An example may make this clear. Automobiles differ on a number of dimensions, but surely safety on the road, gas mileage, and price are three of them. Suppose, for a beginning, we set three levels of each of the three factors. Combining each level of each factor together generates $27\left(3^{3}\right)$ cases. ${ }^{\prime}$ By having a number of 
respondents rate each case, we would be able to determine the weight they put on each dimension in determining their preference. We would expect some consensus on the ratings; we would be surprised if anyone did not put a reasonable weight on safety. However, we would also expect some individual differences in the ratings as well; one respondent might value gas mileage a great deal; another might care more about price.

In the present studies, our goals have caused us to deviate from standard factorial survey methods in several ways. First, our research was theory-driven in a particular way. Because we are interested in only a subset of dimensions that might determine judgments, we designed cases that varied only on those dimensions rather than on all of the possible dimensions that might contribute to human judgments. Specifically, we examined the dimensions of a crime that were signified by legal codes as important, such as culpability or the presence or absence of excusing conditions. We also examined the plausible alternate dimensions that had some claim to be included within the legal codes and along which we suspected our respondents might assess the cases. Certain dimensions that do not have a claim to be included within the legal code were omitted from the studies. For instance, a considerable body of research suggests that the physical attractiveness of the defendant can make a considerable difference in the sentence handed down for a crime. Despite this fact, there is no argument that recommends including such a dimension in legal codes, and we did not include a physical attractiveness dimension in our studies.

Second, although it will be relevant in future studies, we were not initially concerned with a highly precise assessment of group or individual differences in judgments, so we did not include the larger numbers of respondents that would have been required to assess such differences in a more precise fashion. Also, we did not do the careful sampling of a defined population that would be required to precisely generalize our results - with a known degree of error-to this population. Our reasons for this, discussed in Chapter 1 , involved a decision as to what we thought was valuable to achieve in these initial studies (investigating the moral intuitions of the community and discrepancies between those intuitions and the legal codes).

The procedures we used for examining the community's views on appropriate punishments for various crimes can be quickly overviewed. We contacted people to participate in our studies and asked for their views on the appropriate level of liability to assign to perpetrators of various crimes that we described to them. Each individual read about a particular crime case, "a scenario" in our vocabulary, and was asked to decide whether a criminal sentence was appropriate for the perpetrator. Individuals, "subjects" or "respondents" as we call them, then read another crime scenario and assigned a punishment to it. The sets of scenarios that our respondents were given usually were identical in a set of core elements and differed only on the dimensions that we thought would make a difference in their liability judgments or were thought by criminal codes to make such a difference. 
By this method of examining the differing sentences assigned to closely related cases, we sought to determine whether shared community notions of justice exist and, if so, on which issues, as well as the ways in which such notions compare to current law.

For example, criminal codes often treat the crime of forcible sexual intercourse differently if it is committed between individuals who have had a previous sexual relationship. Is this in accord with the way people currently think about rape? To determine this, we first developed a description of a rape that could function as the core of a scenario. To form the "stranger" scenario, we then added to that core a few sentences making it clear that the two parties were strangers to one another. To form another of the scenarios, we added to the core a few sentences making it clear that there had been a previous sexual relationship between the two parties. In this way, we formed the various scenarios that were needed for investigating the various issues in sexual offenses. Using the same general procedure of core and additions to the core designed to create the variations of interest to codes and community standards, we developed the sets of scenarios that we used for all of our studies.

Reported in this book are 18 studies that were designed and executed in seminars at Rutgers University School of Law in Autumn of 1990 and Spring 1991, with the help of faculty and graduate students from the Princeton University Department of Psychology. Some of the studies informed us as to conduct that the community believes should be criminalized or as to the conditions that exculpate a normally blameworthy violation of a legal rule. Other studies were directed at community standards for appropriate behavior in defense of self or property. In still others, on the vexing questions of actions committed while the offender is intoxicated or insane, we returned to some of the oldest questions at the intersection of law and social science. In the book, we discuss the results of our studies and attempt to draw out the implications of our findings for the criminal code. To help the reader evaluate the evidence, we now will take a closer look at our research methodology and particularly at its potential pitfalls.

\section{STRENGTHS AND LIMITATIONS OF OUR RESEARCH METHODS}

Each study presented subjects with a series of scenarios depicting variations of a criminal episode. Each scenario embodied a particular variable or combination of variables that were to be tested. The subjects typically were asked to indicate the liability that they would impose given the facts described, and their responses to the different scenarios were compared to determine the effect of the variable or variables.

For non-social-science readers, the dangers and limitations of such "scenario" research should be noted. Briefly, three difficulties exist. First, the scenarios may not be perceived by the respondents as we hoped they would be. Second, because our version of the experimental design asks the same respondent to respond to 
many versions of the same core scenario, the differences between those scenarios are highlighted and called to the respondent's attention in a way that they might not be in other situations. Third, the people we tested, "the samples we drew" in technical parlance, were not selected to represent the population of the United States or even of a particular state or jurisdiction. They were individuals whom we contacted who were willing to participate. In the end, more than seven hundred individuals had participated in our studies.

Next we will say a bit more about each of the difficulties that we have just described, what we did to combat them, and what limits they still impose on our findings.

The first, that "the scenarios might not be perceived by the respondents as we hoped they would be," really references a whole family of related concerns. When we were writing scenarios about the amount of force that it is legitimate to use in self-defense, for instance, suppose we attempted to create a case in which the defender used just sufficient force to stop the attack on him. But did the subjects read the case in that way? That is an open question. The standard procedure to answer the question involves asking the respondent to report not only on the liability he or she would assign to the person but on the various ways that he or she perceived the details of the case. So in this instance, we would ask the respondents to tell us "if the force used was just sufficient to deter the attack" or greater or less than that. These questions that test the respondent's general perceptions of the story (and whether these perceptions agree with the ones that the researchers intended to create) are called "manipulation checks." Sometimes we "passed" the checks and sometimes we did not. That is, sometimes the respondents read the stories as we intended, and sometimes, even though we wrote and rewrote numerous versions of the stories, they did not.

Further, it is not enough to confirm that the subjects perceive the scenario as presenting the factor that the researcher wishes to have represented. One needs to be careful that a change in one element of the story, intended to create one perception, does not create others as well. For instance, in some jurisdictions, an insanity defense is provided if an individual suffers from what is called a "control dysfunction." In other jurisdictions, only an individual who suffers from a "cognitive dysfunction" qualifies for the defense. To test which formulation agrees with the views of the respondents, we needed to create a scenario version in which a person assaults or kills another and does so because he has a control dysfunction rather than a cognitive dysfunction. (And, in another version, vice versa.) To see that the scenarios were correctly interpreted, we asked readers questions about what degree of both dysfunctions they inferred from the story. Not surprisingly, it was often the case that the reader inferred both a control and a cognitive dysfunction from information that we had hoped would create the inference of one dysfunction but not the other. People process information in rich, multiple, and complex ways, when occasionally we wished that they wouldn't. 
Even confirmation that the tested variables are properly perceived does not guarantee usable results, however. In addition, a researcher must attempt to demonstrate that the scenarios are not perceived as presenting other unintended but potentially influential factors. If such extraneous factors exist and are perceived as being present in varying degrees in different scenarios, differences in liability results may reflect the subjects' reaction to the unintended factor rather than to the variables sought to be tested. One method of reducing such unintended variations is to have all scenarios use the same basic facts-with differences only to reflect the intended variables. While this procedure might seem relatively effective at reducing unwanted variations, it has its limitations. A subject may give different meaning to identical language in different scenarios. Context matters, as we occasionally discovered in our studies.

Given these difficulties, it came as no surprise to us that some studies required five or ten drafts and pretests of the test instrument before they could be administered to the full subject pool. Even where the manipulation seems successful, however, there is always the theoretical possibility that an unidentified factor influenced the liability results. As we learn more about the determinants of liability from the community's perspective, we will be in a better position to identify and control the effect of unintended influences. Only the last study on the last unresolved liability factor can be a perfect study.

Now to the second difficulty. All of our studies employed what is called a within-subjects design. A within-subjects design has each subject respond to all of the scenarios in a study (a between-subjects design, the primary alternative, has each subject respond to only one or some of the scenarios). Within-subjects designs, when they can be used, have an enormous advantage over between-subjects designs: they get rid of a certain kind of error. An illustration will make this clear. Our research question concerns whether people see forcible sexual intercourse between people who have had a previous sexual relationship as less serious than between strangers. If we were to attack this with a between-subjects design, we would give individual $A$ a description of a rape between strangers and individual $B$ a description of a rape between acquaintances. But suppose, by the bad luck of the draw, $A$ was a person who does not think rape of any sort is much of a crime and, thus, assigns the stranger rape case a low penalty. However, person $B$ considers rape of any kind a major offense and assigns the acquaintance rape case a high penalty.

Seeing only those results, we might be led to the odd conclusion that stranger rape is considered a less-serious offense than acquaintance rape! More likely we might conclude that people saw no difference between them. ${ }^{2}$ Note that these results are not inconsistent with the possibility that both persons $A$ and $B$ see stranger rape as more worthy of punishment than acquaintance rape. A withinsubjects design would reveal this. Person $A$, who rated the stranger rape low, would rate the acquaintance rape even lower. Person $B$, who rated the acquain- 
tance rape as requiring a stiff prison sentence, would rate the stranger rape as requiring an even higher sentence.

So a within-subjects design is preferable from this point of view-if using it does not cause other problems. Given what we want to study, does its use cause other problems? Yes, but we judged them to be manageable, and so we opted to use within-subject designs. Now to an account of those problems.

One disadvantage of a within-subjects design is that, to keep the task manageable for subjects, the number of scenarios in a study must be limited. On balance, we thought that we could live with the limitation on the number of scenarios. There also is the danger that, where multiple scenarios are given to a single subject, the order in which a subject sees the scenarios may affect his or her responses. We attempted to minimize the potential order effects by "randomizing" the scenario order. Thus, different groups of subjects considered the scenarios in a different order. This makes possible a statistical test for what are called "order effects," and they proved not to be of particular concern.

The main problem in a within-subjects design is the possibility that subjects will focus more directly on the variable being tested than they might in other circumstances. Because subjects see all of the test scenarios and because the scenarios differ only in relation to the variables being tested, the differences that are being tested inevitably are obvious to the subjects. If subjects seek to give results that are expected of them (as much social science research suggests), they may tend to give greater weight to the differences between scenarios than they might if they confronted these differences in another context.

Actually, there are two related differences here. First, subjects may give deference to distinctions that they do not believe are relevant. Second, subjects may exaggerate the significance that they give to a factor that they do find relevant. We sought to minimize these possibilities by insisting to subjects that there were no right answers and that it was acceptable to find that differences between scenarios were not significant. Each study contained instructions to this effect. In fact, subjects frequently gave "no difference" responses to a series of clearly different scenarios, even though the instrument's design was classically thought to suggest to them that the researchers wanted to see different responses. So we were not overly concerned with subjects being driven to find nonexistent differences between scenarios. We ended up thinking that having subjects who were aware that they were comparing cases was useful, because the subjects generated a more informed and thoughtful response-something we thought valuable for our specific purposes.

Another difficulty with our studies is not inherent in the research design but lies instead in the particular procedures we used for selecting our respondents. Putting it inelegantly, we grabbed whomever we could get our hands on. Typically, the subjects were neighbors, family, or friends of the students. Law students, lawyers, and persons involved in the criminal justice process, such as police officers, were barred as subjects because we thought that their responses might be driven by their knowledge of the details of the legal codes. 
Having said all of that, our subjects did show a reasonable demographic variation. The number of subjects that took part varies among the studies. Forty subjects per study is typical. Demographic information was collected on the subjects, and the 307 subjects in the first semester's sample had the following demographic characteristics:

\begin{tabular}{lrlrllll} 
Age & & & & & \multicolumn{2}{c}{$\begin{array}{l}\text { Political } \\
\text { Affiliation }\end{array}$} & $\%$ \\
Less than 20 & $\%$ & Income (U.S. dollars) & $\%$ & Education & $\%$ & & \\
$20-29$ & 0.7 & Less than 10,000 & 3.0 & High school & 26.4 & Democrat & 32.3 \\
$30-39$ & 37.2 & $10,000-24,000$ & 14.2 & College & 47.2 & Independent & 31.1 \\
$40-49$ & 17.8 & $25,000-39,000$ & 28.3 & Graduate degree & 26.4 & Republican & 36.6 \\
$50-59$ & 24.2 & $40,000-54,000$ & 21.0 & & & & \\
$60-69$ & 10.4 & $55,000-69,000$ & 15.5 & Sex & $\%$ & & \\
$70-79$ & 5.7 & $70,000-95,000$ & 11.6 & Female & 56.4 & \\
80 or more & 3.7 & More than 100,000 & 6.4 & Male & 43.6 &
\end{tabular}

These results suggest considerable diversity in the subject population. We thought these accidental samples were a reasonable place to begin our research. As the research continues and (as we hope) others are drawn into it, it may be useful to turn to more self-consciously drawn samples that are constructed to be demonstrably representative of various populations that are defined by the code-drafting conditions as central. For instance, if a state legislature was contemplating a change in the legal code of the state, then one would want to carefully draw a representative sample of the population of that state.

It would also be useful to use a research design that including some elements of a between-subjects design. We have argued that the awareness of the differences between conditions that is created by the within-subjects design is not likely to affect the outcomes of the study, but it would be well to verify this when the results were going to affect code drafting.

\section{THE PENALTY SCALE AND WHAT CAN BE LEARNED FROM THE SUBJECTS' PENALTY RESPONSES}

An identical liability-punishment scale was used in each study to enable us to make some comparisons across studies as well as within studies.

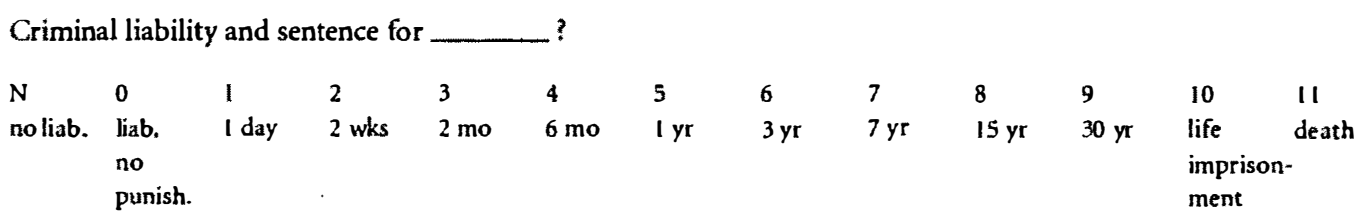

The penalties on the scale were selected after an examination of the offense classification schemes used in current American criminal codes. The relative relation between each point on the scale represents the typical relation between grades of offenses in the states that use the more refined grading schemes (e.g., New York, 
Illinois, Virginia, and Florida). The Model Penal Code is atypical in this respect, with fewer classifications (5) than most state codes (9). Because of this characteristic of the scale, the results could be understood in liability terms (the grade of an offense) as well as punishment terms (the length of a term of imprisonment).

What can we learn from the subjects' responses to such a scale? Examining the experimental design gives us some answers to this question. Suppose that our respondents, on the average, assign a liability scale score of 7.8 (this translates into 13.4 years). This can be useful in giving us a very approximate sense of the amount of liability and punishment that the community thinks is appropriate for this offense. But it strikes us that it would be inappropriate to try to infer from their rating the grading of the offense, as it is doubtful that members of the community have strong feelings that a particular grade or length of sentence is essential. More likely, people may have only a general sense of the approximate degree of punishment that is appropriate.

This observation is important to the analysis and use of liability results. The amount of punishment imposed by subjects in a given scenario should be understood as providing no more than a general idea of where punishment should fall on the absolute scale. So the results should not be taken to mean that 13.4 years ( 7.8 on the penalty scale) and 2.4 years ( 5.7 on the scale) are, in the subjects' view, the specific punishments appropriate for stranger rape and spousal rape, respectively. Every rape case will be different; the liability responses in any rape scenario represent only the subjects' view as to that particular case's description. Further, there also is some question as to what the subjects have in mind when they select a value on the penalty scale. Do they fully understand how much punishment is suffered through a sentence of 13.4 years imprisonment? Would their views change if they knew more? Although the instructions tell them to assume that the sentence will be served in full, are they sufficiently skeptical about current early release practices to the extent that they impose a higher sentence to account for this possibility? Is their notion of the "going rate" for this offense distorted by news of the high sentences that are commonly imposed (but not served) under the practice of early release? These and other uncertainties make the use of the liability results as absolute measures inappropriate.

But exactly because we use a within-subjects design, the differences in sentences assigned across variations in the same core scenario give us what we regard as reasonably precise information of a comparative sort. By assigning different liability scores in these comparisons, the respondents can with some precision identify those situations that they see as more and less condemnable than others and those factors that increase and decrease the assignments of punishments.

What this means is that the results are most useful as a means of comparing the subjects' views of different scenarios. A liability mean of 7.8, where a person rapes a stranger, compared to 5.7, where the person rapes a spouse, would suggest that the community sees stranger rape as more serious than spousal rape. 
This does not mean that the test results cannot be tied back to current sentencing practices. In many of the studies reported in this book, we had subjects rate "control" scenarios that describe relatively common forms of the study's offense, for which the current sentencing practice in any given jurisdiction may be predictable. By comparing the liability results to these benchmarks, one can get a rough idea of what the liability results would mean in current practice terms. For example, the felony-murder study included three control cases of rather straightforward purposeful, reckless, and negligent killings not committed in the course of another offense. By comparing the felony-murder results to each other, one can learn which variations are seen as more (or less) blameworthy. By comparing the results of each felony-murder variation to those of the control scenarios, one can determine which of the traditional homicide grades-murder, manslaughter, and negligent homicide - the subjects see each of the felony-murder scenario variations most akin to in overall blameworthiness.

Having said all of this, we still think that sometimes the absolute value of a sentence assigned can illuminate a community standard. It may give some general sense of the level of seriousness that is perceived. The data mentioned in the different rape cases, for example, suggests that while spousal rape is viewed as less serious than stranger rape, it nonetheless is seen as a serious offense- $a$ view contrary to the common law and Model Penal Code rules, which provided a complete defense to spouses against charges of forcible intercourse.

Still, one corollary to these observations about the limitations of scenario research results is that singling out the exact liability assigned to any scenario within a study is rarely of value. The nature of the research puts the primary focus of the results on comparisons between scenarios within a study. And if the conclusions drawn from the results are to be reliable, the difficulties concerning subject perception and scenario manipulation already described must be overcome. As the readers examine the study reports, we would remind you of the need to keep these points in mind. This illustrates the care with which these results must be used; we report them to begin a discussion rather than end one.

\section{THE QUESTION OF “CONSENSUS”: AGREEMENT AND DISAGREEMENT AMONG RESPONDENTS}

Many of the analyses of the data including in the 18 studies in this book compare current law to the statistical means of the subjects' liability responses, with the latter taken by us as representing the community's views. Of course, the subjects' liability mean is a reliable indicator of the community view only if the underlying methodology is sound. ${ }^{3}$ Moreover, even if the methodology is sound, liability means alone do not always tell us all we need to know about the community's view. While a liability mean can always be calculated, it can mask considerable disagreement among the subjects. The liability mean does not disclose the level of agreement. To measure degree of agreement among respondents, it is customary 
to use some measure of the "spread" or "dispersion" of their responses. The standard measure of dispersion is a statistic called the "standard deviation." It has a number of useful properties, specifically that 68 percent of the sample's responses lie within one standard deviation of the mean of the distribution. ${ }^{4}$

In the pilot projects described in this volume, the level of agreement varies considerably from scenario to scenario. Some of this variaton is artificial, that is, the product of the test instrument rather than a reflection of disagreement on the substantive issue. Apparent disagreement among subjects increases as the scenarios are open to greater differences of interpretation. Diversity in the subjects' perceptions of the situation naturally translates into diversity of their responses to the situation. Even with general agreement on how a scenario is perceived, however, there will be diversity of opinion on some issues. This is especially true in the studies in this book because controversy was one of the criteria used to select issues for study.

Empirically, it turned out that a considerable degree of agreement among respondents exists on many matters. For some scenarios, there exists near unanimity that punishment is inappropriate. ${ }^{5}$ For other scenarios, there exists near unanimity that some kind of punishment is appropriate. ${ }^{6}$ In these scenarios, the mean standard deviation of the liability responses is 1.39 . For a normal distribution, this means that 68 percent of all responses fall within 1.39 points of the mean on the penalty scale. ${ }^{7}$

We are struck by this degree of agreement. It is significant that agreement exists even on issues that have probably never been the subject of public discussion, for it suggests that the shared notions are the result of some process other than intellectual or political analysis, or direct knowledge of a societal consensus. We have frequently referred to an individual's judgment of appropriate liability as "intuitive," but in fact it is likely to be grounded in shared cultural understandings of the differential seriousness of different crimes, what counts as intentional, and so on.

However, other scenarios generate a significant range of responses. In 20 percent of the scenarios, the standard deviation of the liability responses exceeds $3.50{ }^{8}$ This raises an interesting question. What level of agreement ought to be required before the expressed view of the "mean" subject is taken as giving us a "community standard"? Recall that we have already conceded that there are valid reasons why a legal code does not conform to a community standard. Let us assume, however, that we are facing a particular case in which we grant the relevance of a community standard to code formulation. When is a community standard "standard enough" to be used as a basis for formulating doctrine? On the one hand, at least a majority is required even to call a "position" a community's "view." On the other hand, it no doubt is rare that every member of a community agrees with a proposed rule or principle for adjudicating blame. Should more than a majority be required? If so, how much less than absolute agreement may be tolerated? 
Precedent might be found in the two-thirds or other supermajority proportion typically required for a legislature to override the veto of an executive. The proportion required to modify a state's constitution, sometimes three-fourths, ${ }^{9}$ is another possible analogy. No particular proportion stands out, however, as an obvious logical preference. Beyond requiring that the proportion represent a substantial majority, the particular choice seems somewhat arbitrary. One might require a sufficiently high percentage so that the position will not be likely to change over short periods of time. A potential problem with requiring only a bare majority is this potential for slight shifts in community views to mandate changes in the liability rules. Indeed, such concern for the disruption that comes with toofrequent changes may be at the root of the high proportions required to override an executive-branch decision or to change a constitution.

Another reason to require more than a bare majority stems from the reasons for considering the community's views, discussed in the introductory chapter. If the utilitarian goal is to create clear moral credibility in the criminal law, it follows that the proportion of agreement must be high. The view of a bare majority can easily be dismissed as a matter on which reasonable people can disagree. A bare majority, after all, means that people are about equally divided on the issue. It is hardly persuasive to those in the minority to claim that "a majority" disagree with them, if that majority can be changed with the decision of one person. A two-thirds proportion means that for every person in the minority, two people in the majority hold a contrary view. A three-quarters majority means that the minority are outnumbered three to one. One of these latter proportions seems more likely to give the sense of a strongly shared view, which would be needed to persuade the members of the minority to reconsider their view.

Another argument derives from the utilitarian interest in maximizing the deterrent effect and cooperative appeal of the criminal law. The larger the proportion of people who share in the majority view on an issue of blameworthiness, the greater will be the benefit to the criminal law of adopting that view, all other things being equal. At the very least, those who share in the view will see greater moral credibility in the criminal law and the larger that number, the larger the overall effect.

These observations suggest that a supermajority proportion is appropriate for the just-desert goal as well. If philosophers care about the community's views, they certainly will be less inclined to reexamine a philosophically derived rule if it conflicts only with the views of one person more than the number who support it. The same may be said of us nonphilosophers. Only large majorities on an issue are likely to be significant in causing us to reassess what we think is and is not morally blameworthy.

One argument against requiring more than a majority comes from the fact that the legal code must adopt some position. If this is so, should it not adopt the majority view over a minority view? The goal here is not to make criminal justice administration a democratic function; the community ought not be voting the re- 
sults in the adjudication of individual cases. The argument here is that, if a majority of the community share one view on a rule for the distribution of criminal liability to be applied to all members in the community, that rule generally ought to be preferred to a minority-supported rule. ${ }^{10}$

Whatever conclusion one reaches on the degree of agreement that ought to be required to support a code position, no reform ought to be undertaken without such information on the degree of agreement. More advanced analysis of the data collected in the studies described in this book and more advanced studies than these can give a clearer picture of how much agreement exists on a specific issue. The studies described here are meant simply to illustrate the kinds of things that empirical research can teach about substantive criminal-law issues. 


\section{Appendix B: Text of Stimulus Instrument Scenarios}

\section{STUDY 1: \\ OBJECTIVE REQUIREMENTS OF ATTEMPT}

Scenario 1: Thought Only (TH)

(W) Ray, a locksmith, recalls working on a safe in a coin shop. The safe was kept in a back room and always contained valuable coins. Ray thinks about how easily he could sneak into the back room during normal business hours and "crack" the safe. Ray decides that he will rob the safe in the coin shop. Before he does anything to prepare for the robbery, Ray tells a friend that he has decided to rob the safe.

\section{Scenario 2: Substantial Step (SS)}

(I) Ray, a locksmith, recalls working on a safe in a coin shop. The safe was kept in a back room and always contained valuable coins. Ray decides that he will rob the safe in the coin shop. To make sure that the safe is still there, Ray goes to the coin shop and checks out the situation before the robbery. Ray tells a friend what he has decided to do.

\section{Scenario 3: Unequivocality (EQ)}

(L) Ray, a locksmith, recalls working on a safe in a coin shop. The safe was kept in a back room and always contained valuable coins. Ray decides that he will rob the safe in the coin shop. To make sure that the safe is still there, Ray goes to the coin shop and checks out the situation before the robbery. Ray determines that he needs a special tool to crack the safe. He buys the parts he needs, and cuts and welds them to make the special tool, which has no lawful purpose. Ray tells a friend what he has decided to do.

Scenario 3a: Renounces (EQR)

(A) Ray, a locksmith, recalls working on a safe in a coin shop. The safe was kept in a back room and always contained valuable coins. Ray decides that he will rob the 
safe in the coin shop. To make sure that the safe is still there, Ray goes to the coin shop and checks out the situation before the robbery. While casing the coin shop, Ray meets the old man who owns the shop. Ray feels sympathy for the old man, whose business would be crushed by the robbery. Out of sympathy for the old man, Ray decides not to rob the safe. Ray tells a friend what he has done.

\section{Scenario 4: Probable Desistance (PD)}

(M) Ray, a locksmith, recalls working on a safe in a coin shop. The safe was kept in a back room and always contained valuable coins. Ray decides that he will rob the safe in the coin shop. To make sure that the safe is still there, Ray goes to the coin shop and checks out the situation before the robbery. Ray tells a friend about his plans to rob the safe the next day. His friend tells the police. The next day Ray drives to the coin shop to rob the safe, but when he is just one block away he is stopped by two undercover policemen who were alerted by Ray's friend.

\section{Scenario 5: Dangerous Proximity (PX)}

(P) Ray, a locksmith, recalls working on a safe in a coin shop. The safe was kept in a back room and always contained valuable coins. Ray decides that he will rob the safe in the coin shop. To make sure that the safe is still there, Ray goes to the coin shop and checks out the situation before the robbery. Ray tells a friend about his plans to rob the safe the next day. His friend tells the police. The next day Ray goes to the coin shop and slips into the back room, where he begins to crack the safe. Before Ray is able to open the safe, however, two undercover policemen burst into the room and arrest him.

\section{Scenario 5a: Dangerous Proximity-Renounces (PXR)}

(T) Ray, a locksmith, recalls working on a safe in a coin shop. The safe was kept in a back room and always contained valuable coins. Ray decides that he will rob the safe in the coin shop. To make sure that the safe is still there, Ray goes to the coin shop to check out the situation before the robbery. The next day Ray goes to the coin shop and meets the old man who owns it. While the owner helps another customer, Ray slips into the back room. As he is about to crack the safe, Ray feels sympathy for the owner, whose business would be crushed by the robbery, and decides not to crack the safe. Ray tells a friend about what he did and why he decided not to rob the safe.

\section{Scenario 5b: Dangerous Proximity—Desists Out of Fear (FR)}

$(H)$ Ray, a locksmith, recalls working on a safe in a coin shop. The safe was kept in a back room and always contained valuable coins. Ray decides that he will rob the safe in the coin shop. To make sure that the safe is still there, Ray goes to the coin shop to check out the situation before the robbery. The next day Ray goes to the coin shop and meets the old man who owns it. While the owner helps another 
customer, Ray slips into the back room. As he is about to crack the safe, Ray hears someone say, "Good morning Officer Smith." Ray looks into the next room and sees a police of ficer, and decides not to crack the safe out of fear of being caught in the act. Ray goes home and later tells a friend about what he did and why he decided not to rob the safe.

\section{Scenario 6: Completed Offense}

(N) Ray, a locksmith, recalls working on a safe in a coin shop. The safe was kept in a back room and always contained valuable coins. Ray decides that he will rob the safe in the coin shop. To make sure that the safe is still there, Ray goes to the coin shop to check out the situation before the robbery. The next day Ray goes to the coin shop and meets the old man who owns it. While the owner helps another customer, Ray slips into the back room and cracks the safe. Ray slips away with a briefcase full of valuable coins. That night Ray tells a friend about what he did, and his friend tells the police. The next day two policemen search Ray's home with a search warrant, find the coins, and arrest him.

\section{Scenario 6a: Completed Offense-Renounces and "Undoes" (CPR)}

(O) Ray, a locksmith, recalls working on a safe in a coin shop. The safe was kept in a back room and always contained valuable coins. Ray decides that he will rob the safe in the coin shop. To make sure that the safe is still there, Ray goes to the coin shop to check out the situation before the robbery. The next day Ray goes to the coin shop and meets the old man who owns it. While the owner helps another customer, Ray slips into the back room and cracks the safe. Ray slips away with a briefcase full of valuable coins. On the way home Ray feels sympathy for the owner of the coin shop, whose business will be crushed by the robbery, and decides to return the coins before they are discovered missing. Ray returns to the coin shop, cracks the safe, replaces the coins and goes home. Later Ray tells a friend about what he did and why he decided to return the coins.

\section{Scenario 6b: Completed Offense-Renounces but Unable to "Undo"}

(R) Ray, a locksmith, recalls working on a safe in a coin shop. The safe was kept in a back room and always contained valuable coins. Ray decides that he will rob the safe in the coin shop. To make sure that the safe is still there, Ray goes to the coin shop to check out the situation before the robbery. The next day Ray goes to the coin shop and meets the old man who owns it. While the owner helps another customer, Ray slips into the back room and cracks the safe. Ray slips away with a briefcase full of valuable coins. On the way home Ray feels sympathy for the owner of the coin shop, whose business will be crushed by the robbery, and decides to return the coins before they are discovered missing. Ray returns to the coin shop, but as he enters the store two policemen, called when the owner discovered the robbery, see a coin sticking out of Ray's briefcase and arrest him. 
STUDY 2:

CREATING A CRIMINAL RISK

Scenario 1: Slight Injury

(R) Mary and Tom have been married for fifteen years. Mary is unhappy with the marriage, and decides to kill Tom to inherit his money and avoid a messy divorce. Tom has cereal for breakfast every morning before work, to which he always adds raisins from a large box. Intending to kill Tom, just before breakfast Mary injects poison into one of the raisins from the box, returns it to the box, and shakes the box. Unbeknownst to Mary, the poison that she uses becomes less effective with time, until it is totally harmless after a few hours. In addition, Mary is mistaken as to the amount of poison required to cause death, and if Tom eats the raisin that is poisoned at breakfast, he will only suffer mild stomach cramps.

\section{Scenario 2: Moderate Injury}

(I) Mary and Tom have been married for fifteen years. Mary is unhappy with the marriage, and decides to kill Tom to inherit his money and avoid a messy divorce. Tom has cereal for breakfast every morning before work, to which he always adds raisins from a large box. Intending to kill Tom, just before breakfast Mary injects poison into one of the raisins from the box, returns it to the box, and shakes the box. Unbeknownst to Mary, the poison that she uses becomes less effective with time, until it is totally harmless after a few hours. In addition, Mary is mistaken as to the amount of poison required to cause death, so that if Tom eats the raisin that is poisoned at breakfast, he will suffer material injury to his digestive tract.

\section{Scenario 3: High Injury}

(S) Mary and Tom have been married for fifteen years. Mary is unhappy with the marriage, and decides to kill Tom to inherit his money and avoid a messy divorce. Tom has cereal for breakfast every morning before work, to which he always adds raisins from a large box. Intending to kill Tom, just before breakfast Mary injects poison into one of the raisins from the box, returns it to the box, and shakes the box. Unbeknownst to Mary, the poison that she uses becomes less effective with time, until it is totally harmless after a few hours. If Tom eats the raisin that is poisoned at breakfast, he will die.

\section{Scenario 4: Slight Injury}

(K) Mary and Tom have been married for fifteen years. Mary is unhappy with the marriage, and decides to kill Tom to inherit his money and avoid a messy divorce. Tom has cereal for breakfast every morning before work, to which he always adds one piece of fruit from the fruit bowl. Intending to kill Tom, just before breakfast Mary injects poison into one of the two pieces of fruit in the bowl. Unbeknownst 
to Mary, the poison that she uses becomes less effective with time, until it is totally harmless after a few hours. In addition, Mary is mistaken as to the amount of poison required to cause death, so that if Tom eats the piece of fruit that is poisoned at breakfast, he will only suffer mild stomach cramps.

\section{Scenario 5: Moderate Injury}

(O) Mary and Tom have been married for fifteen years. Mary is unhappy with the marriage, and decides to kill Tom to inherit his money and avoid a messy divorce. Tom has cereal for breakfast every morning before work, to which he always adds one piece of fruit from the fruit bowl. Intending to kill Tom, just before breakfast Mary injects poison into one of the two pieces of fruit in the bowl. Unbeknownst to Mary, the poison that she uses becomes less effective with time, until it is totally harmless after a few hours. In addition, Mary is mistaken as to the amount of poison required to cause death, so that if Tom eats the piece of fruit that is poisoned at breakfast, he will suffer material injury to his digestive tract.

\section{Scenario 6: High Injury}

(F) Mary and Tom have been married for fifteen years. Mary is unhappy with the marriage, and decides to kill Tom to inherit his money and avoid a messy divorce. Tom has cereal for breakfast every morning before work, to which he always adds one piece of fruit from the fruit bowl. Intending to kill Tom, just before breakfast Mary injects poison into one of the two pieces of fruit in the bowl. Unbeknownst to Mary, the poison that she uses becomes less effective with time, until it is totally harmless after a few hours. If Tom eats the piece of fruit that is poisoned at breakfast, he will die.

\section{Scenario 7: Slight Injury}

(D) Mary and Tom have been married for fifteen years. Mary is unhappy with the marriage, and decides to kill Tom to inherit his money and avoid a messy divorce. Tom has cereal for breakfast every morning before work, to which he always adds raisins from a large box. Intending to kill Tom, just before breakfast Mary injects poison into almost all of the raisins in the box. Unbeknownst to Mary, the poison that she uses becomes less effective with time, until it is totally harmless after a few hours. In addition, Mary is mistaken as to the amount of poison required to cause death, and if Tom eats the raisins that are poisoned at breakfast, he will only suffer mild stomach cramps.

\section{Scenario 8: Moderate Injury}

(E) Mary and Tom have been married for fifteen years. Mary is unhappy with the marriage, and decides to kill Tom to inherit his money and avoid a messy divorce. Tom has cereal for breakfast every morning before work, to which he always adds 
raisins from a large box. Intending to kill Tom, just before breakfast Mary injects poison into almost all of the raisins in the box. Unbeknownst to Mary, the poison that she uses becomes less effective with time, until it is totally harmless after a few hours. In addition, Mary is mistaken as to the amount of poison required to cause death, so that if Tom eats the raisins that are poisoned at breakfast, he will suffer material injury to his digestive tract.

\section{Scenario 9: High Injury}

(A) Mary and Tom have been married for fifteen years. Mary is unhappy with the marriage, and decides to kill Tom to inherit his money and avoid a messy divorce. Tom has cereal for breakfast every morning before work, to which he always adds raisins from a large box. Intending to kill Tom, just before breakfast Mary injects poison into almost all of the raisins in the box. Unbeknownst to Mary, the poison that she uses becomes less effective with time, until it is totally harmless after a few hours. If Tom eats the raisins that are poisoned at breakfast, he will die.

\section{Scenario 10: Slight Injury}

(T) Mary and Tom have been married for fifteen years. Mary is unhappy with the marriage, and decides to kill Tom to inherit his money and avoid a messy divorce. Tom has cereal for breakfast every morning before work, to which he always adds raisins from a large box. Intending to kill Tom, just before breakfast Mary injects poison into the raisins in the box. Tom eats the poisoned raisins. However, Mary made a mistake as to the amount of poison required to cause death, and Tom suffers only mild stomach cramps.

\section{Scenario 11: Moderate Injury}

(H) Mary and Tom have been married for fifteen years. Mary is unhappy with the marriage, and decides to kill Tom to inherit his money and avoid a messy divorce. Tom has cereal for breakfast every morning before work, to which he always adds raisins from a large box. Intending to kill Tom, just before breakfast Mary injects poison into the raisins in the box. Tom eats the poisoned raisins. However, Mary made a mistake as to the amount of poison required to cause death, and Tom suffers only material injury to his digestive tract.

\section{Scenario 12: High Injury}

(Z) Mary and Tom have been married for fifteen years. Mary is unhappy with the marriage, and decides to kill Tom to inherit his money and avoid a messy divorce. Tom has cereal for breakfast every morning before work, to which he always adds raisins from a large box. Intending to kill Tom, just before breakfast Mary injects poison into the raisins in the box. Tom eats the poisoned raisins, and dies. 


\section{STUDY 3: \\ OBJECTIVE REQUIREMENTS OF COMPLICITY}

Scenario 1: Only Thinks of Helping

(H) Because John knows that Catherine is unhappily married, he wonders if she longs for her husband's death, which would make her a rich widow. She strikes him as a woman quite capable of murder, and he often thinks about approaching her and suggesting a plan in which she could kill her husband and get away with it. If she did decide to do it, John realizes that he would be willing to help her. Before he can sound her out on the subject, however, Catherine shoots her husband dead.

\section{Scenario 2: Failed Attempt to Help}

(A) Finally, Catherine decides to murder her husband by shooting him and claiming that it was an accident.

One night at a party Catherine confides her murder plan to her sister and says she is going to try to buy a gun. They are unaware that John has overheard their conversation. $\mathrm{He}$ is secretly delighted. He does not tell Catherine what he has learned. The next day, he takes his own pistol and drives over to Catherine's house to give it to her. By the time he gets there, however, Catherine has already bought a gun and has used it to shoot her husband dead.

\section{Scenario 2a: Failed Attempt to Help/Murder Fails}

(N) Finally, Catherine decides to murder her husband by shooting him and claiming that it was an accident.

One night at a party Catherine confides her murder plan to her sister and says she is going to try to buy a gun. They are unaware that John has overheard their conversation. He is secretly delighted. He does not tell Catherine what he has learned. The next day, he takes his own pistol and drives over to Catherine's house to give it to her. When he gets there, however, he sees police in the house and learns that Catherine has already shot at her husband, but missed.

Scenario 3: Encourages/No Help

(D) Finally, Catherine decides to murder her husband by shooting him and claiming that it was an accident.

She confides her plan to John, sensing correctly that he will be delighted. He agrees with her that she should kill her husband. The next day, Catherine shoots her husband dead.

\section{Scenario 4: Minimal Help}

(S) Finally, Catherine decides to murder her husband by shooting him and claiming that it was an accident. 
She confides her planto John, sensing correctly that he will be delighted. John agrees with her that she should kill her husband. She says she is going downtown that afternoon to buy a gun. John gives her the name of a gun store, where she goes and buys a gun. That night she uses it to shoot her husband dead.

\section{Scenario 4a: Minimal Help/Murder Fails}

(O) Finally, Catherine decides to murder her husband by shooting him and claiming that it was an accident.

She confides her plan to John, sensing correctly that he will be delighted. John agrees with her that she should kill her husband. She says she is going downtown that afternoon to buy a gun. John gives her the name of a gun store, where she goes and buys a gun. That night she uses it to shoot at her husband, but she misses, and he is unharmed.

\section{Scenario 5: Substantial Help}

(M) Finally, Catherine decides to murder her husband by shooting him and claiming that it was an accident.

Before she buys a gun, she stops at John's office and reveals her plan to him, sensing correctly that he will be delighted. John agrees that her plan is a good one. When she says she is on her way to buy a gun, John says, "I'll give you mine." He reaches into a drawer and hands her his pistol. She uses it that night to shoot her husband dead.

\section{Scenario 6: Necessary Help}

(E) Finally, Catherine decides to murder her husband by shooting him and claiming that it was an accident.

She confides her plan to John, realizing that he will be secretly delighted. He encourages her, and agrees that her plan is a good one. But one day she comes to his office in despair and tells him that she has been unsuccessful in buying a gun illegally and has decided to abandon her murder plan. At that point, John reaches into his desk drawer and hands her his gun. When she confesses her total ignorance of firearms, he instructs her how to use it. She takes the gun and uses it that night to shoot her husband dead.

\section{Scenario 6a: Necessary Help/Murder Fails}

(P) Finally, Catherine decides to murder her husband by shooting him and claiming that it was an accident.

She confides her plan to John, realizing that he will be secretly delighted. He encourages her, and agrees that her plan is a good one. But one day she comes to his office in despair and tells him that she has been unsuccessful in buying a gun illegally and has decided to abandon her murder plan. At that point, John reaches into his desk drawer and hands her his gun. When she confesses her total igno- 
rance of firearms, he instructs her how to use it. She takes the gun and uses it that night to shoot at her husband, but she misses, and he is unharmed.

\section{Scenario 7: Unique and Necessary Help}

(I) Finally, Catherine decides to murder her husband by shooting him and claiming that it was an accident.

She goes to John's office and reveals her plan to him, sensing correctly that he will be delighted. He agrees with her that her plan is a good one, but he interrupts her to say, "When I left your husband an hour ago, he confided in me that he fears you are going to kill him. He is home packing right now to leave the country, and he plans on telling the police of his suspicions about you on his way to the airport." Catherine leaves John's of fice immediately at this news and goes home, where she finds her husband ready to leave for the airport. She shoots him dead.

\section{Scenario 8: Masterminds}

(G) John is a compulsive gambler and deeply in debt. He has thought of killing his business partner to gain control of the oil company, but is afraid the murder would be traced to him because the bad feelings between the two men are wellknown. John knows that Catherine is unhappily married, and he wonders if she, too, longs for her husband's death. She strikes him as a woman capable of murder. It occurs to him that if he could persuade Catherine to do the murder, they would both be very rich. He feels free to remind her of what a rich widow she will become one day. He says to her, "Why wait?" Then he outlines a plan whereby she could shoot her husband and make it look like an accident. Catherine is startled, but she thinks it over and agrees to his idea. The next day, she shoots her husband dead, just as John planned it.

\section{STUDY 4: \\ OMISSION LIABILITY}

\section{Scenario 1: Stranger}

(Q) Walt and Vic are on a pier built over a body of deep water. Walt is 38 years old. Vic is 16 years old. Walt and Vic are unrelated and do not know each other. Suddenly, Pete, a stranger, intentionally pushes Vic into the water. Vic calls out"Help! I'm drowning." Pete then immediately runs away, practically certain that Vic will drown. Walt is also practically certain that Vic will drown. Walt cannot swim. But there is a lif esaving flotation device on the pier. Walt does not want Vic to drown and knows that he need only throw the flotation device into the water to rescue Vic. But Walt does not throw the flotation device into the water. Vic drowns. Later, Walt explains - “I didn't want him to drown. But I just didn't want to get too involved." 


\section{Scenario 2: Parent}

(U) Walt and Vic are on a pier built over a body of deep water. Walt is 38 years old. Vic is 16 years old. Walt is Vic's father. Suddenly, Pete, a stranger, intentionally pushes Vic into the water. Vic calls out- "Help! I'm drowning." Pete then immediately runs away, practically certain that Vic will drown. Walt is also practically certain that his son Vic will drown. Walt cannot swim. But there is a lifesaving flotation device on the pier. Walt does not want his son Vic to drown and knows that he need only throw the flotation device into the water to rescue Vic. But Walt does not throw the flotation device into the water. Vic drowns. Later, Walt explains- "I didn't want him to drown. But I just didn't want to get too involved."

\section{Scenario 3: Contract}

(E) Walt and Vic are on a pier built over a body of deep water. Walt is 38 years old. Vic is 16 years old. Walt and Vic are unrelated and do not know each other. Walt is working as a security guard whose job is to protect people and property on the pier. Suddenly, Pete, a stranger, intentionally pushes Vic into the water. Vic calls out- "Help! I'm drowning." Pete then immediately runs away, practically certain that Vic will drown. Walt is also practically certain that Vic will drown. Walt the security guard cannot swim. But there is a lif esaving flotation device on the pier. Walt does not want Vic to drown and knows that he need only throw the flotation device into the water to rescue Vic. But Walt does not throw the flotation device into the water. Vic drowns. Later, Walt explains- "I didn't want him to drown. But I just didn't want to get too involved."

\section{Scenario 4: Assumption}

(S) Walt and Vic are on a pier built over a body of deep water. Walt is 38 years old. Vic is 16 years old. Walt and Vic are unrelated and do not know each other. Suddenly, Pete, a stranger, intentionally pushes Vic into the water. Vic calls out"Help! I'm drowning." Pete then immediately runs away, practically certain that Vic will drown. Walt is also practically certain that Vic will drown. Walt cannot swim. But there is a lifesaving flotation device on the pier. Another stranger approaches Walt and says- "I'll get the flotation device." Walt replies-“Wait. You go and get help. I'll see what I can do to rescue him." The other person does as Walt suggests. Walt does not want Vic to drown and knows that he need only throw the flotation device into the water to rescue Vic. But Walt does not throw the flotation device into the water. Vic drowns. Later, Walt explains - "I didn't want him to drown. But I just didn't want to get too involved."

\section{Scenario 5: Stranger-High Danger}

(T) Walt and Vic are on a pier built over a body of deep water. Walt is 38 years old. Vic is 16 years old. Walt and Vic are unrelated and do not know each other. Suddenly, Pete, a stranger, intentionally pushes Vic into the water. Vic calls out"Help! I'm drowning." Pete then immediately runs away, practically certain that 
Vic will drown. Walt is also practically certain that Vic will drown. There is no lifesaving flotation device on the pier. But Walt is an excellent swimmer. Walt does not want Vic to drown and knows that someone will have to dive into the water to rescue Vic. There is no one else on the pier. But Walt knows that man-eating sharks inhabit the body of water. So Walt does not dive into the water to rescue Vic. Vic drowns. Later, Walt explains-“I didn't want him to drown. But I was concerned about being attacked by sharks."

\section{Scenario 6: Stranger-Low Danger}

(I) Walt and Vic are on a pier built over a body of deep water. Walt is 38 years old. Vic is 16 years old. Walt and Vic are unrelated and do not know each other. Suddenly, Pete, a stranger, intentionally pushes Vic into the water. Vic calls out"Help! I'm drowning." Pete then immediately runs away, practically certain that Vic will drown. Walt is also practically certain that Vic will drown. There is no lifesaving flotation device on the pier. But Walt is an excellent swimmer. Walt does not want Vic to drown and knows that someone will have to dive into the water to rescue Vic. There is no one else on the pier. But Walt knows that the water may be cold and that there may be a current. So Walt does not dive into the water to rescue Vic. Vic drowns. Later, Walt explains - "I didn't want him to drown. But I was concerned that I might get muscle cramps and possibly drown myself."

\section{Scenario 7: Stranger-High Inconvenience}

(O) Walt and Vic are on a pier built over a body of deep water. Walt is 38 years old. Vic is 16 years old. Walt and Vic are unrelated and do not know each other. Suddenly, Pete, a stranger, intentionally pushes Vic into the water. Vic calls out"Help! I'm drowning." Pete then immediately runs away, practically certain that Vic will drown. Walt is also practically certain that Vic will drown. There is no lifesaving flotation device on the pier. But Walt is an excellent swimmer. Walt does not want $\mathrm{Vic}$ to drown and knows that someone will have to dive into the water to rescue Vic. There is no one else on the pier. Walt knows that it would not be dangerous to dive into the water. But Walt is unemployed and is on his way to an important job interview. So Walt does not dive into the water to rescue Vic. Vic drowns. Later, Walt explains_- “I didn't want him to drown. But I was concerned about missing my job interview."

\section{Scenario 8: Stranger-Low Inconvenience}

(N) Walt and Vic are on a pier built over a body of deep water. Walt is 38 years old. Vic is 16 years old. Walt and Vic are unrelated and do not know each other. Suddenly, Pete, a stranger, intentionally pushes Vic into the water. Vic calls out"Help! I'm drowning." Pete then immediately runs away, practically certain that Vic will drown. Walt is also practically certain that Vic will drown. There is no lifesaving flotation device on the pier. But Walt is an excellent swimmer. Walt does not want Vic to drown and knows that someone will have to dive into the water to 
rescue Vic. There is no one else on the pier. Walt knows that it would not be dangerous to dive into the water. But Walt is wearing a new silk suit. So Walt does not dive into the water to rescue Vic. Vic drowns. Later, Walt explains_- "I didn't want him to drown. But I was concerned about getting wet."

\section{STUDY 5:}

\section{USE OF DEADLY FORCE IN SELF-DEFENSE}

\section{Scenario 1: Killing, No Self-Defense}

(K) Paul works in the city and legally carries a gun for protection. One night while he is walking down a deserted city street on his way back home, a man comes up to him and asks for some money. Paul is in a bad mood and tells the man to go away. The man continues to pester Paul until Paul says "you asked for it." He then shoots and kills the man.

\section{Scenario 2: Killing, Self-Defense}

(I) Paul works in the city and legally carries a gun for his own protection. One night while he is walking down a deserted city street on his way back home, a man jumps out of an alley attacking Paul with a knife. The man will kill him unless Paul acts fast. Paul pulls his gun and kills the attacker.

\section{Scenario 3: Knows Deadly Force Is Not Necessary Because Unarmed Attacker}

(L) Paul works in the city and legally carries a gun for his own protection. One night while he is walking down a deserted city street on his way back home, a man jumps out of an alley attacking Paul. Paul realizes that the man is unarmed and that he could definitely scare the man away just by pushing him, but he pulls his gun and kills the unarmed attacker.

\section{Scenario 4: Knows Deadly Force Is Not Necessary Because Could Retreat}

(X) Paul works in the city and legally carries a gun for his own protection. One night while he is walking down a deserted city street on his way back home, a man jumps out of an alley attacking Paul with a knife. Paul notices that the man is limping and he realizes that he can easily run the half block to his house and be completely safe from his attacker, but instead he pulls his gun and kills the man.

Scenario 5: Knows Deadly Force Is Not Necessary Because Could Retreat from Home

(S) Paul works in the city and legally carries a gun for his own protection. One night while he is relaxing at home a man kicks in the front door of his house. The 
man is armed with a knife and Paul realizes that unless he acts fast the man will kill him. Paul is standing by the back door to his house and he can retreat in complete safety, but Paul grabs his gun and kills the armed attacker.

\section{Scenario 6: Believes Deadly Force Is Necessary but Mistaken} as to Threat

(M) Paul works in the city and legally carries a gun for his own protection. One night while he is walking down a deserted city street on his way back home, a man jumps out of an alley attacking Paul. Paul believes that the man is armed with a knife and that the man will kill him unless he acts fast. Paul pulls his gun and kills his attacker. Paul later learns that the man was unarmed and could not have seriously injured him.

\section{Scenario 7: Believes Deadly Force Is Necessary but Mistakenly} Believes Retreat Not Possible

(U) Paul works in the city and legally carries a gun for his own protection. One night while he is walking down a deserted city street on his way back home, a man jumps out of an alley attacking Paul with a knife. Paul believes that the man will kill him unless he acts fast. Paul pulls his gun and kills the attacker. Paul did not realize at the time, however, that the man had a bad leg and that he could have easily run away from the man in complete safety.

\section{Scenario 8: Believes Deadly Force Is Necessary but} Actor Provokes Attack

(C) Paul works in the city and legally carries a gun for his own protection. One night while he is walking down a deserted city street on his way back home a man comes up to him and asks for some money. Paul annoyed that there are panhandlers in his neighborhood, picks up a pipe and hits the man in the side of the head, intending to seriously injure him. The man does not fall but instead pulls out a knife and attacks Paul. The man will kill him unless Paul acts fast. Paul pulls his gun and kills the attacker.

\section{Scenario 9: Believes Deadly Force Is Not Necessary} but Mistakenly Believes Deadly Force Legal

(Y) Paul works in the city and legally carries a gun for his own protection. One night while he is walking down a deserted city street on his way back home, a man jumps out of an alley attacking Paul. Paul knows that the man is unarmed and cannot seriously injure him. Believing that he is justified in doing so, Paul pulls his gun to defend himself and shoots and kills the unarmed attacker. 


\section{STUDY 6: \\ USE OF FORCE IN DEFENSE OF PROPERTY}

\section{Scenario 1: Necessary Force}

(J) When Joe arrives at home from work, he finds a man attempting to steal his motorcycle. Joe immediately yells, "Hey! What do you think you are doing? Get away from that bike!" The man ignores Joe and continues in his attempt to hot wire the motorcycle. Joe approaches the man and grabs him around the arm. The man shrugs Joe off and continues hot wiring. Finally, Joe takes a swing at the man and hits him in the face. The man appears to be in pain and he runs off. The man is later apprehended by the police.

\section{Scenario 2: Questionably Necessary Force}

(L) When Joe arrives at home from work with his wife, he finds a man attempting to steal his motorcycle. Believing that it is absolutely necessary to protect his property, Joe approaches the man and punches him in the face. The man appears to be in pain and he runs off. Joe's wife begins to yell at Joe that the man was small and not very muscular and Joe probably could have scared him off with a yell. Joe later realizes that his wife was right. The man is later apprehended by the police.

\section{Scenario 3: Necessary Force Applied by Device}

(O) A man sees Joe riding his new motorcycle and he follows Joe home to find out where Joe lives. The next day, while Joe is at work, the man returns to steal Joe's motorcycle. The motorcycle is parked in a locked garage, but the man has brought the proper tools to gain entry. After working on the lock for 20 minutes, the man successfully breaks through and opens up the garage door. When the door is fully opened an automatic device which Joe had previously set up is triggered and the man is hit in the face with a mini-bean bag. This breaks his nose and he stops in his efforts to steal Joe's motorcycle and runs off. The man is later apprehended by the police.

\section{Scenario 4: No Imminent Threat (Perceived as Not Immediately Necessary)}

(C) Joe finds a man outside his house attempting to steal his motorcycle. Joe yells, "Hey! What do you think you're doing? Get away from that bike!" The man looks up and replies, "O.K. man, but I'll be back for your bike later when you are gone. Consider it as good as gone." The man holds his hand out and shows Joe that he has made an imprint of the keyhole of Joe's motorcycle. Joe realizes that this man is going to have a key made to fit Joe's bike so that he can quickly steal the bike at any time in the future. Joe is leaving his house to catch a plane for a business trip which he cannot delay. There is nothing else Joe can do to protect his motorcycle. Joe approaches the man and attempts to get the mold out of his hand. The man is 
strong and does not flinch. Joe then takes a swing at the man, hitting him in the face. The man appears to be in pain, drops the clay mold and runs off. The man is later apprehended by the police.

\section{Scenario 5: More Than Necessary Force by Choice}

(T) When Joe arrives at home from work, he finds a man attempting to steal his motorcycle. The man is of small build and is not very muscular. Joe realizes that he can simply scare the man away by yelling at him. He nonetheless approaches the man and punches him in the face. The man appears to be in pain and he runs off. The man is later apprehended by the police.

\section{Scenario 6: Deadly Force, Knowing Not Lawful}

(Y) Joe arrives home to find a man attempting to steal his motorcycle. Joe requests the man to stop but the man refuses and continues in his effort to hotwire the cycle. Joe grabs the man by the arm but the man easily pulls away from him and continues with his work. Joe approaches the man again and punches him in the face. The man is not deterred. Joe picks up a stone and strikes the man on the head. The man is knocked down but is able to stand up again and has just about completed his work. While Joe believes that it may not be lawful to use a gun to prevent the theft of a motorcycle, he sees no other way to stop the man. He goes to his house just a few steps away, retrieves his gun, returns and shoots the man. The man survives and is later taken into custody by the police.

\section{Scenario 7: Deadly Force, Believing It Lawful}

(Z) Joe arrives home to find a man attempting to steal his motorcycle. Joe requests the man to stop but the man refuses and continues in his effort to hotwire the cycle. Joe grabs the man by the arm but the man easily pulls away from him and continues with his work. Joe approaches the man again and punches him in the face. The man is not deterred. Joe picks up a stone and strikes the man on the head. The man is knocked down but is able to stand up again and has just about completed his work. Joe believes that the law allows him to use his gun to protect his property when it is absolutely necessary. He goes to his house just a few steps away, retrieves his gun, returns and shoots the man. The man survives and is later taken into custody by the police.

\section{STUDY 7:}

\section{CITIZENS' LAW ENFORCEMENT AUTHORITY}

The eight scenarios below are premised on the following set of facts:

Suzanne and William Smith are a married couple living in a two-story home. Suzanne is 39 years old and William is 40 years old. Suzanne is a secretary and works 9:00 a.m. to 5:00 p.m. William works the 7:00 p.m. to 3:00 a.m. shift at a 
local car manufacturing company. Suzanne is typically home alone at night. When she goes to sleep, she keeps a weapon in the nightstand next to her bed in case of an emergency.

\section{Scenario 1: Rape: Deadly Force-Actual Offender}

(R) One night while William is at work, Suzanne is asleep in their bedroom upstairs. Suddenly, Suzanne is jerked awake out of a sound sleep by a man who immediately overpowers her. Suzanne is extremely frightened. The man quickly subdues her, rapes her, and starts to leave.

As the man makes his way out of her bedroom, Suzanne realizes that if she does not detain the man there is a great possibility that the man will never be apprehended. Suzanne reaches into the drawer of her night stand, pulls out a handgun and shouts, "stop you bastard or I'll shoot!" As the man dashes for the door, Suzanne jumps out of bed and races after him. The man runs down the stairs and out of the back screen door. As Suzanne reaches the back door she raises the gun and shoots through the screen door into the dark. She hears the thump of a body hitting the ground and when she opens the door she finds that she has shot and killed the man who raped her. The milkman, making his early morning deliveries, was standing nearby looking surprised.

\section{Scenario 2: Rape: Deadly Force-Mistaken Identity}

(C) One night while William is at work, Suzanne is asleep in their bedroom upstairs. Suddenly, Suzanne is jerked awake out of a sound sleep by a man who immediately overpowers her. Suzanne is extremely frightened. The man quickly subdues her, rapes her, and starts to leave.

As the man makes his way out of her bedroom, Suzanne realizes that if she does not detain the man there is a great possibility that the man will never be apprehended. Suzanne reaches into the drawer of her night stand, pulls out a handgun and shouts, "stop you bastard or I'll shoot!" As the man dashes for the door, Suzanne jumps out of bed and races after him. The man runs down the stairs and out of the back screen door. As Suzanne reaches the back door she raises the gun and shoots through the screen door into the dark. She hears the thump of a body hitting the ground and when she opens the door she finds that the man she shot and killed was not the man who raped her but was the milkman making his early morning deliveries.

\section{Scenario 3: Rape: Nondeadly Force-Actual Offender}

(I) One night while William is at work, Suzanne is asleep in their bedroom upstairs. Suddenly, Suzanne is jerked awake out of a sound sleep by a man who immediately overpowers her. Suzanne is extremely frightened. The man quickly subdues her, rapes her, and starts to leave. 
As the man makes his way out of her bedroom, Suzanne realizes that if she does not detain the man there is a great possibility that the man will never be apprehended. Suzanne reaches into the drawer of her night stand, pulls out a stun gun (an instrument which will temporarily stun an individual but will not cause serious bodily injury) and shouts, "stop you bastard or I'll shoot!" As the man dashes for the door, Suzanne jumps out of bed and races after him. The man runs down the stairs and out of the back screen door. As Suzanne reaches the back door she raises the stun gun and shoots through the screen door into the dark. She hears the thump of a body hitting the ground and when she opens the door she finds that she has shot and stunned the man who raped her. The milkman, making his early morning deliveries, was standing nearby looking surprised.

\section{Scenario 4: Rape: Nondeadly Force-Mistaken Identity}

(K) One night while William is at work, Suzanne is asleep in their bedroom upstairs. Suddenly, Suzanne is jerked awake out of a sound sleep by a man who immediately overpowers her. Suzanne is extremely frightened. The man quickly subdues her, rapes her, and starts to leave.

As the man makes his way out of her bedroom, Suzanne realizes that if she does not detain the man there is a great possibility that the man will never be apprehended. Suzanne reaches into the drawer of her night stand, pulls out a stun gun (an instrument which will temporarily stun an individual but will not cause serious bodily injury) and shouts, "stop you bastard or I'll shoot!" As the man dashes for the door, Suzanne jumps out of bed and races after him. The man runs down the stairs and out of the back screen door. As Suzanne reaches the back door she raises the stun gun and shoots through the screen door into the dark. She hears the thump of a body hitting the ground and when she opens the door she finds that the man she shot and stunned was not the man who raped her but was the milkman making his early morning deliveries.

\section{Scenario 5: Property Destruction: Deadly Force-Actual Offender}

(J) One night while William is at work, Suzanne is asleep in their bedroom upstairs. Suddenly, Suzanne is jerked awake out of a sound sleep by a sound outside of her bedroom window. She gets out of bed, looks outside and sees a man setting fire to the inside of her car. Suzanne realizes that if she does not detain the man there is a great possibility that the man will never be apprehended. She reaches into the drawer of her night stand, pulls out a handgun and shouts out of the window, "stop you bastard or I'll shoot!" Suzanne runs down the stairs and out of the front door. When she is outside she sees a man running away at the bottom of her driveway. Suzanne raises the gun and shoots. She sees the man fall to the ground. The man Suzanne shot and killed was the man who set her car on fire. The milkman, making his early morning deliveries, was standing nearby looking surprised. 


\section{Scenario 6: Property Destruction: Deadly Force-Mistaken Identity}

(H) One night while William is at work, Suzanne is asleep in their bedroom upstairs. Suddenly, Suzanne is jerked awake out of a sound sleep by a sound outside of her bedroom window. She gets out of bed, looks outside and sees a man setting fire to the inside of her car. Suzanne realizes that if she does not detain the man there is a great possibility that the man will never be apprehended. She reaches into the drawer of her night stand, pulls out a handgun and shouts out of the window, "stop you bastard or I'll shoot!" Suzanne runs down the stairs and out of the front door. When she is outside she sees a man running away at the bottom of her driveway. Suzanne raises the gun and shoots. She sees the man fall to the ground. The man Suzanne shot and killed was not the man who set her car on fire but was the milkman who was making his morning deliveries but who saw the fire and was running to call for help.

\section{Scenario 7: Property Destruction: Nondeadly Force-Actual Offender}

(O) One night while William is at work, Suzanne is asleep in their bedroom upstairs. Suddenly, Suzanne is jerked awake out of a sound sleep by a sound outside of her bedroom window. She gets out of bed, looks outside and sees a man setting fire to the inside of her car. Suzanne realizes that if she does not detain the man there is a great possibility that the man will never be apprehended. She reaches into the drawer of her night stand, pulls out a stun gun (an instrument which will temporarily stun an individual but will not cause serious bodily injury) and shouts out of the window, "stop you bastard or I'll shoot!" Suzanne runs down the stairs and out of the front door. When she is outside she sees a man running away at the bottom of her driveway. Suzanne raises the stun gun and shoots. She sees the man fall to the ground. The man Suzanne shot and stunned was the man who set her car on fire. The milkman, making his early morning deliveries, was standing nearby looking surprised.

\section{Scenario 8: Property Destruction: Nondeadly Force-Mistaken Identity}

(N) One night while William is at work, Suzanne is asleep in their bedroom upstairs. Suddenly, Suzanne is jerked awake out of a sound sleep by a sound outside of her bedroom window. She gets out of bed, looks outside and sees a man setting fire to the inside of her car. Suzanne realizes that if she does not detain the man there is a great possibility that the man will never be apprehended. She reaches into the drawer of her night stand, pulls out a stun gun (an instrument which will temporarily stun an individual but will not cause serious bodily injury) and shouts out of the window, "stop you bastard or I'll shoot!" Suzanne runs down the stairs and out of the front door. When she is outside she sees a man running away at the bottom of her driveway. Suzanne raises the stun gun and shoots. She sees the man fall to the ground. The man Suzanne shot and stunned was not the 
man who set her car on fire but was the milkman who was making his morning deliveries but who saw the fire and was running to call for help.

\section{STUDY 8: \\ OFFENSE CULPABILITY REQUIREMENTS AND MISTAKE/ACCIDENT DEFENSES}

\section{Scenario 1: As to Causing Damage to House}

(O) Chris Bradley lives in a small three bedroom house with a wooden shed in the backyard which leans up against a fence which divides his property from that of his next door neighbor. In July, Chris decides to store some of the chemical samples sold by his company in his shed until the warehouse being built at work is completed. The next day, Chris and two of his employees unload a small truck load of various chemical samples into Chris's shed. Unfortunately, the temperature steadily rises during the next week and the increased heat causes some of the barrels of chemicals to spontaneously combust and Chris's shed catches on fire. The fire spreads to his neighbor's house which is destroyed. Fortunately, Chris's neighbors are away on vacation and no one is injured. The fire then extinguishes itself. Chris Bradley is arrested for arson.

(a) Knowing

(IV) Now, assume the following: Chris Bradley was practically certain the chemicals would explode, but stored them in the shed anyway because he was angry with his neighbor.

(b) Reckless

(III) Now, assume the following: Chris Bradley was aware of a substantial chance that the chemicals could explode, but decided to store them in the shed anyway because he was unhappy with his neighbor.

(c) Negligent

(II) Now, assume the following: It never occurred to Chris Bradley that the chemicals would explode, but a reasonable person would have been aware that there was a risk of explosion and would have taken precautions to prevent it.

(d) Faultless

(I) Assume the following: It never occurred to Chris Bradley that the chemicals would explode because the barrels were improperly labeled by the manufacturing company which supplied the chemicals and as labeled were not subject to the risk of explosion. Thus Chris Bradley could not have been aware of the risk of explosion. 


\section{Scenario 2: As to Causing Damage to Unimproved Property}

(R) Peter Jones lives in a peaceful rural area in a big old farmhouse with a barn in the back. The barn leans up against the fence which divides his property from that of his next door neighbor. In July, Peter decides to store some of the chemical samples sold by his company in his barn until the warehouse being built at work is completed. The next day, Peter and two of his employees unload a small truck load of various chemical samples into Peter's barn. Unfortunately, the temperature steadily rises during the next week and the increased heat causes some of the barrels of chemicals to spontaneously combust and Peter's barn catches on fire. The fire spreads to his neighbor's property and an entire field is destroyed. Fortunately, Peter's neighbors are on vacation and no one is injured. The fire then extinguishes itself. Peter Jones is arrested for arson.

(a) Knowing

(IV) Now, assume the following: Peter Jones was practically certain the chemicals would explode, but stored them in his barn anyway because he was angry at his neighbor.

(b) Reckless

(III) Now, assume the following: Peter Jones was aware of a substantial chance that the chemicals could explode, but decided to store them in his barn anyway because he was unhappy with his neighbor.

(c) Negligent

(II) Now, assume the following: It never occurred to Peter Jones that the chemicals would explode, but this possibility would have occurred to a reasonable person.

(d) Faultless

(I) Assume the following: It never occurred to Peter Jones that the chemicals would explode because the barrels were improperly labeled by the manufacturing company which supplied the chemicals and as labeled were not subject to the risk of explosion. Thus Peter Jones could not have been aware of the risk of explosion.

\section{Scenario 3: As to House Belonging to Another}

(C) Bill Smith lives in a relatively quiet neighborhood, except for Brad Wilson, who bought the house next door. Wilson has little regard for the peace and quiet of the neighborhood. In addition to having noisy late night parties, he has allowed his house and property to become an eyesore. Over the course of the last two years the house has become virtually uninhabitable. After repeatedly complaining to Wilson, to no avail, about the parties and the condition of the house, Bill Smith decides that the only way to resolve the problem is to buy the house 
from Wilson. Smith, through his lawyer, makes such an attractive offer to Wilson, that Wilson quickly signs the agreement of sale. To celebrate the hefty profit he will make from the sale of his house when the deal is finalized at the closing in a couple of months, Wilson packs up all his belongings and departs for a two week island vacation. After Smith is certain that Wilson is gone, he surveys the property and decides that the house is worthless and purposefully burns the house to the ground. Upon Wilson's return from vacation, Wilson is very upset to find that his house has been destroyed and that there will be no closing. Subsequently, Bill Smith is informed that until the closing had actually taken place the house was still owned by Brad Wilson. Bill Smith is arrested for arson.

(a) Knowing

(IV) Now, assume the following: Bill Smith knew that the house was not his yet, but burned the house anyway because he was angry at his neighbor.

(b) Reckless

(III) Now, assume the following: Bill Smith was aware of a substantial chance that the house might not be his yet, but he went ahead and burned the house anyway because he was unhappy with his neighbor.

(c) Negligent

(II) Now, assume the following: It never occurred to Bill Smith that the property was not his when he burned it, but this possibility would have occurred to a reasonable person.

(d) Faultless

(I) Assume the following: It never occurred to Bill Smith that the house was not his yet because when the agreement of sale was signed his lawyer said to him, "Congratulations Bill, you've just bought yourself some peace of mind."

\section{Scenario 4: As to Unimproved Property Belonging to Another}

(U) Tom Janson lives in an area of small family owned farms and open fields that is relatively quiet, except for Jack Nelson who bought the fields next to Janson's farm. Nelson has little regard for the peace and quiet beauty of the area. In addition to having noisy parties and motorcycle races in the fields, he has allowed the fields to become overgrown and unsightly. Over the course of the last two years the fields have become an eyesore. After repeatedly complaining to Nelson, to no avail, about the parties, the motorcycles and the condition of the fields, Janson decides that the only way to resolve the problem is to buy the fields from Nelson. Janson, through his lawyer, makes such an attractive offer to Nelson, that Nelson quickly signs the agreement of sale. To celebrate the hefty profit he will make from the sale of his fields when the deal is finalized at the closing in a couple of months, 
Nelson heads off for a two week island vacation. After Janson is certain that Nelson is gone, he surveys the fields and decides that in their current condition they are worthless and purposefully burns the fields to the ground. Upon Nelson's return from vacation, Nelson is very upset to find that his fields have been destroyed and that there will be no closing. Subsequently, Tom Janson is informed that until the closing had actually taken place the fields were still owned by Jack Nelson. Tom Janson is arrested for arson.

(a) Knowing

(IV) Now, assume the following: Tom Janson knew that the fields were not his yet, but he burned them down anyway because he was angry with his neighbor.

(b) Reckless

(III) Now, assume the following: Tom Janson was aware of a substantial chance that the fields might not be his yet, but went ahead and burned them down anyway because he was unhappy with his neighbor.

(c) Negligent

(II) Now, assume the following: It never occurred to Tom Janson that the fields were not his when he burned them, but this possibility would have occurred to a reasonable person.

(d) Faultless

(I) Assume the following: It never occurred to Tom Janson that the fields were not his yet because when the agreement of sale was signed his lawyer said to him, "Congratulations Tom, you've just bought yourself some peace of mind."

\section{Scenario 5: As to Victim's Lack of Consent in Rape}

( $\mathrm{T})$ Louis Haggarty lives in Nevada, in a county where prostitution is legal, and visits a house of prostitution once a month. His favorite room in the house is called the "Rape Room" where the prostitute "pretends" to be asleep and the client "pretends" to attack her and have forcible sexual intercourse with her. After Louis's most recent visit to the prostitution house he is arrested for rape.

(a) Knowing

(IV) Now, assume the following: Louis was practically certain that the "prostitute" really had been kidnapped, but had forcible sexual intercourse with her anyway.

(b) Reckless

(III) Now, assume the following: That night the "prostitute" told Louis that she had been kidnapped by the owners of the prostitution house and was being kept 
there against her will. Louis knew that there was a substantial chance that her story was true because the house had been in trouble before for kidnapping, but Louis had forcible sexual intercourse with her anyway.

(c) Negligent

(II) Now, assume the following: That night the "prostitute" told Louis that she had been kidnapped by the owners of the prostitution house and was being kept there against her will. Louis had heard from some friends that the prostitutes were telling wild stories to liven things up. The woman, however, told Louis again that she was being held against her will. Louis thinks to himself, "Probably not, but her story might be true." Louis, however, has forcible sexual intercourse with her anyway.

(d) Faultless

(I) Assume the following: That night the "prostitute" told Louis nothing and he proceeded to have forcible sexual intercourse with her. Neither Louis nor any reasonable person would have had any reason to know that the woman was being held against her will.

\section{Scenario 6: As to Victim Being Underage in Statutory Rape}

(N) David Johnson met Stacey Collins at his health club which he visits approximately three times a week. After talking to Stacey on numerous occasions at the health club, David asks Stacey to go out with him on a Friday night. David and Stacey go to dinner and then dancing and finally back to David's apartment where they engage in consensual intercourse. The next Monday, David Johnson is arrested for statutory rape. Stacey Collins is fourteen years old, below the legal age of consent.

(a) Knowing

(IV) Now, assume the following: David Johnson knew that Stacey Collins was underage on the night they went out, but engaged in sexual intercourse with her anyway.

(b) Reckless

(III) Now, assume the following: David Johnson was aware of a substantial chance that Stacey Collins was underage on the night they went out, but engaged in sexual intercourse with her anyway.

(i) Negligent

(II) Now, assume the following: It never occurred to David Johnson that Stacey Collins was underage on the night they went out and engaged in sexual intercourse, but this possibility would have occurred to a reasonable person. 
(d) Faultless

(I) Assume the following: It never occurred to David Johnson and would not have occurred to a reasonable person that Stacey Collins was underage on the night they went out and engaged in sexual intercourse because she told him she was twenty-one and even had fake identification, which she showed to the bouncer at the club where they went dancing.

\section{STUDY 9: \\ CULPABILITY REQUIREMENTS FOR COMPLICITY}

In each of the following six cases, assume the following:

Mark and Gregory arrive at the plant where they both work.-Because Gregory has been drinking alcoholic beverages and is intoxicated, Mark is driving the automobile, which is borrowed from one of their joint friends. Mark has not been drinking. After they park; Gregory asks Mark for the car keys so that he can drive home to change before work.

\section{Scenario 1: Purposeful as to Assisting Driving, Knowing as to Causing Death}

(C) Gregory says that if he rushes, and uses the West Gate as a short cut, he can make it back to the plant before the shift starts. Mark says, "Yeah, go ahead. Bring me back a jacket." Mark knows that the West Gate is now crowded with people coming to work and he is certain that if he gives the keys to Gregory, Gregory will hit someone at the gate and kill them. Nonetheless, he gives Gregory the car keys. Gregory speeds off toward the West Gate and, because of dangerous driving due to intoxication, he strikes and kills two workers just arriving for work through the West Gate.

\section{Scenario 2: Purposeful as to Assisting Driving, Reckless as to Causing Death}

(U) Mark says, "Yeah, go ahead. Bring me back a jacket." Mark is aware that because of Gregory's intoxication, there is a chance that if he gives the keys to Gregory, Gregory may have an accident and kill someone. Nonetheless, he gives the car keys to Gregory and proceeds into the plant. Gregory drives off for his house to change and ten minutes later, because of dangerous driving due to intoxication, Gregory collides with another car, killing the two passengers in the car.

\section{Scenario 3: Knowing as to Assisting Driving, Knowing as to Causing Death}

(L) Gregory says that if he rushes, and uses the West Gate as a short cut, he can make it back to the plant before the shift starts. Mark knows that the West Gate is now crowded with people coming to work and he is certain that if he gives the 
keys to Gregory, Gregory will hit someone at the gate and kill them. Nonetheless, Mark pleads with Gregory not to drive because he (Gregory) is too intoxicated. Gregory continues to insist. Mark gives him the keys, and then proceeds into the plant. Gregory gets into the car and speeds off toward the West Gate. Because of dangerous driving due to intoxication, he strikes and kills two workers just arriving for work through the West Gate.

\section{Scenario 4: Knowing as to Assisting Driving, Reckless as to Causing Death}

(P) Mark is aware that, because of Gregory's intoxication, there is a chance that if he gives the keys to Gregory, Gregory may have an accident and kill someone. Nonetheless, he pleads with Gregory not to drive because he (Gregory) is too intoxicated. Gregory continues to insist. Mark gives him the keys and then proceeds into the plant. Gregory gets into the car and drives off for his house to change. Ten minutes later, because of dangerous driving due to intoxication, Gregory collides with another car, killing the two passengers in the car.

\section{Scenario 5: Reckless as to Assisting Driving, Knowing as to Causing Death}

(A) Gregory says that if he rushes, and uses the West Gate as a short cut, he can make it back to the plant before the shift starts. Mark tells Gregory that he (Gregory) is too drunk to drive and proceeds into the plant with Gregory following him. In the locker room, Mark puts his valuables, including the car keys, on the locker room bench. Before he heads for the bathroom, it occurs to him that Gregory might take the keys. Mark knows that the West Gate is now crowded with people coming to work. If Gregory takes the keys, Mark is certain that Gregory will hit someone at the gate and kill them. Mark nonetheless leaves the keys on the bench. When he returns, Gregory has taken the keys and left the plant. Gregory speeds off toward the West Gate and, because of dangerous driving due to intoxication, he strikes and kills two workers just arriving for work through the West Gate.

\section{Scenario 6: Reckless as to Assisting Driving, Reckless as to Causing Death}

(B) Mark tells Gregory that he (Gregory) is too drunk to drive and proceeds into the plant with Gregory following him. In the locker room, Mark puts his valuables, including the car keys, on the locker room bench. Before he heads for the bathroom, it occurs to him that Gregory might take the keys and, if he does, Mark believes that Gregory may have an accident and kill someone. Mark nonetheless leaves the keys on the bench. When he returns, Gregory has taken the keys and left the plant. Gregory drives toward his house to change and ten minutes later, because of dangerous driving due to intoxication, Gregory collides with another car, killing the two passengers in the car. 


\section{STUDY 10: VOLUNTARY INTOXICATION}

\section{Scenario 1: Purposeful Killing-Control}

(X) Brian, upset with his roommate for stealing his girlfriend, wants to kill him. When his roommate arrives home, Brian starts beating his roommate. His roommate later dies from the beating.

\section{Scenario 2: Reckless Killing-Control}

(O) Brian is upset with his roommate for stealing his girlfriend. Brian wants to severely beat his roommate but does not want to kill him. When his roommate arrives home, Brian starts striking his roommate over the head with a lead pipe. His roommate later dies from the beating.

\section{Scenario 3: Pre-Intoxication Purposeful Killing-Purposeful Intoxication}

(B) Brian, upset with his roommate for stealing his girlfriend, wants to kill his roommate. Brian plans to beat his roommate over the head with a heavy object until his roommate dies. First, however, Brian drinks two six-packs of beer in the course of two hours to steel his nerves. Brian knows his alcohol tolerance is generally low. By the time he has finished the last beer, Brian is extremely intoxicated. At this point, Brian can barely stand up. His thought processes and vision are severely impaired. His roommate then arrives home. Brian starts striking his roommate over the head with a lead pipe. His roommate later dies from the beating. The next day, Brian does not remember the beating.

\section{Scenario 4: Pre-Intoxication Purposeful Killing-Reckless Intoxication}

( $\mathrm{T})$ Brian, upset with his roommate for stealing his girlfriend, wants to kill his roommate. Brian plans to beat his roommate over the head with a heavy object until his roommate dies. First, however, Brian goes out with his friends. Brian has recently been taking medication for his chronic back pain. Although he thinks that the medication's warning states that the consumption of alcohol might cause in toxication, Brian disregards the warning and consumes 3 beers. Brian becomes extremely intoxicated. At this point, Brian can barely stand. His thought processes and vision are severely impaired. Brian somehow makes it back to his home. When his roommate arrives home, Brian starts striking his roommate over the head with a lead pipe. His roommate later dies from the beating. The next day, Brian does not remember the beating.

\section{Scenario 5: Pre-Intoxication Purposeful Killing-Negligent Intoxication}

(P) Brian, upset with his roommate for stealing his girlfriend, wants to kill his roommate. Brian plans to beat his roommate over the head with a heavy object until his roommate dies. First, however, Brian goes out with his friends. Although he has been taking medication for his chronic back pain, Brian has never read the 
medication's warning. The warning clearly states that the consumption of alcohol while on the medication will result in extreme intoxication. Brian has 3 beers with his friends. Brian becomes extremely intoxicated. At this point, Brian can barely stand. His thought processes and vision are severely impaired. Brian somehow makes it back to his home. When his roommate arrives home, Brian starts striking his roommate over the head with a lead pipe. His roommate later dies from the beating. The next day, Brian does not remember the beating.

\section{Scenario 6: Pre-Intoxication Reckless Killing-Purposeful Intoxication}

(J) Brian is upset with his roommate for stealing his girlfriend. Brian wants to severely beat his roommate to scare him but does not want to kill his roommate. First, however, Brian drinks two six-packs of beer in the course of two hours to steel his nerves. Brian knows his alcohol tolerance is generally low. By the time he finishes the last beer, Brian is extremely intoxicated. At this point, Brian can barely stand. His thought processes and vision are severely impaired. When his roommate arrives home, Brian starts striking his roommate with a lead pipe. His roommate later dies from the beating. The next day, Brian does not remember the beating.

\section{Scenario 7: Pre-Intoxication Reckless Killing-Reckless Intoxication}

(H) Brian is upset with his roommate for stealing his girlfriend. Brian wants to severely beat his roommate to scare him but does not want to kill his roommate. First, however, Brian goes out with his friends. Brian has recently been taking medication for his chronic back pain. Although he is aware of the medication's warning that the consumption of alcohol might cause intoxication, Brian disregards the warning and consumes 3 beers. Brian becomes extremely intoxicated. At this point, Brian can barely stand. His thought processes and vision are severely impaired. Brian somehow makes it back home. When his roommate arrives home, Brian starts striking his roommate with a lead pipe. His roommate later dies from the beating. The next day, Brian does not remember the beating.

\section{Scenario 8: Pre-Intoxication Reckless Killing-Negligent Intoxication}

(W) Brian is upset with his roommate for stealing his girlfriend. Brian wants to severely beat his roommate to scare him but does not want to kill his roommate. First, however, Brian goes out with his friends. Although he has been taking medication for his chronic back pain, Brian has never read the medication's warning. The warning clearly states that the consumption of alcohol while on the medication will result in extreme intoxication. Brian has 3 beers with his friends. Brian becomes extremely intoxicated. At this point, Brian can barely stand. His thought processes and vision are severely impaired. Brian somehow makes it back home. When his roommate arrives home, Brian starts striking him with a lead pipe. His roommate later dies from the beating. The next day, Brian does not remember the beating. 
Scenario 9: Pre-Intoxication Faultless Killing-Purposeful Intoxication

(M) Brian is upset with his roommate for stealing his girlfriend. Although he knows his alcohol tolerance is generally low, Brian consumes 2 six-packs of beer within the course of 2 hours. By the time he finishes the last beer, Brian is extremely intoxicated. At this point Brian can barely stand. His thought processes and vision are severely impaired. Then, Brian's friend Joe, who lives in another town, stops by for a visit. Upon Joe's arrival, Brian loses control of himself and starts striking Joe with a lead pipe. Joe later dies from the beating. The next day, Brian does not remember the beating.

\section{Scenario 10: Pre-Intoxication Faultless Killing-Reckless Intoxication}

(A) Brian, upset with his roommate for stealing his girlfriend, decides to go out with his friends. Brian has recently been taking medication for his chronic back pain. Although he thinks that the medication's warning states that the consumption of alcohol might cause intoxication, Brian disregards the warning and consumes 3 beers. Brian becomes extremely intoxicated. At this point, Brian can barely stand. His thought processes and vision are severely impaired. Noticing that Brian is intoxicated, Joe, one of Brian's friends, decides to drive Brian home. Upon arriving at his home, Brian loses control and starts striking Joe with a lead pipe. Joe later dies from the beating. The next day, Brian does not remember the beating.

\section{Scenario 11: Pre-Intoxication Faultless Killing-Negligent Intoxication}

(L) Brian, upset with his roommate for stealing his girlfriend, decides to go out with his friends. Although he has been taking medication for his chronic back pain, Brian has never read the medication's warning. The warning clearly states that the consumption of alcohol while on the medication will result in extreme intoxication. Brian has 3 beers with his friends. Brian becomes extremely intoxicated. At this point, Brian can barely stand. His thought processes and vision are severely impaired. Noticing that Brian is intoxicated, Joe, one of Brian's friends decides to drive Brian home. Upon arriving at his home, Brian loses control of himself and starts striking Joe with a lead pipe. Joe later dies from the beating. The next day, Brian does not remember the beating.

\section{STUDY 11: INDIVIDUALIZATION OF THE OBJECTIVE STANDARD OF NEGLIGENCE}

\section{Scenario A: Commission-Death}

(S) Sam decides that he wants to go hunting by himself in a very remote area out West. He drives for half a day on a gravel road through the mountains without seeing another car, house, or store. Sam camps out and is amazed at how quiet it is; he feels so far away from people. He thinks how great it would be to have a cabin there. He guesses there is a lot of wildlife, including bears, in the woods 
around him. Just recently he read Alaska Bear Tales, a collection of stories about bear encounters.

Early in the morning, after he finished a tasty breakfast of bacon and eggs, Sam hears a noise in the brush and quickly grabs his gun and fires it in the direction of the noise. Then he hears nothing. He runs through the thicket and evergreens to see what he has shot. He discovers that he has killed another hunter.

\section{Characteristic (11) Cultural Norms}

(4S) Sam is an American Indian. In his tribe, the men hunt alone. They hunt in remote areas away from any people. Unlike most hunters, it is normal for the men to shoot at anything. This is because their kill is their food. No one ever killed another hunter using this hunting method.

Characteristic (5S) Substandard Education

Sam had never been hunting before.

Characteristic (6S) Old Age

At age 82 , Sam has gray hair and is very wrinkled.

\section{Characteristic (7S) Religion (Knowledge)}

Sam's religion is not a traditional one, but. its beliefs include the fact that the forest, though beautiful and peaceful, is also filled with animals that are evil because they can be violent to man, and man is God's image. It is the duty of believers in the faith to destroy evil wherever they encounter it. Sam knows this from his religious lessons and he is very devout.

Characteristic (8S) Recent Upset

Sam was mugged only two nights ago.

Characteristic (9S) Below-Normal Intelligence

No matter how much Sam studied in school, he just could not understand the material.

Characteristic (10S) Lack of Knowledge (Culture)

Sam is originally from the Outback of Australia. They do not have firearms. They hunt with spears and know nothing about guns. Even though he can use a gun, Sam still doesn't really know the powerful impact of a gun and the distance a bullet can travel.

Characteristic (11S) Immaturity

Sam is a senior in high school and is seventeen years old.

Characteristic (12S) Upbringing (Knowledge)

When he was a child, Sam used to accompany his father to hunting club meetings, and even occasionally, on a hunting trip with his father and uncle. 
Characteristic (13S) Advanced Experience

Sam has a college degree. He teaches part-time at the community college and is working on another college degree.

\section{Characteristic (14S) Upbringing (Knowledge)}

Though no one in Sam's family has ever hunted, Sam's parents are both very saf ety-conscious people. Their young children followed the traffic rules for riding their bikes. They had their children take a driver education course before getting their licenses. The whole family had an escape plan in case of fire in the home. Everyone always had to wear their seatbelts. "Safety First" was the family motto.

Characteristic (15S) Religion (Norms)

Sam's religion holds that he absolutely must never worry about anything because God's will takes care of everything. Worrying would mean a lack of faith.

\section{Characteristic (16S) Genetic Irregularity}

No matter what they did or where they were, both of Sam's parents were accident-prone. They said they always tried to be careful. But they couldn't help it. Sam's grandparents were the same. They were just an accident-prone family. The family doctor testified that there is an actual physical cause of their tendency to act too quickly which causes their accident-prone behavior, which is, in turn, caused by a hereditary enzyme deficiency.

Characteristic (17S) Above-Normal Intelligence

Sam always scored the top score on standardized tests at school, including the Iowa Test in grade school and the I.Q. test in high school.

\section{Scenario B: Omission-Death}

(M) Mart is the parent of Jennine, age 2. Jennine had always been a colicky baby. When she fussed, there was nothing that could be done for her. Mart usually leaves Jennine in front of the television, occasionally checking on her. One day, Jennine starts to cry a lot, holding her head and vomiting most of her food. She also shakes uncontrollably, which she has never done before. This goes on for two days. On the third day, Jennine dies. An autopsy reveals that she died of lead poisoning and that timely medical intervention would likely have saved her life.

\section{Characteristic (4M) Religion (Norms)}

The religion that Mart, as an adult, chooses to follow forbids seeking medical treatment for illness.

\section{Characteristic (5M) Upbringing (Knowledge)}

Mart was orphaned when she was a baby. She was raised in a very nice orphanage, which sent the children to public schools. Usually there was only one staff 
member on duty to care for 10 children per shift. The children were kept separated by age, so they never saw the younger children being taken care of.

\section{Characteristic (6M) Cultural Norms}

Mart lives in a very tight-knit community in a remote part of Maine. Everyone there is committed to keeping "civilization" away. The nearest doctor is in a town 75 miles away and everyone thinks that is just close enough. The community does not want the intrusion that a "town doctor" would be. They had a town meeting once and everyone said, "Who needs lawyers and doctors-if it weren't for them, there wouldn't be such a 'rat race.' We like the simple life. That's why most of us left places like New York to live here." They all like their community just the way it is and are proud of being a self-reliant community.

\section{Characteristic (7M) Immaturity}

Since Mart is too young to drink alcohol, she just has a soda when she goes to any party that serves alcohol. Last year her favorite rock group was New Kids on the Block; now she loves Vanilla Ice. Mart is sixteen years old.

Characteristic (8M) Below-Normal Intelligence

Mart works in a sheltered workshop. She is a slow learner compared to other people.

\section{Characteristic (9M) Recent Upset}

Mart's mother and husband were very recently killed in an accident.

Characteristic (10M) Above-Normal Intelligence

Mart is a firm believer in learning as much as possible. She received her Bachelor's degree. Also, she took a mini-psychology course called "Parent Effectiveness Training" when she found out she was pregnant.

\section{Characteristic (11M) Religion (Knowledge)}

Mart knows from her religion that vomiting is not illness. Rather, the religion teaches that vomiting is a sign that evil spirits are being cast away. It teaches that when a child vomits, the child needs to be left alone for God to do his work against the evil.

\section{Characteristic (12M) Upbringing (Environment)}

Normally Mart's parents hardly ever took their children to the doctor. They always said that if you just waited 2 weeks, you would go to the doctor a lot less.

Characteristic (13M) Above-Normal Intelligence

Since first grade Mart was always an honor student. Learning just comes naturally to her. 
Characteristic (14M) Genetic Irregularity

Mart's grandmother and mother seemed to have all kinds of different accidents and didn't understand how or why they happened. Even though they were smart and caring people and otherwise fine, the family doctor testified that all three women had a hereditary hormonal imbalance which causes them to be less observant of what goes on around them than most people would be in the same situation.

Characteristic (15M) Old Age

Mart is eighty-one years old and Jennine's grandmother.

Characteristic (16M) Lack of Knowlege (Culture)

Recently, Mart came to the United States from what is thought of as a "Third World Country." Because of a shortage of doctors, there was little medical care in her country, except for trauma. So, the medical care they know of consists mostly of surgical intervention or taking care of broken bones. They don't know that doctors take care of children for illnesses.

Characteristic (17M) Substandard Education

Even though Mart was an average student, she only finished grade school.

\section{Scenario C: Omission-Property Damage}

(R) Ry owns an eight unit apartment building in Rochester; he has a duty to maintain the building properly. He also lives in one of the apartments. Last week, a fire started in the building, causing $\$ 500,000$ of property damage before the fire was brought under control. Fortunately, no lives were lost and no one was seriously injured.

An investigation later determined how the fire started. The building hadn't been painted in some time and so much paint had peeled off that most of the hallways had piles of paint in the corners. In the hallway where the fire started, the overhead light was just a naked light bulb. Someone had removed the protective light fixture and it had never been replaced. Apparently the fire started when a large piece of paint landed on the hot, naked bulb, caught fire, and fell to the floor before burning up, where it ignited other paint peelings.

Ry was unaware that these conditions existed. Because he had a separate entrance to his own apartment and rarely went into the common hallways, he didn't know there was a risk of fire. He had not seen the flaked paint. He did not know that the protective light fixture was missing.

Characteristic (4R) Old Age

Whenever anyone asks just how old eighty year old Ry is, he always says that he is "older than sand." 
Characteristic (5R) Advanced Experience

Ry's job experience includes building maintenance work.

Characteristic (6R) Genetic Irregularity

A geneticist testified that there is a gene that can cause sporadic forgetfulness and lack of attentiveness. After studying Ry's parents and Ry, he concluded that Ry has inherited the trait.

\section{Characteristic (7R) Upbringing (Knowledge)}

Ry never saw either parent ever do any maintenance work on their house. Because of his father's job, they moved a lot into new homes that never needed painting or any other kind of maintenance work. As a result, he has no knowledge of what building maintenance entailed.

\section{Characteristic (8R) Below-Normal Intelligence}

Ry is willing to try to learn new things, but not too many people have the patience to teach him. He just doesn't catch on very quickly.

\section{Characteristic (9R) Religion (Knowledge)}

Ry's religion teaches him that whatever was good could stand the test of time and whatever was evil would not last. If a tree grows for 100 years, it is because of good. He knows that if a car falls apart or if a roof caves in, it is because of evil spirits. He knows there is nothing anyone could do about such occurrences. He knows this is a universal truth.

\section{Characteristic (10R) Above-Normal Intelligence}

Ry always learns more quickly than most other people. In school, he was a better than average student. He even skipped one grade.

\section{Characteristic (11R) Upbringing (Environment)}

Ry grew up in a city that is very overcrowded-so it's hard to find an apartment. His family was glad to have found theirs. As a result, his own family always repaired and maintained their own apartment. They never thought of having the landlord do any of it. From this upbringing, Ry believed maintenance was something tenants take care of.

\section{Characteristic (12R) Lack of Knowledge (Culture)}

$\mathrm{Ry}$ is a member of an Indian tribe that lives on a reservation in Northern Maine where he lived most of his life. They still speak their native tongue. Their homes are $\log$ cabins. Everything is in its natural state. They have never painted anything. They have no electricity. They know nothing about man-made paint and 
its characteristics or about the operation of light bulbs. Ry was left the apartment building by an uncle who left the reservation.

Characteristic (13R) Substandard Education

Ry was an average student, but only went as far as the fifth grade.

Characteristic (14R) Cultural Norms

Ry comes from a country that has a very strict standard of privacy. No one ever entered another person's home unless invited. To do so would be an insult. He believes that entering common hallways violates a tenant's privacy.

\section{Characteristic (15R) Recent Upset}

Just after Ry acquired the apartment building, his daughter died from leukemia.

\section{Characteristic (16R) Religion (Norms)}

Ry's religion does not allow him to use man-made products such as paint. He is trying to find a paint made from natural products.

Characteristic (17R) Immaturity

Ry is only nineteen years old and is still unsure of all his goals in life. The apartment building was left to Ry in his aunt's will.

\section{STUDY 12: INSANITY}

\section{Scenario 1: Murder}

(Q) John Hardey is angry with Jack Turner for making disparaging remarks about him. He goes to Jack's house, waits until he is alone, then bludgeons him to death with an ax handle.

\section{Scenario 2: Self-Defense}

(R) Dennis Harkins is the owner of a small convenience store. At about 10 p.m., a man enters the store, pulls out a knife, and demands the money in the cash register. Harkins refuses to hand it over and takes a policeman's "night stick" from under the counter. As the man lunges at him, Harkins strikes him on the head to defend himself. The man subsequently dies from the injury.

\section{Scenario 3: Mistaken Identity}

(Z) Dennis Harkins is the owner of a small convenience store. At about 10 p.m., a man enters the store, robs Harkins at knifepoint, and flees. Harkins gives chase with a policeman's "night stick" that he keeps under the counter but loses the sus- 
pect during the chase. As he is returning to the store, having given up the chase, he sees the man standing on a porch talking with others. Harkins approaches the man, demands his money back, and tells the others to call the police, which they do. The man denies being the robber. Harkins is aware that the man might not be the robber but thinks that he probably is. He and Harkins get into a fight, during which Harkins beats the man with his "night stick." The man subsequently dies from the injuries. Another man, similar in appearance is later arrested and convicted for the robbery.

\section{Scenario 4: High Control, Low Cognitive}

(I) Stanley Charlson has been twice committed to a mental hospital, each following an attempt to disfigure or mutilate himself. On the first occasion, he stuck his hand into a fire in a fireplace and held it there; on the second, he cut his left shin repeatedly with a large bread knife. On both occasions, his injuries would have been life-threatening had he not been stopped by others who happened onto the scene. Other than these two episodes, Stanley is able to function and has many friends and a good relationship with his family. On a Sunday afternoon he goes to visit his parents and his younger brother, Peter, who lives with them. The back room windows of their house overlook a shallow river. Stanley calls Peter from the front room to look at a boat traveling down the river. While the boy is looking out of the window, Stanley picks up a wooden mallet and strikes the boy twice on the head, killing him instantly. When his mother enters the room, he is standing over the boy, with the mallet still in his hand and a horrified look on his face. He can give no explanation to his mother as to why he did what he did, saying simply that "something came over me and made me do it." When the police arrive, they find him huddled in the corner of the back room. He is transported to the local county hospital for treatment. In interviews with doctors and private talks with his mother, he describes that at the time he hit Peter on the head he was well aware of what he was doing and that it was wrong but felt subject to an overwhelming compulsion that "took control of his body," and compelled him to do what he did, although he has no idea why. Court-appointed psychiatrists testify that at the time of his conduct causing Peter's death he was mentally ill, suffering from severe impulse control disorder.

\section{Scenario 5: High Control, Low Cognitive}

(C) Michael Monte was discharged from the Navy at the age of 17 after a psychiatric examination showed that he suffered "from a profound personality disorder that renders him unfit for Naval service." He now lives alone in a boarding house and, because of repeated outbursts of temper, has no close friends. He has not held a job for more than two weeks at a time and is always on the verge of being evicted from his room for his unpredictable behavior. His landlady is tolerant of his minor misconducts because she feels sorry for him, believing that he is not al- 
ways in control of himself. "He is as sweet as can be for a while, then will turn to a very black mood and blow up at whoever happens to be around," she explains. "He is always very sorry immediately after and makes a nuisance of himself trying to apologize." On this particular day, Michael is in one of his black moods when he leaves the building in the morning. When he returns that afternoon he seems to his landlady to be even more distressed. She asks him if he is "ok" as he passes her door. He does not respond. Twenty minutes later one of the other tenants knocks on Michael's door and demands that Michael turn his music down. He continues to pound on the door for several minutes. Michael suddenly opens the door swinging a baseball bat, striking the surprised tenant in the head, killing him instantly. When the landlady reaches the landing, she finds Michael, standing over the body, as if frozen. She checks the body and tells Michael that the man is dead. Michael gasps, falls to his knees-_"Why did I do that? I knew I shouldn't have hit him." Court-appointed psychiatrists testify that at the time of the killing Michael knew what he was doing and knew that it was wrong, but that he suffers from severe anger control disorder and, as a result, was not able to control his conduct.

\section{Scenario 6: Medium Control, High Cognitive}

(G) Mrs. Jeanne Cogdon lives with her husband Frank and her daughter Pat, age 15. Mrs. Cogdon suffered a severely traumatic experience when she became lost during a camping trip two years earlier. She was found after six days, suffering from exposure, disorientation, and severe depression. Since that time, she has been seeing a psychiatrist, who is treating her for post traumatic stress disorder. On this particular night, she goes to bed at 10:30 p.m. as usual and at 1:30 a.m. she awakes in order to check on her daughter, Pat. She sees Pat and becomes terrified because she thinks she is seeing Pat being attacked by moles. She screams "the moles are going to get us. They are attacking Pat!" Jeanne attempts to protect Pat by picking up a hockey stick and striking Pat's bed several times including one blow to Pat's head that kills her. When Jeanne's husband arrives she is striking at different parts of Pat's desktop although the desktop is actually empty. She yells to her husband, "you've got to help, the moles are hurting Pat." Her husband tells her to put the stick down, and she does. Psychiatrists testify that she was hallucinating at the time of the killing, as a result of post-traumatic stress disorder.

\section{Scenario 7: Low Control, High Cognitive}

(V) Jeffrey stays in his room most of the time, with the shades pulled and the lights out. Every month he must go to the hospital for counseling with a psychiatrist. The trips are very stressful for Jeffrey, who becomes more agitated as the day for his monthly trip approaches. He is afraid that someone "will get him," he tells his mother and is upset with the hospital for making him go. She tries to assure him that everything will be fine, and that he should leave for the bus immediately. Jeffrey leaves the house, walking quickly, heading for the bus stop three blocks 
away. Two women and a young man are already at the stop waiting for the bus. Although the young man has done nothing, Jeffrey becomes frightened and feels physically threatened by him. He finds a stone and hides it in his pocket in order to defend himself. Jeff rey waits to board after the other people but the young man, who is ahead of him in line, steps out of line and bends to one knee to tie his shoe. The young man stands up just as Jeffrey passes him. Jeffrey imagines that the man is about to attack him, reacts by hitting the youth in the face with the rock that he had hidden in his pocket. As the young man staggers, Jeffrey hits him again on the side of the head, killing him. Jeffrey explains to onlookers that the young man was about to attack him. Court-appointed psychiatrists testify that at the time of his conduct causing the young man's death, Jeffrey was suffering from severe paranoid schizophrenia.

\section{STUDY 13: \\ IMMATURITY AND INVOLUNTARY INTOXICATION}

\section{Scenario 1: Control-Murder}

(G) Mike, age 30, is playing poker with his brother Joe late one evening while both are visiting their grandmother. Neither brother is particularly fond of the other but this evening, for some unknown reason, they appear more antagonistic than ever. When the poker game is over, Mike waits for Joe to fall asleep and pours gasoline, which he gets from his grandmother's garage, over Joe and lights a match. Joe dies quickly in the ensuing fire.

\section{Scenario 2: High Control}

(R) Mike, age 30, is playing poker with his brother Joe late one evening while both are visiting their grandmother. Mike recently started taking a prescription drug to control pain caused by a shoulder injury. Mike's doctor did not warn him about taking this drug in conjunction with any other medications, and it did not occur to Mike to ask about any possible interactions. Mike does not drink alcoholic beverages. Before beginning their poker game, Mike starts to feel as though he is coming down with a cold and decides to take an over-the-counter cold capsule.

During the game the normally calm and mild-natured Mike says particularly malicious things to his brother and suggests that Joe "buy" his grandmother's love by purchasing expensive gifts for her that Mike could never afford. Joe says to Mike, "Other than the television I bought her last year for her birthday, what have I given her?" Mike responds, sarcastically, "Only a television, huh?" and runs over to the set and proceeds to throw it out the living room window. Joe, upon entering the living room, screams "What the hell are you doing, Mike?" Noticing the kerosene can next to the heater, Mike picks up the can, splashes kerosene on Joe and says "I'll show you what I'm doing-I'm going to turn you into a great ball of fire," and throws a match on Joe. Joe dies quickly in the ensuing fire. When his grandmother enters the room she finds Mike sitting on the floor, crying, and 
mumbling "I can't believe what I've done. I knew it was wrong when it happened but I couldn't stop myself. If you can hear me Joe, I'm sorry." When questioned, a court-appointed doctor states that the medication prescribed for Mike interacted with a common cold remedy, causing Mike to totally lose his ability to control his actions.

\section{Scenario 3: High Cognitive}

(A) Mike, age 30, is playing poker with his brother Joe late one evening while both are visiting their grandmother. Mike recently started taking a prescription drug to control pain caused by a shoulder injury. Mike's doctor did not warn him about taking this drug in conjunction with any other medications, and it did not occur to Mike to ask about any possible interactions. Mike does not drink alcoholic beverages. Before beginning their poker game, Mike starts to feel as though he is coming down with a cold and decides to take an over-the-counter cold capsule.

Shortly after the beginning of the game, Mike, who has never had any psychological impairments, notices that his cards all seem to be Jacks and that the faces on the cards appear to be laughing in a haunting manner. As Mike begins to relate his visions to Joe, Mike sees Joe slowly transform into a bull, a snake, and finally, a ghost. Mike, while taking steps backward into the living room screams at his vision to "stay away from me." Mike picks up the kerosene can next to his grandmother's heater, splashes kerosene over Joe and lights a match. Joe dies quickly from the ensuing fire. When his grandmother enters the room she finds Mike standing proudly over Joe's enflamed body. Mike turns to her and says: "I was playing cards with Joe but he turned into this ghost that was going to kill me!" When questioned, a court-appointed doctor says that the medication prescribed for Mike interacted with a common cold remedy, causing Mike to experience hallucinations which completely distorted reality for Mike throughout the evening.

\section{Scenario 4: Low Control}

(T) Mike, age 30, is playing poker with his brother Joe late one evening while both are visiting their grandmother. Mike recently started taking a prescription drug to control pain caused by a shoulder injury. Mike's doctor did not warn him about taking this drug in conjunction with any other medications, and it did not occur to Mike to ask about any possible interactions. Mike does not drink alcoholic beverages. Before beginning their poker game, Mike starts to feel as though he is coming down with a cold and decides to take an over-the-counter cold capsule.

During the game the normally calm and mild-natured Mike says particularly malicious things to his brother and suggests that Joe "buy" his grandmother's love by purchasing expensive gifts for her that Mike could never afford. Joe says to Mike, "Other than the television I bought her last year for her birthday, what have I given her?" Mike thinks to himself "You know, he's right. I should apologize." But several moments later Mike feels angry again. Mike grabs the television and 
proceeds to throw it out the living room window. Joe, upon entering the living room, yells "What the hell are you doing, Mike?" Noticing the kerosene can next to his grandmother's heater, Mike splashes kerosene on Joe and pushes him to the floor. While reaching into his pocket for matches, Mike reasons to himself: "This is silly. I could really hurt Joe over nothing." Joe, while still on the floor, yells "You moron, what are you doing?" Mike's anger wells up again. Mike then lights a match and throws it on Joe. Joe dies quickly from the ensuing fire. When his grandmother enters the room she finds Mike sitting on the floor, crying, and mumbling "I can't believe what I've done. I knew it was wrong when it happened and I thought I could stop myself but in the end, I just couldn't. If you can hear me Joe, I'm sorry." When questioned, a court-appointed doctor states that the medication prescribed for Mike interacted with a common cold remedy, resulting in a substantial, but not complete loss of emotional self-control.

\section{Scenario 5: Low Cognitive}

(E) Mike, age 30, is playing poker with his brother Joe late one evening while both are visiting their grandmother. Mike recently started taking a prescription drug to control pain caused by a shoulder injury. Mike's doctor did not warn him about taking this drug in conjunction with any other medications, and it did not occur to Mike to ask about any possible interactions. Mike does not drink alcoholic beverages. Before beginning their poker game, Mike starts to feel as though he is coming down with a cold and decides to take an over-the-counter cold capsule.

Shortly after the beginning of the game, Mike, who has never had any psychological impairments, begins to say particularly malicious things to Joe, including comments about Joe's weight problem. After a few moments Joe has had enough of the verbal attack and makes a vulgar hand gesture to Mike. Mike then thinks "Geez, if he's angry enough to do that, he might even attack me. I'd better protect myself." When Joe gets up from the table to go to the bathroom, Mike gets a can of kerosene from his grandmother's living room and hides it under the card table. When Joe returns he first goes over to the sink to get a glass of water. While Joe is looking for a glass, Mike thinks "I bet Joe's looking for a knife to stab me! I've got to protect myself!" Mike then splashes kerosene over Joe, pushes him to the ground, and throws a lighted match on him. Joe dies quickly from the ensuing fire. When questioned, a court-appointed doctor states that the medication prescribed for Mike interacted with a common cold remedy, resulting in a substantial, but not complete loss of ability to appreciate the nature of his conduct or that it was wrong.

\section{Scenario 6: Low Control and Cognitive}

(S) Mike, age 30, is playing poker with his brother Joe late one evening while both are visiting their grandmother. Mike recently started taking a prescription drug to 
control pain caused by a shoulder injury. Mike's doctor did not warn him about taking this drug in conjunction with any other medications, and it did not occur to Mike to ask about any possible interactions. Mike does not drink alcoholic beverages. Before beginning their poker game, Mike starts to feel as though he is coming down with a cold and decides to take an over-the-counter cold capsule.

During the game the normally calm and mild-natured Mike says particularly malicious things to his brother and suggests that Joe "buy" his grandmother's love by purchasing expensive gifts for her that Mike could never afford. Joe, while making a vulgar hand gesture at Mike, says: "Other than the television I bought her last year for her birthday, what have I given her?" Mike then thinks: "You know, he's right, but he's awfully upset at what I said. I want to apologize but I'm afraid to say anything." Several moments later Mike begins to feel angry again, grabs his grandmother's television and throws it out the living room window. Joe yells, "What the hell are you doing, Mike?" Mike then thinks: "Oh my gosh, he's really angry now-I'd better protect myself." Mike then picks up the can of kerosene next to his grandmother's heater, splashes kerosene on Joe, and pushes Joe to the ground. Mike thinks: "This is silly. I could really hurt Joe over nothing, but I think he might try to hurt me." Joe, while still on the floor, yells "You moron, what are you doing?" Mike's anger wells up again. Mike then lights a match and throws it on Joe. Joe dies quickly from the ensuing fire. When questioned, a court appointed doctor states that the medication prescribed for Mike interacted with a common cold remedy, resulting in substantial, but not complete, loss of ability of self-control and substantial, but not complete, loss in his ability to appreciate the nature of his conduct or that it was wrong.

\section{Scenario 7: 10-Year-Old}

(O) Mike, age 10, is trading baseball cards with his brother Joe late one evening while both are visiting their grandmother. Neither brother is particularly fond of the other but this evening, for some unknown reason, they appear more antagonistic than ever. When the "trading session" is over, Mike waits for Joe to fall asleep and pours gasoline, which he gets from his grandmother's garage, over Joe and lights a match. Joe dies quickly from the ensuing fire.

\section{Scenario 8: 14-Year-Old}

(P) Mike, age 14, is repairing his Puch Moped with his brother Joe late one evening while both are visiting their grandmother. Neither brother is particularly fond of the other but this evening, for some unknown reason, they appear more antagonistic than ever. When the repairs are finished, Mike waits for Joe to fall asleep and pours gasoline, which he gets from his grandmother's garage, over Joe, and lights a match. Joe dies quickly from the ensuing fire. 


\section{Scenario 9: 18-Year-Old}

(I) Mike, age 18, is watching "Late Night with David Letterman" with his brother Joe late one evening while both are visiting their grandmother. Neither brother is particularly fond of the other but this evening, for some unknown reason, they appear more antagonistic than ever. When the program is over, Mike waits for Joe to fall asleep and pours gasoline, which he gets from his grandmother's garage, over Joe, and lights a match. Joe dies quickly from the ensuing fire.

\section{STUDY 14: \\ DURESS AND ENTRAPMENT DEFENSES}

\section{Scenario 1: Control-No Duress or Inducement}

(E) Chris, a Navy veteran with no prior criminal record, needs money quickly. To get it, he agrees to make a delivery of eight ounces of cocaine for Tom, a local drug dealer. While making the delivery, Chris is stopped for a motor vehicle violation. A subsequent lawful search of the car results in the discovery of the cocaine. The police arrest Chris and charge him with possession of cocaine with intent to distribute.

\section{Scenario 2: High Coercion}

(P) Chris is a Navy veteran with no prior criminal record. Chris meets Tom at a baseball game and their friendship develops over the course of several weeks. Chris's friend tells him that Tom is "no good, he is involved in all kinds of drugs." Chris thereafter tries to avoid Tom as much as possible. A week later, Chris receives a telephone call from Tom asking for a favor. Chris quickly cuts off the conversation on the pretext that he has relatives over. Three days later Tom calls Chris and asks him to deliver eight ounces of cocaine for him. Tom is very insistent, stating that Chris is going to do it, but Chris still refuses. The following evening Chris receives another call from Tom. This time Tom is very loud, "You're going to deliver this stuff for me. Remember, you just moved into a place that has a dark entrance, and you leave that entrance with your wife and children ... You and your family are going to jump at shadows when you leave that dark entrance. If you call the police about this, you will be very sorry. Just deliver the stuff and I won't bother you again." After hearing this, Chris agrees to make the delivery. While making the delivery, Chris is stopped for a motor vehicle violation. A subsequent lawful search of the car results in the discovery of the cocaine. The police arrest Chris and charge him with possession of cocaine with intent to distribute.

\section{Scenario 3: Low Coercion}

(A) Chris, a Navy veteran with no prior criminal record, is working as a truck driver for Tom. Tom tells Chris he wants him to deliver eight ounces of cocaine. 
Chris initially refuses, but after Tom tells him that his employment will be terminated if he does not transport the cocaine, he agrees. While making the delivery, Chris is stopped for a motor vehicle violation. A subsequent lawful search of the car results in the discovery of the cocaine. The police arrest Chris and charge him with possession of cocaine with intent to distribute.

\section{Scenario 4: No Prior Record-Agent}

(T) Chris is a Navy veteran with no prior criminal record. He is unemployed and depressed about his financial condition. Buck was in the Navy with Chris and, in fact, saved Chris's life while in the service. Since leaving the Navy, Buck has become an undercover narcotics agent. He approaches Chris pretending to be a drug dealer seeking help on a delivery and insists that Chris should help him in return for his saving Chris's life while in the service. Chris refuses, saying that he will do anything for Buck except commit a crime. Buck insists, "Mylife is at stake now. If you don't make this delivery my connection will kill me. Are you saying you won't save my life?" Chris relents and agrees to make the delivery. Buck makes arrangements for Chris to deliver eight ounces of cocaine for him the following day. While making the delivery, Chris is stopped for a motor vehicle violation by Buck and other narcotics officers. A subsequent lawful search of the car results in the discovery of the cocaine. The police arrest Chris and charge him with possession of cocaine with intent to distribute.

\section{Scenario 5: Prior Record-Agent}

(N) Chris, a Navy veteran, has a string of arrests and convictions for various drug offenses. The word on the street is that Chris is looking to get back into the drug business. Chris is pursuing several people whom he believes may need help in their own drug businesses. Buck was in the Navy with Chris and, in fact, saved Chris's life while in the service. Since leaving the Navy, Buck has become an undercover narcotics agent. When he learns about Chris he is saddened, but when he is assigned to target Chris he decides he must do his job. He approaches Chris pretending to be a drug dealer seeking help on a delivery and insists that Chris should help him in return for his saving Chris's life while in the service. Chris readily agrees. Buck makes arrangements for Chris to deliver eight ounces of cocaine the following day. While making the delivery, Chris is stopped for a motor vehicle violation by Buck and other narcotics officers. A subsequent lawful search of the car results in the discovery of the cocaine. The police arrest Chris and charge him with possession of cocaine, with intent to distribute.

\section{Scenario 6: No Prior Record-Buddy}

(R) Chris is a Navy veteran with no prior criminal record. He is unemployed and depressed about his financial condition. Jake was in the Navy with Chris and, in fact, saved Chris's life while in the service. Since leaving the Navy, Jake has turned 
to dealing drugs to make a living. When he hears that Chris is in town he approaches him seeking help on a drug delivery, insisting that Chris owes it to him in return for his saving Chris's life while in the service. Chris refuses, saying that he will do anything for Jake except commit a crime. Jake insists, " $M y$ life is at stake now. If you don't make this delivery my connection will kill me. Are you saying you won't save my life?" Chris relents and agrees to make the delivery. Jake makes arrangements for Chris to deliver eight ounces of cocaine for him the following day. While making the delivery, Chris is stopped for a motor vehicle violation. A subsequent lawful search of the car results in the discovery of the cocaine. The police arrest Chris and charge him with possession of cocaine with intent to distribute.

STUDY 15:

\section{THE SERIOUSNESS OF THE OFFENSE-SEXUAL OFFENSES}

\section{Scenario 1: Forcible Intercourse-Straight}

(C) Pam exercises three afternoons a week at the health club where she belongs. Alex is also a member of the health club. He is a 28 year old recently divorced general contractor. One evening Pam leaves the club and Alex follows her to the parking lot. It is late and there is no one anywhere near. Suddenly, Alex rushes up behind Pam and pushes her behind a dumpster. He tells her not to scream or resist or he will kill her. He forces her to have sexual intercourse.

\section{Scenario 2: Forcible Intercourse-Date}

(R) Pam exercises three days a week at the health club where she belongs. Alex is also a member of the health club. He is a 28 year old recently divorced general contractor. He had dated Pam for a few months when they were both in college. He remembers that they had slept together only for the last month they were dating. He has not seen or spoken to her in four years. He says hello to Pam one day and they speak for a few minutes. Alex asks if they could work out together the following day and she agrees to meet him and then go out for drinks. The next evening after going out for drinks, Pam invites Alex to her apartment for coffee. They sit on the sofa and talk about old times. Suddenly Alex reaches out and begins kissing her. He tells her that if she screams or resists he will kill her. He then forces her to have sex.

\section{Scenario 3: Forcible Intercourse-Live Together}

(L) Pam and Alex are lovers and have been living together for twoyears. They first met when Pam was a junior in college and Alex was a bartender at a local bar. Pam graduates from college and she is accepted into a law school which is two thousand miles away. She tells Alex that she is going to law school and does not want him to come with her. She tells him she is leaving for good and does not want to 
see him anymore. She asks him to sleep on the sofa or at his brother's place. He is extremely angry and hurt by her decision to leave. He comes into the bedroom and they start fighting. Alex pushes Pam onto the floor. He tells her that if she resists or screams he will kill her. He forces her to have sex with him.

\section{Scenario 4: Forcible Intercourse-Married}

(A) Pam and Alex have been married for two years. They first met when Pam was a junior in college and Alex was a bartender at a local bar. They married that same year. Pam graduates from college and she is accepted into a law school which is two thousand miles away. She tells Alex that she is going to law school and she does not want him to come with her. She tells him she is leaving for good and wants a divorce. Pam then asks Alex to sleep on the sofa or at his brother's place. He is extremely angry and hurt by her decision to leave. He comes into the bedroom and they start fighting. Alex pushes Pam onto the floor. He tells her that if she screams or resists, he will kill her. He forces her to have sex with him.

\section{Scenario 5: Forcible Intercourse-Homosexual}

(W) Alex and David are lovers and have been living together for two years. They met at a gay bar when David was a junior in college and Alex was a bartender. David graduates from college and is accepted into a law school which is two thousand miles away. He tells Alex that he is going to law school and he does not want Alex to come with him. He also tells Alex that he is leaving for good and does not want to see him anymore. David asks Alex to sleep on the sofa or at his brother's place. Alex is extremely angry and hurt by David's rejection. He comes into the bedroom and they start fighting. Alex pushes David onto the floor. He tells David if he screams or resists, he will kill him. Alex forces David to have sex with him.

\section{Scenario 6: Consensual Intercourse-Statutory}

(I) Pam exercises three days a week at a health club where she belongs. She is fourteen years old. Alex also works out at the health club. He is a nineteen year old sophomore in college but he remembers Pam from junior high school. She had been an eighth grader when he was a senior. He walks over to her and says hello. They speak for a few minutes and arrange to work out together the next day. The following evening, after working out, Pam invites Alex to her home and tells him her parents are away. When they get to her house, they sit on the sofa and begin kissing. Pam wants to have sex with Alex and sexual intercourse ensues.

\section{Scenario 7: Consensual Intercourse-Statutory-Prior Promiscuity}

(M) Pam exercises three days a week at a health club where she belongs. She is fourteen years old. Alex is also a member of the health club. He is a nineteen year old sophomore in college but he remembers Pam from junior high school. She had been an eighth grader when he was a senior. He remembers catching her in 
the boy's locker room with one of his football teammates. They were having sex behind the lockers. From what he heard she had slept with quite a few other guys on the team when he was in high school. However she had never gotten around to Alex. He thinks to himself that it is about time he gets some. He walks over to her and says hello. They speak for a few minutes and arrange to work out together the next day. The following evening, after working out, Pam invites Alex to her home and tells him her parents are away. When they get to her house, they sit on the sofa and begin kissing. Pam wants to have sex with him and sexual intercourse ensues.

\section{Scenario 8: Consensual Intercourse-Mentally Handicapped Female}

(S) Pam is a young woman with Down's Syndrome who participates in physical therapy three afternoons a week at a local health club. Down's Syndrome is a type of mental retardation which originates at birth. There are distinguishing physical features which many people affected by Down's Syndrome display: cleft palate, almond shaped eyes, and a childlike personality. Alex is a member of the health club. He is a 28 year old recently divorced general contractor. He notices that Pam is mentally handicapped. Alex is a good friend of the trainer who teaches the class. He asks the trainer if he can "help out" teaching the class. During the class, Alex and Pam become good friends. After exercising, Alex walks Pam back to the home where she lives with several other mentally handicapped people and a supervisor. They sit on the sofa and begin kissing. Pam wants to have sexual intercourse with Alex and sexual intercourse ensues.

\section{Scenario 9: Consensual Intercourse-Mentally Handicapped Male}

(E) Peter is a young man with Down's Syndrome who goes for physical therapy three afternoons a week at a local health club. Down's syndrome is a type of mental retardation which originates at birth. There are distinguishing physical features which many people affected by Down's Syndrome display: cleft palate, almond shaped eyes, and a childlike personality. Alexandra is a member of the health club. She is a 28 year old recently divorced secretary. She notices that Peter is mentally handicapped. Alexandra is a good friend of the trainer who teaches the class. She asks the trainer if she can " help out" teaching the class. During the class Alexandra and Peter become good friends. After exercising, Alexandra walks with Peter back to the home where he lives with several other mentally handicapped people and a supervisor. They sit on the sofa and begin kissing. Peter wants to have sexual intercourse with Alexandra. Sexual intercourse ensues.

\section{Scenario 10: Consensual Intercourse-Female in Jail}

(N) Pam is a woman who is confined in a women's medium security prison. She dutifully performs all required chores and is a model prisoner. Alex is the guard who supervises the cell block where Pam resides. They frequently converse and 
know each other by name. Alex comes into her cell one day when her cellmate is gone. He sits on her bed and strikes up a conversation. Alex leans over and kisses Pam and she wants to have sexual intercourse with him. Sexual intercourse ensues.

\section{STUDY 16: \\ THE CULPABILITY OF THE PERSON—FELONY MURDER}

\section{Scenario 1: Purposeful Killing}

(B) Mark is furious with his best friend Pete for making derogatory remarks. Mark tells his wife that he is going to kill Pete. He purchases a gun, and shoots Pete in the head while he is looking away, killing him instantly.

\section{Scenario 2: Reckless Killing}

(R) Mark is furious with his new neighbors; this is the fifth night in a row that they've had wild parties. The house is packed with drunken, loud and unruly guests. Mark decides to scare the inconsiderate neighbors and teach them a lesson; he loads his pistol and shoots two bullets from his bedroom window towards the neighbor's crowded entertainment room 50 feet away. One of the bullets strikes a guest killing him instantly.

\section{Scenario 3: Negligent Killing}

(U) Mark, assuming that his gun was unloaded, but without first double checking the chamber, shows his friend Pete how to clean a handgun. In fact the gun is loaded. While Mark demonstrates the "proper" procedures, he inadvertently pulls the trigger while the gun is pointed at Pete, killing him instantly.

\section{Scenario 4: Purposeful Shooter, Purposeful Co-Felon, Owner Victim}

(G) Mark and Pete plan to rob a liquor store. They agree to "waste" the cashier if he does not hand over the money immediately without a hassle. Mark and Pete enter the liquor store with loaded guns and demand the cash. The owner is reluctant to hand over the day's earnings and tries to talk them out of the robbery. Mark and Pete get impatient and decide to shoot the cashier. Mark aims the gun at the owner's head and pulls the trigger, killing him instantly. Pete comments, "good job man, he had it coming!"

\section{Scenario 5: Negligent Shooter, Negligent Co-Felon, Owner Victim}

(E) Mark and Pete plan to rob a liquor store. They agree that no one should get hurt but that they should carry unloaded guns, nonetheless, to make the cashier 
think that they "mean business." Mark and Pete enter the liquor store without first checking their weapons to ensure that they were unloaded; in fact, the guns happened to be loaded at the time. They demand the cash but the owner is reluctant. Mark is so nervous about the whole endeavor that his hands begin to shake uncontrollably, and when he motions at the cashier with his pistol to place the money in the sack, he accidentally discharges the gun, killing the cashier instantly. Pete is shocked and yells out "you idiot, look what you've done!" Mark shakes his head in disbelief and cries, "Oh no, oh no!"

\section{Scenario 6: Purposeful Shooter, Negligent Co-Felon, Owner Victim}

(H) Mark and Pete plan to rob a liquor store. They agree that no one should get hurt but that they should carry unloaded guns nonetheless to let the cashier know that they "mean business." Mark tells his girlfriend that even though they agreed not to hurt anyone, he would carry a loaded gun anyway and "waste" the cashier if he did not comply immediately. Mark and Pete enter the liquor store (Mark with a loaded gun, Pete with an unloaded gun) and demand the cash. The cashier is hesitant to hand over the money. Mark gets impatient and shoots the cashier, killing him instantly. Although Pete is aware of Mark's violent tendencies, he is nonetheless surprised at Mark's actions and yells "you idiot, look what you've done!" Mark simply responds, "hey man, he had it coming."

\section{Scenario 7: Negligent Shooter, Purposeful Co-Felon, Owner Victim}

(O) Mark and Pete plan to rob a liquor store. They agree not to hurt anyone but that they should carry unloaded guns to make the cashier think they "mean business." Pete loads his gun anyway and decides to "waste" the cashier if he does not comply immediately. Prior to the robbery, Mark inadvertently picks up Pete's loaded gun leaving Pete the unloaded gun. They enter the store and demand the money; the cashier is reluctant. Resolving to shoot the cashier, Pete raises his gun. Before he has a chance to fire, Mark's gun goes off. Mark was so nervous that when he motioned to the cashier to put the money in the bag, he inadvertently pulled the trigger, killing the cashier instantly. Mark shakes his head in confusion, and yells "oh no, what did I do?" But Pete is unflustered and says "good job man, he had it coming!" Mark suddenly realizes that he had Pete's gun. Recalling Pete's violent tendencies, the infamous phrase begins to echo in Mark's mind: "I should have known."

\section{Scenario 8: Purposeful but Innocent Shooter, Purposeful Co-Felon, Felon Victim}

(L) Mark and Pete plan to rob a liquor store. They agree to "waste" the cashier if he does not hand over the cash immediately. They enter the store with loaded guns and demand the cash. The owner is reluctant and seems to be stalling. Both 
Mark and Pete get impatient and decide to shoot the owner. As they raise their guns, a shot goes off and Mark falls to the floor. Apparently, the owner's wife was hiding in the back room with a rifle. Hoping to kill the gunmen and save her husband, she aimed the rifle and shot Mark, killing him instantly. She yells to Pete "drop it or you're next!" Fearing the same fate as his partner, Pete surrenders.

\section{Scenario 9: Purposeful but Innocent Shooter, Negligent Co-Felon, Felon Victim}

(A) Mark and Pete plan to rob a liquor store. They agree that no one should get hurt but that they should carry unloaded guns to make the cashier think they "mean business." Mark and Pete enter the liquor store with unloaded guns and demand the cash. The owner is reluctant and seems to be stalling. To everyone's surprise, a shot goes off and Mark falls to the ground. Apparently, the owner's wife was hiding in the back room with a rifle. Hoping to kill the gunmen and save her husband, she aimed the rifle and shot Mark, killing him instantly. She yells to Pete "drop it or you're next!" Fearing the same fate as his partner, Pete surrenders.

\section{Scenario 10: Negligent but Innocent Shooter; Purposeful Co-Felon, Felon Victim}

(N) Mark and Pete plan to rob a liquor store. They agree to "waste" the cashier if he does not hand over the money immediately. They enter the store with loaded guns and demand the cash. The owner is reluctant and seems to be stalling. Both Mark and Pete get impatient and decide to shoot the owner. As they raise their guns, a shot goes off and Mark falls to the floor. Apparently, in an effort to scare away the gunmen, the owner's wife stepped out of the back room with a rifle aiming at the gunmen. However, she was so nervous and inexperienced with the rifle that while she pointed it at the gunmen, she inadvertently pulled the trigger killing Mark instantly. When Mark falls to the floor, she cries, "oh no, what have I done?" Pete flees but is subsequently apprehended by police.

\section{Scenario 11: Negligent but Innocent Shooter, Purposeful Co-Felon, Owner Victim}

(D) Mark and Pete plan to rob a liquor store. They agree to "waste" the cashier if he does not hand over the cash immediately. They enter the store with loaded guns and demand the money. The owner seems to be stalling. Mark and Pete get impatient and decide to shoot the owner. As they start to raise their guns, the owner suddenly falls to the floor. Apparently, the owner's wife stepped out of the back room with a rifle. Although she knew she was unskilled, she aimed the rifle at the gunmen in an attempt to scare them away and save her husband. However, she was so nervous that her hands began to shake uncontrollably and she inadvertently pulled the trigger while the gun was actually pointed at her husband, killing him instantly. She screams, "oh no what have I done!" Mark and Pete flee but are subsequently apprehended. 


\section{STUDY 17: THE STRENGTH OF THE PERSON'S CONNECTION WITH THE PROHIBITED RESULT—CAUSATION REQUIREMENTS}

\section{Scenario 1: Murder-Control}

(B) Because Smith made disparaging remarks about them, Luman and Alma decide to kill Smith. They go to Smith's house and while Alma serves as a watchman at the front door, Luman enters the house and stabs Smith in the chest, killing him instantly. Luman and Alma flee, but both are subsequently apprehended.

\section{Scenario 2: Attempt-Control}

(X) Because Smith made disparaging remarks about them, Luman and Alma both decide to kill Smith. They go to Smith's house and while Alma serves as a watchman, Luman shoots at Smith through a window but misses him. Luman and Alma flee but are subsequently apprehended.

\section{Scenario 3: Subsequent Killer}

(I) Fred and Hunter, who do not know each other, are each angry with Eric, each for a different reason. Fred goes to Eric's house and stabs Eric in the chest. The wound is such that Eric cannot be saved and will die in four hours. Immediately after Fred leaves, Hunter arrives at Eric's house and, unaware of what Fred has done, he shoots Eric in the head, killing him instantly. Fred and Hunter are subsequently apprehended.

\section{Scenario 4: Allergy}

(N) Because Smith made disparaging remarks about them, Luman and Alma decide to kill Smith. They go to Smith's house and while Alma serves as a watchman at the front door, Luman enters the house and stabs Smith in the side. Luman and Alma leave thinking that Smith is dead but in fact the wound is not itself sufficient to cause Smith's death. A neighbor calls the police and an ambulance. Smith is taken to the hospital and is treated. Because he has a rare allergy, Smith dies during treatment from an allergic reaction to a commonly used drug. Luman and Alma are subsequently apprehended.

\section{Scenario 5: Careless Nurse}

(S) Because Smith made disparaging remarks about them, Luman and Alma decide to kill Smith. They go to Smith's house and while Alma serves as a watchman at the front door, Luman enters the house and stabs Smith in the side. Luman and Alma leave thinking that Smith is dead but in fact the wound is not itself sufficient to cause Smith's death. A neighbor calls the police and an ambulance. Smith is taken to the hospital and is treated. A nurse carelessly injects the wrong medication and Smith dies. Luman and Alma are subsequently apprehended. 


\section{Scenario 6: Accident on Way to Hospital}

(P) Because Smith made disparaging remarks about them, Luman and Alma decide to kill Smith. They go to Smith's house and while Alma serves as a watchman at the front door, Luman enters the house and stabs Smith in the chest. Luman and Alma leave thinking that Smith is dead. A neighbor calls the police and an ambulance. Smith is taken to the hospital, undergoes surgery, and recovers. Two months later, Smith is killed in a traffic accident on his way to the hospital for post-operative treatment for his injury.

\section{Scenario 7: Construction Accident}

(L) Because Smith made disparaging remarks about them, Luman and Alma decide to kill Smith. They go to Smith's house and while Alma serves as a watchman, Luman shoots at Smith through a window but misses him. To escape further attacks, Smith flees out the back door. Ten blocks later, Smith is killed instantly when a construction crane cable snaps and drops steel beams on the sidewalk below.

STUDY 18:

PUNISHMENT FOR MULTIPLE OFFENSES

\section{Scenario 1: One Victim}

(A) $\mathrm{Al}$ is angry with one of his colleagues at the office where he used to work. One afternoon he returns to the office with a baseball bat intending to hurt Paul. Al hits Paul with the bat, breaking several of his bones. Al is later arrested and subsequently convicted for assaulting a person with a weapon.

\section{Scenario 2: Two Victims, Immediate}

(D) Chris is angry with two of his colleagues at the of fice where he used to work. One afternoon he returns to the office with a baseball bat intending to hurt them. Chris hits Dave with the bat, breaking several of his bones. Then Chris hits Eric and breaks several of his bones too. Chris is later arrested and subsequently convicted for assaulting two people with a weapon.

\section{Scenario 3: Four Victims}

(U) Fred is angry with four of his colleagues at the office where he used to work. One afternoon he returns to the office with a baseball bat intending to hurt them. Fred hits John with the bat, breaking several of his bones. Then Fred hits Ray and breaks several of his bones too. Fred also hits Tom and Jay, breaking several bones of each one of them. Fred is later arrested and subsequently convicted for assaulting four people with a weapon. 


\section{Scenario 4: Seven Victims}

(I) Gary is angry with seven of his colleagues at the office where he used to work. One afternoon he returns to the office with a baseball bat intending to hurt them. Gary hits Stan with the bat, breaking several of his bones. Then Gary hits Ron and breaks several of his bones too. Gary hits Tim and Mike, breaking several bones of each one of them as well. Additionally, Gary breaks several of Paul's, Sam's and Walt's bones as a result of hitting each one of them with the bat. Gary is later arrested and subsequently convicted for assaulting seven people with a weapon.

\section{Scenario 5: One Item}

(N) Bob knows that construction companies will pay significant amounts of money for empty oil drums. He plans to steal a drum and selects a gas station where no one will come around during his theft. After the station is closed and everyone has gone home, Bob steals an oil drum without being noticed. Bob is later arrested and subsequently convicted for stealing the oil drum.

\section{Scenario 6: Two Items}

(J) Don knows that construction companies will pay significant amounts of money for empty oil drums. He plans to steal several drums and selects two gas stations where no one will come around during his theft. After the stations are closed and everyone has gone home, Don goes to one and steals an oil drum without being noticed. He then goes to the other gas station and again steals an oil drum without being noticed. Don is later arrested and subsequently convicted for stealing two oil drums.

\section{Scenario 7: Four Items}

(S) Frank knows that construction companies will pay significant amounts of money for empty oil drums. He plans to steal several drums and selects four gas stations where no one will come around during his theft. After the stations are closed and everyone has gone home, Frank goes to one and steals an oil drum without being noticed. He then goes to another and again steals an oil drum without being noticed. Later that same evening, Frank visits two more gas stations and, with no one around to see him, takes an oil drum from each one. Frank is later arrested and subsequently convicted for stealing four oil drums.

\section{Scenario 8: Four Items, One Victim (Gas Station)}

(T) Rich knows that construction companies will pay significant amounts of money for empty oil drums. He plans to steal several drums and selects a gas station where no one will come around during his theft. After the gas station is closed and everyone has gone home, Rich steals four oil drums. Rich is later arrested and subsequently convicted for stealing the four oil drums. 


\section{Scenario 9: Seven Items}

(C) Harry knows that construction companies pay large sums of money for empty oil drums. He plans to steal several drums and selects seven gas stations where no one will come around during his theft. After the stations are closed and everyone has gone home, Harry goes to one and steals an oil drum without being noticed. He then goes to another gas station and again steals an oil drum without being noticed. Later that same evening, Harry visits two more gas stations and, with no one around to see him, takes an oil drum from each one. Before the evening is over, Harry occasions three more gas stations and takes one oil drum from each without ever being noticed. Harry is later arrested and subsequently convicted for stealing seven oil drums.

\section{Scenario 10: Assault, Two Victims, Two Week Delay}

(E) Ian is angry with two of his colleagues at the office where he used to work. One afternoon he returns to his office with a baseball bat intending to hurt them. Rick, one of his intended victims, is there, and Ian hits him with the bat, breaking several of his bones. Jim, the other colleague, is not present. Two weeks later, Ian is thinking about his time at the office and becomes angry again. He returns to the office with the bat, and on this occasion Jim is present. Ian hits Jim with the bat, breaking several of his bones. Ian is later arrested and subsequently convicted for assaulting two people with a weapon.

\section{Scenario 11: Theft, Two Items, Two Week Delay}

(F) Jeff knows that construction companies will pay significant amounts of money for empty oil drums. He plans to steal a drum and selects a gas station where no one will come around during his theft. After the station is closed and everyone has gone home, Jeff steals an oil drum without being noticed. Two weeks later Jeff has the same idea and does the same thing again. He goes to another gas station and again steals an oil drum without being noticed. Jeff is later arrested and subsequently convicted for stealing two oil drums.

\section{Scenario 12: Assault, Two Victims, Two Year Delay}

(O) Steven is angry with two of his colleagues at the office where he used to work. One afternoon he returns to his office with a baseball bat intending to hurt them. Charlie, one of his intended victims, is there, and Steven hits him with the bat, breaking several of his bones. Kevin, the other colleague, is not present. Two years later, Steven is thinking about his time at the office and becomes angry again. He returns to his office with the bat, and on this occasion Kevin is present. Steven hits Kevin with the bat, breaking several of his bones. Steven is later arrested and subsequently convicted for assaulting two people with a weapon. 
Scenario 13: Theft, Two Items, Two Year Delay

(R) Mark knows that construction companies will pay significant amounts of money for empty oil drums. He plans to steal a drum and selects a gas station where no one will come around during his theft. After the station is closed and everyone has gone home, Mark steals an oil drum without being noticed. Two years later Mark has the same idea and does the same thing again. He goes to another gas station and again steals an oil drum without being noticed. Mark is later arrested and subsequently convicted for stealing two oil drums. 


\section{Appendix C: \\ Liability Score/Imprisonment Term Translation Table}

At various points in the text, we translate liability scores in terms of imprisonment. In this appendix, we show the table that we used to do so. The translation formulae we used also are given (following the table). Our thanks to Justin McIntyre for preparing these translations.

\begin{tabular}{llllll}
$y$ & $x$ & $y$ & $x$ & $y$ & $x$ \\
\hline 1.0 & 1.0 day & 3.7 & 4.8 months & 6.4 & 4.6 years \\
1.1 & 2.3 days & 3.8 & 5.2 months & 6.5 & 5.0 years \\
1.2 & 3.6 days & 3.9 & 5.6 months & 6.6 & 5.4 years \\
1.3 & 4.9 days & 4.0 & 6.0 months & 6.7 & 5.8 years \\
1.4 & 6.2 days & 4.1 & 6.6 months & 6.8 & 6.2 years \\
1.5 & 7.5 days & 4.2 & 7.2 months & 6.9 & 6.6 years \\
1.6 & 8.8 days & 4.3 & 7.8 months & 7.0 & 7.0 years \\
1.7 & 10.1 days & 4.4 & 8.4 months & 7.1 & 7.8 years \\
1.8 & 11.4 days & 4.5 & 9.0 months & 7.2 & 8.6 years \\
1.9 & 12.7 days & 4.6 & 9.6 months & 7.3 & 9.4 years \\
2.0 & 14.0 days & 4.7 & 10.2 months & 7.4 & 10.2 years \\
2.1 & 2.6 weeks & 4.8 & 10.8 months & 7.5 & 11.0 years \\
2.2 & 3.2 weeks & 4.9 & 11.4 months & 7.6 & 11.8 years \\
2.3 & 3.8 weeks & 5.0 & 12.0 months & 7.7 & 12.6 years \\
2.4 & 4.4 weeks & 5.1 & 1.2 years & 7.8 & 13.4 years \\
2.5 & 5.0 weeks & 5.2 & 1.4 years & 7.9 & 14.2 years \\
2.6 & 5.6 weeks & 5.3 & 1.6 years & 8.0 & 15.0 years \\
2.7 & 6.2 weeks & 5.4 & 1.8 years & 8.1 & 16.5 years \\
2.8 & 6.8 weeks & 5.5 & 2.0 years & 8.2 & 18.4 years \\
2.9 & 7.4 weeks & 5.6 & 2.2 years & 8.3 & 19.5 years \\
3.0 & 8.0 weeks & 5.7 & 2.4 years & 8.4 & 21.0 years \\
3.1 & 2.4 months & 5.8 & 2.6 years & 8.5 & 22.5 years \\
3.2 & 2.8 months & 5.9 & 2.8 years & 8.6 & 24.0 years \\
3.3 & 3.2 months & 6.0 & 3.0 years & 8.7 & 25.5 years \\
3.4 & 3.6 months & 6.1 & 3.4 years & 8.8 & 27.0 years \\
3.5 & 4.0 months & 6.2 & 3.8 years & 8.9 & 28.5 years \\
3.6 & 4.4 months & 6.3 & 4.2 years & 9.0 & 30.0 years \\
\hline
\end{tabular}

$y=$ Liability score; $x=$ Term of imprisonment 


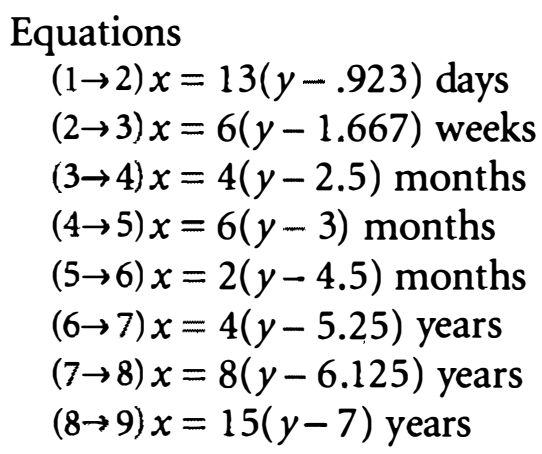




\section{Notes}

\section{CHAPTER 1}

1. Where work on popular assessment of blame has been done, as in studies in "attribution of blame" (see, e.g., Shaver, 1985), the work understandably is designed for psychologists, not lawyers or legal reformers. The issues generally are formulated in ways different from current law, and the distinctions tested are distinctions other than those that current law relies upon.

2. Though a large portion of criminal cases are disposed of by guilty plea, the terms of plea agreements are typically set with each side projecting the likely outcome at a jury trial.

3. A number of studies have confirmed this relationship. As Tyler (1990) has shown, citizens of our society are motivated to obey various laws not simply to avoid "being caught" but because they believe in the moral weight of those laws. A society that systematically applies the criminal justice system to events and actions that the community regards as not blameworthy risks destroying this motive to adhere to the laws. It risks becoming a society in which the only motive not to commit "criminal" actions is to avoid being caught and punished. It risks creating a society in which deterrence is the primary consideration that sentencing can address. As various writers (cited later in the text) have argued, a society in which adherence to laws depends primarily on considerations of deterrence is a society that will have real difficulties in obtaining compliance to its laws.

4. Thus the discovery of conduct that the community judges wrong but the legal code does not criminalize at least raises a question that deserves investigation. As the reader will be aware, there are dangers involved in the "criminalization" of certain actions, such as acts of omission. Nonetheless, it would at least be useful to know what the criminal justice system is risking when it chooses not to criminalize a particular action.

5. As the reader will be aware, the legal system has available to it punishment options that do not involve prison, such as community service or house arrest. In a separate study, we attempt to work out the correspondences that people see between these different sentencing alternatives so that, for instance, we might be able to say that the set of subjects saw a month of weekend confinements as about equal to a week in jail (see Harlow, Darley, and Robinson, 1994). In the studies reported here, we instructed subjects that if one of these other punishments seemed to them the one to assign, they were to work out an equivalent prison sentence for it and assign that. Particularly for the cases in which our subjects gave higher sentences, prison terms were their preferred option.

6. For these reasons, it would have been foolish for us, in the sense of being wasteful of money and effort, to begin this investigation of the field by going immediately to the costly and ponderous task of polling stratified national samples of subjects. One would do that next for the subsample of our studies that seemed to have been technically successful and generated interesting results.

\section{CHAPTER 2}

1. There are exceptions, of course. Some avid Communists, for example, might argue against the desirability of a competitive market economy. 
2. For a general discussion and defense of this minority position, see Model Penal Code $\$$ 5.05(1), p. 2 (1985).

3. An example of a case in which the dangerous proximity test is not satisfied is found in Commonwealth v. Peaslee, 59 N.E. 55 (Mass. 1901) (the act of solicitation-asking an employee to ignite prepared combustibles - could not be used to satisfy the objective element of attempt). For a discussion of the dangerous proximity test, see Model Penal Code $\$ 5.0$ l, p. 40 (Tent. Draft No. 10, 1960). For a discussion of the difficulties in stating a persuasive rationale for this test, see Williams (1961), \$201.

4. See, generally, Model Penal Code $\$ 5.01$, comment pp. 38-48 (Tent. Draft No. 10, 1960); and Fletcher (1978), pp. 135-144.

5. By interpolation within our liability scale, we are able to figure out the length of the sentence, in days, months, and years, that the respondents are assigning to the individuals. When it is illuminating to do so, we will report the results of those interpolations to you. The liabililty score translation table that we used is reproduced in Appendix $C$.

6. See Model Penal Code $\$ 5.01$ (4) (except for an attempt to commit a first degree felony, i.e., murder, which is graded as a second degree felony).

7. In this study, we asked subjects whether they thought the different scenarios matched the different criteria set up by the code. For instance, we asked subjects to indicate the extent of their agreement that "the actor had taken a substantial step toward completion of the crime," or the extent of their agreement that "the actor had gone beyond the point of probable desistance." The questions used legal language to define the various attempt tests. Our respondents had trouble with this task, tending to see all scenarios as fitting many of the legal definitions (an inaccurate perception). We suspect that this occurred because the task somewhat overloaded the subjects. The results cited in the text make clear that the subjects do see important differences between the scenarios. In future research, it will be useful to return to the question of the subjects' understandings of the legal definitions of various crime elements as well as mental states of the perpetrators.

8. It would be useful for a future study to examine more closely what people see as the point of "dangerous proximity." The common-law concept may have embodied an intuitive notion shared by the community, but the common law is sufficiently vague in its statement that predictability in application is difficult.

9. The risk issue is an exception to our previous comment that there is a rather sparse social science literature on punishment issues, but the relevant literature in social psychology deals with the issue of risk only tangentially. The relevant literature is known as "defensive attribution" literature and is reviewed in Shaver (1985). For an argument that attempts to bring the concepts of seriousness and probability of harm risked into the psychological literature and that provides some evidence that people do work out a calculus of risk considerations, see Karlovac and Darley (1988).

10. That the state of mind as to risk was seen as constant across all conditions is no doubt partially due to the fact that each subject saw every case and would realize that they were given identical information about state of mind. Here one of the advantages of a within-subjects design comes into focus.

11. As concerns the degree of contribution, the United States Sentencing Commission Guidelines Manual (1994) sets forth the following framework:

\section{\$3B1.1. Aggravating Role}

Based on the defendant's role in the offense, increase the offense level as follows:

(a) If the defendant was an organizer or leader of a criminal activity that involved five or more participants or was otherwise extensive, increase by 4 levels. 
(b) If the defendant was a manager or supervisor (but not an organizer or leader) and the criminal activity involved five or more participants or was otherwise extensive, increase by 3 levels.

(c) If the defendant was an organizer, leader, manager, or supervisor in any criminal activity other than described in (a) or (b), increase by 2 levels.

\section{\$3B1.2. Mitigating Role}

Based on the defendant's role in the offense, decrease the of fense level as follows:

(a) If the def endant was a minimal participant in any criminal activity, decrease by 4 levels.

(b) If the defendant was a minor participant in any criminal activity, decrease by 2 levels.

In cases falling between (a) and (b), decrease by 3 levels.

12. This recognition-that encouraging another to commit a crime may be critical in bringing about the actual occurrence of that crime-is made in several areas of the law and seems psychologically sensible. A person may waver in his or her resolve to commit a crime, and the encouragement of others may be a critical factor in causing him or her to actually go ahead with the act.

13. On the one hand, we may have a ceiling effect here, in which substantial involvement in murder is sufficient to trigger a sentence near the maximum allowed. In further research, one might examine this possibility by creating various degrees of complicity with more minor crimes. On the other hand, it is also possible that the ceiling is set not by the maximum penalty that the legal system imposes-life imprisonment or the death penalty-but by the maximum sentence that is actually given to the individual who is the main perpetrator of the crime. In this instance, then, the maximum sentence would be the life sentence that is assigned to the wife. If, in the minds of our respondents, the highly complicit individual deserves a sentence of about one grade down from that of the perpetrator, such a reduction may be the maximum warranted in the community's view, though the accomplice's involvement is "substantial" or greater. As we say, this needs to be examined in further research.

14. In each of these instances of a duty to rescue, the person is legally obliged to do only what he or she is physically capable of doing and need not expose themselves to danger (e.g., a parent need not jump in front of a train to save a child)—Model Penal Code $\$ 2.01(1)$. See Robinson (1984), \$87(b)(3) and (4).

15. The liability means for the three duty scenarios are all statistically significantly higher than that for the control (stranger) scenario ( $p=.000$ to .002$)$ but are not statistically significantly different from each other $(p=n s)$.

16. Notice an incongruity in one comparison. Why do subjects impose less liability in the control, no-inconvenience scenario than in the low- and high-inconvenience scenarios? One would expect more liability as the inconvenience is less. First, it may be because the no-inconvenience scenario, as a control case, was not included in the randomization and, thus, always given first and judged more leniently. Second, once the subjects begin focusing on inconvenience as a person's excuse for not saving the victim, they may impose higher liability because they are offended by the triviality of the excuse. In the control scenario, the issue of excuse is never raised.

17. This generally corresponds to the penalty range provided in the Rhode Island and Wisconsin duty rescue statutes cited earlier in this study, which make the failure to act a "petty misdemeanor" (six months maximum) and a "Class C misdemeanor" (fine not to exceed $\$ 500$, or imprisonment not to exceed 30 days, or both), respectively. 
18. One might speculate that the degree of danger or inconvenience also would alter the liability of a person who has a legal duty to act, but this was not tested in our omission study.

\section{CHAPTER 3}

1. Liability means for purposeful or knowing killings in other studies range from 9.46 to 10.42 (see Studies 2, 3, 10,12,13,16, and 17).

2. For a discussion of these general principles and how they are manifested in the Code's detailed rules, see Robinson (1984), \$131(c) and (d).

3. While the person who mistakenly believes he is authorized to use deadly force in protection of property is given slightly higher liability than the person who is aware that such force probably is not permitted - which is an odd result - the liability means for the two cases are not statistically different.

4. This percentage was calculated from data not presented in Table 3.5.

5 . We do not know what the subjects' reactions would be if the thief were killed. One might speculate that the liability would be significantly higher. This would be a useful point for a future study to investigate.

6. For example, liability for assault, which requires negligently causing bodily injury, would be imposed if the person recklessly or negligently caused such injury [MPC $\$ 211.1$ (1)(b)]. Liability for reckless endangerment, which requires recklessly creating a risk of serious bodily injury, would be imposed if the person recklessly created such a risk [MPC $\$ 211.2$ ].

7. This assumes that the person is also judged nonreckless as to injuring the innocent person [MPC $\$ \$ 3.09(3)$ and 211.1(1)]. The subjects perceive the victimized person as being unaware of a risk of injuring an innocent person (Table 3.10, column $d$ ). Future research in such cases ought to test more carefully the effect of culpability level on liability.

8. However, the distribution of their responses among the two categories that impose no punishment is worthy of remark. A majority of the subjects would impose formal criminal liability in these cases ( 70 percent in the rape arrest; 77 percent in the property destruction arrest). As we have noted in previous studies, "liability but no punishment" is a common response of our subjects in those cases in which the person's actual conduct is disapproved of but the person is not seen as meriting the punishment of a prison term.

9. Under the Code, citizens are rarely authorized to use deadly force for law enforcement purposes [MPC $\$ 3.07(2)(b)]$.

10. The Code determines the amount of force permitted according to the seriousness of the underlying offense in only one respect: Deadly force is authorized for arrest when used by a law enforcement officer, or at his or her direction, for a felony involving the use of deadly force but not for other offenses [MPC $\$ 3.07(2)(b)$ ].

11. While most subjects would not impose punishment in three of the four scenarios where an innocent person is injured or killed, a majority would impose liability. The common use of this "liability but no punishment" option suggests other reforms, which are discussed in Chapter 7.

\section{CHAPTER 4}

1. The six base scenarios were given to the respondents in random order. The four variations of each scenario were given together, in reverse order of culpability level (faultlessness, negligence, recklessness, and then knowledge). Methodologically, it would have been better, though logistically more difficult, to randomize the order of the variations as well.

2. See the general discussion of the development of the grading scale in Chapter 1 . The Model Penal Code has fewer grades than most codes. 
3. There remains a statistically significant difference, however, among each value within the group.

4. One such offense is found in Model Penal Code $\$ 220.2(1)$. Causing a catastrophe purposely or knowingly is graded higher than causing it recklessly.

5. Before this can effectively be done, however, the problem of conflicting functions-announcing ex-ante rules of conduct and adjudicating ex post individual violations of the rulesmust be resolved. If it is not resolved, the subjects' desire to impose liability to reaffirm the rules of conduct can contaminate the definition of minimum culpability elements. We will return to this topic in our final discussion in Chapter 7.

6. 125 N.H. 57, 480 A. 2d 870 (1984).

7. Recall the core story, which involves an individual giving the other a set of car keys. We attempt to make that act seem either purposeful or knowing. Intuitively, it is difficult to cause people to see a person giving another car keys as purposefully causing the other to take them and drive. A better case of purposefulness might involve him giving the keys deliberately to the other and urging him to use them-but that would have "unstandardized" our core scenario. Occasionally we pay the price, in terms of the subjects' perceptions of the cases, for standardization.

8. See the previous footnote. The consequence of death seems causally distant and problematic enough from the accomplice's act so that it was difficult for our subjects to perceive that act as completely knowing.

9. However-and interestingly-notice in column $d$ of Table 4.6, that, on average, around 50 percent of our respondents would assign the now familiar "liability but no punishment" verdict in these four cases. Again, they use this particular verdict, which condemns conduct but does not incarcerate individuals, for the person who recklessly leaves car keys around for a drunken friend to take (case 6).

10. One of us has suggested in another work that a prosecutor might argue that the "conduct constituting the offense" is the conduct of becoming intoxicated, rather than the conduct more immediately causing the death. This would allow the law to take into account a person's culpability as to the offense at this earlier time, but this approach has some limitations. Most notably, it gives the prosecutor a greater burden than he or she otherwise would have in establishing an adequate causal connection between the conduct constituting the offense (getting intoxicated) and the resulting death. See, generally, Robinson (1985).

11. More generally, in future research it would be beneficial to investigate the differential effects of degree of risk on assigned liability.

12. It would have been useful to include scenarios of faultlessness as to becoming intoxicated to confirm that liability would not have been imposed by our respondents in such a case. It may be difficult, however, to construct believable scenarios of a person who is purposeful or reckless as to killing but faultless as to becoming intoxicated. In further research it also would be useful to develop other scenarios of negligence with respect to becoming intoxicated in which the individual was not in an angry and hostile emotional state-to see to what degree the conjunction of those two factors led to the judgments we see here.

13. The practical difficulty with this approach may be in the increased burden in establishing the causal connection between this conduct in becoming intoxicated and the subsequent death. This could be solved with a rebuttable evidentiary presumption but such a presumption might constitute a constitutionally impermissible shift of the burden of persuasion under Wilbur $\mathrm{v}$. Mullaney, 421 U.S. 684 (1975).

14. Our study asked subjects whether a particular characteristic would increase or decrease the extent of liability that they would impose on the person. In reality, the individualizing of the reasonable-person standard would simply make it more or less likely that the person would be held negligent; it would not, under current doctrine, serve to raise or lower liability. It seems reasonable to assume, however, that the subjects' liability responses would take account of the same factors that informed their negligence judgments. 
15. Recall that the stories that were used across the three scenarios of negligence differed. So, for instance, coming from a cultural background that was likely to create lack of knowledge about the risk (characteristic 9) might not make a difference to subjects in the case of commission, or we might not have created a set of specific circumstances that seemed to our subjects to be a valid case of lack of knowledge.

\section{CHAPTER 5}

1. The general mistake excuses also are of this category but their excusing conditions operate in a different way. See, generally, Robinson (1982).

2. The first two are commonly recognized [e.g., Model Penal Code $\$ 2.04(3)$ ]. The third rarely is recognized as a defense-we know only of N.J. Stat. Ann. $\$ 2 \mathrm{C}: 2-4(\mathrm{c})(3)-$ but has much support in the legal literature.

3. That the respondents were not able to accurately reproduce the legal language of the defense is not surprising. However, the study authors claimed more-that the respondents were not able to identify the elements of insanity that the legal system deems relevant.

4. This does not mean, however, that the two kinds of defenses for mental illness-mental illness negating a culpability element and general insanity-are mutually exclusive. Some forms of mental illness, especially severe cognitive dysfunctions, may provide either kind of defense. See, generally, Robinson (1984).

5. McNaughten's Case, 8 Eng. Rep. 718, 722 (1843).

6. See, e.g., Parsons v. State, 81 Ala. 577, 2 So. 854 (1887).

7. 18 U.S. Code $\$ 17$. For a description of which states have adopted which formulation, see Robinson (1984), $\$ 173(a)$ nn. 1-5.

8. See Robinson (1984) at n. 5. (Idaho, Montana, and Utah have abolished their insanity defense; Connecticut has reached essentially the same result through other means.)

9. For the record, here is what we attempted. We focused the details of the case description on either the cognitive or the control dysfunction, describing in the first case what we thought would be a high degree of dysfunction and in the second case, a low degree of dysfunction. Since, for instance, the cognitive-dysfunction case description left the control dysfunction unspecified (and vice versa), we thought that would cause the omitted dysfunction to be perceived as low. That would have created cases of high and low cognitive dysfunction, with the control dysfunction low, and cases of high and low control dysfunction, with the cognitive dysfunction low.

10. Strictly speaking, this is not completely matched to the ways in which the civil system deals with mental illness, since it is not likely to specify a term of commitment, but rather a commitment until either something like a cure has been achieved or the individual is no longer dangerous to others. To choose between a civil term of commitment of indeterminant length (until some particular end state has been achieved) versus a criminal term of fixed duration is a diffcult task. Those making the choice, among other things, need to have a position on the success of the psychiatric system in producing the cure and knowing when it is likely to be produced. These issues will need to be dealt with in future research; our concern in this set of studies is largely with the criminal justice system and the liabilities that it assigns.

11. Recall that the respondents did not have the option of "incapacitation until cured or nondangerous."

12. An example may clarify why this is important. It might well be that the respondents' answer patterns showed a perfect correlation between a legal and common language version of a statement. Still, one would not want to treat them as equivalent if, on the average, the respondents disagreed that the test specified in the legal version of the statement was met and the test specified in the common language version was not met, and this possibility is not ruled out by the perfect correlation. 
13. Much of the current debate about the appropriate age of transition from the juvenile to the adult criminal justice system centers around these ages.

14. They were also told that the person with the criminal record was looking to get back into the drug business. This certainly strengthened the respondents' perception that the person was predisposed to the criminal act, but in retrospect it would have been better to let those perceptions be affected by prior convictions alone in order to achieve a clearer determination of the extent to which prior convictions, without additional information, signify predisposition to respondents.

15. In order to maintain the inducements as constant, in the agent condition, the agent is actually a prior acquaintance of the entrapped person, who saved the person's life when they were in the Navy together. In the buddy condition, the inducer is the same acquaintance-but is not an agent of the police.

\section{CHAPTER 6}

1. This does not extend after a time when the couple are no longer living together as husband and wife [MPC $\$ 213.6(2)]$.

2. Rape and gross sexual imposition are offenses only where the victim is a female [MPC $\$$ 213.1(1) and (2)]. This is also true of statutory rape [MPC $\$ 213.3(1)]$.

3. However, from another perspective, it is worth noting that the act of inviting another person into one's home is perceived by some as moving toward consenting to sexual intercourse. Here, one hears an echo of the familiar refrain, "she should have known better than to...."

4. Despite the fact that the Code uses "deviate" intercourse as an aggravation for forcible rape, it does decriminalize "deviate" intercourse between consenting adults [MPC $\$ 213.2$, p. 2 (1980)].

5. Unlike most of the studies, the sexual offenses study was not given through the subject pool, which assured relatively diverse subjects. Instead, most of the subjects were of two professional groups, psychologists/social workers and librarians. Minor differences were found between the responses of social worker/psychologists and non-social-worker subjects (16 social workers, 23 non-social-workers). Social workers gave statistically significantly lower liability than non-social-workers for the two forcible intercourse scenarios in which the heterosexual aggressor and victim were married or living together.

6. Because the subject matter suggested that males and females might give different responses, the data also was analyzed for such differences. No statistically significant difference was detected between the responses of male and female subjects ( 12 men, 27 women). See also footnote 5 .

7. See, e.g., MPC $\$ 210.2(1)(a), 210.3(1)(a)$, and 210.4(1).

8. See, e.g., MPC $\$ 2.06(3)(a)(i i)$ and (4).

9. Most jurisdictions also have a corresponding misdemeanor-manslaughter rule, which treats all killings during a misdemeanor as manslaughter, without regard for the person's culpability as to causing the death.

10. See, e.g., Calif. Penal Code $\$ 189$ (West 1994); 18 Pa. Stat. Ann. $\$ 2502$ (b) (Purdon 1994); N.Y. Penal Law $\$ 125.25(3)$ (McKinney 1994).

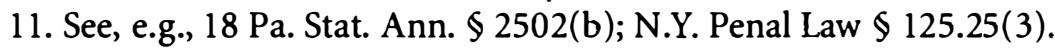

12. See, e.g., Jackson v. State, 286 Md. 430, 408 A. 2d 711 (1979).

13. See, e.g., Commonwealth v. Thomas, 382 Pa.639, 117 A. 2d 204 (1955).

14. See, e.g., Fletcher (1980) and Pirsig (1963).

15. Or is it? In retrospect, it strikes us that the control scenarios in this study are somewhat more distant from the experimental scenarios than they were in other studies. Specifically, it strikes us that the manslaughter liability score is somewhat higher than we would expect and that this may be because it involved a person deliberately shooting into a house in which he 
knew other people were partying, a case in which the person's action seems likely to cause a death. The reader should keep in mind that this may create an artificially high reference point for manslaughter.

16. Indeed, a jury might conclude that, given the obvious potential for starting a gunfight, such an armed robber is reckless as to causing death (i.e., he must have been aware of a substantial risk that his conduct could cause a death). If that were the case, the felony-murder rule would be unnecessary here; normal homicide grading would be adequate to impose liability equal to or in excess of that imposed by the subjects. However, the fact that most subjects perceive the armed robber as being only negligent, not reckless, as to causing death in the negligence scenarios (all of which involve armed robbery) suggests that juries would not routinely find felons reckless as to causing death from the fact of the armed robbery alone.

17. This may reflect the subjects' tendency to vary liability according to the strength of the causal connection. See the causation study (Study 17) discussed later in this chapter.

18. This occurs where the person does not have the relatively high culpable state of mind required for attempt liability.

19. See American Law Institute Floor Debate on MPC $\$ 2.03(1)(a), 1962$ ALI Proceedings, pp. 77-79 and 135-139.

20. Requiring that a cause be "a substantial factor in causing a result" suggests that other factors may contribute to and be necessary for the result. Thus, the "substantial factor" need not be sufficient by itself to cause the result.

21. See MPC $\$ 2.03(1)(a)$.

22. See discussion of the United States Sentencing Commission Guidelines in Chapter 2, note 11 (Study 3, "Objective Requirements of Complicity").

23. The lower liability assigned by the respondents in the traffic accident scenario (8.03, or 15 years) suggests this interpretation, but a better design would have been to include for comparison a scenario with a traffic accident involving the ambulance on the way to the hospital for the victim's original treatment. In the four cases of complex causation, although occasionally a statistically significant difference in liability assignment appears, the differences are not of great magnitude.

24. Varying the time interval also provides an interesting test of the theory that pure consecutive sentences for multiple offenses are inappropriate, because the first offense already punishes the offender's demonstrated willingness to break the law and therefore need not be taken into account in determining the punishment for the second offense. As the offenses become further separated by time, it becomes more clear that they are not part of a single episode during which the person never stopped to fully contemplate his past lawbreaking, increasing the likelihood that the individual is seen as having a criminal character, thereby in turn strengthening the argument for consecutive sentences.

25. In passing, we note an interesting apparent contradiction. This "multiple-offense discount" tends to be applied only when a person is sentenced for all offenses at the same time; an offense for which the person has been previously sentenced does not act to reduce a sentence on a subsequent conviction-it increases it. The latter pattern is instantiated in the practice of giving heavier sentences for "habitual of fenders." In most jurisdictions, it is appropriate to give a harsher sentence for an offense committed a second time; in some jurisdictions, a person who has committed three or more offenses is given a sentence of considerably greater length, as a habitual offender. The notion here is probably that the first, more lenient sentence did not fulfill its purpose of deterring the offender and thus a harsher sentence is appropriate and, relatedly, that a habitual offender has provided sufficient evidence that he or she needs to be locked away to protect others. Sentencing considerations also may rest upon a notion that to violate society's rules- - once specifically warned and previously punished-is to show a disregard for the authority of such rules so as to deserve a greater punishment. Elucidating these matters will require future research; we did not address them in this study. 
26. Notice that, in making the assault cases plausible, we made them connected by taking place in the same workplace, with the assaulter seeking out different co-workers and hitting them in turn. The thief moves from gas station to gas station, and so the respondents were likely to perceive that more time intervened between the incidents of theft than of assault. Future research will be needed to sort out the effects of this difference on liability ratings.

27. Obviously, a person who committed a theft or assault two weeks or two years ago has committed an offense "in the past." If our subjects responded to this reading of the question, they would certainly agree that this person had committed past offenses. We were instead interested in whether our respondents thought that the person had committed similar actions in the past that had not been discovered, and we worded the question to make this clear.

28. The United States Sentencing Commission guidelines recognize forty-three "offense levels" [USSC Guidelines Manual, Ch. 5, Pt. A (1994)].

29. The Model Penal Code recognizes three degrees of felonies and two other classificationsmisdemeanors and petty misdemeanors. A sixth classification, violations, are judged too trivial or too absent of culpability to be crimes (MPC $\$ \$ 1.04$ and 6.01 ).

\section{CHAPTER 7}

1. See Model Penal Code $\$ 5.05(1)$. The one exception is that an unsuccessful attempt to commit a first-degree felony, such as murder, is graded as a second-degree felony.

2. See the objective requirements for attempt case, Study 1 (6.12 for completed theft versus a maximum of 5.35 for an unsuccessful attempted theft); see also the causation case, Study 17 (9.89 for murder versus 7.25 for an unsuccessful attempted murder).

3. Compare Mansfield (1964) with Schulhof er (1974).

4. See, e.g., the case of a killing perpetrated during the course of a robbery $(10.11$ for the principal versus 9.56 for the accomplice, where both are purposeful or knowing as to the killing; 8.78 for the principal versus 7.31 for the accomplice, where both are negligent as to the killing); or the causality case ( 9.89 for the principal versus 8.89 for the accomplice, in a case of murder; 7.25 for the principal versus 6.67 for the accomplice, in a case of attempted murder).

5. See the omission liability case (Study 4), specifically the contrasts between the liabilities assigned the person who created the danger to the victim and the liabilities assigned the person who fails to rescue the victim.

6. However, this is possible in a sophisticated sentencing system. For examples of how a factor now treated as a minimum requirement might be drafted to alter liability and punishment by degrees, see Robinson (1987).

7. If this solution were introduced, would there be a continuing need for sentencing guidelines? Perhaps. Those who establish the guidelines could do so with the purpose of refining the liability judgment rather than with the purpose (now served) of essentially making the judgment. Under the current system, the elaborate adjudication process serves primarily to determine whether there will or will not be liability. Why would it not be preferable for the system to do more-to make a binding judgment setting the approximate degree of the person's punishment?

8. Subjects not only did this implicitly, where they selected a sentence of one day [or two weeks], but commonly did it explicitly by selecting the "liability but no punishment" (0) option.

9. It would be possible to attempt to salvage the rationality of this verdict within deterrence theory by suggesting that the individual found "guilty" but not given a jail term will be punished by informal societal mechanisms--such as loss of prestige or job. Since the application of these informal sanctions will vary wildly as a result of a good many forces having nothing to do with the severity of the crime, this rescue seems implausible to us.

10. See, generally, Robinson (1990).

11. Green's report of this phenomenon is contained in chapter 8 of his book. 
12. It is, of course, difficult to estimate how often this happens. From a recent (September 29, 1991) 20-20 broadcast on women in prison for killing abusive and battering spouses, one emerges with the strong impression that some of these women have been convicted and sent to prison for an offense that is essentially identical to that committed by other women who were not convicted.

13. For a general discussion of how sentencing systems might be constructed to better capture the subtleties of community views, see Robinson (1987).

14. See, generally, Robinson, “Are Criminal Codes Irrelevant?” (1994).

\section{APPENDIX A}

1. As the calculating reader will have noticed, adding further factors or deciding to sample more levels of a factor quickly leads to the generation of a remarkably large number of casesmore cases than one can expect a respondent to rate without error-inducing boredom or more obvious signs of mutiny. When the logic of the situation requires a large number of cases, the factorial survey experts simply sample among the cases and give a subset of cases to each respondent. They have developed procedures that still enable them to estimate the overall population response and the differences between the responding individuals.

2. In the between-subjects design, this problem is solved by randomly assigning subjects to conditions, with the thought that some subjects who give low sentences will end up in both conditions, as will subjects who give high sentences, and these differences will cancel each other out as the data are aggregated.

3. Throughout Chapters 2 through 6 we have discussed some of the difficulties within individual studies. As we have said before, we intend our studies to demonstrate the need for larger social science research projects than the pilot projects undertaken in this work.

4. Those versed in statistics will know that this is true only if the variable in question is normally distributed. By and large our distributions are normal, and the exceptions to this rule have been duly noted in the discussion.

5. This was the case for about 23 of the total set of 171 scenarios.

6. This was the case for 56 of the 171 scenarios.

7. Many of the liability distributions were not normal, however. For example, where a factor in the scenario leads some subjects to give a complete defense but not others, the resulting distribution is likely to be bimodal, with responses grouped at extreme ends of the penalty scale if the offense at issue is a serious one. The large resulting standard deviation might suggest a wide range of disagreements when, in fact, the subjects disagreed only on a single issue - the propriety of a defense-and otherwise have significant unanimity within each of the two tested groups. The effect is due in part to subjects coinciding with the law in its practice of treating most issues as discontinuous functions.

In fact, rarely was the standard deviation so large as to suggest bimodality. The mean standard deviation of all scenarios in all studies is 2.25 . When the scenarios containing "no liability" responses are omitted, the mean standard deviation drops to $1.66(\mathrm{~N}=56)$. When all scenarios containing either "no liability" or "liability but no punishment" are omitted, the mean standard deviation drops to $1.39(\mathrm{~N}=33)$.

8 . Some of these no doubt are explained by the severe bimodal distribution caused by a person's failure to get a defense to a serious offense, as discussed in note 7. A particularly useful study for future research might be an investigation of the sources of agreement and disagreement among the community. On what kinds of issues are there greater shared intuitive notions? On which are there less-shared notions? A profitable study could be done even using existing data.

9. Florida Art. XI, $₫ 1$; Illinois Art. XIV, $₫ 2$; New Jersey Art. IX, $\$ 1$. [Other requirements include two-thirds (California Art. XVIII, \ 1) or a majority (New York Art. XIX, § 1).] 
10. The troublesome cases, of course, are those where the rule is by no means neutral in its effect but falls more heavily in its application upon one group than upon another, especially if that group is the minority that opposes the rule. Some would say that all rules are of this nature; thus, the need to avoid the tyranny of the majority that would come with relying upon community views. The goal of this book is not to argue that majority views should be followed at the expense of minorities who would be injured by the rule. It is, rather, to argue that the majority view should be followed if it is at the expense of crime control measures. The ignored minority here is likely to be academics and criminal justice professionals who would give priority to crime control over individual justice. That choice, or balance, is one that is more appropriately determined by majority vote. 


\section{References}

American Law Institute. 1985. Model Penal Code and commentaries.

Baumeister, R. F., and Darley, J. M. 1982. "Reducing the biasing effect of perpetrator attractiveness in jury simulation." Personality and Social Psychology Bulletin 8, pp. 286-292.

Blunk, R. A. and Sales, B. D. 1977. "Persuasion during the voir dire." In B. D. Sales, ed., Psychology and the Legal Process. New York: Spectrum.

Carpenter, B., and Darley, J. M. 1978. "A naive analysis of counteraggression." Personality and Social Psychology Bulletin 4, pp. 68-72.

Chilton, R., and DeAmicis, J. 1975. "Overcriminalization and the measurement of consensus." Sociology and Social Research 59, pp. 318-329.

Cowan, C. L.; Thompson, W. C.; and Ellsworth, P. C. 1984. "The effects of death qualification on jurors' predispositions to convict and on the quality of deliberation." Law and Human Behavior 8, pp. 53-79.

Dane, F. C., and Wrightsman, L. S. 1982. "Effects of defendants' and victims' characteristics on jurors' verdicts." In N. Kerr and R. Bray, eds., The Psychology of the Courtroom. New York: Academic Press.

Darley, J. M., and Schultz, T. R. 1990. "Moral rules: Their content and acquisition." Annual Review of Psychology 41, pp. 525-556.

Darley, J. M., and Zanna, M. 1982. "Making moral judgements." American Scientist 70, pp. 515522.

Eitzen, D. S., and Timmer, D. A. 1985. Criminology: Crime and Criminal Justice. New York: John Wiley and Sons.

Elwork, A.; Sales, B. D.; and Alfini, J. J. 1982. Making Jury Instructions Understandable. Charlottesville, Va: Michie.

Erikson, M., and Gibbs, J. 1979. "On the perceived severity of legal penalties." The Journal of Criminal Law and Criminology 70, pp. 102-116.

Feinberg, J. 1984. Harm to Others: The Moral Limits of the Criminal Law. New York: Oxford University Press.

Finkel, N. J. 1990. "Capital felony-murder, objective indicia, and community sentiment." Arizona Law Review 32, pp. 819-913.

1988. "Insanity on trial." In B. D. Sales, ed., Perspectives in Law and Psychology 8. New York: Plenum Press.

Finkel, N. J., and Duff, K. B. 1991. "Felony-murder and community sentiment: Testing the Supreme Court's assertions." Law and Human Behavior 15, pp. 405-429.

Finkel, N. J.; Shaw, R.; Bercaw, S.; and Koch, J. 1985. "Insanity defenses: From the jurors' perspective." Law and Psychology Review 9, pp. 77-92.

Finkel, N. J., and Smith, S. F. 1993. "Principals and accessories in capital felony-murder: The proportionality principle reigns supreme." Law and Society Review 27, pp. 129-156.

Fischoff, B. 1975. "Hindsight does not equal foresight: The effect of outcome knowledge on judgement under uncertainty." Journal of Experimental Psychology: Human Perception and Performance 1, pp. 288-299.

Fletcher, G. P. 1980. "Reflections on felony-murder." Southwestern University Law Review 12, pp. 413-429. 
1978. Rethinking Criminal Law. New York: Little, Brown.

Fox, V. 1985. Introduction to Criminology (2d ed.). Englewood Cliffs, N.J.: Prentice-Hall.

Gescheider, G.; Catlin, E.; and Fontana, A. 1982. "Psychophysical measurement of the judged seriousness of crimes and severity of punishments." Bulletin of the Psychonomic Society 19, pp. 275-278.

Grasmick, H. G., and Green, D. E. 1980. "Legal punishment, social disapproval, and internalizations as inhibitors of illegal behavior." Journal of Criminal Law and Criminology 71, pp. 321335.

Green, T. 1985. Verdict According to Conscience: Perspectives on the English Trial Jury, 1200-1800. Chicago: University of Chicago Press.

Hans, V. P. 1986. "An analysis of public attitudes toward the insanity defense." Criminology 24, pp. 393-414.

Hans, V. P., and Slater, D. 1984. “'Plain crazy': Lay definitions of legal insanity." International Journal of Law and Psychiatry 7, pp. 105-114.

Harlow, R. E.; Darley, J. M.; and Robinson, P. H. 1994. "The severity of intermediate penal sanctions: The importance of community perceptions and a psychophysical scale for their measurement." Journal of Quantitative Criminology (forthcoming).

Hogarth, J. 1971. Sentencing as a Human Process. Toronto: University of Toronto Press.

Jacob, H. 1980. "Deterrent effects on formal and informal sanctions." In J. Brigham and D. W. Brown, eds., Policy Implementation. Beverly Hills: Sage Publications.

Jones, E., and Davis, K. 1965. "From acts to dispositions: The attribution process in person perception." In Advances in Experimental Social Psychology (Vol. 2). New York: Academic Press.

Kadish, M. R., and Kadish, S. H. 1973. Discretion to Disobey. Stanford: Stanford University Press.

Karlovac, M., and Darley, J. M. 1988. "Attribution of responsibility for accidents: A negligence law analogy." Social Cognition, 6, pp. 287-318.

Kassin, S. M., and Wrightsman, L. S. 1988. The American Jury on Trial. New York: Hemisphere. 1979. "On the requirements of proof: The timing of judicial instructions and mock juror verdicts." Journal of Personality and Social Psychology 37, pp. 1877-1887.

Kelley, H. 1967. "Attribution theory in social psychology." In D. Levine, ed., Nebraska Symposium on Motivation (Vol. 15). Lincoln: University of Nebraska Press.

Kulka, R. A., and Kessler, J. D. 1978. "Is justice really blind? The influence of litigant physical attractiveness on juridical judgement." Journal of Applied Social Psychology 8, pp. 366-381.

Levi, M., and Jones, S. 1985. "Public and police perceptions of crime seriousness in England and Wales." British Journal of Criminology 25, pp. 234-250.

Livingston, E. 1833. A System of Penal Law, Code of Procedure. Philadelphia: J. Kay, Jr. and Brother; Pittsburgh: John I. Kay.

Macauley, T. B. 1837. A Penal Code Prepared by the Indian Law Commissioners. Calcutta: Bengal Military Orphan Press.

Mansfield, J. H. 1964. "Hart and Honoré, causation in the law-A comment." Vanderbilt Law Review 17, p. 488.

Meier, R. F., and Johnson, W. T. 1977. "Deterrence as social control: The legal and extralegal production of conformity." American Sociological Review 42, pp. 292-304.

Newman, G., and Trilling, C. 1975. "Public perceptions of criminal behavior: A review of the literature." Criminal Justice and Behavior 2, pp. 217-236.

Pasewark, R. A., and Pantle, M. L. 1979. "Insanity plea: Legislator's view." American Journal of Psychiatry 136, pp. 222-223.

Pasewark, R. A., and Seidenzahl, D. 1980. "Opinions concerning the insanity plea and criminality among mental patients." Bulletin of the American Academy of Psychiatry and Law 1, pp. 199-202.

Pirsig, M. E. 1963. “Proposed Revision of the Minnesota Criminal Code." Minnesota Law Review 47, pp. $417-463$. 
Robinson, P. H. 1994. “Are criminal codes irrelevant?" Southern California Law Review 68. . 1994. "A functional analysis of criminal law." Northwestern University Law Review 88, pp. 857-913.

1990. "Rules of conduct and criminal adjudication." University of Chicago Law Review

57, pp. 729-771.

1987. “A sentencing system for the 21 st century?" Texas Law Review 66, pp. 1-61. 1985. "Causing the conditions of one's own defense: A study in the limits of theory in criminal law doctrine." Virginia Law Review 71, pp. 1-63.

1984. Criminal Law Defenses. St. Paul: West Publishing.

. 1982. "Criminal law defenses: A systematic analysis." Columbia Law Review 82, pp.

199-291.

Robinson, P. H., and Grall, J. 1983. "Element analysis in the definition of offenses: The Model Penal Code and beyond." Stanford Law Review 35, pp. 681-762.

Rossi, P., and Nock, S., eds. 1982. Measuring Social Judgments: The Factorial Survey Approach. Beverly Hills: Sage Publications.

Sarat, A. 1977. "Studying American legal cultures: An assessment of survey evidence." Law and Society Review 11, pp. 427-488.

Scheflin, A., and Van Dyke, J. 1980. "Jury nullification: The contours of a controversy." Law and Contemporary Problems 43, pp. 52-115.

Schulhofer, S. J. 1974. "Harm and punishment: A critique of emphasis on the results of conduct in the criminal law." University of Pennsylvania Law Review 122, p. 1497.

Shaver, K. 1985. The Attribution of Blame: Causality, Responsibility, Blameworthiness. New York: Springer Verlag.

Silberman, M. 1976. "Toward a theory of criminal deterrence." American Sociological Review 41, pp. 442-461.

Steadman, H. J., and Braff, J. 1983. "Defendants not guilty by reason of insanity." In B. D. Sales, ed., Perspectives in Law and Psychology (Vol. 6). New York and London: Plenum Press.

Tittle, C. R. 1980. Sanction and Social Deviance: A Question of Deterrence. New York: Praeger.

Tyler, T. 1990. Why People Obey the Law. New Haven: Yale University Press.

United States Sentencing Commission. 1994. Guidelines Manual (with Amendments through Nov. 1, 1993). St. Paul: West Publishing.

von Hirsch, A., and Jareborg, N. 1991. "Gauging criminal harm: A living-standard analysis." Oxford Journal of Legal Studies 11, pp. 1-38.

Wells, G. L. and Loftus, E. F., eds. 1984. Eyewitness Testimony: Psychological Perspectives. New York: Cambridge University Press.

Williams, G. 1961. Criminal Law: The General Part (2d ed.). London: Stevens.

Wolfgang, M., and Weiner, N. 1982. Criminal Violence. Beverly Hills: Sage Publications. 


\section{Index}

Accident defenses. See Culpability requirements

Accidental result, 182

Accident scenarios, 184

Accomplice. See Complicity

"Accomplice discount," 178, 180, 197

dichotomous vs. continuous functions, 208

in causation, $185-186$

Age and the negligence standard, 118

Agreement between code and community standards, 203-204

Alfini, J. J., 3

American Law Institute

insanity test, 129, 130

necessary cause requirement, 182

test for involuntary intoxication, 140

Allergic reaction to drugs scenario, 184

Attempt, grading of, 23

code-community disagreement, 206

dichotomous vs. continuous functions, 208

Attempt, objective requirements of, 15-16 code-community disagreement, 205

dangerous proximity, 22

"liability but no punishment," 26-27

objective elements of, study summary, 27-28

probable desistance test, 15

renunciation defense, $16,23-25$

substantial step test, 15

text of scenarios, 229-231

thought only, 21

undo offense, 16, 25-26 unequivocality test, 15-16

Baumeister, R., 3

Beating of co-workers scenario, 191

Bercaw, S., 128

Blameless rule violation. See Excuse, doctrines of

"Blameless violation" verdict, 212

Blameworthiness, 83-84

Blameworthy rule violation. See

Culpability, doctrines of

"Blameworthy violation" verdict, 212

Blunk, R. A., 3

Braff, J., 128

"But for" cause, 181

Carpenter, B., 63

Catlin, E., 8

Causation requirements, 181-189

dichotomous vs. continuous functions, 208-210

study summary, 188-189

text of scenarios, 277-278

Changing community standards, 169

Chilton, R.,13

Circumstance offense element, 85

Citizen's law enforcement authority. See

Law enforcement authority

Civil commitment of insane offender, 133

Code drafting, 214-215

Code-community conflicts, jury as resolver of, 212-215

Coercion, 147, 155

Cognitive dysfunction, 155 
Cognitive impairment due to insanity, 130

Collateral elements, culpability with regard to, 95

Community perceptions, law-psychology issues, 3

Community standards, $1-7,10-11$

degree of agreement for, 227-228

sources of, 227

Community views, why they should matter, 5-7

\section{Complicity}

aspect of felony murder, 169

culpability requirements for, 96-105: study summary, 103-105; text of scenarios, 252-253

objective requirements of, 33-42: study summary, 41-42; text of scenarios, 235-237

Concurrent sentences for multiple of fenses, 189, 196, 199

Conduct offense element, 85

Conflict between community views and criminal codes, 201-216

Consecutive sentences for multiple offenses, 189-190, 196, 199

Consensus, 225-228

Consensus as supermajority, 227

Construction-crane accident scenario, 184

Continuous functions vs. dichotomous functions, $208-210$

Control dysfunction, 155

Control impairment due to insanity, 130

"Control" scenarios, 225

Core element, culpability with regard to, 94

Cowan, C. L., 3

Creeping wounds, 213

Crime, fear of, 3

Criminal code primary prohibitions, 13 secondary prohibitions, 13

Criminal conduct. See Criminalization, doctrines of

Criminal facilitation, 104-105

Criminal liability without punishment, 210-212
Criminalization

chapter summary, 50-51

doctrines of, 13-52

Culpability as affecting grade, 169-181

as determinate of grade, 159

as to becoming intoxicated, 114

chapter summary, 123-125

doctrines of, 83-125

pre-intoxication, 106, 107

Culpability requirement; core vs. collateral, 95

Culpability requirements, 84-96 accident defense, 85

code-community disagreement, 204205

dichotomous vs. continuous functions, 208-210

study summary, 94-96

text of scenarios, 247-252

Culpability requirements for complicity, 96. See also Complicity, culpability requirements for

Cultural background and the negligence standard, 118

Dane, F. C., 3

Dangerous proximity test, $15,27,50$

Darley, John M., 3, 28, 54, 63

Davis, K., 195

Deadly force in defense of property, 64 in exercise of law enforcement authority, 72

in self defense, 54-64

DeArnicis, J., 13

Defense of property, use of force in, 64-72 study summary, 71-72

text of scenarios, 242-243 use of deadly force in, 64

Degree of punishment deserved. See

Grading, doctrines of

Demand characteristics, 222

Demographic information on subjects, 222-223

Dichotomous functions vs. continuous functions, 208-210 
Disability excuses, 127

Disagreement between code and community, 204-208

Doctrines of excuse. See Excuse, doctrines of

Drowning person scenario, 42-43

Drunk driver, giving keys to, 97-98

Drunken killing, 107

Due process, 209

Duff, K. B., 177

Duress defense, 147-155 study summary, 154-155 text of scenarios, 269-270

Duty to help, 42-43

Eitzen, D. S., 3

"Elevating" culpability for complicity above that of substance offense, 97

Ellsworth, P. C., 3

Elwark, A., 3

Entrapment def ense, 147-155 objective formulation, 148-149 study summary, 147-155 subjective formulation, 148-149 text of scenarios, 269, 270-271

Erikson, M., 8

Excuse, doctrines of, 127-155, 204 chapter summary, 155

Excuse disability, 127

Factorial survey, 217

Factual cause requirement, 181, 183-184

Feinberg, J., 158

Felony murder, 169-171, 225

code-community disagreement, 205206

study summary, 179-181

text of scenarios, 274-276

See also Murder

Felony-manslaughter rule, proposal for, 178, 179, 181, 197-198. See also Manslaughter

Finkel, N. J., 128, 177

Fischoff, B., 28

Fontana, A., 8

Forcible intercourse. See Rape

Fox, V., 3
Functions of criminal law, 5

Gender and the negligence standard, 118

Genetic makeup and the negligence standard, 118

Gesceider, G., 8

Gibbs, J., 8

Goetz, Bernhardt, 212

Grading, doctrines of, 175-200 chapter summary, 197-199

Grall, Jane A., 84

Grasmick, H. G., 7, 203

Green, T., 7, 64, 203, 212, 213

Habitual offender, 197

Hans, V. P., 128, 129

Harm, occurence of ("resulting harm"), $26,32-33,35,51$

Harm caused or risked, as affecting grade, 159

Hinckley, Jr., John, 129

Homicide, 158

Negligent, 157, 169, 180

See also Felony murder

Immaturity, 139-147

study summary, 146-147

text of scenarios, 265, 268-269

"In the actor's situation," 116-117

Individual differences among respondents, 218

Individualization of the objective standard of negligence. See Objective standard of negligence, individualization of

Inducement, by police officer, 147

Insanity, 128-139

cognitive dysfunction prong, $129,133-$ $139,140-147$

control dysfunction prong, 129, 133

139, 140-147

general defense, 129

irresistible impulse test, 130

McNaughten test, 129

negating an offense element, 129

study summary, 137-139

text of scenarios, 262-265 
Intoxication, involuntary, 139-147

study summary, 146-147

text of scenarios, 265-268

Intoxication, voluntary, 105-116

study summary, 114-116

text of scenarios, 254-256

Irresistible impulse insanity test, 130

Irresistible impulse test for involuntary intoxication, 140

Jacob, H., 7, 203

Jareborg, N., 158

Johnson, W. T., 7, 203

Jones, E., 13, 195

Jury

decision making, 3

nullification, 212-214

as a resolver of code-community

conflicts, 212-215

Justice, community sense of, 1

Justice of the system as a source of compliance power, 202

Justification

chapter summary, 79-81

defenses, 53-54

doctrines of, 53-81

force authorized, code-community disagreement, 207

mistake as to, code-community disagreement, 206

Kadish, M. R., 7

Kadish, S. H., 7

Karlovac, M., 28

Kassin, S., 3, 7

Kelley, H., 195

Kessler, J. D., 3

Koch, J., 128

Kulka, R. A., 3

Law enforcement authority, 72-79

mistake as to, 72

text of scenarios, $243-247$

Lay definitions of insanity, 128

Legal cause, 184

Legal causer requirement, 181

Legality principle, 209
Levi, M., 13

Liability as a function of culpability, 203

"Liability but no punishment" attempt, 26-27

doctrines of criminalization, 50

option on liability scale, 17-19

Liability results, tables presenting, 17-21

Liability scale, 8, 223-225

coding of responses, 17-19

imprisonment term translation table, 283-284

"liability but no punishment" option, 17-19

no liability option, 17

Livingston, E., 43

Locksmith theft scenario, 16

Loftus, E. F., 3

Macauley, T. B., 43

Malum in se offense, 13

Malum prohibition offenses, 13

Manipulation check questions, 29-31, 220

Manslaughter, 157, 169

McNaughten

insanity test, 129

involuntary intoxication test, 140

Meier, R. F., 7, 203

Mental def ect. See Insanity

Mental disease. See Insanity

Mental illness. See Insanity

Mental retardation and the negligence standard, 118

Mistake defense

as to age of sexual partner, 86

as to consent to intercourse, 86

as to law enforcement authority, 72

as to self-defense, 55, 79, 127

See also Culpability requirements

Mistake excuses, 55

Model Penal Code

ALI insanity test, 129-130

attempt, dangerous proximity test, 1415

atypical of grading classifications, 224

causation requirements, 181

complicity, 34, 96

culpability requirements, 84,116 
definition of negligence, 117

duress defense, 147

entrapment, 148

immaturity defense, 139

"in the actor's situation," 119

involuntary intoxication def ense, 139

justification defenses, 54

law enforcement authority, 72

mistake as to self-def ense, 55

mistake defenses, 85

objective elements of defenses, 85-86

rejection of felony-murder rule, 170171

renunciation defense, 16

requirement of recklessness, 88

sexual offenses, 160

voluntary intoxication defense, 105

Moral credibility of the law as a source of compliance power, 201, 202

Moral intuitions of individuals, 1-7, 10-11

Multiple offenses

punishment for, 189-197

study summary, 196-197

text of scenarios, 278-281

"Multiple-offense discount," 190

Murder, 157, 169. See also Felony murder

Necessary cause, 181-182

Necessity requirement in self-defense, 54

Negligence, 116

criminal, 117

objective standard of: individualization of, 116-123; text of scenarios, 256262; study summary, 123

Negligent killing during felony, 169-170

Newsman, G., 13

NGRI (not guilty by reason of insanity), 128

"No liability" option on liability scale, 17

"No violation" verdict, 212

Nock, S., 217

Nonexculpatory defense, entrapment, 149

Nurse's careless error scenario, 184

Objective elements of of fense definition, 85
Occurrence of resulting harm as affecting grade, 159

Offense culpability requirements. See Culpability requirements

Offense grading, 223-224

Omission liability, 42-48

code-community disagreement, 208

study summary, 48-50

text of scenarios, 237-240

Pantle, M. L., 128

Pasewark, R. A., 128

Penalty scale. See Liability scale

Physical attractiveness of defendant, 218

Poison

husband scenario, 29

slow-acting scenario, 181

Police agent as entrapper, 154

Princeton University Department of

Psychology, 219

Probable desistance test for attempt, 15, 27

Prohibited result, connection with. See

Causation requirements

Prohibitions, legal, 13

Property

destruction of house scenario, 86

maximum force allowable in defense of, 71

proportionality requirement in defense of, 64

vs. person offenses, as affecting grade, 190

Punishment, degree deserved. See Grading, doctrines of

Purpose requirement in complicity, 96

Randomizing scenario order, 222

Rape, 157-158, 161-164

between homosexual couple, 164

cohabitation and, 161, 164

date, 161, 164

mistake as to lack of consent, 86

pursuing rapist scenario, 72

statutory, 158, 160, 165 (see also Mistake defenses, as to age of sexual partner)

use of force in restraining one who has committed, 72-78 
Reagan, Ronald, attempted assassination of, 129

Reasonable person, 116 in duress, 147 in self-defense, 63

Recklessness, 118

Religious beliefs and the negligence standard, 118

"Remote" cause, 182

Renunciation test, 16, 27

Research methodology, 217-228 factorial survey, 217 limitations, 10-11 overview, 7-11 scenario research, 218-219 special methods for negligence standard study, 121-122 strengths and limitations, 219-223

Respondent sampling, 222-223

Result accountability for, 181 offense element, 85

Rhode Island duty to rescue statute, 44 Risk, creating a criminal, 28-33 text of scenarios, 232-234

Risk of harm, 159

Robinson, Paul H., 5, 54, 84, 139, 212

Roommate killed for attracting affection of girlfriend scenario, 107

Rossi, P., 217

Rutgers University School of Law, 219

Sales, B. D., 3

Sarat, A., 203

Scenario research, $8-10,19,218=219$

Scenarios, text of, 229-281

Scheflin, A., 7

Schultz, T. R., 3

Seidenzahl, D., 128

Self-defense

maximum force allowable in, 58

mistake as to, $27,55,60,62,73,75-76$, 79

panhandler scenario, 63 proportionality requirement in, 54 retreat rule in, 59-60, 62 seriousness of threat, $54,57-58$ use of deadly force in, 54-64: text of scenarios, 240-241; study summary, 63-64

Sentencing guidelines, 158, 213-214

Seriousness of offense, as affecting grade, 160-169

Setting fire to brother scenario, 140

Sexual intercourse consensual, 160-161 deviate, 164-165 with a person in custody or control, 166 with retarded person, 168

Sexual offenses, 160-169 code-community disagreement, 204 gender based, 165 study summary, 167-169 text of scenarios, 271-274 See also Mistake defenses; Rape

Shaw, R., 128

Silberman, M., 7, 203

Slater, D., 129

Smith, J. F., 177

Social science research, xiii-xiv, 2-3

Spring guns, use of, 65,68

Standard deviation, 226

Steadman, H. J., 128

Stun gun, use of, 73

Subject population, demographic information, 222-223

Subjects, agreement and disagreement among, 225-228

"Substantial capacity" criteria for insanity test, 129,138

Substantial step text, 15, 27, 50

"Subway shooter," Bernhardt Goetz, 212

Sufficient cause, 181-182

Theft

coin shop scenario, 16 motorcycle scenario, 65 oil drums scenario, 191

Thompson, W. C., 3

Time interval between offenses, 190-191 as affecting total punishment, 189-190 Timmer, D. A., 3

Tittle, C. R., 7, 203 
Traffic accident on way to hospital scenario, 184

Trilling, C., 13

Tyler, T., 6, 7, 203

Underage. See Immaturity

Unequivocality test, 15-16, 27

United States Sentencing Commission guidelines aggregation of value, 189-190,193 categories of complicity, 34

Utilitarian justification for punishment, 201

Van Dyke, J., 7
Voluntary intoxication. See Intoxication, voluntary

von Hirsch, A., 158

Weiner, N., 3

Wells, G. L., 3

Wife shoots husband with help of friend scenario, 34-35

Wisconsin duty to rescue statute, 44

Within-subjects design, 222, 224

Wolfgang, M., 3

Wrightsman, L. S., 3, 7

Zanna, M., 54 
Praise for

\section{JUSTICE, LIABILITY \& BLAME}

"Through a wide-ranging study that is solidly grounded in an impressive knowledge of current legal doctrine, Robinson and Darley bring the area of "gap" studies, which examines the discrepancy between law in theory and law in action, to a new and more sophisticated level.... The rich source of data and its direct relevance to a wide variety of legal questions suggest that this volume will become a central reference in future discussions of public views about the law."

-Tom Tyler

University of California at Berkeley

"Robinson and Darley creatively investigate whether criminal law's various doctrines of liability and blame are congruent with the attitudes of ordinary people and suggest the proper legal response to inconsistency. Justice, Liability, and Blame is must reading for those concerned with the integrity and efficacy of the criminal law."

-Stephen J. Morse University of Pennsylvania Law School

"This book is clearly written and is an important event in the development of effective collaboration between lawyers and psychologists."

-Geoffrey Stephenson author of The Psychology of Criminal Justice University of Kent at Canterbury

For order and other information, please write to:

Westriew Press

5500 Central Avenuc - Boulder, Colorado $80301-2877$

36 Lonsdale Road • Summertown • Oxford OX2 7EW 